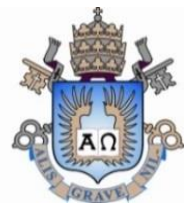

Edgardo Rafael Castro Pacheco

Desenvolvimento e validação experimental em usina hidrelétrica de alternativas de cálculo da efetividade de trocadores de calor

Dissertação de Mestrado

Dissertação apresentada como requisito parcial para obtenção do grau de Mestre pelo Programa de Pós-Graduação em Metrologia (Área de concentração: Metrologia para Qualidade e Inovação) da PUC-Rio.

Orientador: Maurício Nogueira Frota Coorientador: José Daniel Hernández Vásquez

Rio de Janeiro Dezembro de 2020 
Edgardo Rafael Castro Pacheco

\section{Desenvolvimento e validação experimental em usina hidrelétrica de alternativas de cálculo da efetividade de trocadores de calor}

Dissertação apresentada como requisito parcial para obtenção do grau de Mestre pelo Programa de Pós-Graduação em Metrologia (Área de concentração: Metrologia para Qualidade e Inovação) da PUC-Rio.

Prof. Maurício Nogueira Frota

Orientador

Programa de Pós-Graduação em Metrologia - PUC-Rio

Prof. José Daniel Hernández Vásquez

Coorientador

Programa de Engenharia Mecânica, Universidad Antonio Nariño - FIMEB/Colômbia

Prof. Florian Alain Yannick Pradelle

Departamento de Engenharia Mecânica - PUC-Rio

Prof. Nicolás Giraldo Peralta

Programa de Engenharia Mecânica, Universidad Antonio Nariño - FIMEB/Colômbia

Prof. Carlos Roberto Hall Barbosa

Programa de Pós-Graduação em Metrologia - PUC-Rio

Rio de Janeiro, 22 de dezembro de 2020 
Todos os direitos reservados. É proibida a reprodução total ou parcial do trabalho sem autorização da universidade, do autor e do orientador.

\section{Edgardo Rafael Castro Pacheco}

Formado em Engenharia Mecânica (2018) pela Faculdade de Engenharia da Universidad del Atlántico. Colômbia. Pesquisador do Projeto de P\&D Light/Aneel Ref. 5161010/2016, intitulado Cabeça de Série de um sistema inovador de limpeza de trocadores de calor de hidrogeradores. Julho de 2019.

Ficha Catalográfica

Castro Pacheco, Edgardo Rafael

Desenvolvimento e validação experimental em usina hidrelétrica de alternativas de cálculo da efetividade de trocadores de calor / Edgardo Rafael Castro Pacheco; orientadores: Maurício Nogueira Frota, José Daniel Hernández Vásquez. - 2020.

119 f.: il. color.; $30 \mathrm{~cm}$

Dissertação (mestrado)-Pontifícia Universidade Católica do Rio de Janeiro, Centro Técnico Científico, Programa de Pós-Graduação em Metrologia, 2020.

Inclui bibliografia

1. Metrologia - Teses. 2. Metrologia para Qualidade e Inovação Teses. 3. Metrologia. 4. Incerteza. 5. Trocadores de calor. 6. Hidrogerador. 7. Efetividade térmica. I. Frota, Maurício Nogueira. II. Hernández Vásquez, José Daniel. III. Pontifícia Universidade Católica do Rio de Janeiro. Centro Técnico Científico. Programa de PósGraduação em Metrologia. IV. Título. 
"Dedico esta obra à minha família, amigos e namorada: que são meu motor e combustível." 


\section{Agradecimentos}

Primeiramente agradeço a Deus, que permitiu que tudo acontecesse, ao longo de minha vida. Ele é, e será sempre, o Mestre de todos os mestres.

Ao CNPq e à PUC-Rio, pelos auxílios concedidos, sem os quais este trabalho e minha presença nesse país não poderiam ter sido possíveis.

Ao Professor Maurício Nogueira Frota, pela orientação e confiança concedidas, grande apoio, ajuda, paciência e presteza, e pelos inúmeros conselhos e palavras sabias que se tornaram na chave para desenvolver este trabalho e manter o foco nesses dias difíceis de confinamento social imposto pela pandemia.

Ao co-orientador, Professor José Daniel Vásquez Hernández, por ter sido a ponte institucional que permitiu o meu acesso à esta conceituada instituição de ensino e pesquisa e, também, pelo apoio, confiança, amizade e enorme conhecimento sobre incerteza de medição, tema chave na solução dos diversos problemas combatidos nesta pesquisa de mestrado.

Aos profissionais da PUC-Rio, em especial às secretárias Marcia e Paula do PósMQI e aos coordenadores de laboratórios que sempre facilitaram o meu acesso. Agradecimentos também são devidos aos gestores e profissionais de manutenção da usina Fontes Nova, de propriedade da Light Energia S/A, pelo acesso e apoio nas rodadas de medições realizadas nos trocadores de calor. A todos os professores do Programa de Pós-Graduação em Metrologia, pelo conhecimento compartilhado com entusiasmo e afetividade nas interessantes e enriquecedoras disciplinas que tive oportunidade de cursar durante o Mestrado de Metrologia.

À minha mãe Virginia Elena e ao meu pai Edgardo Castro, por todo o apoio e incondicional amor em todos os momentos da minha vida. Às minhas irmãs Beatriz e Mariana, pelo carinho, amor, respeito e inspiração. A minha namorada Heidy Cassiani, pela sua compreensão e amor para superar essa etapa da minha vida e, também, a meus amigos e familiares, que sempre se fizeram presentes.

Aos colegas e amigos de classe, especialmente Melissa Costa, Vinicius Tostes, Rodrigo Halfeld e Maria Alexandra Matallana, pelos momentos divertidos que passamos e pela incansável ajuda prestada, tornando-se membros de minha família mesmo sem compartilhar laços sanguíneos.

Aos membros da banca de defesa de minha dissertação, por terem aceitado avaliar o trabalho e prestar o seu endosso a este processo independente da avaliação.

O presente trabalho foi realizado com apoio da Coordenação de Aperfeiçoamento de Pessoal de Nível Superior - Brasil (CAPES) - Código de Financiamento 001. 


\section{Resumo}

Castro Pacheco, Edgardo Rafael. Frota, Mauricio Nogueira (Orientador). Vásquez Hernández, José Daniel (Co-orientador). Desenvolvimento e validação experimental em usina hidrelétrica de alternativas de cálculo da efetividade de trocadores de calor. Rio de Janeiro, 2020. 119p. Dissertação de Mestrado Programa de Pós-Graduação em Metrologia (Área de concentração: Metrologia para Qualidade e Inovação), Pontifícia Universidade Católica do Rio de Janeiro.

Esta dissertação teve como objetivo desenvolver uma sistemática de monitoramento para avaliar, em tempo real, a efetividade térmica de trocadores de calor (água-ar) do sistema de arrefecimento de hidrogeradores. A motivação resultou da possibilidade de se estabelecer ganhos de efetividade pela racionalização do procedimento de limpeza. Como metodologia de desenvolvimento do trabalho, duas estratégias foram perseguidas: (i) proposição de alternativas de cálculo da efetividade sem a necessidade de medir a temperatura de saída do ar (fluido quente do trocador) em um complexo escoamento perturbado por sucessivos descolamentos da camada limite em torno de cada tubo do trocador e (ii) validação da alternativa de cálculo da efetividade com base em dados reais de monitoramento de um trocador de calor de hidrogerador, em operação contínua, mesmo durante a sua limpeza on-line, portanto sem requerer a parada técnica das turbinas. Dentre os resultados, duas alternativas de cálculo da efetividade do trocador foram desenvolvidas: (i) via solução numérica do sistema de equações que governam os mecanismos de transferência de calor e (ii) via uma versão adaptada do método $\varepsilon$-NTU, que avalia a efetividade de um trocador de calor de seis passes modelando-o como um arranjo em série de seis trocadores de um único passe. As alternativas de cálculo da efetividade apresentam concordância de cerca de $1 \%$ e com baixo nível de incerteza $(0,012)$, podendo diferir em até $30 \%$ quando confrontadas com o método usual fundamentado na medição da temperatura de saída do ar. Como conclusão, as alternativas propostas mostraram-se adequadas para calcular a efetividade do trocador de calor do sistema de arrefecimento dos hidrogeradores da usina Fontes Nova (Piraí/RJ), monitorado ao longo de um período de 11 meses e sem requerer a interrupção da geração.

\section{Palavras-chave}

Metrologia; trocadores de calor; hidrogeradores; efetividade térmica; coeficiente global de transferência de calor; NTU. 


\section{Abstract}

Castro Pacheco, Edgardo Rafael. Frota, Mauricio Nogueira (Advisor). Vásquez Hernández, José Daniel (Co-advisor). Development and experimental validation in a hydroelectric plant of alternatives for calculating the effectiveness of heat exchangers. Rio de Janeiro, 2020. 119p. Dissertação de Mestrado - Programa de Pós-Graduação em Metrologia (Área de concentração: Metrologia para Qualidade e Inovação), Pontifícia Universidade Católica do Rio de Janeiro.

This dissertation aimed to develop a monitoring system to evaluate, in real time, the thermal effectiveness of heat exchangers (water-air) of the cooling system of hydrogenerators. The motivation resulted from the possibility of establishing gains in effectiveness by rationalizing the cleaning procedure. As a methodology for the development of the work, two strategies were pursued: (i) proposition of alternatives for calculating effectiveness without the need to measure the outlet temperature of the air (hot fluid of the exchanger) in a complex flow disturbed by successive detachments of the boundary layer around each tube of the exchanger and (ii) validation of the alternative of calculating the exchanger effectiveness based on real data acquired during the continuous operation of the hydrogenerator unit, including the online cleaning process of the exchanger without the technical stop of the turbines. Among the results, two alternatives for calculating the effectiveness of the exchanger were developed: (i) via a numerical solution of the system of equations that govern the heat transfer mechanisms involved and (ii) via an adapted version of the $\varepsilon$-NTU method, which evaluates the effectiveness of a six-pass heat exchanger modeling it as a series arrangement of six single pass heat exchangers. The alternatives for calculating the exchanger effectiveness have an agreement of about $1 \%$ and with low level of uncertainty (0.012), which may differ by up to $30 \%$ when compared with the usual method based on the measurement of the outlet air temperature. In conclusion, the proposed alternatives proved to be adequate to calculate the effectiveness of the heat exchanger of the cooling system of the hydrogenerators at the Fontes Nova plant (Piraí / RJ), monitored over a period of 11 months and without requiring interruption of the generation.

\section{Keywords}

Metrology; heat exchangers; hydrogenerators; thermal effectiveness; overall heat transfer coefficient; NTU 


\section{Sumário}

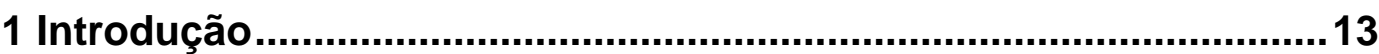

1.1 Definição do problema de pesquisa ............................................17

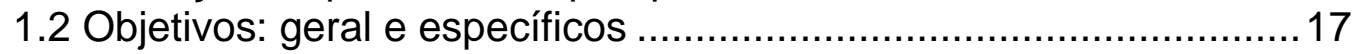

1.3 Metodologia .................................................................... 18

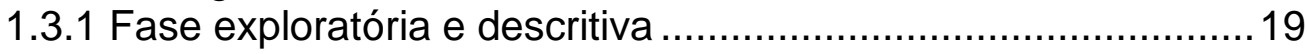

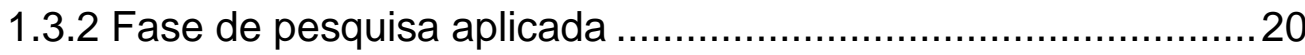

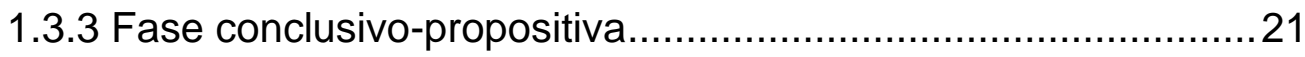

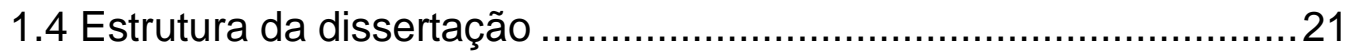

2 Fundamentos teóricos da transferência de calor.............................23

2.1 Breve histórico ...................................................................23

2.2 Mecanismos de transferência de calor de interesse ao estudo ......24

2.3 Tipos de trocadores de calor e suas aplicações .............................25

2.4 Estudo de caso: trocador de calor de hidrogerador .......................28

2.4.1 Coeficiente global de transferência de calor .............................30

2.4.2 Balanço térmico .................................................................... 33

2.4.3 Dificuldade experimental associada ao método convencional..34

2.5 Efetividade térmica: o conceito e alternativas de cálculo ..................42

2.5.1 O conceito de efetividade .................................................... 42

2.5.2 Métodos convencionais para o cálculo da efetividade ...............46

2.5.2.1 Método essencialmente experimental ...............................46

2.5.2.2 Método da temperatura média logarítmica (LMTD) .............47

2.5.2.3 Método NTU para o cálculo da efetividade .........................49

2.5.3 O fator de incrustação...........................................................53

3 Análise da incerteza associada ao estudo de caso .........................57

3.1 Fundamentos da expressão da incerteza de medição ....................57

3.1.1 O conceito de incerteza associada à medição..........................57

3.1.2 Cálculo dos componentes da incerteza ..................................59

3.1.2.1 Incerteza associada à resolução do instrumento .................59

3.1.2.2 Incerteza associada à repetibilidade do instrumento ...........59

3.1.2.3 Incerteza associada ao polinômio de ajuste ........................60

3.1.3 Fator de abrangência...........................................................61

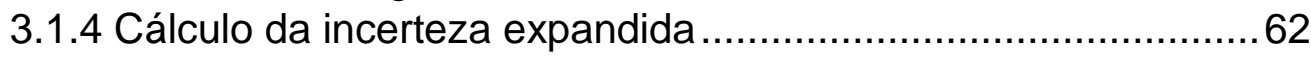

3.2 Incerteza de medição: estratégia de monitoramento da efetividade62

3.2.1 Identificação das fontes primárias de incerteza .........................62

3.2.2 Incerteza associada ao cálculo da efetividade...........................64

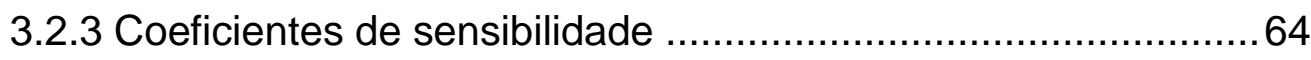

4 Alternativas de cálculo da efetividade ............................................69

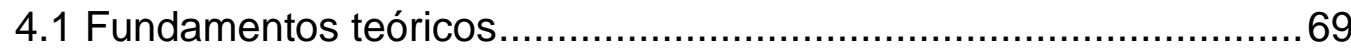

4.1.1 Cálculo da efetividade do trocador: sistema de equações ........69

4.1.2 Método numérico para solução do sistema de equações ..........77

4.2 Considerações sobre o código proposto .........................................79

4.3 Formulação do método NTU para o tipo de trocador em estudo ....80

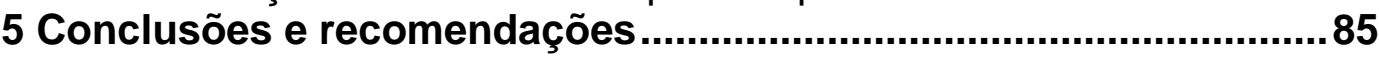

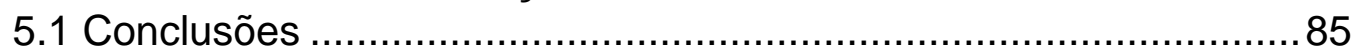

5.2 Recomendações para desdobramentos futuros ............................ 86 
6 Referências bibliográficas

Apêndice A: Resultados de medições de monitoramento da efetividade.92

Apêndice B: Cálculo da efetividade pelas equações de governo ..............99

Apêndice C: Cálculo da efetividade pela abordagem matricial $\varepsilon-N T U ~ . . .102$

Apêndice D: Incerteza associada ao cálculo da efetividade...................108

Apêndice E: Coeficiente global U e resistência térmica Rf.....................114

Apêndice F: Caracterização dos regimes hidrodinâmicos (ar e água) ...117

\section{Lista de Tabelas}

Tabela 1. Valores típicos do coeficiente de transferência de calor ......................... 31

Tabela 2. Parâmetros e faixa de validade da Equação (7) ..................................... 35

Tabela 3. Resultados da análise de sensibilidade para o cp, ar e cp, ag ................ 36

Tabela 4. Extrato de resultados de medição e cálculos intermediários .................. 37

Tabela 5. Expressões para cálculo da efetividade pelo método $\varepsilon-N T U$............51

Tabela 6. Coeficiente global de transferência de calor e resistência térmica).......54

Tabela 7. Valor médio das temperaturas envolvidas no cálculo de $\varepsilon$....................65 65

Tabela 8. Cálculo da efetividade: contribuição das incerteza individuais.............67 67

Tabela 9. Polinômios de cálculo de parâmetros auxiliares para a água ................. 72

Tabela 10. Dados estimados para os parâmetros do arranjo de trocador ............... 74

Tabela 11. Áreas entre os tubos do escoamento externo de ar ..............................74

Tabela 12. Regime hidrodinâmicos dos escoamentos dos fluidos de trabalho do TC....75

Tabela 13. Polinômios de cálculo de parâmetros auxiliares para o ar................... 76

Tabela 14. Dimensões das aletas dos tubos do trocador de calor........................... 77

Tabela 15. Resumo do cálculo da área de troca de calor......................................... 77

Tabela 16. Extrato dos dados compilados, 23/07 a 24/08 de 2019 ....................... 79

Tabela 17. Comparação entre as alternativas 1,2 e 3 .......................................... 84

Tabela 18. Medição de monitoramento do TC (jul a ago/2019) ...........................92

Tabela 19. Medição de monitoramento do TC (ago a out/2019)........................... 93

Tabela 20. Medição de monitoramento do TC (out a dez/2019) .......................... 95

Tabela 21. Medição de monitoramento do TC (dez/2019 a jan/2020)................... 96

Tabela 22. Medição de monitoramento do TC (jan a fev/2020) ............................97

Tabela 23. Medição de monitoramento do TC (fev a abr/2020) ............................98

Tabela 24. Extrato de resultados de medições (julho a out/2019)..........................99

Tabela 25. Extrato de resultados de medições (out/2019 a jan/2020) .................. 100

Tabela 26. Extrato de resultados de medições (jan a abr/2020) .......................... 101

Tabela 27. Extrato de resultados de medições (05/jul a 11/ago/2019) ................ 102

Tabela 28. Extrato de resultados de medições (12/ago a 17/out/2019) ................ 103

Tabela 29. Extrato de resultados de medições (18/out a 15/nov/2019)................ 104

Tabela 30. Extrato de resultados de medições (16/nov a 26/dez/2019) ............... 105

Tabela 31. Extrato de resultados de medições (27/dez/2019 a 07/fev/2020) ...... 106

Tabela 32. Extrato de resultados de medições (08/fev a 06/abr/2020)................ 107

Tabela 33. Resultados do mês de julho a agosto de 2019 .................................. 108

Tabela 34. Incerteza associada à medição (dados entre ago a out/2019) ............. 109

Tabela 35. Incerteza associada à medição (dados entre out a nov/2019) ............ 110

Tabela 36. Incerteza associada à medição (dados entre nov/2019 a jan/2020) ...111 
Tabela 37. Incerteza associada à medição (dados entre jan a fev/2020) ............. 112

Tabela 38. Incerteza associada à medição (dados entre fev a abr/2020) ............. 113

Tabela 39. Coeficiente global e resistência às incrustações (jul a out/2019) ...... 114

Tabela 40. Coeficiente global e resistência às incrustações (out/2019 a jan/2020) 115

Tabela 41. Coeficiente global e resistência às incrustações (jan a abr/2020)...... 116

Tabela 42. Número de Reynolds - interior do trocador (jul a out/2019) ........... 117

Tabela 43. Número de Reynolds - interior do trocador (out/2019 a jan/2020)... 118

Tabela 44. Número de Reynolds - interior do trocador (jan a abr/2020)........... 119

\section{Lista de Figuras}

Figura 1. Desenho da pesquisa, seus componentes e métodos ............................. 19

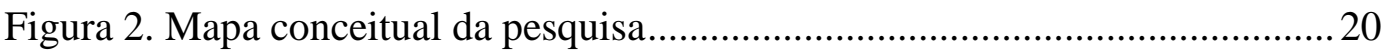

Figura 3. Trocador de calor casco-tubo de um único passe ................................ 26

Figura 4. Classificação de trocadores segundo a natureza do escoamento ........... 27

Figura 5. Unidade hidrogeradora e posicionamento dos trocadores de calor ........ 29

Figura 6. Trocador de calor aberto para limpeza manual (limpeza off-line) .......... 30

Figura 7. Perfil de temperatura e formação da incrustação nos tubos do TC ......... 32

Figura 8. Balanço térmico entre os fluidos de trabalho do trocador....................... 33

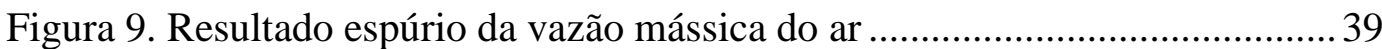

Figura 10. Ventoinhas que forçam o fluxo de ar nos tubos do TC....................... 40

Figura 11 Faces de saída e de entrada do ar no trocador de calor ......................... 40

Figura 12. Representação gráfica típica da função $\varepsilon$-NTU...................................5. 52

Figura 13. Variação da resistência térmica imposta pela incrustação .....................55

Figura 14. Diagrama de Ishikawa aplicável à Equação (48) ................................ 63

Figura 15. Diagrama de Ishikawa aplicável à Equação (18) ................................64

Figura 16. Coeficientes de sensibilidade associados ao cálculo da efetividade .... 66

Figura 17. Esquema do arranjo de tubos do trocador estudado ............................. 73

Figura 18. Esquema dos tubos aletados do trocador de calor................................. 76

Figura 19. Comparação entre as alternativas de cálculo da efetividade................ 83

\section{Símbolos, Siglas e Abreviaturas}

\begin{tabular}{lll}
\multicolumn{2}{l}{ Símbolos } & Unidades \\
$A$ & Área de troca de calor & {$\left[\mathrm{m}^{2}\right]$} \\
$a$ & Coeficiente do polinômio de ajuste & \\
$A_{s}$ & Área transversal & {$\left[\mathrm{m}^{2}\right]$} \\
$C$ & Capacidade térmica do fluido & {$[\mathrm{kW} / \mathrm{K}]$} \\
$c$ & Quociente entre capacidades térmicas dos fluidos & \\
$c_{p}$ & Calor específico do fluido à pressão constante & {$[\mathrm{kJ} /(\mathrm{kg} \mathrm{K})]$} \\
$d$ & Diferencial exato &
\end{tabular}




\begin{tabular}{|c|c|c|}
\hline$D$ & Diâmetro & {$[\mathrm{m}]$} \\
\hline$F F$ & Fator de incrustação & \\
\hline$h$ & Coeficiente de transferência de calor por convecção & {$\left[\mathrm{kW} /\left(\mathrm{m}^{2} \mathrm{~K}\right)\right]$} \\
\hline$J$ & Matriz Jacobiana & \\
\hline$k$ & Fator de abrangência ${ }^{1}$ & \\
\hline$k$ & Coeficiente de condução de calor & {$[\mathrm{kW} /(\mathrm{m} \mathrm{K})]$} \\
\hline$L$ & Espessura da parede do tubo & {$[\mathrm{m}]$} \\
\hline$\ell$ & Altura da aleta & {$[\mathrm{m}]$} \\
\hline$\dot{m}$ & Vazão mássica & {$[\mathrm{kg} / \mathrm{s}]$} \\
\hline$n$ & Número de elementos & \\
\hline NTU & Número de unidades térmicas & \\
\hline $\mathrm{Nu}$ & Número de Nusselt & \\
\hline$p$ & Número de coeficientes do polinômio de ajuste & \\
\hline $\mathrm{Pr}$ & Número de Prandtl & \\
\hline$\dot{Q}$ & Taxa de transferência de calor & {$[\mathrm{kW}]$} \\
\hline$R$ & Resistência térmica & {$\left[\left(\mathrm{m}^{2} \mathrm{~K}\right) / \mathrm{kW}\right]$} \\
\hline$R e$ & Número de Reynolds & \\
\hline$s$ & Desvio padrão amostral & \\
\hline$S_{D}$ & Espaçamento diagonal ao escoamento & {$[\mathrm{m}]$} \\
\hline$S_{L}$ & Espaçamento longitudinal ao escoamento & [m] \\
\hline$S_{T}$ & Espaçamento transversal ao escoamento & [m] \\
\hline$T$ & Temperatura & {$\left[{ }^{\circ} \mathrm{C}\right]$} \\
\hline$t$ & Espessura da aleta & {$[\mathrm{m}]$} \\
\hline$t$ & Número de passos do trocador de calor & \\
\hline$U$ & Coeficiente global de transferência de calor ${ }^{2}$ & {$\left[\mathrm{~kW} /\left(\mathrm{m}^{2} \mathrm{~K}\right)\right]$} \\
\hline$U$ & Incerteza expandida associada à medição & \\
\hline$u$ & Componente tipo A da incerteza & \\
\hline$u_{c}$ & Incerteza combinada associada a uma medição & \\
\hline$u_{\text {inst }}$ & Incerteza associada à resolução do instrumento & \\
\hline$u_{s}$ & Incerteza associada ao ajuste & \\
\hline$V$ & Velocidade do escoamento & {$[\mathrm{m} / \mathrm{s}]$} \\
\hline$w$ & Espaçamento entre aletas & {$[\mathrm{m}]$} \\
\hline$x$ & Observação medida & \\
\hline $\bar{x}$ & Média amostral das observações & \\
\hline$y$ & Grandeza calculada do mensurando & \\
\hline $\bar{y}$ & Média da grandeza do mensurando calculada & \\
\hline
\end{tabular}

\section{Símbolos gregos}

$\Delta \quad$ Diferença entre valores

$\delta \quad$ Diferencial inexato

$\partial \quad$ Diferencial parcial

\footnotetext{
${ }^{1}$ Em sintonia à nomenclatura clássica de transferência de calor e de incerteza de medição, o símbolo $\boldsymbol{k}$ foi mantido para simbolizar tanto o Coeficiente de Transferência de Calor por condução [kW/ (m $\mathrm{K})$ ] quanto o fator e abrangência $\mathrm{k}$ (adimensional).

${ }^{2}$ Analogamente, o símbolo $\boldsymbol{U}$ foi utilizado para denotar o Coeficiente Global de Transferência de Calor $\left[k W /\left(m^{2} K\right)\right]$ e a Incerteza expandida.
} 
$\varepsilon \quad$ Efetividade de transferência de calor

$\varphi \quad$ Graus de liberdade

$\mu \quad$ Viscosidade dinâmica

$v \quad$ Viscosidade cinemática

[Pa s]

$\left[\mathrm{m}^{2} / \mathrm{s}\right]$

\section{Subscritos}

$\begin{array}{ll}\text { ag } & \text { Água } \\ \text { ar } & \text { Ar } \\ c & \text { Fluido frio } \\ f & \text { Incrustação } \\ h & \text { Fluido quente } \\ i & \text { Lado de dentro } \\ \text { in } & \text { Entrada } \\ j & \text { j-ésimo elemento } \\ \text { limpo } & \text { Valor em condição de sujeira } \\ \text { lm } & \text { Média logarítmica } \\ m & \text { Média } \\ \text { max } & \text { Valor máximo } \\ \text { min } & \text { Valor mínimo } \\ n & \text { n-ésimo elemento } \\ \text { o } & \text { Lado de fora } \\ \text { out } & \text { Saída } \\ \text { parede } & \text { Referência à parede } \\ \text { real } & \text { Valor real } \\ \text { sujo } & \text { Valor na condição de limpeza }\end{array}$

\section{Sobrescritos}

$k \quad$ k-ésimo elemento

$n \quad$ grau- $n$ do polinômio 


\section{Introdução}

A presente dissertação de mestrado propõe uma alternativa, em tempo real, de controle metrológico do desempenho térmico e hidrodinâmico de trocadores de calor de hidrogeradores. O propósito desta alternativa é gerar ganhos de efetividade (que por sua vez resultam em ganhos econômicos) e otimizar os procedimentos de manutenção corretiva dos equipamentos responsáveis pelo arrefecimento térmico do hidrogerador.

No contexto dessas premissas, o trabalho explora alternativas relacionadas ao monitoramento contínuo do desempenho do sistema de arrefecimento de hidrogeradores ao longo de um período pré-programado de operação do sistema de geração. Este processo envolve, também em tempo real, a análise das incertezas associadas às medições das grandezas físicas impactantes no cálculo da efetividade dos trocadores de calor em operação na usina hidrelétrica.

A norma NBR-5462 (NBR-5462, 1994) define a confiabilidade de equipamentos industriais em função da sua capacidade operativa durante um dado intervalo de tempo. Ou seja, a confiabilidade de operação de um determinado equipamento está sempre associada à variável tempo. Esta confiabilidade pode ser avaliada, estatisticamente, a partir de uma distribuição de probabilidade normalmente exponencial ou Weibull ${ }^{3}$ (Chu et al. 2010; Okabe et al., 2008; Li, 2004; Jardine et al., 1985) —, que considera os parâmetros associados às condições reais de operação do equipamento objeto do estudo. Outro conceito relevante associado à segurança de operação do equipamento é a mantenabilidade, definida nesta mesma norma (NBR-5462, 1994) como a "capacidade de um equipamento para receber uma manutenção durante um intervalo de tempo especificado, levando-se em consideração, os custos associados". Ambos os conceitos confiabilidade e mantenabilidade - estão associados a uma função temporal, entendida como crítica no processo de monitoramento de trocadores de calor.

No que concerne à Metrologia, um erro comumente praticado é definir a confiabilidade metrológica de equipamentos (e.g.: validade de um certificado de calibração, tempo de vida do equipamento) sem definir um prazo para a sua

\footnotetext{
${ }^{3}$ A Análise Weibull é uma metodologia usada para realizar análises de dados de vida. Os dados de vida são o resultado de medições da vida útil de um produto. A análise de Weibull é um método eficaz para determinar as características de confiabilidade e tendências de uma população usando um tamanho de amostra relativamente pequeno de dados de teste de campo ou laboratório.
} 
validade. Esses aspectos do controle metrológico do desempenho de trocadores de calor de hidrogeradores serão abordados neste trabalho, que visa oferecer alternativas de manutenção, em tempo real, para esses tipos de equipamentos. Desse processo resultam não apenas benefícios técnicos e redução de custos gerados pela otimização de intervenções de manutenção e limpeza dos trocadores, mas, também, ganhos econômicos obtidos pela racionalização de interrupções da geração. Na sua essência, o controle metrológico de qualquer processo reflete o entendimento das incertezas associadas às medições requeridas para a sua adequada caracterização.

Diversas abordagens para a análise da incerteza de medição têm sido estudadas por especialistas da área em áreas de interesse na engenharia (Lira \& Grientschnig, 2017; Lira, 2016), visando o aproveitamento de recursos, os desenvolvimentos metodológicos voltados à redução das incertezas associadas à medição dos parâmetros críticos que caracterizam os procedimentos de cálculo de grandezas físicas associadas aos processos em estudo, mais especificamente, o cálculo da efetividade do trocador de calor. Mais recentemente, estudiosos da área se preocupam não apenas com os ganhos de efetividade de seus processos físicos, mas, também, com a capacidade inovativa no planejamento e execução de seus processos administrativos e industriais. (Miranda K.F., 2015).

No que concerne aos processos físicos, poucos são ainda os trabalhos citados na literatura especializada relacionados à análise de incerteza de medição associada a processos de transferência de calor em trocadores de calor de hidrogeradores. Uma revisão da bibliografia sobre o tema de pesquisa permitiu identificar trabalhos relacionados à incerteza associada à medição de parâmetros críticos utilizados no monitoramento da operação dos equipamentos utilizados para assegurar o adequado arrefecimento de hidrogeradores. Destacam-se os trabalhos de Park et al. (2017) e de Cho (2007), diretamente relacionados à incerteza associada à medição, notadamente dos aspectos térmicos e hidrodinâmicos e das propriedades dos fluidos de trabalho utilizados em trocadores de calor (James et al., 2007).

Pela sua abundância em usinas hidrelétricas, a água é comumente utilizada como o "fluido frio" de trabalho dos trocadores de calor de hidrogeradores, suscetível, entretanto, a contaminações por detritos, depósitos minerais e microorganismos, que são indutores de acúmulo de incrustações nas paredes internas dos tubos do trocador. A presença de incrustações nas passagens internas dos tubos do trocador é altamente indesejável já que, não apenas comprometem os mecanismos 
de transferência de calor, como também, drasticamente, impactam nos custos de bombeamento do fluido refrigerante, inegavelmente comprometendo a eficácia de operação do hidrogerador (Frota et al., 2019).

Há uma variedade de técnicas de limpeza para restaurar as condições hidrodinâmicas e, portanto, a efetividade do trocador de calor (Bott, 1997). Dependendo do tipo de material presente na água, podem ser usadas técnicas de limpeza química (Bott, 1996, 1997; Frota et al., 2014); limpeza magnética (Vemeiren, 1958; Baker e Judd, 1996), limpeza eletrônica (Fan e Cho, 1997; Fan, 1997; Cho e Choi, 1998; Cho et al., 1998; Romo et al., 2007, Takahashi et al., 2002; Braga et al., 2011), ou limpeza por abrasão (Castro-Pacheco et al., 2019).

De um modo geral, todas as citadas técnicas de limpeza acima referenciadas (denominadas técnicas off-line) requerem a parada técnica das turbinas. Embora comumente apresentadas como técnicas de limpeza que não demandam a parada técnica da turbina, também as técnicas que utilizam dispositivos magnéticos e/ou eletrônicos para excitarem o escoamento visando desprender a incrustação das paredes internas do trocador, também essas técnicas acabam requerendo a interrupção da geração já que apenas removem parte da incrustação.

Para evitar as desvantagens associadas a cada uma dessas técnicas, outras alternativas de limpeza de trocadores de calor de hidrogeradores vêm sendo estudadas no âmbito de uma linha de pesquisa do Programa de Pós-Graduação em Metrologia da PUC-Rio, que já concluiu três Projetos de P\&D para o setor elétrico, todos eles devidamente documentados em relatórios de projetos de $\mathrm{P} \& \mathrm{D}$ realizados (Frota, 2013; Frota, 2014; Frota, 2018). Deste esforço de pesquisa e desenvolvimento, resultou uma alternativa on-line de limpeza, que permite a desobstrução total dos tubos dos trocadores de calor do hidrogerador sem a necessidade da parada técnica da turbina hidráulica, portanto, sem requerer a interrupção da geração. A implementação desse processo on-line de limpeza foi viabilizada por um equipamento construído e validado por pesquisadores do Programa de Metrologia da PUC-Rio, denominado pela sua sigla SIREA (Sistema Injetor e Recuperador de Esferas Abrasivas), que faz uso de um sistema servohidráulico que injeta e recupera esferas abrasivas nos tubos do trocador, assim removendo, de forma contínua e controlada, a indesejável incrustação, que tão drasticamente compromete a efetividade térmica do sistema, sem interromper a geração de energia elétrica (Frota, 2018). 
O desenvolvimento desses projetos produziu, em paralelo, trabalhos de final de curso de engenharia, pesquisas de mestrado e publicações sobre o tema, com o foco concentrado em trocadores de calor utilizados no arrefecimento de hidrogeradores (Braga et al., 2011; Frota et al., 2014; Oliveira, 2015; Nunes, 2018; Oliveira, 2016; Barbosa et al., 2017; Oliveira et al., 2017, Rios et al., 2017; e Rios, 2017). Mais recentemente, ainda como resultado de trabalho desta linha de pesquisa, um estudo relacionado à incerteza associada ao cálculo da efetividade de trocadores de calor (Frota et al, 2019) foi apresentado em relevante congresso internacional sobre o tema, que reúne fabricantes e estudiosos em processos de limpeza de trocadores de calor (décima terceira Edição do Heat Exchanger Fouling and Cleaning Conference, realizado na Polônia, em 2019). A participação neste fórum especializado constituiu parte da estratégia de avaliar a atualidade do tema e de coletar informações sobre o complexo fenômeno de formação no fouling no interior dos tubos, fenômeno este que cria dificuldades experimentais para a medição de propriedades físicas associada ao escoamento dos fluidos de trabalho que estes precisam superar a resistência (variável no tempo) imposta pela incrustação. A participação neste fórum especializado inspirou a definição do tema desta pesquisa de mestrado, que desenvolveu alternativas não convencionais de cálculo da efetividade de trocadores de calor de hidrogeradores sem a necessidade de se realizar a medição da temperatura de saída do fluido quente do trocador (ar). A alternativa proposta elimina uma dificuldade de caráter experimental, conceitualmente discutida na seção 2.6, já que o seu entendimento depende da formulação do conceito de efetividade térmica.

O trabalho não apenas desenvolve alternativas de cálculo da efetividade do trocador, como, também, valida as alternativas propostas com base em dados reais de monitoramento dos trocadores de calor de um dos hidrogeradores da usina hidrelétrica Fontes Nova, controlada pela Light Energia S/A que, interessada nos resultados da pesquisa, facilitou o acesso às suas instalações da usina Fontes Nova (Piraí/RJ) permitindo implementar um sistema de medição para monitoramento de grandezas físicas relacionadas à operação dos trocadores de calor de um dos três grupos hidrogeradores da usina (Grupo hidrogerador C). 


\section{1}

\section{Definição do problema de pesquisa}

A busca por ganhos de eficiência operacional em trocadores de calor de hidrogeradores requer, dentre outros fatores que são próprios dos processos convencionais de limpeza, uma ação coordenada de manutenção preventiva para orientar a parada técnica das turbinas antes que seu desempenho térmico/hidrodinâmico esteja excessivamente comprometido. Usualmente, processos de manutenção requerem a indesejável parada dos hidrogeradores para viabilizar a limpeza manual (por escovamento) das superfícies internas dos tubos do trocador de calor, que ficam impregnados de incrustações de diferentes naturezas.

Nesse contexto, a pesquisa suscita o seguinte questionamento: como calcular a efetividade de trocadores de calor do tipo água-ar, com o ar escoando externamente aos tubos, em escoamento cruzado, porém sem a necessidade de medir a temperatura de saída do ar (fluido quente do trocador)?

Deste questionamento de caráter global, resultam os seguintes questionamentos específicos:

- Quais são as grandezas físicas críticas que impactam no cálculo da incerteza de medição e da efetividade de trocadores de calor?

- Qual a relevância de se definir critérios específicos para se avaliar, em tempo real, a incerteza associada ao cálculo da efetividade de trocadores de calor de hidrogeradores?

- Que alternativas de ferramentas computacionais podem contribuir para resolver o sistema não linear de equações que governam os mecanismos de transferência de calor entre os fluidos de trabalho do trocador de calor objeto do estudo visando o cálculo da efetividade e das incertezas associadas?

\section{2}

\section{Objetivos: geral e específicos}

Com o propósito de responder à questão principal, o objetivo central da dissertação é propor uma metodologia de cálculo da efetividade térmica de trocadores de calor de feixes de tubos paralelos, de fluxo cruzado, usualmente utilizados no sistema de arrefecimento de hidrogeradores. Considerando a dificuldade experimental de se medir a temperatura de saída do ar (fluido de trabalho quente do trocador de calor), que escoa externamente aos tubos em um escoamento cruzado, permanentemente instável pelos sucessivos descolamentos da camada limite do escoamento externo em torno dos tubos, o trabalho propõe 
alternativas de cálculo da efetividade do trocador sem a necessidade de se medir a temperatura de saída do ar. Entende-se que a efetividade deve ser analisada a partir da medição das grandezas físicas impactantes, que geram uma grande quantidade de dados durante o processo contínuo de monitoramento do desempenho do hidrogerador. Para atingir este objetivo principal, os seguintes objetivos específicos foram definidos:

- Identificar as grandezas físicas críticas que impactam no cálculo da efetividade do trocador de calor e avaliar as incertezas associadas à medição dessas grandezas;

- Estudar alternativas distintas de cálculo da efetividade do trocador visando orientar o monitoramento do sistema de arrefecimento do hidrogerador.

- Avaliar alternativas de métodos numéricos capazes de resolver o sistema não linear de equações que regem os mecanismos de transferência de calor associados à solução do problema em estudo.

\section{3}

\section{Metodologia}

De acordo com a sistemática proposta por Vergara (2002), a pesquisa pode ser classificada, quanto aos seus fins, como uma pesquisa de tipo descritiva, aplicada e intervencionista.

A Figura 1 apresenta o desenho da pesquisa, desenvolvida segundo duas vertentes de análise (exploratória / descritiva e experimental), seguidas das fases da pesquisa aplicada e da fase conclusiva.

Quanto aos meios de investigação relacionados aos aspectos térmicos e hidrodinâmicos, a metodologia da pesquisa envolve:

- Pesquisa bibliográfica e documental sobre o tema geral e temas centrais da pesquisa, como são indicados na fase exploratória e descritiva da Figura 1;

- Identificação das grandezas físicas críticas que impactam na incerteza de medição associada ao cálculo da efetividade de trocadores de calor;

- Desenvolvimento de uma metodologia para se estimar a incerteza associada à efetividade de trocadores de calor;

- Avaliação da confiabilidade metrológica dos diferentes instrumentos utilizados na medição das grandezas físicas monitoradas durante o processo de coleta de dados. 

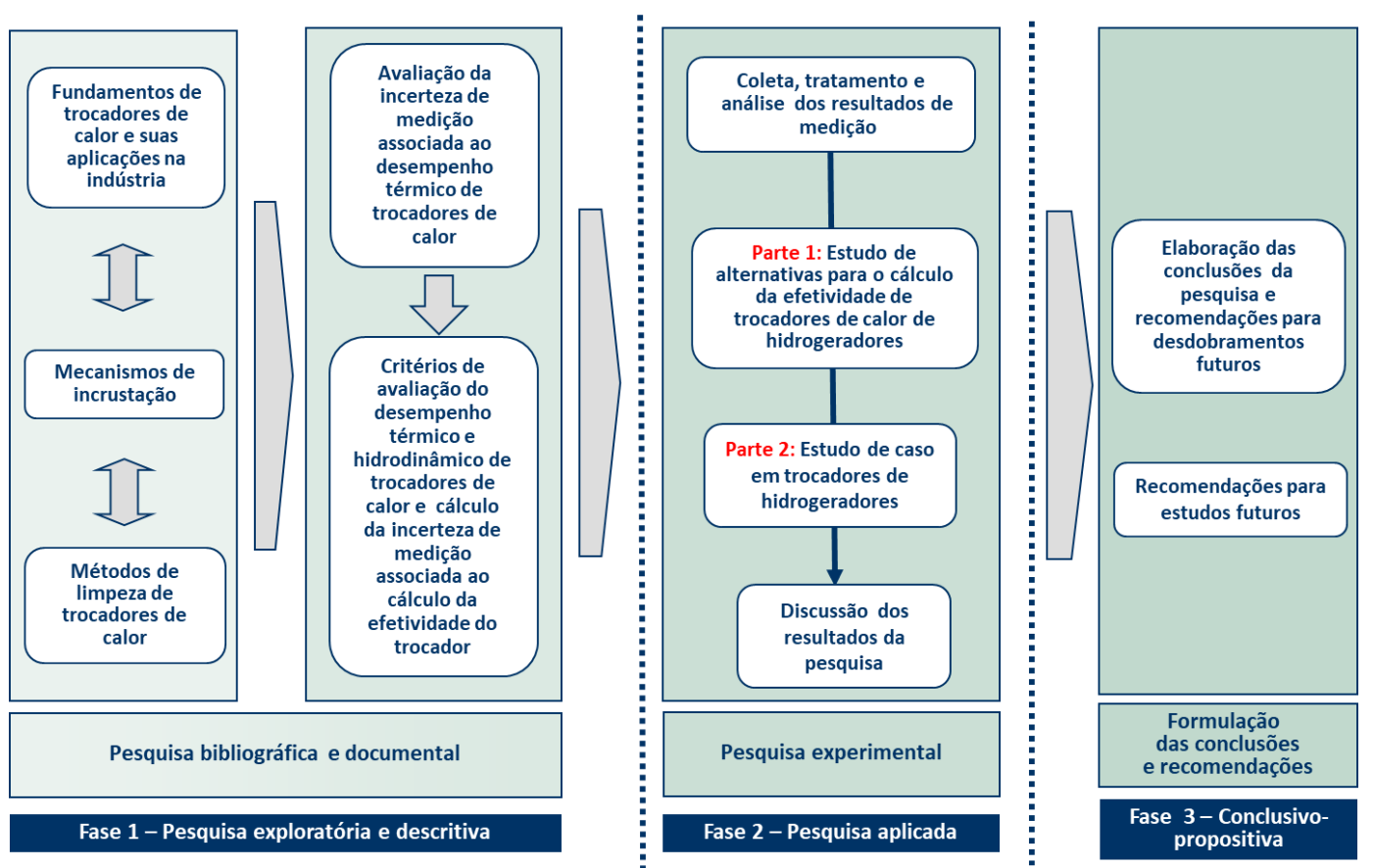

Figura 1. Desenho da pesquisa, seus componentes e métodos

\subsection{1 \\ Fase exploratória e descritiva}

Esta fase partiu de uma pesquisa bibliográfica e documental, focada em identificar trabalhos conceituais, empíricos e documentos de referência para a delimitação no tema central da pesquisa: "Desenvolvimento e validação experimental em usina hidrelétrica de alternativas de cálculo da efetividade de trocadores de calor". Na sequência, aprofundou-se a revisão bibliográfica, buscando-se trabalhos no campo dos trocadores de calor e suas aplicações no âmbito industrial, mesmo que estudos sobre o desempenho desses equipamentos, assim como uma revisão dos métodos alternativos de limpeza. Na sequência, pesquisou-se a ainda incipiente literatura relacionada à análise de incerteza associada ao cálculo da efetividade de trocadores de calor. A pesquisa bibliográfica sobre o tema confirma a originalidade do trabalho proposto, tendo em vista que a alternativa usual de cálculo da efetividade de trocadores de calor fundamenta-se na medição de temperaturas dos fluidos de trabalho, incluindo-se a temperatura de saída do fluido quente, considerada problemática do ponto de vista experimental.

A pesquisa documental cobriu estudos de normas e guias para o cálculo e expressão da incerteza (GUM, 2008) associada à medição de grandezas físicas impactantes e alternativas de métodos numéricos para se resolver o sistema não 
linear de equações que regem os mecanismos de troca de calor entre os fluidos de trabalho do trocador de calor objeto do estudo. Dentre os documentos normativos mais relevantes, foram identificados a normativa própria de trocadores de calor (TEMA, 1941; NBR-5462, 1994; NBR12555, 1991; ISO12212, 2012).

A partir dos resultados da pesquisa bibliográfica e documental, o trabalho concentrou-se na etapa experimental, baseada na coleta, tratamento e análise de dados de medição, assim como uma modelagem conceitual do fenômeno estudado, que propôs uma simplificação do modelo de cálculo da efetividade de trocadores.

A Figura 2, a seguir, apresenta o mapa conceitual da pesquisa, uma visão geral e esquemática dos resultados da pesquisa.

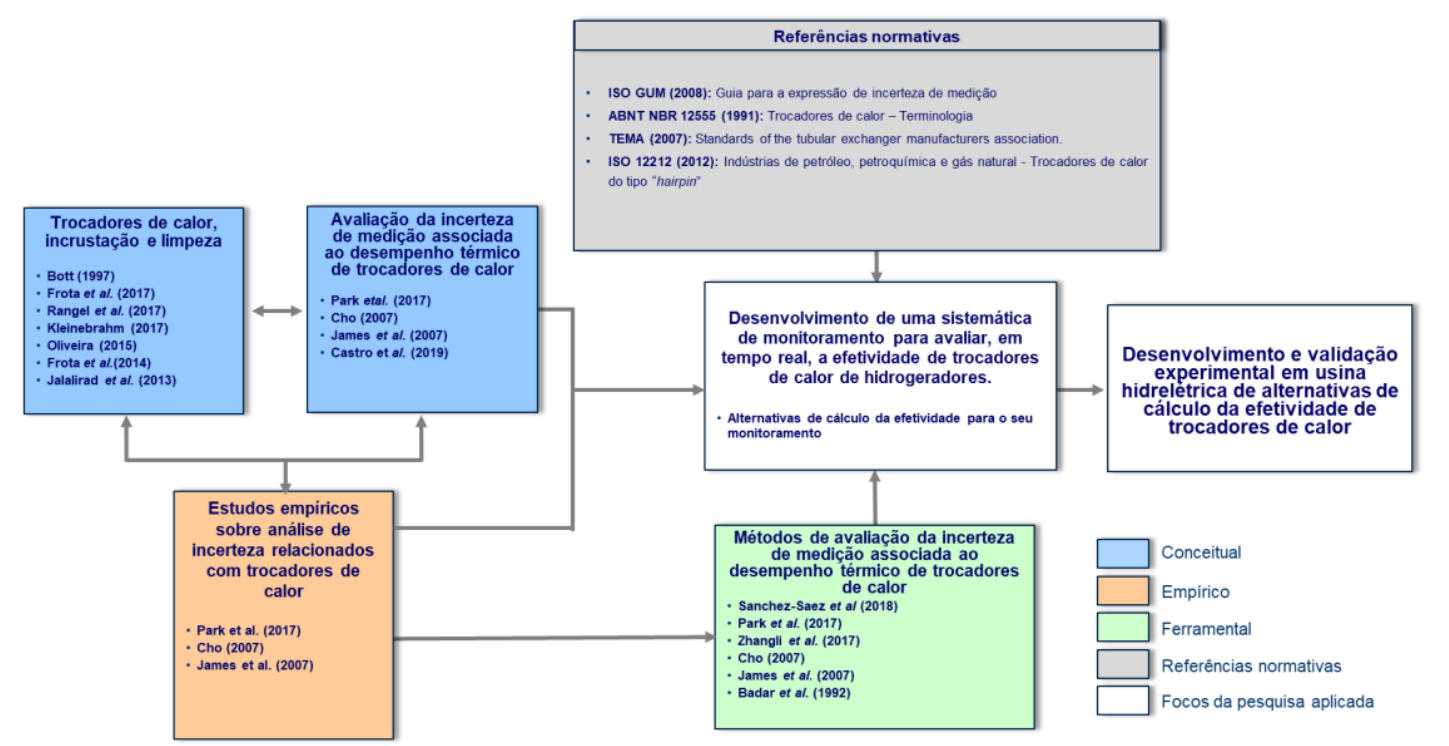

Figura 2. Mapa conceitual da pesquisa

\subsection{2}

Fase de pesquisa aplicada

Com o objetivo de desenvolver a sistemática de monitoramento proposta na fase anterior, o trabalho considerou adequada a confiabilidade metrológica dos instrumentos utilizados na medição das diferentes grandezas envolvidas no processo de coleta de dados, tal qual documentado no Relatório de P\&D responsável por esta parte do desenvolvimento (Frota, 2018). As medições de temperatura dos fluidos de trabalho do trocador foram realizadas por termo resistências do tipo Pt-100, enquanto as medições de pressão por transdutores capacitivos.

Na sequência, trabalhou-se nos processos de coleta e tratamento dos dados de medição, que fundamentam a metodologia e a sistemática de monitoramento da 
efetividade de trocadores de calor durante o regime normal e contínuo de funcionamento do hidrogerador. Beneficiando-se dos resultados do esforço de trabalho desenvolvido pelo mencionado projeto de $\mathrm{P} \& \mathrm{D}$, foi possível desenvolver alternativas de cálculo para avaliar o desempenho térmico dos trocadores de calor.

\subsection{3}

\section{Fase conclusivo-propositiva}

No curso de desenvolvimento desta fase final da pesquisa, foram elaboradas as conclusões da pesquisa e formuladas sugestões de temas para estudos acadêmicos futuros, entendidos como desdobramentos naturais da pesquisa de mestrado.

\section{4}

\section{Estrutura da dissertação}

A dissertação encontra-se estruturada em seis capítulos, incluindo esta introdução.

O capítulo 2 resume os conceitos clássicos da transferência de calor requeridos para fundamentar uma análise do desempenho térmico de trocadores de calor, notadamente de trocadores tubulares utilizados no arrefecimento térmico de hidrogeradores. Discute os tipos clássicos de trocadores de calor existentes no mercado e suas aplicações no setor industrial, principalmente no âmbito na geração de energia. O capítulo discute, também, as diferentes alternativas de limpeza comumente utilizadas para assegurar eficácia do funcionamento dos trocadores de calor. Do ponto de vista teórico, conceitua o que a literatura especializada consagrou definir como "efetividade térmica do trocador" e discute os parâmetros para a medição e avaliação do desempenho térmico e hidrodinâmico de trocadores de calor. Na sequência, apresenta e discute as alternativas de cálculo da efetividade em função dos parâmetros de monitoramento disponíveis.

O capítulo 3 descreve os fundamentos da incerteza de medição; a classificação dos tipos de incerteza associada à medição das grandezas físicas correlacionadas; outros conceitos aplicáveis à propagação e expressão da incerteza expandida associada e propõe uma sistemática de monitoramento da incerteza associada às medições críticas que impactam no cálculo da efetividade térmica do trocador de calor. 
O capítulo 4 descreve as alternativas de cálculo da efetividade do trocador de calor enquanto acoplado ao sistema de geração hidrelétrica e discute os resultados das medições realizadas em tempo real. Na sequência, expressa a incerteza associada às medições críticas que impactam no cálculo da efetividade do trocador de calor. Nesse contexto, discute os fundamentos teóricos que regem os mecanismos de transferência de calor entre os fluidos de trabalho do trocador estudado e desenvolve as alternativas de cálculo da efetividade visando seu monitoramento em tempo real. Entendido como contribuição original do trabalho, propõe um algoritmo de cálculo da efetividade do trocador fundamentado na medição das grandezas físicas monitoradas durante a operação do trocador. Complementando a análise, valida as alternativas propostas de cálculo da efetividade fazendo uso de dados reais obtidos pelo monitoramento dos trocadores de calor de um dos hidrogeradores em operação na usina hidrelétrica Fontes Nova.

Finalizando, o capítulo 5 apresenta as conclusões da pesquisa e encaminha propostas para desdobramentos futuros do trabalho. 


\section{2 \\ Fundamentos teóricos da transferência de calor}

\section{1}

\section{Breve histórico}

O conceito físico de calor está intimamente relacionado com o homem desde a pré-história, sendo um dos primeiros fenômenos naturais caracterizados pelo homem. Entretanto, só em meados do século XIX, o homem conseguiu um real entendimento físico do conceito associado a calor (Silva, 2013; Camelo, 2008).

Em 1798, o estadunidense Benjamin Thompson (1753-1814) demostrou que o calor podia ser gerado pelo atrito entre dois corpos (Martins, 1994; Taton, 1972). Não conseguindo explicar o fenômeno da transferência de calor, cientistas do século XVIII conceberam a existência do que foi à época denominado de calórico, um pseudo fluido ("fluido imponderável”) com características bem definidas (desprovido de massa, incolor, inodoro e insípido) que, embora artificial, permitia explicar a transferência de energia (calor) entre dois corpos (o corpo quente cedendo calórico para o corpo frio!). Essa sutil conceituação (errônea, mas conveniente à época) somente caiu por terra em 1843 com o trabalho do físico inglês Joule (18181889), que explicou o calor como uma forma de energia.

Hoje o conceito de calor encontra-se substancialmente consolidado e é definido como "uma forma de energia em trânsito entre dois corpos com temperaturas distintas", que resulta da energia associada ao movimento aleatório de átomos e moléculas. Esse conceito fundamenta-se no desenvolvimento da teoria cinética que considera as moléculas como partículas de matéria em movimento e, consequentemente, dotadas de energia cinética.

$\mathrm{Na}$ realidade, a formalização hoje aceita do conceito de calor se beneficiou de outros estudos paralelos anteriores sobre a teoria cinética, em meados do século XVIII, com o trabalho de Mikhail Lomonosov (1747), seguido dos trabalhos de Georges-Louis Le Sage (1818), John Herapath (1816) e John James Waterston (1843), que ligavam suas pesquisas com o desenvolvimento de explicações mecânicas da gravitação. Mas foi somente em 1856 que August Krönig propôs um modelo simples de gás-cinético, que considerava apenas o movimento de translação das partículas. Na sequência de outros relevantes estudos, Rudolf Clausius (1857) descreveu os movimentos translacional, rotacional e vibracional das moléculas e introduziu o conceito de "livre caminho médio de uma partícula", enquanto James 
Clerk Maxwell (1859) conceituou o átomo como "um ponto material, envolvido e cercado por forças potenciais", assim postulando que o choque de uma "molécula flutuante" contra um corpo sólido em sucessão constante causa a chamada "pressão do ar" e dos outros gases." Baseado nesses conceitos revolucionários, formulou a primeira lei estatística na física. Coube a Ludwig Boltzmann (1871) generalizar a realização de Maxwell e formular a distribuição de Maxwell-Boltzmann, ineditamente estabelecendo a conexão logarítmica entre entropia e probabilidade. Mas foi somente no início do século XX, com os inovadores trabalhos de Einstein (1905) e Smoluchowski (1906), que o movimento browniano sucedeu previsões quantitativas precisas baseadas na teoria cinética, quando os átomos deixaram de ser considerados "estruturas puramente hipotéticas".

\section{2}

\section{Mecanismos de transferência de calor de interesse ao estudo}

Em Física, o fenômeno transferência de calor (também denominado transmissão, propagação, transferência térmica) denota a transferência de energia térmica de uma massa (corpo) mais quente para uma massa mais fria, ou seja, entre dois sistemas de temperaturas diferentes. Três são os mecanismos clássicos de transferência de calor, i.e.: condução, convecção e radiação (Bergman, 2011; Cengel, 2009; Welty et al., 1982).

No que concerne ao projeto de pesquisa objeto desta dissertação de mestrado - trocadores de calor de hidrogeradores_-, dois são os mecanismos dominantes (condução e convecção) de transferência de calor entre os fluidos de trabalho (usualmente água e ar) do trocador, a seguir conceituados:

- Condução de calor é a transferência de energia térmica através das partes sólidas do trocador (paredes das tubulações e carcaça do trocador), na direção do gradiente de temperatura imposto. A condução de calor resulta da energia cinética dos átomos e moléculas (isto é, o calor), transferido por colisões entre átomos e moléculas vizinhas. $\mathrm{O}$ calor flui das temperaturas mais altas (moléculas com maior energia cinética) para as temperaturas mais baixas (moléculas com menor energia cinética). A capacidade dos materiais conduzirem calor é denominada condutividade térmica do material. Em geral, sólidos são melhores condutores que os líquidos, e estes, melhores que os gases.

- Convecção refere-se ao processo de transmissão de calor que ocorre a partir da movimentação de um meio fluido (massa fluida, gasosa ou líquida), de uma região para outra. No caso dos trocadores de calor, as paredes das tubulações e da carcaça do trocador, em contato com os fluidos de trabalho, impõem um gradiente de temperatura que induzem movimentos nos fluidos 
de trabalho do trocador. O mecanismo de convecção é denominado de convecção natural quando resulta da diferença de densidade, induzida por diferenças de temperatura presentes no próprio meio fluido. Em ambos os processos de transferência de calor experimentados pela água ("fluido frio", que escoa no interior dos tubos do trocador) e pelo ar ("fluido quente", que é forçado externamente a esses tubos) esses são denominados convecção forçada, já que o fluido é impulsionado por uma bomba hidráulica e o ar (escoando por fora dos tubos do trocador) é forçado por pás fixadas no rotor do gerador. Externamente ao trocador, usualmente imerso no ar externo da casa de máquinas, ocorrerá um mecanismo de convecção natural caso a temperatura externa da carcaça esteja a uma temperatura superior à temperatura do ar externo. Um trocador de calor eficaz é aquele que consegue maximizar os mecanismos de troca entre os fluidos de trabalho, mantendo a temperatura da carcaça externa à temperatura do ar externo do meio ambiente que o envolve; em outras palavras, aquele cuja convecção natural seja desprezível, assim indicando um bom desempenho térmico do trocador de calor. Nesse contexto, o trocador de calor de alta efetividade é aquele que maximiza a troca de calor entre o fluido quente (ar) e o fluido "frio" (água), no caso do trocador de calor utilizado para resfriamento do núcleo do hidrogerador.

\section{3 \\ Tipos de trocadores de calor e suas aplicações}

Sem pretender fazer uma extensa revisão da literatura, esta seção descreve, de forma sucinta, os principais tipos de trocadores de calor, notadamente os trocadores de calor do tipo tubular, portanto factíveis de serem submetidos a um processo de limpeza (para remoção da incrustação que se deposita no interior dos tubos) pela técnica de limpeza on-line concebida pelo Programa de Pós-Graduação em Metrologia da PUC-Rio, técnica essa que faz uso de artefatos de limpeza (esferas abrasivas) que são transportadas pelo próprio fluido de trabalho (água), que circula pela ação de uma bomba hidráulica e que realiza a limpeza sem a necessidade de interromper a geração.

Um trocador de calor é caracterizado por permitir a transferência de energia entre seus fluidos de trabalho (usualmente dois, comumente denominados fluidos "quente" e "frio" do trocador).

A literatura especializada apresenta a classificação dos trocadores de calor. Essa classificação depende, principalmente, do arranjo dos tubos, do número de passos e do sentido do escoamento (Cengel, 2009). No geral, os trocadores de calor podem ser classificados como: (i) regeneradores, (ii) trocadores de tipo aberto e (iii) trocadores de tipo fechado ou recuperadores (Welty, 1982). 
Os regeneradores são trocadores que permitem o escoamento alternado entre os fluidos quente e frio através do mesmo espaço, porém, com a menor mistura possível entre ambos os fluxos. A quantidade de energia transferida do fluido quente ao fluido frio depende, principalmente, da condutividade térmica do material dos tubos, propriedades físico-químicas dos fluidos de trabalho, da geometria e propriedades térmicas das superfícies de troca do trocador (Welty, 1982). Já nos trocadores de tipo aberto, ocorre uma mistura dos fluidos no interior do trocador. Os fluidos quente e frio entram no trocador e saem em uma única corrente (Welty, 1982). Por fim, os recuperadores são trocadores em que os fluidos quente e frio não estão em contato direto, ou seja, não se misturam. Os fluidos de trabalho do trocador estão separados pela parede do tubo, que podem ser superfícies planas ou curvas, dependendo do tipo de trocador. Assim, a transferência de calor, por convecção, é realizada do fluido quente para a parede e desta para o fluido frio, também pelo mecanismo de convecção.

Comumente, os trocadores são classificados pelo seu número de passes, ou seja, pelo número de vezes que um dos fluidos de trabalho (normalmente o "fluido frio") circula pelo trocador em movimentos de "vai e volta". São, assim, denominados trocador de 1 único passe ou trocador de calor múltiplos passes.

Uma configuração comumente usada na indústria é o trocador casco-tubo. Essa configuração apresenta múltiplas formas, em função do número de passes percorrido pelo fluido no interior do casco. Na Figura 3 é mostrada a configuração mais simples, de um único passe (embora de múltiplos tubos); i.e.: o fluido circula pelos tubos dentro do casco uma única vez.

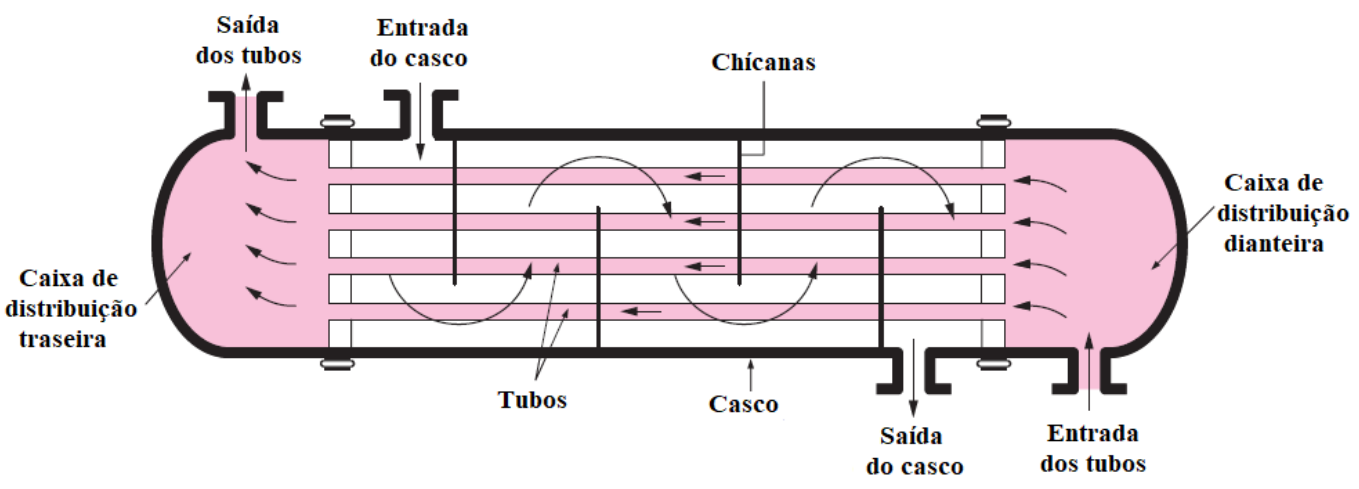

Figura 3. Trocador de calor casco-tubo de um único passe

Fonte: (Cengel, 2009). O fluido frio circula pelo interior dos tubos. 
Usualmente são usadas chicanas para maximizar a troca de calor, já que estas induzem turbulência no escoamento do fluxo cruzado, obrigando ao fluido que escoa externamente ao tubo circular no entorno de todos os tubos do trocador. A Figura 4 ilustra diferentes tipos de trocador de calor.

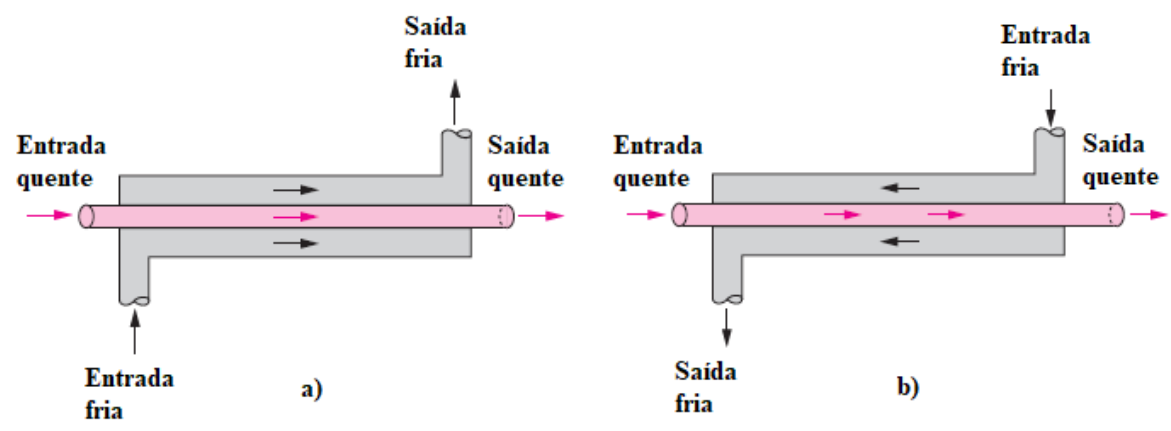

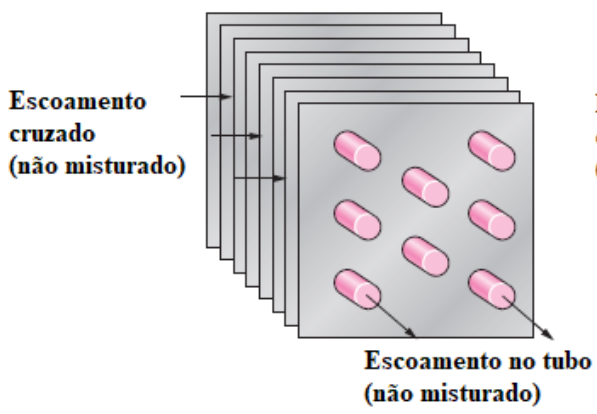

c)

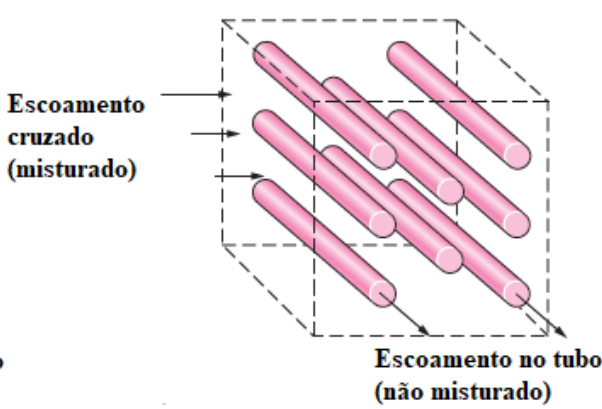

d)

Figura 4. Classificação de trocadores segundo a natureza do escoamento

Fonte: (Cengel, 2009). Figura 4a: escoamento paralelo; Figura 4b: escoamento contracorrente; Figura 4c: escoamento cruzado, não misturado e Figura 4d: escoamento cruzado, misturado.

No que concerne à direção das correntes dos fluidos de trabalho, os trocadores denominam-se: (i) trocadores de calor de escoamento paralelo (Figura 4a), cujos fluidos de trabalho escoam na mesma direção e no mesmo sentido; (ii) trocadores contracorrente (Figura 4b), cujos fluidos de trabalho escoam na mesma direção porém em sentidos opostos e (iii) escoamento cruzado, cujos fluidos escoam perpendicularmente, um em relação ao outro (Cengel, 2009; Welty, 1982).

Em trocadores de calor compactos, normalmente os fluidos de trabalho circulam perpendicularmente um ao outro, configuração essa conhecida como escoamento cruzado. A Figura 4c ilustra um tipo de escoamento sem mistura já que as aletas do trocador de calor forçam o escoamento do fluido através de um determinado espaço entre elas, assim evitando um movimento transversal do fluido (i.e.: paralelo aos tubos). Já na Figura 4d ilustra-se um escoamento com mistura, 
uma vez que o fluido que escoa externamente aos tubos é livre para escoar na direção transversal (Cengel, 2009). Não obstante esta denominação "com mistura" seja usual na literatura, ela não se refere à mistura do fluido "quente" com o fluido "frio", mas, sim, à mistura do fluido que escoa externamente pelos tubos com ele próprio, conforme ilustrado na Figura 4d, na ausência de aletas separadoras.O trocador de calor de duplo tubo é o trocador com a configuração mais simples existente no mercado. A Figura $4 \mathrm{a}$ e Figura $4 \mathrm{~b}$ ilustram duas possíveis configurações: escoamento paralelo e contracorrente, respetivamente. Compõemse de dois tubos concêntricos de diferente diâmetro, pelos quais escoam os fluidos de trabalho; comumente, o fluido quente escoa no tubo e o fluido frio por fora deste.

\section{4}

\section{Estudo de caso: trocador de calor de hidrogerador}

No que concerne esta dissertação de mestrado, o equipamento objeto de estudo é um dos trocadores de calor utilizados no sistema de resfriamento do núcleo de um hidrogerador (equipamento gerador de energia elétrica numa usina hidrelétrica). O trocador de calor é usado no resfriamento do ar que é forçado por meio de pás soldadas no corpo do rotor visando arrefecer o núcleo do rotor e seus cabos de circuitos elétricos. Esse processo de resfriamento ocorre no trocador de calor, por meio do fluido frio, usualmente água da própria usina, captada do canal de fuga das turbinas (i.e.: água que já foi utilizada na geração de energia). Usualmente, nessas instalações, são utilizados trocadores de calor do tipo cruzado, ilustrado na Figura 4d. Um sistema paralelo de arrefecimento dos mancais dos eixos da turbina e do gerador a ele acoplado, faz uso de trocadores de calor água-óleo, de placas planas paralelas, não discutidos neste trabalho.

Para contextualizar, a Figura 5 ilustra uma configuração típica do sistema de arrefecimento de um dos hidrogeradores de uma usina hidrelétrica4. A Figura 5a documenta o momento da retirada para a intervenção de limpeza de um dos trocadores do hidrogerador do grupo C. Na Figura 5 b mostra-se o posicionamento dos seis trocadores de calor instalados no interior da carcaça do hidrogerador.

\footnotetext{
${ }^{4}$ Hidrogerador do grupo gerador $\mathrm{C}$ da usina Fontes Nova, de propriedade da Light Energia S/A, cujo acesso às instalações foi autorizado no âmbito de um projeto de P\&D desenvolvido pelo Programa de Pós-Graduação em Metrologia da PUC-Rio.
} 


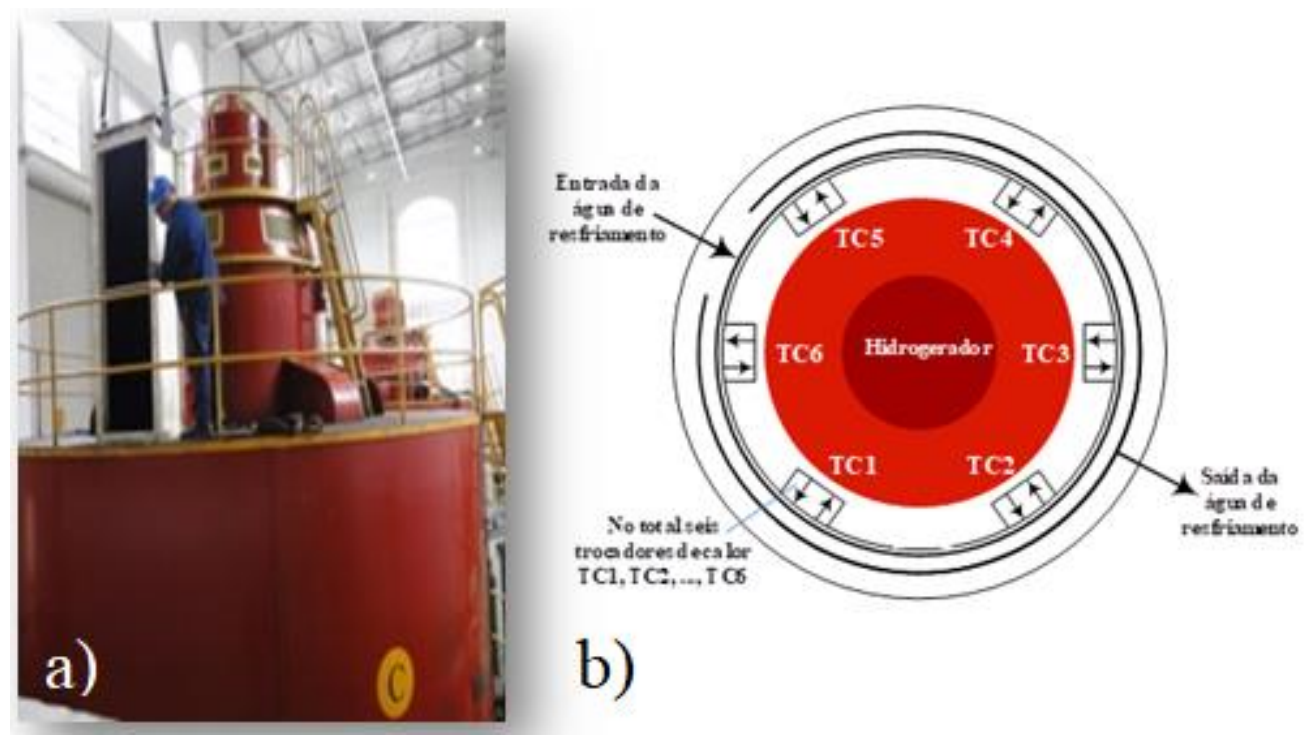

Figura 5. Unidade hidrogeradora e posicionamento dos trocadores de calor

Fig. 5a: ilustra a retirada de um trocador da carcaça e Fig. 5b: seis trocadores instalados

A imagem da esquerda (5a) mostra o hidrogerador com sua carcaça, no interior da qual encontram-se instalados os seis trocadores de calor do sistema de arrefecimento. Em particular, esta figura documenta o momento em que um dos trocadores de calor está sendo desinstalado para ser submetido ao processo off-line de limpeza. Em vista de topo, a figura (5b) ilustra o hidrogerador, circundado por seus seis trocadores de calor (TC1, TC2, ..., TC6). Este desenho esquemático auxilia no entendimento do sistema de resfriamento do hidrogerador e posiciona os trocadores de calor no interior da carcaça do hidrogerador monitorado durante o estudo do desempenho do trocador de calor TC1.

Os trocadores têm, por função, arrefecer o ar forçado pelas pás fixadas no rotor do gerador e cuja função é o resfriamento dos circuitos elétricos do hidrogerador como um todo. Portanto, os trocadores fazem uso da água da geração como "fluido frio" que circula pelos tubos dos trocadores de calor para esfriar o ar ("fluido quente"), que é forçado, em escoamento cruzado, externamente aos tubos do trocador.

A Figura 6 mostra um desses trocadores de calor aberto, permitindo observar seus 75 tubos externamente aletados (diâmetro interno, $D i=23,30 \mathrm{~mm}$; diâmetro externo, $D o=27,90 \mathrm{~mm}$ ). O fluido frio (água) escoamento pelo interior dos tubos, em seis passes, enquanto o fluido quente (ar), que se deseja resfriar, escoa externamente aos tubos aletados. 


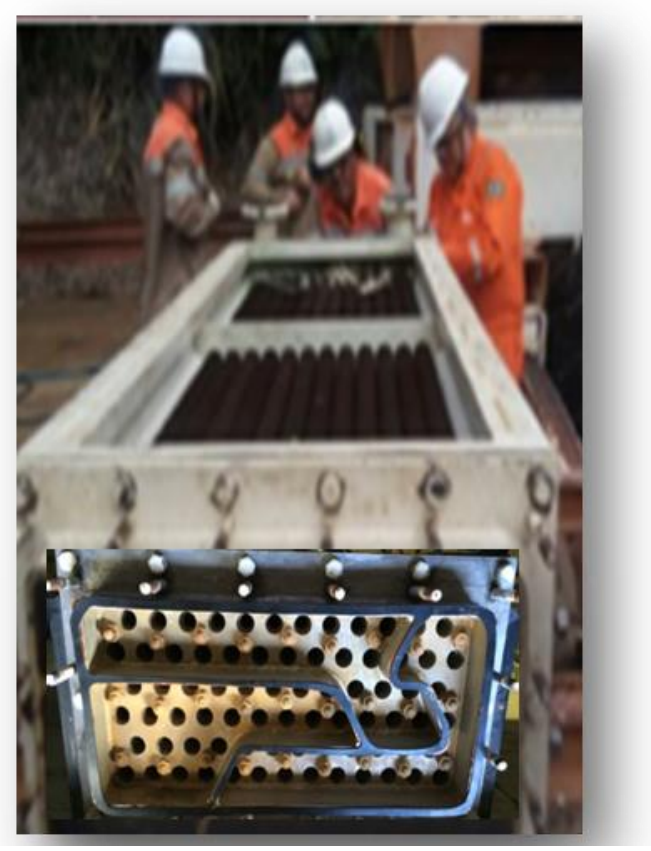

Figura 6. Trocador de calor aberto para limpeza manual (limpeza off-line)

A Figura mostra, também, a parte externa dos tubos aletados ao longo de seu comprimento, em torno dos quais circula o ar, responsável pelo resfriamento do sistema elétrico do hidrogerador.

\subsection{1}

\section{Coeficiente global de transferência de calor}

A Equação (1) descreve os mecanismos clássicos combinados (convecção e condução) de transferência de calor entre os fluidos de trabalho do trocador, na realidade um complexo processo que envolve convecção de calor do lado dos fluidos e condução através das paredes das tubulações (Kays \& London, 1964).

$$
\dot{Q}=U A_{s} \Delta T_{m}
$$

Nesta equação, $\mathrm{U}\left(\mathrm{kW} /\left(\mathrm{m}^{2} . \mathrm{K}\right)\right)$ é o coeficiente global de transferência de calor; $\mathrm{A}_{\mathrm{s}}\left(\mathrm{m}^{2}\right)$, a área de seção transversal e $\Delta \mathrm{T}_{\mathrm{m}}\left({ }^{\circ} \mathrm{C}\right)$, a diferença de temperatura entre os fluidos de trabalho.

Não obstante a aparente forma simples da Equação (1), a determinação do coeficiente global de transferência de calor U-crítico na mensuração do desempenho térmico dos trocadores de calor- é extremamente complexa. A sua determinação depende de diversos fatores, do conhecimento de propriedades físicoquímicas dos fluidos de trabalho, dos materiais envolvidos, dos mecanismos de troca de calor (convecção e condução) e, também, do estado de limpeza/incrustação 
das superfícies de troca de calor. Resultados de inúmeras pesquisas experimentais (Kays \& London, 1964 e Bott , 1997) documentam faixas de variação do coeficiente global de transferência de calor para diferentes configurações de escoamento e tipos de fluidos como é mostrado na Tabela 1.

Tabela 1. Valores típicos do coeficiente de transferência de calor Dados aplicáveis a trocadores de calor (Cengel, 2009)

\begin{tabular}{l|c}
\hline \multicolumn{1}{c|}{ Tipo de trocador de calor } & $\mathbf{U}\left(\mathbf{W} / \mathbf{m}^{2}{ }^{\circ} \mathbf{C}\right)$ \\
\hline Água-água & $850-1700$ \\
Água-óleo & $100-350$ \\
Água-gasolina ou querosene & $300-1000$ \\
Aquecedores de água de alimentação & $1000-8500$ \\
Vapor-óleo combustível leve & $200-400$ \\
Vapor-óleo combustível pesado & $50-200$ \\
Condensador de vapor & $1000-6000$ \\
Condensador de freon (resfriado a água) & $300-1000$ \\
Condensador de amônia (resfriado a água) & $800-1400$ \\
Condensador de álcool (resfriado a água) & $250-700$ \\
Gás-gás & $10-40$ \\
Água-ar em tubos aletados (água nos tubos) & $30-60 * ; 400-850 * *$ \\
Vapor-ar em tubos aletados (vapor tubos) & $30-300 * ; 400-4000 * *$ \\
\hline *Com base na superfície do lado do ar \\
**Com base na superfície do lado da água ou do vapor
\end{tabular}

Quando ambos os mecanismos de transferência de calor, por convecção e condução, são considerados conjuntamente, o produto $\mathrm{UA}_{\mathrm{s}}$ é convenientemente escrito na forma da Equação (2), que descreve o processo global de transferência de calor em regime permanente entre os fluidos quente e frio do trocador:

$$
\frac{1}{U A_{s}}=\frac{1}{U_{i} A_{i}}=\frac{1}{U_{o} A_{o}}=R_{\text {global }}=\frac{1}{h_{i} A_{i}}+R_{\text {parede }}+\frac{1}{h_{o} A_{o}}+R_{f}
$$

Nesta equação, os sub-índices $\boldsymbol{i}$ e $\boldsymbol{o}$ denotam condições interna (inside) e externa (outside), assim diferenciando os escoamentos interno e externo. Mais precisamente, o fluido frio (água) circula pelo interior dos tubos do trocador, enquanto o fluido quente (ar) escoa externamente a esses tubos, em escoamento cruzado; U denota o coeficiente global de transferência de calor, $\left(h_{o}\right.$ e $h_{i}$ ) representam os coeficientes de filme (coeficientes de troca de calor por convecção) do ar e da água, respectivamente. $\mathrm{R}_{\text {parede }}$ denota a resistência térmica por condução imposta pela parede do tubo do trocador e $\mathrm{R}_{\mathrm{f}}$ denota a resistência térmica imposta pela presença das incrustações. A Figura 7 mostra, de forma 
esquemática, o perfil de temperaturas, que decresce de fora para dentro do tubo e, na cor cinza, a indesejável incrustação, que inevitavelmente se forma no interior dos tubos do trocador de calor durante a sua operação.

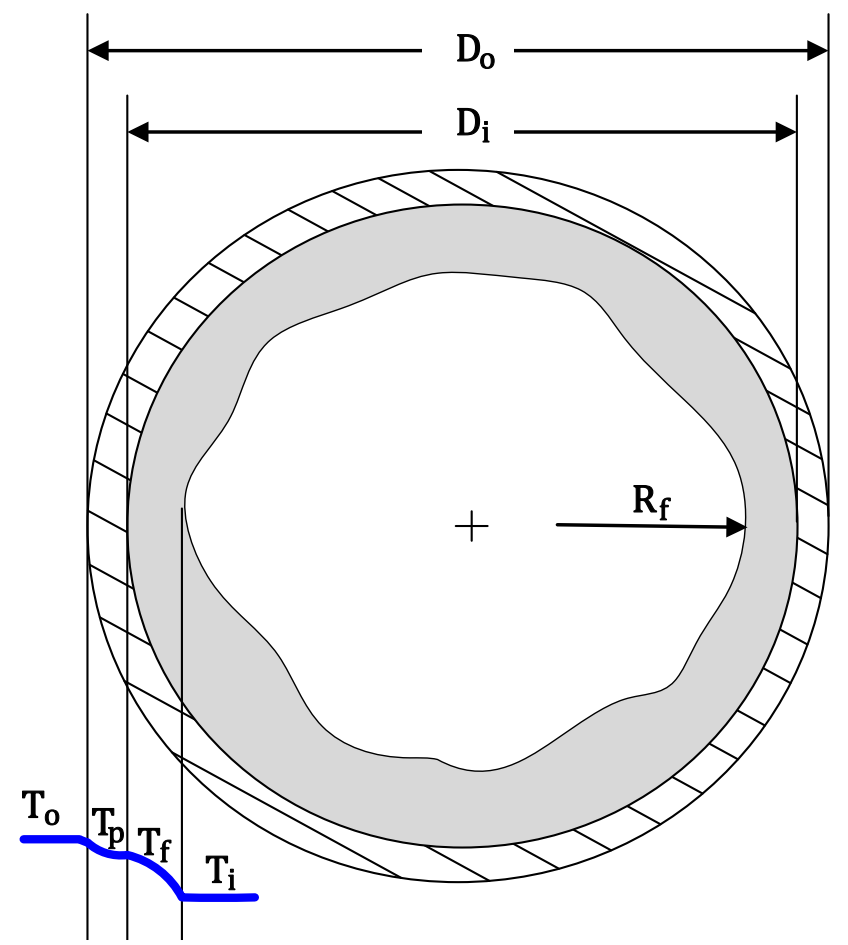

Figura 7. Perfil de temperatura e formação da incrustação nos tubos do TC

A inevitável camada de incrustações formada impõe uma indesejável resistência térmica à transferência de calor entre os fluidos de trabalho. Mensurar o valor desta resistência imposta pela incrustação não constitui tarefa trivial, já que depende da natureza química dos depósitos, cuja natureza e espessura da sedimentação variam com a sazonalidade e com o tempo de uso do trocador.

Tanto a resistência térmica da parede da tubulação como a resistência térmica que resultam da incrustação podem ser calculadas, pelas equações (3) e (4).

$$
\begin{gathered}
R_{\text {parede }}=\frac{\ln \left(D_{o} / D_{i}\right)}{2 \pi k L} \\
R_{f}=\frac{x_{f}}{\lambda}
\end{gathered}
$$

Nestas expressões:

L: é o comprimento do tubo do trocador

$\mathrm{k}$ : o coeficiente de condução de calor do material do tubo.

$\mathrm{D}_{\mathrm{o}}$ : o diâmetro externo do tubo. 
$\mathrm{D}_{i}$ o diâmetro interno do tubo.

$\mathrm{x}_{\mathrm{f}}$ : a espessura média da camada de incrustações.

$\lambda$ : o coeficiente de condução do conjunto de matérias que constituem a camada de incrustações.

Estimativas das resistências impostas ao escoamento e a determinação dos coeficientes de transferência de calor por convecção entre os fluidos de trabalho serão discutidos em capítulos específicos desta dissertação, com o objetivo de detalhar os procedimentos de cálculo da efetividade do trocador de calor.

\subsection{2}

\section{Balanço térmico}

A Figura 8 apresenta o esquema conceitual que fundamenta o balanço térmico.

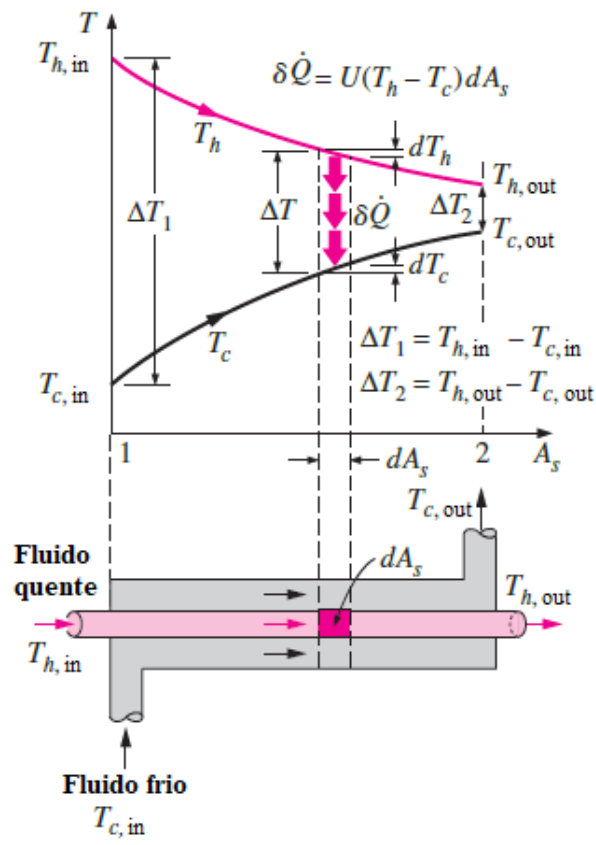

Figura 8. Balanço térmico entre os fluidos de trabalho do trocador Fonte: (Cengel, 2009)

Esta é a representação clássica que descreve a troca de calor entre os dois fluidos de trabalho do trocador ao longo de um elemento infinitesimal da área de troca do trocador. Na sequência desta formulação clássica, na parte superior da figura são mostradas a variações das temperaturas dos fluidos de trabalho que resultam da troca de calor entre esses fluidos (fluido quente esfriando e fluido frio esquentando), enquanto na parte inferior, é identificado (na cor vermelha) o elemento infinitesimal do tubo, associado ao qual se desenvolve o balanço de energia. 
A formulação acima fundamenta-se em dois princípios básicos:

- conservação de massa (matéria não se cria nem se destrói), considerandose a hipótese de que o regime do escoamento é permanente (steady state) e que não existe acumulação ou eliminação de matéria no interior do volume de controle (no entorno do trocador de calor) considerado para análise. Esta é uma hipótese razoável já que o fluido que escoa pelo interior dos tubos (água) é incompressível e que não existe perda de massa por evaporação (as temperaturas de entrada e de saída da água no trocador são inferiores à sua temperatura de evaporação).

- conservação de energia, considerando-se que o trocador de calor opera em regime permanente e que a forma de energia dominante é a troca de calor entre os fluidos de trabalho (para o caso em estudo, são desprezíveis variações de energia cinética e potencial dos fluidos de trabalho).

Essas são as premissas básicas que fundamentam a formulação do cálculo da efetividade do trocador de calor.

Circunscrito à hipótese básica considerada, de considera que todo o calor trocado se dá tão somente entre os fluidos de trabalho do trocador, à luz da Primeira Lei da Termodinâmica (Cengel, 2009), a quantidade de calor trocado pelo fluido frio (água) é igual à quantidade de calor trocada pelo fluido quente (ar), formulação essa que pode ser escrita na forma de taxa pela equação (3), que expressa as quantidades de calor em função da vazão $\dot{m}$ de cada fluido, multiplicada pelo calor específico $c_{p}$ e pela variação das temperaturas extremas experimentadas por cada fluido:

$$
\dot{Q}_{a g}=\dot{m}_{a g} \cdot c_{p, a g} \cdot\left(T_{a g, \text { out }}-T_{a g, \text { in }}\right)=\dot{Q}_{a r}=\dot{m}_{a r} \cdot c_{p, a r} \cdot\left(T_{a r, \text { in }}-T_{a r, \text { out }}\right)
$$

Refletindo o balanço térmico entre os fluidos de trabalho, a Equação (5) também se aplica ao tipo de trocador estudado nesta pesquisa de mestrado (trocador do tipo água-ar, em escoamento cruzado, esquematicamente ilustrado na Figura 4d, e em operação na usina hidrelétrica Fontes Nova).

\subsection{3}

\section{Dificuldade experimental associada ao método convencional}

Embora esta seção refira-se ao cálculo da efetividade térmica de trocadores de calor, o fundamento associado ao seu cálculo é discutido na seção 2.5.

Para caracterizar a dificuldade experimental que se deseja evitar ao propor um método alternativo de cálculo da efetividade do trocador sem a necessidade de 
conhecer o valor da temperatura de saída do ar (e que se constitui no objetivo central desta dissertação de mestrado), cabem as seguintes considerações tomando-se como referência a Equação (5):

- a medição da vazão mássica $\left(\dot{\mathrm{m}}_{\mathrm{ag}}\right)$ e das temperaturas de entrada $\left(\mathrm{T}_{\mathrm{ag}, \mathrm{in}}\right)$ e de saída ( $\left.\mathrm{T}_{\mathrm{ag}, \text { out }}\right)$ da água (fluido de trabalho frio do trocador de calor) são factíveis de serem realizadas com adequada confiabilidade metrológica já que se trata de um escoamento interno (escoamento confinado), em que a vazão é medida por um medidor de vazão ultrassônico do tipo clamp-on e as temperaturas medidas por meio de termo resistências do tipo Pt-100, em ambos os casos utilizando-se instrumentos de medição devidamente calibrados, tal qual documentado no Relatório do projeto de P\&D (Frota, 2019), desenvolvido em sintonia com esta pesquisa de mestrado;

- pelo lado do ar (fluido de trabalho quente do trocador), tanto a medição da vazão $\left(\dot{\mathrm{m}}_{\mathrm{ar}}\right)$ quanto a medição da temperatura de saída $\left(\mathrm{T}_{\mathrm{ar}, \mathrm{out}}\right)$ oferecem dificuldades experimentais à sua medição, já que o ar escoa em escoamento externo forçado circundando os tubos aletados do trocador, o que caracteriza um complexo escoamento, instável, pelos sucessivos descolamentos da camada limite que se forma em torno de cada tubo (a ventoinha formada por pás fixadas no eixo do rotor da turbina é mostrada na Figura 10, em seção subsequente da dissertação).

- ainda pelo lado do ar, a medição da temperatura de entrada $\left(\mathrm{T}_{\mathrm{ar}, \mathrm{in}}\right)$, medida no interior da carcaça de blindagem dos trocadores e do gerador acoplado ao eixo da turbina, diferentemente da temperatura de saída, é factível de ser medida já que, nessa região o escoamento é "bem comportado", isento de perturbações;

- o valor do calor específico da água $\left(c_{\mathrm{p}, \mathrm{ag}}\right)$ foi calculado pela equação polinomial (6) dos valores gerados a partir do software Refprop v9.1 (Lemmon et al., 2013) e o ( $\left.c_{p, a r}\right)$ obtido da Equação (7) (Van Wylen, 2002):

$$
\begin{array}{cc}
c_{p, a g}=4,2062-0,0018 T_{a g}+\left(3,0303 \times 10^{-5}\right) T_{a g}^{2} & (\mathrm{~kJ} / \mathrm{kg} \mathrm{K}) \\
c_{p, a r}=C_{0}+C_{1} \theta+C_{2} \theta^{2}+C_{3} \theta^{3} & (\mathrm{~kJ} / \mathrm{kg} \mathrm{K})
\end{array}
$$

Nesta expressão, $T_{a g}$ é a temperatura da água e $\theta$ representa um parâmetro relacionado à temperatura do ar expressa em Kelvin. A Tabela 2 apresenta os valores dos coeficientes do polinômio de cálculo do calor específico do ar $\left(c_{p, a r}\right)$, numa ampla faixa de temperatura, que inclui a faixa de temperatura do ar que circula pelo trocador de calor estudado (entre $20{ }^{\circ} \mathrm{C}$ e $60{ }^{\circ} \mathrm{C}$ ), portanto compatível com a faixa de aplicabilidade da Equação (7) e dos coeficientes propostos.

Tabela 2. Parâmetros e faixa de validade da Equação (7)

\begin{tabular}{|c|c|c|c|c|}
\hline \multicolumn{4}{|c|}{$\theta=T$ (Kelvin)/1000 } \\
\hline $\boldsymbol{C}_{\mathbf{0}}$ & $\boldsymbol{C}_{\mathbf{1}}$ & $\boldsymbol{C}_{\mathbf{2}}$ & $\boldsymbol{C}_{\mathbf{3}}$ & $\begin{array}{c}\text { Intervalo de } \\
\text { temperatura (K) }\end{array}$ \\
\hline 1,05 & $-0,365$ & 0,85 & $-0,39$ & $250-1200$ \\
\hline
\end{tabular}


- A Tabela 3 resume uma análise de sensibilidade feita para o cálculo do valor do calor específico do ar e da água, considerando-se os valores extremos (da temperatura de entrada e de saída dos fluidos de trabalho) observados no estudo de caso realizado.

Tabela 3. Resultados da análise de sensibilidade para o $c_{p, a r}$ e $c_{p, a g}$

\begin{tabular}{|c|c|c|c|}
\hline \multicolumn{2}{|c|}{$\operatorname{Ar}\left(\Delta \mathrm{T}: 46^{\circ} \mathrm{C}\right)$} & \multicolumn{2}{c|}{ Água $\left(\Delta \mathrm{T}: 16^{\circ} \mathrm{C}\right)$} \\
\hline $\boldsymbol{c}_{\boldsymbol{p}, \text { max }}:$ & $1,0095(\mathrm{~kJ} / \mathrm{kg} \mathrm{K})$ & $\boldsymbol{c}_{\boldsymbol{p}, \boldsymbol{m a x}}:$ & $4,1802(\mathrm{~kJ} / \mathrm{kg} \mathrm{K})$ \\
\hline $\boldsymbol{c}_{\boldsymbol{p}, \boldsymbol{m i n}}:$ & $1,0065(\mathrm{~kJ} / \mathrm{kg} \mathrm{K})$ & $\boldsymbol{c}_{\boldsymbol{p}, \boldsymbol{m i n}}:$ & $4,1815(\mathrm{~kJ} / \mathrm{kg} \mathrm{K})$ \\
\hline Diferença: & $0,29 \%$ & Diferença: & $0,03 \%$ \\
\hline
\end{tabular}

Portando, considerando os resultados mostrados na Tabela 3, relacionados ao trocador de calor do sistema de refrigeração do hidrogerador em operação na usina Fontes Nova, os valores de $c_{p}$ da água e do ar foram calculados com base nas médias das respectivas temperaturas de entrada e de saída dos fluidos de trabalho no trocador. Para o caso do ar, para uma variação máxima de $46{ }^{\circ} \mathrm{C}$ entre as temperaturas de entrada e de saída do trocador, o impacto no valor de $c_{p}$ é inferior a $0,3 \%$. Já para o caso da água a variação máxima que se observa entre as temperaturas de entrada e de saída é de $16{ }^{\circ} \mathrm{C}$, resultando em uma variação do valor do $c_{p}$ inferior a $0,1 \%$.

$\mathrm{Na}$ sequência das considerações apresentadas que objetivam ilustrar a dificuldade experimental relacionada à medição da vazão $\left(\dot{\mathrm{m}}_{\mathrm{ar}}\right)$ e da medição da temperatura de saída $\left(\mathrm{T}_{\mathrm{ar}, \text { out }}\right)$ aqui referida, a Tabela 4 reproduz dados de medição de um dos trocadores de calor (TC) em operação no sistema de refrigeração da unidade hidrogeradora $\mathrm{C}$ da usina Fontes Nova, monitorado pelo projeto de $\mathrm{P} \& \mathrm{D}$ (Frota, 2018) ao longo de 335 dias, dos quais o hidrogerador manteve-se em operação por 281 dias. 
Tabela 4. Extrato de resultados de medição e cálculos intermediários

(Dados coletados durante o processo de monitoramento do trocador para avaliar a sua efetividade térmica e cálculos intermediários)

\begin{tabular}{|c|c|c|c|c|c|c|c|c|c|c|c|c|c|c|c|c|c|c|}
\hline \multirow[b]{3}{*}{ Data } & \multicolumn{11}{|c|}{ DADOS COLETADOS } & \multicolumn{7}{|c|}{ DADOS AUXILIARES } \\
\hline & \multicolumn{6}{|c|}{ Fluido Água } & \multicolumn{4}{|c|}{ Fluido: Ar } & \multirow[b]{2}{*}{$\varepsilon$} & \multirow{2}{*}{$\begin{array}{c}\begin{array}{c}\text { Fluido } \\
\text { Água }\end{array} \\
{\left[\text { TouT }_{\text {ou }} \mathbf{T}_{\text {IN }}\right]} \\
\end{array}$} & \multirow{2}{*}{$\begin{array}{c}\text { Fluido Ar } \\
{\left[\mathbf{T}_{\text {IN }} \text { - TouT }\right]}\end{array}$} & \multirow[t]{2}{*}{$\begin{array}{l}\text { P da } \\
\text { Água }\end{array}$} & \multirow[t]{2}{*}{$\begin{array}{c}\text { Cp da } \\
\text { Água }\end{array}$} & \multirow[t]{2}{*}{$\begin{array}{c}\text { P do } \\
\text { Ar } \\
\end{array}$} & \multirow[t]{2}{*}{$\begin{array}{c}\text { Cp do } \\
\text { Ar }\end{array}$} & \multirow[t]{2}{*}{$\begin{array}{c}\text { Calor } \\
\text { Trocado }\end{array}$} \\
\hline & $\mathbf{P}_{\text {IN }}$ & $\mathbf{T}_{\mathbf{I N}}$ & Pout & Tout & $\mathbf{Q}$ & $\dot{\mathbf{m}}$ & $\mathbf{T}_{\mathbf{I N}}$ & Tout & $\mathbf{Q}$ & $\dot{\mathbf{m}}$ & & & & & & & & \\
\hline$(\mathrm{dd} / \mathrm{mm} / \mathrm{aa})$ & (bar) & $\left({ }^{\circ} \mathbf{C}\right)$ & (bar) & $\left({ }^{\circ} \mathrm{C}\right)$ & $\left(\mathbf{m}^{3} / \mathbf{h}\right)$ & $(\mathrm{kg} / \mathrm{s})$ & $\left({ }^{\circ} \mathrm{C}\right)$ & $\left({ }^{\circ} \mathrm{C}\right)$ & $\left(\mathrm{m}^{3} / \mathbf{h}\right)$ & $(\mathrm{kg} / \mathrm{s})$ & - & $\left({ }^{\circ} \mathbf{C}\right)$ & $\left({ }^{\circ} \mathrm{C}\right)$ & $\mathrm{kg} / \mathrm{m}^{3}$ & $\begin{array}{c}\text { kJ/(kg. } \\
\text { K) }\end{array}$ & $\mathrm{kg} / \mathrm{m}^{3}$ & $\begin{array}{c}\mathrm{kJ} /(\mathbf{k g} . \\
\mathrm{K})\end{array}$ & $\mathbf{k W}$ \\
\hline $20 / 06 / 2020$ & 2,26 & 21,55 & 1,94 & 29,64 & 19,40 & 5,38 & 54,75 & 35,27 & 30092,32 & 9,28 & 0,59 & 8,09 & 19,49 & 998,79 & 4,18 & 1,11 & 1,01 & 182,10 \\
\hline $21 / 06 / 2020$ & 2,25 & 21,77 & 1,93 & 29,90 & 19,91 & 5,52 & 55,08 & 35,43 & 30787,17 & 9,48 & 0,59 & 8,13 & 19,65 & 998,77 & 4,18 & 1,11 & 1,01 & 187,70 \\
\hline $22 / 06 / 2020$ & 2,26 & 22,09 & 1,94 & 30,21 & 20,13 & 5,58 & 55,37 & 35,65 & 30996,32 & 9,54 & 0,59 & 8,12 & 19,73 & 998,74 & 4,18 & 1,11 & 1,01 & 189,57 \\
\hline $23 / 06 / 2020$ & 2,26 & 22,15 & 1,94 & 30,30 & 20,28 & 5,63 & 55,57 & 35,71 & 31120,60 & 9,57 & 0,59 & 8,15 & 19,87 & 998,74 & 4,18 & 1,11 & 1,01 & 191,61 \\
\hline $24 / 06 / 2020$ & 2,25 & 22,05 & 1,93 & 30,22 & 20,13 & 5,59 & 55,46 & 35,67 & 31067,96 & 9,56 & 0,59 & 8,17 & 19,79 & 998,75 & 4,18 & 1,11 & 1,01 & 190,61 \\
\hline $25 / 06 / 2020$ & 2,25 & 21,69 & 1,94 & 29,87 & 19,94 & 5,53 & 55,25 & 35,41 & 30738,84 & 9,47 & 0,59 & 8,18 & 19,84 & 998,78 & 4,18 & 1,11 & 1,01 & 189,17 \\
\hline $26 / 06 / 2020$ & 2,26 & 21,52 & 1,94 & 29,90 & 19,80 & 5,49 & 56,09 & 35,63 & 30402,33 & 9,35 & 0,59 & 8,39 & 20,45 & 998,78 & 4,18 & 1,11 & 1,01 & 192,56 \\
\hline $27 / 06 / 2020$ & 2,26 & 21,53 & 1,94 & 29,87 & 19,68 & 5,46 & 55,71 & 35,44 & 30275,66 & 9,32 & 0,59 & 8,33 & 20,27 & 998,79 & 4,18 & 1,11 & 1,01 & 190,18 \\
\hline $28 / 06 / 2020$ & 2,26 & 21,61 & 1,95 & 29,92 & 19,51 & 5,41 & 55,45 & 35,42 & 30265,17 & 9,32 & 0,59 & 8,31 & 20,03 & 998,78 & 4,18 & 1,11 & 1,01 & 188,03 \\
\hline $29 / 06 / 2020$ & 2,26 & 21,66 & 1,95 & 29,94 & 19,40 & 5,38 & 55,13 & 35,33 & 30286,48 & 9,33 & 0,59 & 8,27 & 19,80 & 998,78 & 4,18 & 1,11 & 1,01 & 186,11 \\
\hline $30 / 06 / 2020$ & 2,28 & 21,60 & 1,96 & 29,99 & 19,77 & 5,49 & 55,95 & 35,45 & 30279,20 & 9,31 & 0,60 & 8,39 & 20,50 & 998,78 & 4,18 & 1,11 & 1,01 & 192,34 \\
\hline $27 / 07 / 2020$ & 2,32 & 21,83 & 1,96 & 29,80 & 18,68 & 5,18 & 55,61 & 36,32 & 28912,88 & 8,89 & 0,57 & 7,97 & 19,29 & 998,77 & 4,18 & 1,11 & 1,01 & 172,69 \\
\hline $29 / 07 / 2020$ & 2,31 & 21,84 & 1,95 & 29,79 & 18,53 & 5,14 & 55,53 & 36,43 & 28867,70 & 8,87 & 0,57 & 7,94 & 19,10 & 998,77 & 4,18 & 1,11 & 1,01 & 170,72 \\
\hline $30 / 07 / 2020$ & 2,32 & 21,78 & 1,96 & 29,74 & 18,25 & 5,06 & 55,40 & 36,42 & 28688,88 & 8,82 & 0,56 & 7,96 & 18,97 & 998,78 & 4,18 & 1,11 & 1,01 & 168,53 \\
\hline $31 / 07 / 2020$ & 2,28 & 21,52 & 1,93 & 29,49 & 17,95 & 4,98 & 55,24 & 36,37 & 28363,48 & 8,72 & 0,56 & 7,97 & 18,87 & 998,80 & 4,18 & 1,11 & 1,01 & 165,80 \\
\hline 01/08/2020 & 2,29 & 21,27 & 1,93 & 29,24 & 18,01 & 5,00 & 55,04 & 36,21 & 28515,33 & 8,77 & 0,56 & 7,97 & 18,84 & 998,82 & 4,18 & 1,11 & 1,01 & 166,47 \\
\hline 02/08/2020 & 2,28 & 21,15 & 1,92 & 29,13 & 17,98 & 4,99 & 54,92 & 36,16 & 28621,06 & 8,81 & 0,56 & 7,99 & 18,76 & 998,83 & 4,18 & 1,11 & 1,01 & 166,46 \\
\hline 03/08/2020 & 2,28 & 21,25 & 1,92 & 29,14 & 17,93 & 4,98 & 54,69 & 36,16 & 28572,40 & 8,80 & 0,55 & 7,90 & 18,52 & 998,83 & 4,18 & 1,11 & 1,01 & 164,13 \\
\hline Média & 2,20 & 24,05 & 1,81 & 29,69 & 21,55 & 5,98 & 54,59 & 36,47 & 24473,02 & 7,53 & 0,60 & 5,64 & 18,12 & 998,67 & 4,18 & 1,11 & 1,01 & 138,75 \\
\hline S: & 0,2200 & 1,8412 & 0,2157 & 2,4257 & 2,8050 & 0,7780 & 6,1431 & 4,1118 & 2966,41 & 0,8537 & 0,06 & 1,5812 & 3,1496 & 0,1860 & 0,0004 & 0,0171 & 0,0003 & 35,1922 \\
\hline $\mathrm{CV}$ & $10,0 \%$ & $7,7 \%$ & $11,9 \%$ & $8,2 \%$ & $13,0 \%$ & $13,0 \%$ & $11,3 \%$ & $11,3 \%$ & $12,1 \%$ & $11,3 \%$ & 0,11 & $28,0 \%$ & $17,4 \%$ & $0,0 \%$ & $0,0 \%$ & $1,5 \%$ & $0,0 \%$ & $25,4 \%$ \\
\hline Mínimo & 1,86 & 20,63 & 1,22 & 24,51 & 14,23 & 3,95 & 44,89 & 28,81 & 19836,91 & 6,20 & 0,45 & 3,16 & 11,09 & 998,26 & 4,18 & 1,05 & 1,01 & 75,56 \\
\hline Máximo & 2,51 & 28,19 & 2,27 & 36,73 & 29,40 & 8,15 & 74,98 & 50,70 & 31620,0 & 9,57 & 0,69 & 11,39 & 30,36 & 999,04 & 4,18 & 1,14 & 1,01 & 269,01 \\
\hline
\end{tabular}

Nota: Os valores de $c_{p}$ da água e do ar estão referenciados às médias das respectivas temperaturas de entrada e de saída no trocador de calor. 
A planilha acima mostra um extrato de uma extensa massa de dados remotamente transmitidas para o Laboratório de monitoramento remoto da PUCRio, dados esses transmitidos diariamente, pelo sistema de medição instalado na usina hidrelétrica. Uma vez transmitidos, esses dados são tratados estatisticamente, permitindo calcular os demais parâmetros de interesse mostrados na planilha. Esta tabela apresenta resultados da medição da vazão da água e das temperaturas e pressão de entrada e de saída de ambos os fluidos de trabalho (água e ar), ao longo do período de monitoramento, documentando as médias das medições realizadas a cada 15 minutos, registradas hora-a-hora na planilha, iniciando às 00:55:00 da manhã de cada dia e encerrando-se às 23:55:00. O cálculo do fator de Incrustação (FF) fundamenta-se em dois parâmetros de referência da efetividade: $\varepsilon_{\text {sujo }}$ e $\varepsilon_{\text {limpo }}$, o primeiro documentando o valor da efetividade imediatamente antes de o trocador ter sido submetido ao processo de limpeza e o segundo, o valor da efetividade medida imediatamente após o trocador ter sido limpo e recolocado em operação.

Os dados transmitidos (“dados crus”) são ajustados por meio de polinômios de ajuste para cada sensor individualmente calibrado. As grandezas físicas controladas são: pressão e temperatura (dos fluidos de trabalho, medidos na entrada e na saída do trocador) e vazão volumétrica da água (medida na entrada). Esses dados fundamentam os cálculos de interesse realizados à luz do balanço térmico, que considera o valor da vazão mássica de água e as taxas de transferência de calor. Essa é a situação em que o cálculo da efetividade do trocador é factível tendo em vista que dados experimentais estão disponíveis.

Com base nos dados medidos (que inclui a temperatura de saída do ar), e fazendo uso (i) da Equação (5), que reflete o balanço de energia entre os fluidos de trabalho do trocador de calor monitorado e (ii) do resultado da medição de temperatura de saída do ar (valor não confiável), calcula-se a vazão de saída do ar, cujo resultado é documentado na Tabela 1 e plotado na Figura 9, exibindo valores não esperados (não confiáveis), já que o perfil de vazão deveria se manter constante, o que não se observa. Embora ambas as vazões (de água e de ar) devessem ser praticamente constantes ao longo do tempo, este comportamento não se verifica. A exemplo da vazão de água que se mantém praticamente constante, a vazão de ar também deveria se manter constante já que o fluxo é impulsionado pelas pás da ventoinha atachada ao eixo do rotor da turbina, cuja rotação é mantida constante para evitar variação de frequência da energia gerada pelo hidrogerador. 
Conforme observado, a vazão de água se mantém constante já que o escoamento é impulsionado por um grupo motor-bomba hidráulica, mantido a potência e rotação constantes. Contrastando com o valor variável da vazão de ar, a vazão de água mantém-se constante (mantida constante a energia gerada pelo hidrogerador), exibindo um pequeno aumento de patamar a partir de fevereiro de 2018, em função da sazonalidade da água dos reservatórios, que experimentam um aumento de temperatura durante os meses quentes do verão. Mesmo sabendo que esta variação da vazão mássica do ar não reflete a física do problema, operadores de trocadores de calor que necessitam estimar o valor da vazão do fluido de trabalho ar costumam considerar o valor da mediana desta distribuição não confiável para obter uma estimativa do valor provável da vazão de ar, tal qual ilustrado na Figura 9.

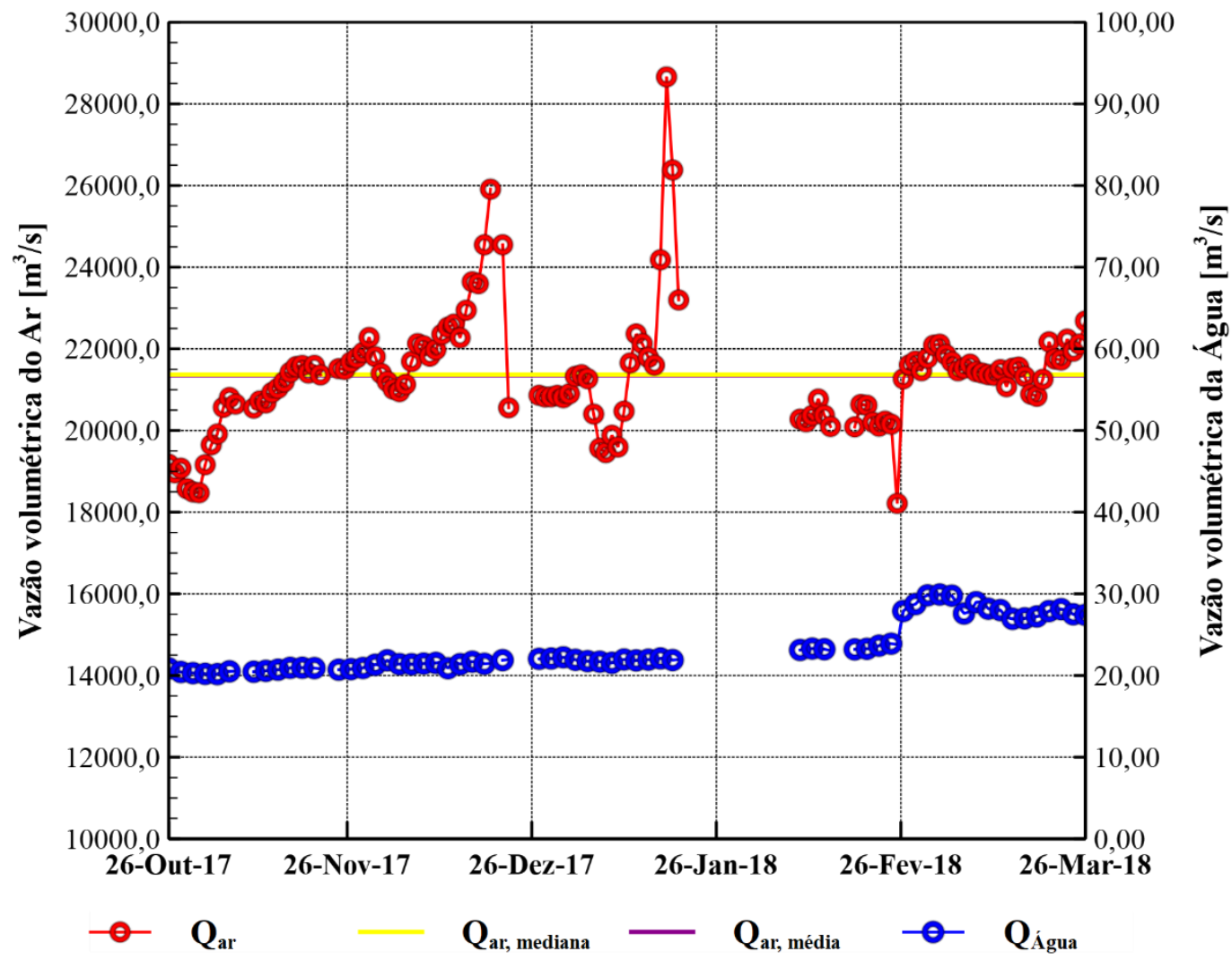

Figura 9. Resultado espúrio da vazão mássica do ar (ar: fluido quente do trocador de calor)

Nesta figura, e para a base de dados analisada, as linhas horizontais que denotam os valores da média e da mediana se confundem.

A Figura 10 ilustra as pás da ventoinha atachada ao rotor da turbina, assim explicando a razão pela qual a vazão de ar deveria se manter constante, o que 
entretanto não ocorre pelo fato de o seu cálculo ter sido baseado no resultado da medição não confiável da temperatura de saída do ar.

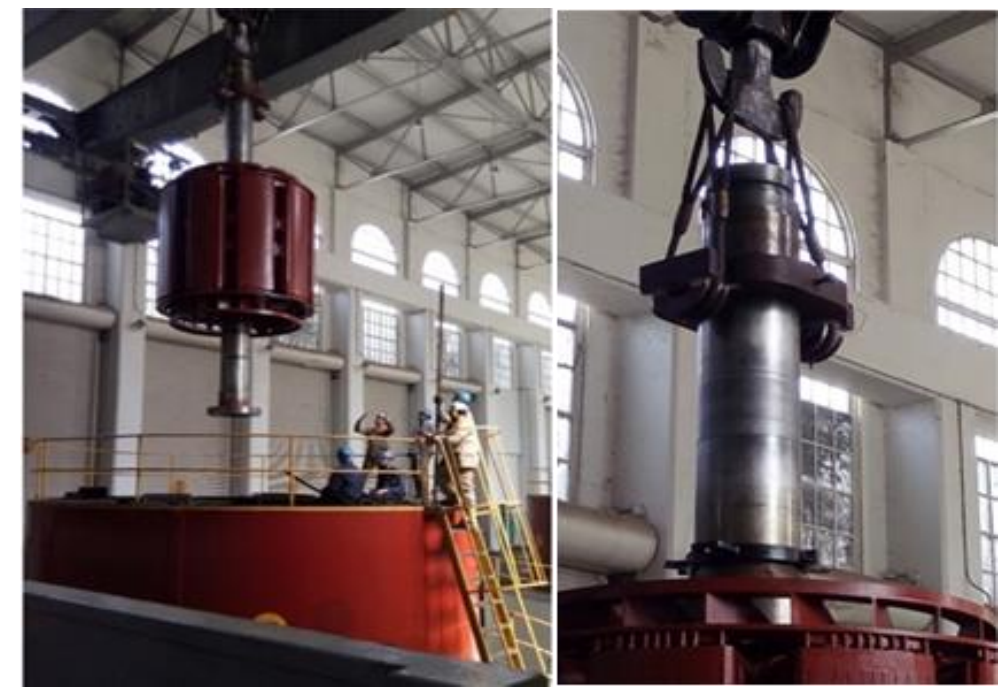

Figura 10. Ventoinhas que forçam o fluxo de ar nos tubos do TC

Para não restar dúvidas sobre a não confiabilidade dos resultados da medição da temperatura de saída do ar, considerações adicionais são feitas com base nas imagens da Figura 11, a seguir.
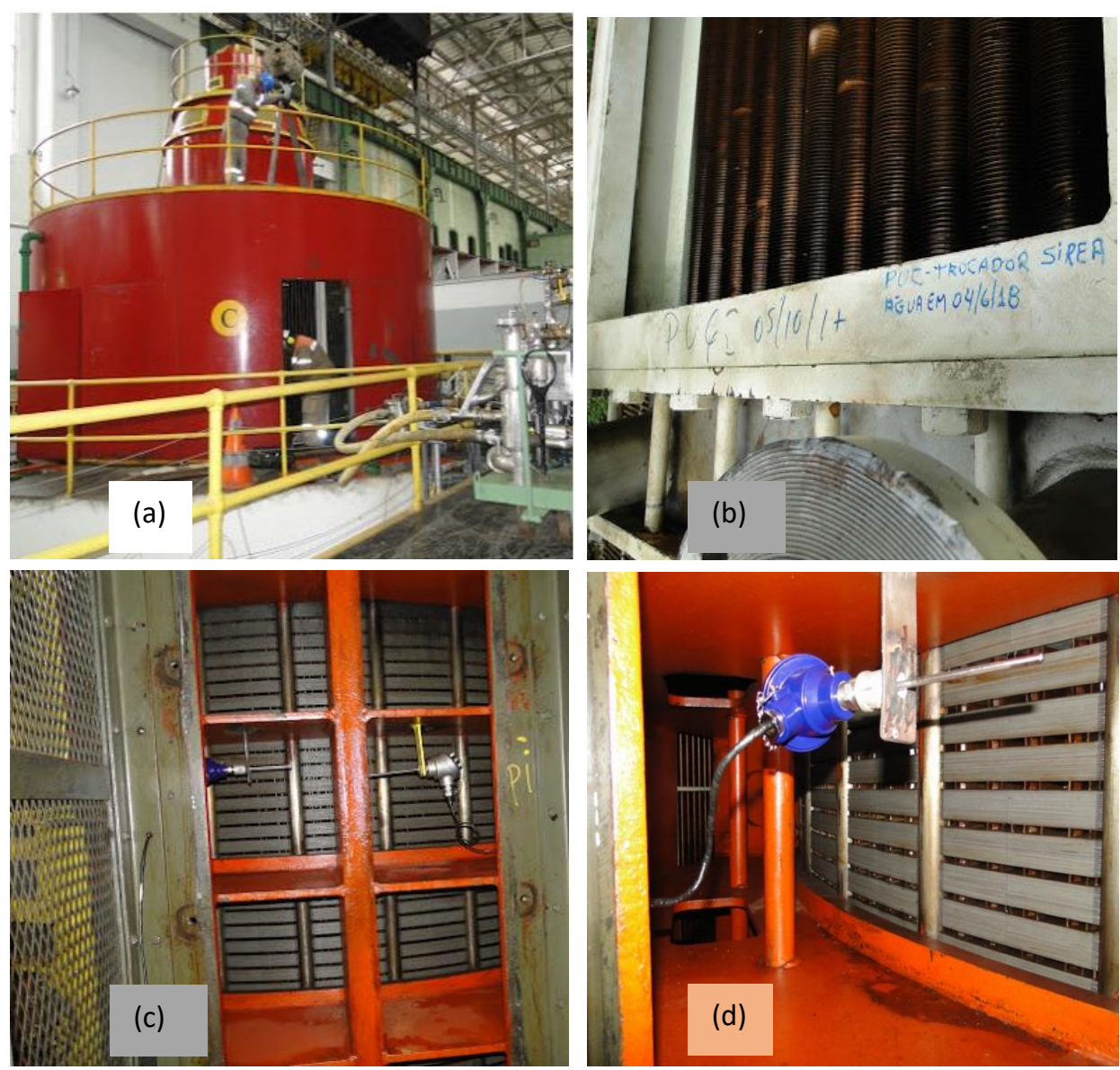

Figura 11 Faces de saída e de entrada do ar no trocador de calor 
As quatro imagens da Figura 11 ilustram ambas as faces do trocador de calor por onde circula, em escoamento forçado, externamente aos tubos, o ar, que é o fluido de trabalho quente do trocador.

A imagem 11a mostra o trocador posicionado na lateral da carcaça do hidrogerador, cuja face de saída pode ser visualizada pela janela aberta na sua carcaça externa. Na realidade, esta imagem documenta o momento em que dois profissionais da equipe de manutenção da usina preparam, com o auxilio de uma ponte rolante, a retirada do trocador que será submetido a um processo off-line de limpeza, a ser realizado no pátio externo da usina após a sua completa retirada e transporte. Mas o que se deseja mostrar nesta foto é a face de saída do trocador, região onde é medida a temperatura de saída do ar após este trocar calor com o fluxo de água (fluido frio do TC), que é forçado pelo interior dos tubos por uma bomba hidráulica. Na imagem 11 b, que mostra uma foto próxima dos tubos aletados da face de saída do TC, pode se observar uma região característica onde ocorre o escoamento do ar de saída, perturbado pelos sucessivos descolamentos das camadas limites que se formam em torno de cada tubo do trocador. É exatamente nessa região perturbada do escoamento que é instalado o Pt-100 utilizado para medir a temperatura de saída do ar, na esteira do escoamento do ar, após este ter circulado externamente aos tubos do TC. Já as imagens 11c e 11d ilustram a face de entrada do trocador, região na qual é medida a temperatura de entrada do TC. Conforme pode ser observado nessas imagens, antes de o ar adentrar pelo interior do TC (perpendicularmente aos tubos), este passa por uma estrutura de placas horizontais paralelas, que criam fendas ("laminadores do fluxo"), que orientam a entrada do ar pelo interior do TC. É nessa região que é instalado o Pt-100 que mede a temperatura do ar de entrada. Conforme explicado, do ponto de vista experimental, a qualidade da medição de temperatura do ar de entrada é superior à de medição do ar de saída do trocador de calor.

Tendo em vista esta dificuldade experimental relacionada à medição da temperatura de saída do ar (responsável por gerar resultados não confiáveis no cálculo da vazão de ar que circula externamente aos tubos do trocador), esta pesquisa de mestrado objetivou desenvolver alternativas de cálculo da efetividade sem a necessidade de se recorrer à medição da temperatura de saída do ar, cujo desenvolvimento será detalhado em seções subsequentes da dissertação. 
Ao se relatar acima a dificuldade experimental associada à medição da temperatura e da vazão de saída do ar, não se deseja dizer que essas medições não sejam possíveis com adequada confiabilidade metrológica via métodos alternativos. O que se está afirmando aqui é que, para o momento da pesquisa realizada no âmbito de um projeto de $\mathrm{P} \& \mathrm{D}$ que se propôs a desenvolver alternativas on line de limpeza de trocadores de calor sem a necessidade de interromper a geração, não foi facultado aos pesquisadores do projeto acesso às faces internas e externas dos trocadores de calor lacrados no compartimento da carcaça externa de proteção do núcleo do hidrogerador. Não só esse acesso não é possível durante a operação do hidrogerador como o acesso à casa de máquinas é controlado de maneira rígida e limitada por períodos ultra limitados.

\section{5}

\section{Efetividade térmica: o conceito e alternativas de cálculo}

\subsection{1}

\section{$O$ conceito de efetividade}

Não obstante a ampla variedade de trocadores de calor existentes no mercado, o seu desempenho é, usualmente, avaliado pela sua efetividade ou por um fator de incrustação, este último, definido em função do primeiro.

O desempenho térmico de um trocador - denominado na literatura especializada por efetividade térmica do trocador - é definido por um conceito essencialmente energético. Mais especificamente, pelo quociente entre (i) o calor efetivamente trocado entre os fluidos de trabalho do trocador e (ii) a quantidade máxima de calor que poderia ser trocada por um trocador ideal (de comprimento infinito). A interpretação física da efetividade baseia-se na relação entre a troca real de calor, comparada com a troca ideal de calor que poderia ser conseguida se o trocador fosse de comprimento infinito (uma "idealização de um processo completo de transferência de calor" entre os fluidos de trabalho do trocador. Esse conceito é descrito pela Equação (8):

$$
\varepsilon=\frac{\dot{Q}_{\text {real }}}{\dot{Q}_{\max }}
$$

Conforme revela esta equação, a efetividade varia entre 0 e $1(0 \leq \varepsilon \leq 1)$, quanto mais próximo ao valor 1, mais o trocador real se aproxima do trocador ideal. 
Já a transferência de calor máxima possível $\dot{\mathrm{Q}}_{\max }$, corresponde à situação em que a transferência de calor ocorra em condições termodinamicamente ideais, nas quais, para um caso de trocador com escoamento em contracorrente (apenas para ilustrar), se cumpriria pelo menos uma das duas seguintes condições: (i) que o fluido frio se aqueça até alcançar a temperatura de entrada do fluido quente ou (ii) que o fluido quente resfrie até chegar à temperatura de entrada do fluido frio o que, teoricamente, só é possível se o trocador for de comprimento infinito. Na hipótese de se conseguir atingir alguma dessas duas condições, esta ocorrerá para o fluido de menor capacidade térmica. Matematicamente, a capacidade térmica do fluido resulta do produto do calor específico do fluido pela sua vazão mássica. Ou seja, a capacidade calorifica é o potencial térmico (ganhar ou ceder calor) associado a um determinado fluido. Assim, a transferência de calor máxima pode ser estimada pela Equação (9):

$$
\dot{Q}_{\max }=C_{\min }\left(T_{h, \text { in }}-T_{c, \text { in }}\right)
$$

Nesta equação,

$\mathrm{C}_{\text {min }}$ : Capacidade térmica mínima entre o fluido quente e frio.

$\mathrm{T}_{\mathrm{h}, \mathrm{in}}$ : Temperatura de entrada do fluido quente.

$\mathrm{T}_{\mathrm{c}, \text { in }}$ : Temperatura de entrada do fluido frio.

A capacidade térmica de um fluido é calculada pela Equação (10):

$$
C_{\min }=\dot{m} c_{p}
$$

cujas variáveis denotam:

$\mathrm{c}_{\mathrm{p}}$ : Calor específico do fluido.

m: Vazão mássica do fluido.

Na Equação (8), $\dot{Q}_{\text {real }}$ é o calor efetivamente trocado pelos fluidos de trabalho, que pode ser calculado pelo lado do fluido quente ou pelo lado do fluido frio, conforme descrito pela Equação (11):

$$
\dot{Q}_{\text {real }}=C_{h}\left(T_{h, \text { in }}-T_{h, \text { out }}\right)=C_{c}\left(T_{c, \text { out }}-T_{c, \text { in }}\right)
$$

Nesta expressão,

$\mathrm{C}_{\mathrm{h}}$ : Capacidade térmica do fluido quente.

$\mathrm{C}_{\mathrm{c}}$ : Capacidade térmica do fluido frio.

$\mathrm{T}_{\mathrm{h} \text {,out }}$ : Temperatura de saída do fluido quente.

$\mathrm{T}_{c, \text { out }}$ : Temperatura de saída do fluido frio. 
A partir do balanço térmico entre os fluidos de trabalho do trocador, é possível calcular a taxa de transferência de calor entre os fluidos de trabalho do trocador pelo lado da água (“fluido frio”). O cálculo pelo lado da água (escoamento interno) é mais conveniente já que este reflete um escoamento hidrodinamicamente bem caracterizado do ponto de vista experimental, que permite a medição com exatidão da vazão e das temperaturas de entrada e de saída da água no trocador. Importante destacar que o mesmo não é possível para o lado do ar, cujas medições da vazão e das temperaturas (de entrada e de saída) do ar são complexas e imprecisas, já que o ar escoa em regime turbulento, externamente aos tubos, em ambiente aberto.

Assim, a taxa real de transferência de calor real $\left(\dot{Q}_{\text {real }}\right)$ trocada entre os fluidos de trabalho pelo lado da água ("fluido frio") pode ser calculada por meio de medições de vazão e de temperatura do fluxo de água pela Equação (12):

$$
\dot{Q}_{\text {real }}=\dot{m}_{a g} c_{p, a g}\left(T_{a g, o u t}-T_{a g, \text { in }}\right)
$$

Desprezando-se eventuais trocas de calor entre a carcaça do trocador e o meio externo (o que é uma hipótese razoável já que os trocadores de calor são projetados para otimizar as trocas de calor entre os fluidos de trabalho), a quantidade de calor calculada pelo lado da água (factível de ser mensurada) é igual à quantidade de calor trocada pelo lado do ar (experimentalmente difícil de ser mensurada), conforme expressa a Equação (13):

$$
\dot{Q}_{a g}=-\dot{Q}_{a r}
$$

Nesta equação o sinal negativo é apenas um indicador da convenção termodinâmica, que define o sentido do fluxo de calor que entra e que deixa o volume de controle. Combinando as equações (12) e (13), obtém-se a Equação (14):

$$
\dot{Q}_{a g}=\dot{m}_{a r} c_{p, a r}\left(T_{a r, \text { in }}-T_{a r, o u t}\right)
$$

Alternativamente reescrita na forma da Equação (15):

$$
\dot{m}_{a r} c_{p, a r}=\frac{\dot{Q}_{a g}}{\left(T_{a r, \text { in }}-T_{a r, o u t}\right)}=C_{p, a r}
$$

Existem duas possibilidades para o valor $C_{\text {min }}$ definido na Equação (10): ou a água é o fluido com menor capacidade térmica ou o ar é o fluido de menor 
capacidade térmica), o que requer o desenvolvimento de duas alternativas de análise. Sabidamente, entretanto, nas condições de trabalho e operação do equipamento de geração, o ar é o fluido de menor capacidade térmica. Assim, a Equação (8) pode ser reescrita na forma:

$$
\varepsilon=\frac{\dot{Q}_{a g}}{C_{p, a r}\left(T_{a r, \text { in }}-T_{a g, \text { out }}\right)}
$$

Substituindo-se o valor de $C_{p, a r}$ dado pela Equação (15) na equação (16), obtém-se:

$$
\varepsilon=\frac{\dot{Q}_{a g}}{\frac{\dot{Q}_{a g}}{\left(T_{a r, \text { in }}-T_{a r, \text { out }}\right)}\left(T_{a r, \text { in }}-T_{a g, \text { in }}\right)}
$$

Equação essa que pode ser rescrita, de forma conveniente, em função de apenas três temperaturas (temperaturas de entrada e de saída do ar e temperatura de entrada da água). Do ponto de vista teórico, é importante ter em mente que a Equação (18) não representa apenas um efeito térmico, já que medido em função de três temperaturas, mas, sim um efeito energético, lembrando que esta equação só foi possível ser reduzida à essa forma compacta com base no balanço térmico e na hipótese de um trocador bem dimensionado, cujas trocas de calor com o meio externo são desprezíveis (o que equivale a dizer que as trocas de calor ocorrem apenas entre os fluidos de trabalho). Nesse contexto, a equação (18) reflete um conceito essencialmente energético.

$$
\varepsilon=\frac{\left(T_{a r, \text { in }}-T_{a r, o u t}\right)}{\left(T_{a r, \text { in }}-T_{a g, \text { in }}\right)}
$$

Conforme mostrado, esta equação permite calcular a efetividade em termos de três temperaturas. Embora possa parecer extremamente conveniente do ponto de vista prático, cabe observar que a Equação (18) depende da temperatura de saída do ar, cuja medição já foi demonstrada não ser trivial. Nesse contexto, encontrar alternativas de cálculo da efetividade do trocador constitui-se no principal desafio perseguido no desenvolvimento desta pesquisa de mestrado. 


\section{5 .2}

\section{Métodos convencionais para o cálculo da efetividade}

Esta seção descreve três alternativas independentes de cálculo da efetividade do trocador de calor, cada uma mais indicada para uma determinada condição:

- Método essencialmente experimental, quando medições são factíveis da vazão de pelo menos um dos fluidos de trabalho e das temperaturas (de entrada e de saída) de ambos os fluidos de trabalho;

- Método da temperatura média logarítmica, aplicável quando são especificadas ambas as temperaturas de entrada e saída dos fluidos e o Coeficiente Global de transferência de calor U;

- Método $\varepsilon$-NTU, proposto por Kays \& London (1964), aplicável quando somente são especificadas as temperaturas de entrada dos fluidos, ambas as vazões dos fluidos de trabalho e o Coeficiente Global de transferência de calor U (as temperaturas de saída dos fluidos não são conhecidas).

Essas alternativas são discutidas nas seções subsequentes.

\subsubsection{1}

\section{Método essencialmente experimental}

O método essencialmente experimental de cálculo da efetividade térmica do trocador de calor é aquele que faz uso de resultados de medições, conforme documentado na Tabela 3, da seção 2.5, que transcreve dados do projeto de P\&D (Frota, 2019) desenvolvido em paralelo à esta pesquisa de mestrado. Esses são resultados de medições, em tempo real, dia-a-dia, utilizados para monitorar a efetividade de alguns trocadores de calor em operação na usina hidrelétrica Fontes Nova, em Piraí, RJ, são transmitidos remotamente para o Laboratório de monitoramento remoto da PUC-Rio. Os dados dessa planilha documentam resultados de medições de temperatura e pressão de entrada e de saída dos fluidos de trabalho (água e ar) do trocador, bem como o resultado da medição da vazão da água. A vazão de saída é calculada pelo balanço térmico entre as trocas de calor calculadas independentemente pelos fluidos de trabalho quente e frio, porém considerando a medição da temperatura de saída do fluido quente (ar), enquanto os valores da capacidade térmica são calculados por meio de equações de estado termodinâmico (definidas nas equações (6) e (7)). Uma vez instrumentado o trocador de calor, a efetividade é calculada pelas três temperaturas que aparecem na Equação (18), assim caracterizando a alternativa essencialmente experimental.

As seções, a seguir, descrevem as outras duas alternativas do cálculo da efetividade, quando apenas parte das grandezas físicas dos fluidos de trabalho são conhecidas. 


\subsubsection{2 \\ Método da temperatura média logarítmica (LMTD)}

Conforme consta da literatura clássica de trocadores de calor, a temperatura entre os fluidos quente e frio varia ao longo do trocador de calor. Assim, resulta conveniente utilizar a temperatura média na análise da efetividade.

Conforme anteriormente mostrado, a Equação (1) é a expressão clássica que permite calcular a taxa de transferência de calor, considerando o coeficiente global de transferência de calor $(U)$, a área de seção transversal $\left(A_{s}\right)$ e a diferença de temperatura entre os fluidos de trabalho $\left(\Delta \mathrm{T}_{\mathrm{m}}\right)$.

Para se definir uma expressão para a diferença de temperatura média logarítmica dos dois fluidos de trabalho do trocador, considerou-se o trocador base, mostrado na Figura 3, que se refere a um trocador de calor de duplo tubo e escoamento paralelo. Para este trocador, a diferença de temperatura $\Delta \mathrm{T}$ entre os fluidos quente e frio é máxima na entrada do trocador, diminuindo em direção à seção de saída.

Em conformidade à esta abordagem de análise, considera-se que toda a troca de calor ocorre internamente entre os fluidos de trabalho (o que equivale a dizer que a superfície externa do trocador está isolada para evitar a transferência de calor por convecção natural entre a carcaça do trocador e o ar do meio externo). Considerase, também (o que é razoável), que não existem variações significativas de energia potencial e cinética nos fluidos de trabalho objeto do balanço de energia. Com base nessa hipótese, o balanço de energia em uma determinada seção diferencial do trocador pode ser expresso pela Equação (19), pelo lado do fluido quente (hot) ou pela Equação (20), pelo lado do fluido frio (cold):

$$
\delta \dot{Q}=-\dot{m}_{h} c_{p, h} d T_{h}
$$

$\mathrm{e}$

$$
\delta \dot{Q}=\dot{m}_{c} c_{p, c} d T_{c}
$$

Ou seja, a quantidade de calor cedida pelo fluido quente é a mesma que a quantidade de calor recebida pelo fluido frio, em qualquer seção do trocador. Resolvendo as Equações (19) e (20) para $\mathrm{dT}_{\mathrm{h}}$ e $\mathrm{dT}_{\mathrm{c}}$ e, explicitando-se a diferença entre esses valores diferenciais de temperatura, obtém-se a Equação (21): 


$$
d T_{h}-d T_{c}=d\left(T_{h}-T_{c}\right)=-\delta \dot{Q}\left(\frac{1}{\dot{m}_{h} c_{p, h}}+\frac{1}{\dot{m}_{c} c_{p, c}}\right)
$$

A taxa de transferência de calor na seção diferencial do trocador pode ser expressa pela Equação (22):

$$
\delta \dot{Q}=U\left(T_{h}-T_{c}\right) d A_{S}
$$

Substituindo a Equação (21) na (22) e, integrando ambos lados, considerando $\left(c_{p, h}, c_{p, c}\right)$ constantes, obtém-se a Equação (23):

$$
\ln \left(\frac{T_{h, \text { out }}-T_{c, \text { out }}}{T_{h, \text { in }}-T_{c, \text { in }}}\right)=-U A_{s}\left(\frac{1}{\dot{m}_{h} c_{p, h}}+\frac{1}{\dot{m}_{c} c_{p, c}}\right)
$$

Finalmente, resolvendo a expressão acima, a partir da taxa de transferência de calor para cada um dos fluidos, obtém-se:

$$
\dot{Q}=U A_{s} \Delta T_{l m}
$$

Reescrevendo a equação acima, é possível explicitá-la para fornecer uma expressão para o cálculo da diferença de temperatura média logarítmica:

$$
\Delta T_{l m}=\frac{\Delta T_{1}-\Delta T_{2}}{\ln \left(\Delta T_{1} / \Delta T_{2}\right)}
$$

$\Delta \mathrm{T}_{1}$ : denota a diferença entre as temperaturas de entrada dos fluidos

$\Delta \mathrm{T}_{2}$ : denota a diferença das temperaturas de saída dos fluidos

$\Delta \mathrm{T}_{\mathrm{lm}}$ : denota a diferença de temperatura média logarítmica (Bergman, 2011;

Cengel, 2009; Welty, 1982).

Esta é a forma apropriada de se expressar a temperatura média logarítmica, comumente utilizada na análise do desempenho térmico de trocadores de calor quando apenas são conhecidas as temperaturas de entrada e saída dos fluidos de trabalho do trocador, bem como o Coeficiente Global de transferência de calor U. Esta metodologia torna-se atrativa para essas situações, aplicável para todos os tipos de trocadores, com escoamento paralelo ou em contracorrente. Assim,

\begin{tabular}{|c|l|}
\hline$\Delta T_{1}=T_{h, \text { in }}-T_{c, \text { in }}$ & Escoamento paralelo \\
$\Delta T_{2}=T_{h, \text { out }}-T_{c, \text { out }}$ & \\
\hline$\Delta T_{1}=T_{h, \text { in }}-T_{c, \text { out }}$ & Escoamento em \\
$\Delta T_{2}=T_{h, \text { out }}-T_{c, \text { in }}$ & contracorrente \\
\hline
\end{tabular}


A temperatura média logarítmica $\Delta \mathrm{T}_{\mathrm{lm}}$ é obtida seguindo-se o perfil de temperatura real dos fluidos de trabalho ao longo do trocador e é uma representação confiável da diferença de temperatura média entre os fluidos quente e frio. Este parâmetro realmente reflete o decaimento da diferença de temperatura local.

Portanto, o método LMTD é muito usado para projetar ou selecionar trocadores de calor, com o propósito de se atingir as condições de operação do processo térmico (temperaturas conhecidas de entrada e de saída) e características do processo de transferência de calor.

\subsubsection{3}

\section{Método NTU para o cálculo da efetividade}

Kays \& London (1964) desenvolveram um método que denominaram efetividade-NTU. Esse método foi motivado para se atribuir praticidade no cálculo da efetividade de trocadores de calor, notadamente para a situação em que não são conhecidas as temperaturas de saída dos fluidos de trabalho, mas que são conhecidas as respectivas vazões mássicas.

O método NTU é baseado no desempenho do trocador de calor, fazendo uso do parâmetro efetividade térmica, parâmetro esse dependente da configuração geométrica do trocador de calor e da configuração de escoamento. Assim, diferentes tipos de trocadores terão diferentes relações para expressar a sua efetividade, porém de forma prática.

Partindo-se da análise realizada para o método LMTD, a Equação (26) pode ser expressa na forma:

$$
\ln \left(\frac{T_{h, \text { out }}-T_{c, \text { out }}}{T_{h, \text { in }}-T_{c, \text { in }}}\right)=-\frac{U A_{s}}{C_{c}}\left(1+\frac{C_{c}}{C_{h}}\right)
$$

lembrando que a quantidade de calor trocada pode ser expressa, independentemente, pelo lado do fluido frio ou pelo lado do fluido quente:

$$
\dot{Q}=C_{c}\left(T_{c, \text { out }}-T_{c, \text { in }}\right)=C_{h}\left(T_{h, \text { in }}-T_{h, \text { out }}\right)
$$

Explicitando-se $\mathrm{T}_{\mathrm{h} \text {,out }}$ (dado de saída) na Equação (27) e substituindo este valor na Equação (26), obtém-se:

$$
\ln \left[1-\left(1+\frac{C_{c}}{C_{h}}\right)\left(\frac{T_{c, \text { out }}-T_{c, \text { in }}}{T_{h, \text { in }}-T_{c, \text { in }}}\right)\right]=-\frac{U A_{s}}{C_{c}}\left(1+\frac{C_{c}}{C_{h}}\right)
$$


Reescrevendo a Equação (8) de definição da efetividade $\varepsilon$ em função das respectivas diferenças de temperaturas associadas à troca de calor e da capacidade térmica dos fluidos de trabalho, obtém-se a expressão:

$$
\frac{T_{c, \text { out }}-T_{c, \text { in }}}{T_{h, \text { in }}-T_{c, \text { in }}}=\varepsilon \frac{C_{\text {min }}}{C_{c}}
$$

Substituindo essa expressão na Equação (28) e resolvendo-a para a efetividade $\varepsilon$, obtém-se a Equação (30):

$$
\varepsilon=\frac{1-e^{\left[-\frac{U A_{s}}{C_{c}}\left(1+\frac{C_{c}}{C_{h}}\right)\right]}}{\left(1+\frac{C_{c}}{C_{h}}\right) \frac{C_{\min }}{C_{c}}}
$$

Substituindo $C_{c}$ ou $C_{h}$ qualquer que seja o mínimo, obtém-se a Equação (31), que permite o cálculo da efetividade de forma conveniente:

$$
\varepsilon=\frac{1-e^{\left[-\frac{U A_{s}}{C_{\min }}\left(1+\frac{C_{\min }}{C_{\max }}\right)\right]}}{\left(1+\frac{C_{\min }}{C_{\max }}\right)}
$$

A expressão $U A_{s} / C_{\min }$ resulta ser um número adimensional, e foi a esse número que Kays e London denominaram NTU, Número de Unidades Térmicas (da tradução de Number of Thermal Units), assim:

$$
N T U=\frac{U A_{s}}{C_{\min }}=\frac{U A_{s}}{\left(\dot{m} c_{p}\right)_{\min }}
$$

Conforme mostrado pela expressão acima, o NTU é proporcional à área $A_{s}$. Portanto, para valores específicos de $\mathrm{U}$ e $\mathrm{C}_{\min }$, o valor do NTU é uma medida da área da superfície de transferência de calor. Portanto, quanto maior o NTU, maior será a área do trocador de calor (maior será o seu porte).

O resultado acima apresentado refere-se à expressão da efetividade para o caso específico de trocador de dois passos (duplo tubo) e escoamento paralelo. Considerando, entretanto, que as configurações geométricas e de escoamento são variadas, cada tipo de trocador terá a sua expressão para a efetividade NTU. Porém, em termos gerais, a efetividade de um trocador pode ser escrita pela Equação (33): 


$$
\varepsilon=f u n c ̧ a ̃ o(N T U, c)
$$

equação genérica essa, na qual $\boldsymbol{c}$ denota uma quantidade adimensional definida pela razão entre as capacidades térmicas mínima e máxima dos fluidos de trabalho, conforme descrito pela Equação (34):

$$
c=\frac{C_{\min }}{C_{\max }}
$$

Kays e London (1964) desenvolveram expressões práticas para diferentes configurações geométricas de trocadores de calor e de escoamento para o cálculo da efetividade $\varepsilon$, equações essas que ainda hoje são usualmente utilizadas no meio industrial. As equações obtidas encontram-se apresentadas na Tabela 5.

Tabela 5. Expressões para cálculo da efetividade pelo método $\varepsilon-N T U$

Fonte: Kays \& London (1964)

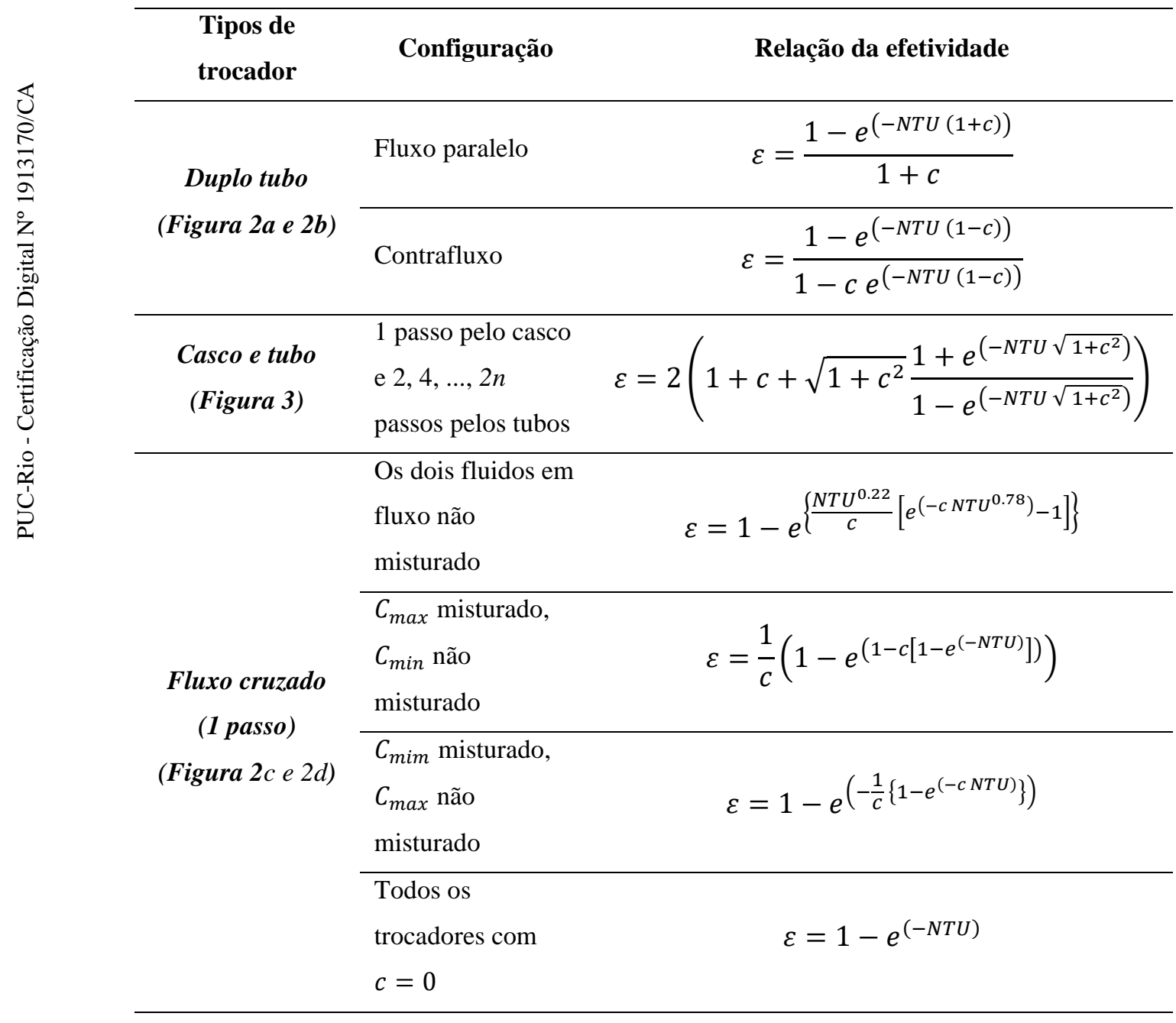


Conforme pode se comprovar pelo caráter das equações apresentadas na Tabela 5, para os diferentes tipos de trocador de calor, o valor da efetividade cresce com o valor do NTU, atingindo um valor assintótico, conforme ilustrado na Figura 12. Estas equações ilustram a variação típica da efetividade em função do parâmetro NTU para um determinado tipo de trocador de calor. Cabe observar que a equação que se aplica ao caso do trocador de fluxo cruzado, similar ao estudado nesta pesquisa de mestrado, aplica-se tão somente ao caso do trocador de um único passe, em que a água ("fluido frio") escoa pelo interior dos tubos, enquanto o ar ("fluido quente") escoa externamente aos tubos, em fluxo cruzado. Embora similar, a expressão derivada por Kays \& London não se aplica diretamente ao trocador estudado, que possui seis passes e aletas externas nos tubos (dispositivo que melhora as trocas de calor entre os fluidos de trabalho).

A Figura 12, a seguir, ilustra resultados de outro trabalho descrito na literatura (Welty, 1982), que estudou diferentes trocadores de calor.
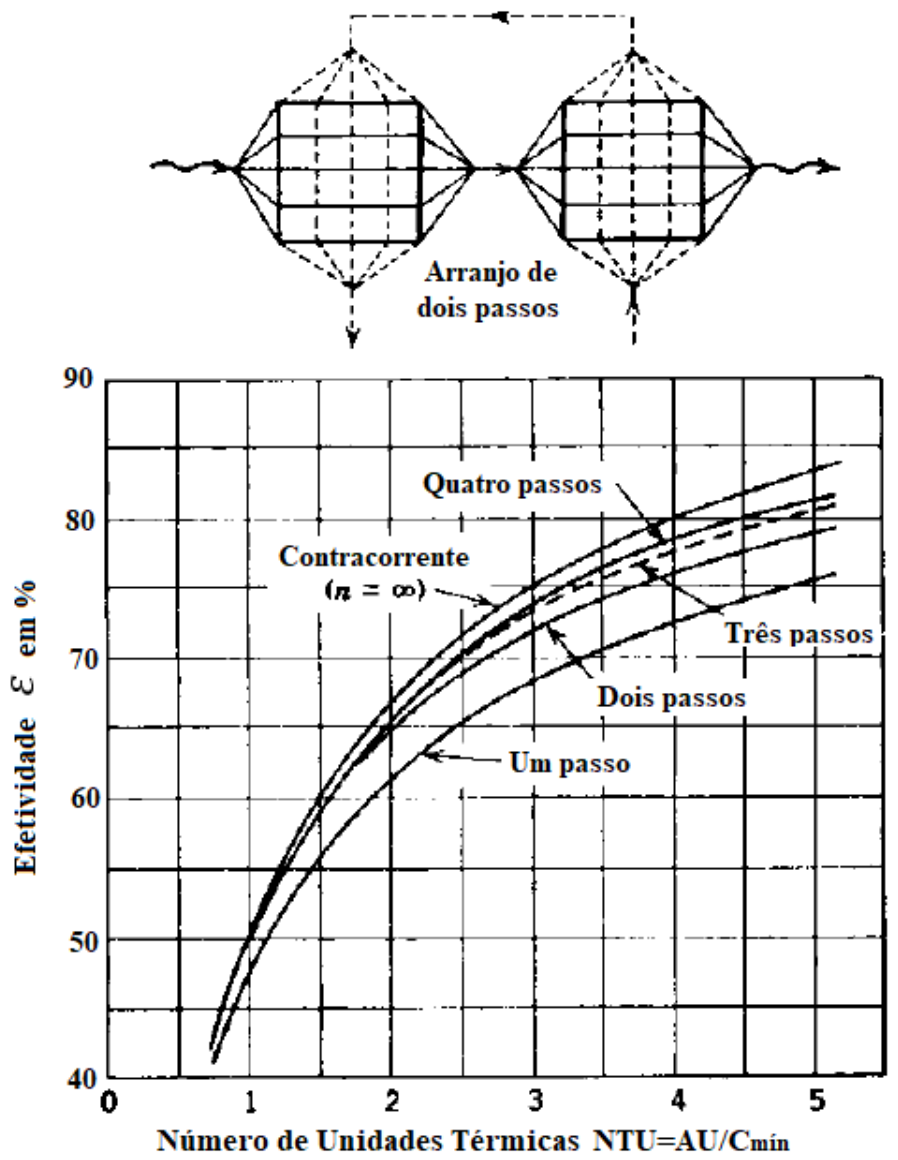

Figura 12. Representação gráfica típica da função $\varepsilon$-NTU

Representação para um trocador do tipo cruzado, fluidos escoando em sentido perpendicular um ao outro. Fonte: (Welty, 1982) 
A figura ilustra trocadores de calor com o número de passes variando entre 1 e 4, bem como a condição ideal "em contracorrente, que corresponderia a um número infinito de passos). Essas curvas, entretanto, não se aplicam ao trocador estudado, que possui múltiplos passes e aletas, que direcionam o fluxo externo de ar em escoamento cruzado. A observação do comportamento dessas curvas efetividade-NTU permite concluir que trocadores de grande porte (i.e.: NTU se aproximando de 2) possuem um baixo valor do que se denomina custo-benefício de operação, que é o parâmetro que caracteriza o aspecto econômico relacionado ao desempenho térmico do trocador.

Desenvolver uma alternativa de cálculo da efetividade do trocador de calor alvo desta pesquisa de mestrado constitui-se em um dos objetivos deste trabalho, cujo desenvolvimento requer a manipulação adequada das equações globais que governam os mecanismos de transferência de calor entre os fluidos de trabalho. Esta nova formulação requer não apenas eliminar a dificuldade experimental associada à medição da temperatura de saída do ar (fluido quente, mas, também, o efeito das aletas nos tubos do trocador.

\subsection{3}

\section{O fator de incrustação}

Associado à efetividade, pode-se definir o fator de incrustação (FF), que se constitui em um parâmetro prático para avaliar o estado de limpeza do trocador dado pela Equação (35):

$$
F F=\frac{\varepsilon_{\text {limpo }}-\varepsilon}{\varepsilon_{\text {limpo }}-\varepsilon_{\text {sujo }}} \quad(0<F F<1)
$$

Conforme definido na equação acima, o fator de incrustação FF (Fouling Factor) é definido em termos dos valores de referência $\varepsilon_{\text {limpo }}$ (valor calculado logo após o trocador ter sido submetido ao processo usual de limpeza das superfícies de troca de calor) e $\boldsymbol{\varepsilon}_{\text {sujo }}$ (valor de referência na condição de trocador sujo, que deve ser determinado no último dia de operação antes de o trocador ser submetido a um novo processo de limpeza). Essas definições são de interesse prático para se monitorar o desempenho térmico do trocador já que a sua efetividade $\varepsilon$ diminui (e o fator de incrustação FF aumenta), à medida em que as superfícies de troca de calor (notadamente as superfícies internas dos tubos do trocador) vão sendo incrustadas pelo uso contínuo do trocador. 
O acúmulo dessa camada de incrustação nas superfícies dos tubos do trocador de calor é considerado uma resistência térmica ao fluxo de calor. Essa resistência varia, teoricamente, de zero (ausência de incrustações) a um valor positivo (pois os depósitos sólidos se acumulam nas superfícies do trocador). A literatura sobre trocadores de calor (Bott, 1997; Kakaç \& Liu, 2002; entre outros) teorizam a resistência térmica do trocador $\mathrm{R}_{\mathrm{f}}\left(\mathrm{m}^{2} \mathrm{~K} / \mathrm{W}\right)$ pela Equação (36), que mede instantaneamente o quanto a condição atual do trocador com incrustações (sujo) se desvia de sua condição original de limpeza, esta última tomada como um valor de referência de linha de base. $U_{\text {sujo }}$ é o coeficiente global de transferência de calor após o processo de limpeza e o $\mathrm{U}_{\text {limpo }}$ o maior coeficiente obtido após um dos processos de limpeza (para o período total de estudo, $\mathrm{U}_{\text {limpo }}=0,243 \mathrm{~kW} / \mathrm{m}^{2} \mathrm{~K}$ ). A Tabela 6 apresenta valores calculados do coeficiente global e da resistência.

$$
R_{f}=\frac{1}{U_{\text {sujo }}}-\frac{1}{U_{\text {limpo }}}
$$

Tabela 6. Coeficiente global de transferência de calor e resistência térmica ( $U$ e $R_{f}$ )

\begin{tabular}{|c|c|c|c|c|c|}
\hline Data & $\mathbf{U}$ & $\mathbf{R f}$ & $\mathbf{D a t a}$ & $\mathbf{U}$ & $\mathbf{R f}$ \\
\hline $\mathbf{( d d / m m} / \mathbf{a a})$ & $\left(\mathbf{k W} / \mathbf{m}^{2} \mathbf{K}\right)$ & $\left(\mathbf{m}^{2} \mathbf{K} / \mathbf{k W}\right)$ & $\mathbf{( d d / m m / a a})$ & $\left(\mathbf{k W} / \mathbf{m}^{2} \mathbf{K}\right)$ & $\left(\mathbf{m}^{2} \mathbf{K} / \mathbf{k W}\right)$ \\
\hline $05 / 07 / 2019$ & 0,439 & 2,272 & $04 / 08 / 2019$ & 0,643 & 1,550 \\
\hline $06 / 07 / 2019$ & 0,432 & 2,310 & $05 / 08 / 2019$ & 0,644 & 1,547 \\
\hline $07 / 07 / 2019$ & 0,429 & 2,323 & $06 / 08 / 2019$ & 0,635 & 1,569 \\
\hline $08 / 07 / 2019$ & 0,430 & 2,317 & $07 / 08 / 2019$ & 0,630 & 1,581 \\
\hline $09 / 07 / 2019$ & 0,480 & 2,079 & $08 / 08 / 2019$ & 0,599 & 1,663 \\
\hline $10 / 07 / 2019$ & 0,519 & 1,921 & $09 / 08 / 2019$ & 0,613 & 1,626 \\
\hline $12 / 07 / 2019$ & 0,627 & 1,589 & $10 / 08 / 2019$ & 0,597 & 1,670 \\
\hline $13 / 07 / 2019$ & 0,650 & 1,532 & $11 / 08 / 2019$ & 0,592 & 1,684 \\
\hline $23 / 07 / 2019$ & 0,696 & 1,432 & $12 / 08 / 2019$ & 0,584 & 1,708 \\
\hline $24 / 07 / 2019$ & 0,686 & 1,451 & $22 / 08 / 2019$ & 0,517 & 1,930 \\
\hline $25 / 07 / 2019$ & 0,685 & 1,455 & $23 / 08 / 2019$ & 0,532 & 1,875 \\
\hline $26 / 07 / 2019$ & 0,681 & 1,463 & $24 / 08 / 2019$ & 0,524 & 1,901 \\
\hline $27 / 07 / 2019$ & 0,677 & 1,470 & $10 / 09 / 2019$ & 0,510 & 1,955 \\
\hline $28 / 07 / 2019$ & 0,669 & 1,488 & $11 / 09 / 2019$ & 0,517 & 1,927 \\
\hline $29 / 07 / 2019$ & 0,665 & 1,497 & $12 / 09 / 2019$ & 0,515 & 1,935 \\
\hline $30 / 07 / 2019$ & 0,663 & 1,502 & $13 / 09 / 2019$ & 0,515 & 1,934 \\
\hline $31 / 07 / 2019$ & 0,660 & 1,509 & $14 / 09 / 2019$ & 0,516 & 1,930 \\
\hline $01 / 08 / 2019$ & 0,651 & 1,529 & $15 / 09 / 2019$ & 0,510 & 1,956 \\
\hline $02 / 08 / 2019$ & 0,639 & 1,560 & $16 / 09 / 2019$ & 0,507 & 1,965 \\
\hline $03 / 08 / 2019$ & 0,641 & 1,555 & $17 / 09 / 2019$ & 0,505 & 1,975 \\
\hline
\end{tabular}


Os cálculos apresentados na Tabela 6 referem-se à alternativa \#2 proposta para o cálculo da efetividade, explicada na secção 4.1. Os dados desta tabela representam um extrato entre 05/07 e 17/09 de 2019, da base de dados completa, incluída no Apêndice E.

Como era de se esperar, observa-se que o valor do coeficiente global de transferência de calor aumenta com a intervenção de limpeza, enquanto o valor da resistência da incrustação diminui. Comportamento este que reflete a natureza do fenômeno físico associado aos mecanismos de transferência de calor entre os fluidos de trabalho do trocador, já que o processo de limpeza objetiva, essencialmente, remover as incrustações.

A Figura 13 ilustra a variação da resistência térmica $R_{f}$, calculada a partir dos resultados das medições de monitoramento diário do trocador de calor ao longo do estudo, conforme dados documentados na Tabela 3.

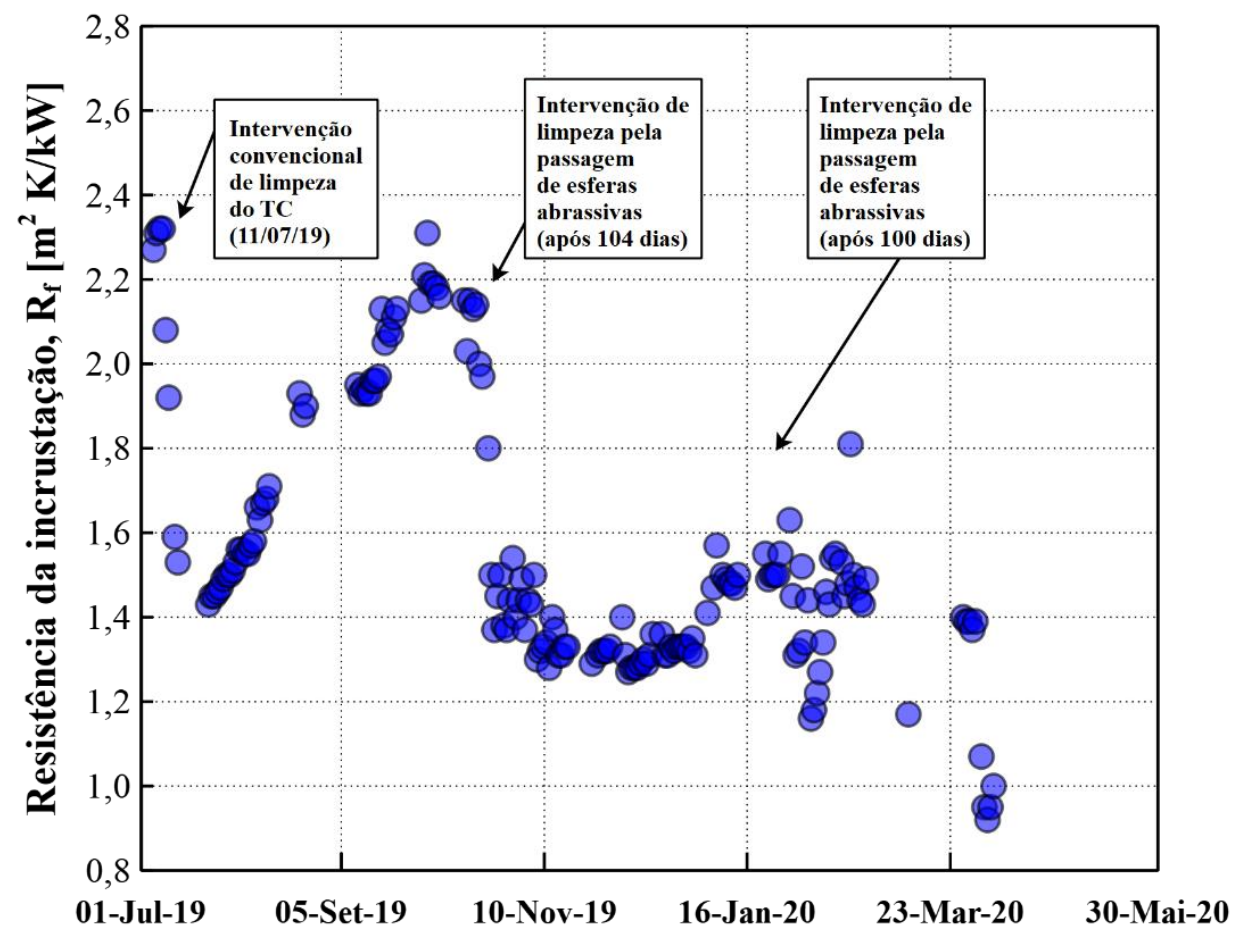

Figura 13. Variação da resistência térmica imposta pela incrustação

Tendo em vista que o processo de limpeza online (limpeza por esferas abrasivas) não requer a interrupção da geração de energia (parada da turbina), esta pode ocorrer em diferentes momentos da operação do hidrogerador. Os dados da figura acima mostram claramente o aumento da resistência térmica (imposto pela incrustação) na data de 11/07/2019, atingindo um valor superior a 2,2 $\left(\mathrm{m}^{2} \cdot \mathrm{K} / \mathrm{kW}\right)$, resistência essa que caiu drasticamente para um patamar inferior a 1,6 $\left(\mathrm{m}^{2} \cdot \mathrm{K} / \mathrm{kW}\right)$ 
imediatamente após o processo parcial online limpeza. À medida que o trocador continuou operando no sistema de resfriamento do hidrogerador, a resistência imposta pela nova incrustação que continuou sendo formada, voltou a crescer para o mesmo patamar, i.e.: acima de $2\left(\mathrm{~m}^{2} \cdot \mathrm{K} / \mathrm{kW}\right)$. Após um novo período de operação, de 104 dias, uma nova limpeza nos tubos do trocador permitiu reduzir a resistência para um patamar ainda mais baixo, inferior a $1,4\left(\mathrm{~m}^{2} \cdot \mathrm{K} / \mathrm{kW}\right)$, caracterizando uma limpeza mais intensa (i.e.: um número maior de ciclos de limpeza pela técnica de esferas abrasivas foi realizado nos tubos do TC, sem, entretanto, interromper a geração). No final de janeiro/2020, após outros 100 dias de operação do trocador, outra intervenção de limpeza foi realizada. Os dados da figura ilustram as vantagens do processo de limpeza online por esferas abrasivas, permitindo ao operador controlar o nível aceitável da resistência imposta ao escoamento, ajustando o número de ciclos de limpeza. 


\section{3}

\section{Análise da incerteza associada ao estudo de caso}

No contexto de um tópico bastante amplo relacionado à expressão da incerteza de medição, este capítulo revê os conceitos básicos requeridos para fundamentar a análise das incertezas associadas às medições impactantes no cálculo da efetividade de um trocador de calor do tipo tubular, de múltiplos passes, com escoamento externo cruzado, utilizado no arrefecimento de um hidrogerador.

\section{1}

\section{Fundamentos da expressão da incerteza de medição}

A calibração de um determinado instrumento de medição consiste na comparação do valor indicado por este instrumento com o valor indicado pelo padrão utilizado na sua calibração, com o objetivo de encontrar o erro e a incerteza associada à medição. Com base no tratamento estatístico desses dados, realizado à luz dos preceitos do guia internacional para expressão da incerteza de medição, ISO GUM (GUM, 2008), o cálculo da "incerteza associada à medição" realizada pelo instrumento de medição requer:

- informações constantes do Certificado de Calibração do padrão utilizado na calibração do instrumento de medição em análise, mais especificamente, a incerteza declarada associada à calibração do padrão, assim assegurando-se rastreabilidade das medições ao sistema internacional de unidades (SI);

- determinação do fator de abrangência $\boldsymbol{k}$, associado aos graus de liberdade do processo de calibração.

Exalta-se, aqui, a absoluta necessidade de se apresentar resultados de medição fundamentados em um certificado de calibração com validade metrológica (i.e.: emitido por laboratório acreditado segundo normas e protocolos internacionalmente acordados por organizações independentes de reconhecimento mútuo). Somente com base no certificado de calibração é que se consegue assegurar rastreabilidade da medição às unidades do Sistema Internacional de unidades (SI), sistema esse gerenciado pela Organização Internacional de Pesos e Medidas.

\subsection{1}

\section{O conceito de incerteza associada à medição}

A incerteza do resultado de uma medição reflete a falta de conhecimento associado ao valor da grandeza a ser medida. Todas as incertezas que impactam no resultado da medição devem ser expressas no mesmo nível de confiança, convertendo-as em incertezas padrão. Uma incerteza padrão é uma margem cujo 
tamanho pode ser considerado como "mais ou menos 1 (um) desvio padrão". A incerteza padrão denota a incerteza de uma média (não apenas sobre a dispersão dos valores). Uma incerteza padrão é geralmente mostrada pelo símbolo u (GUM, 2008); Bell, 1999). Sem se preocupar com a origem dessas fontes de incerteza, de forma geral, estas podem ser de dois tipos.

A incerteza Tipo A reflete o componente estocástico da incerteza de medição, avaliado por meio de análise estatística de todos os valores medidos obtidos sob uma condição de medição predefinida. Pode ser estimada mediante a Equação (37)

$$
u=\frac{s}{\sqrt{n}}
$$

Lembrando que o desvio padrão amostral $s$ é dado pela Equação (38).

$$
s=\sqrt{\left(\frac{1}{n-1}\right) \cdot \sum_{i=1}^{n}\left(x_{i}-\bar{x}\right)^{2}}
$$

Nesta expressão, $\mathrm{x}_{\mathrm{i}}$ denota cada resultado de medição, experimentalmente obtido, enquanto $\bar{x}$ denota a média amostral, calculada pela Equação (39)

$$
\bar{x}=\left(\frac{1}{n}\right) \cdot \sum_{i=1}^{n} x_{i}
$$

A incerteza Tipo B - qualquer incerteza distinta da incerteza do Tipo Arevela o componente de incerteza associado ao dispositivo de medição utilizado, portanto requer informação adicional. O conjunto de informações requeridas usualmente pode incluir:

- resultados de medições anteriores;

- experiência ou conhecimento geral do comportamento e propriedades dos materiais e instrumentos utilizados;

- especificações do fabricante;

- dados fornecidos por certificados de calibração ou outros certificados;

- incerteza atribuída aos valores de referência de livros e manuais.

As incertezas padrão individuais, calculadas pelas avaliações do Tipo A ou Tipo B, são usualmente combinadas pela raiz da soma dos quadrados. O parâmetro obtido como resultado desse procedimento matemático é chamado de incerteza padrão combinada, denotada por $\mathrm{u}_{\mathrm{c}} \mathrm{ou} \mathrm{u}_{\mathrm{c}}(\mathrm{y})$, conforme descrito na expressão:

$$
u_{c}^{2}(y)=u_{1}^{2}+u_{2}^{2}+\ldots+u_{n}^{2}
$$


Em diversas situações, o mensurando y não é medido diretamente, mas determinado a partir de $\mathrm{n}$ grandezas $\mathrm{x}_{1}, \mathrm{x}_{2}, \ldots, \mathrm{x}_{\mathrm{n}}$, por uma relação funcional $\mathrm{f}$ :

$$
y=f\left(x_{1}, x_{2}, \ldots, x_{n}\right)
$$

Assim, o cálculo da incerteza padrão combinada nesse caso, pode ser realizado em conformidade ao GUM (2008), pela Equação (41):

$$
u_{c}^{2}(y)=\sum_{i=1}^{n}\left(\frac{\partial f}{\partial x_{i}}\right)^{2} u^{2}\left(x_{i}\right)
$$

Cada $\mathrm{u}\left(\mathrm{x}_{\mathrm{i}}\right)$ é uma incerteza-padrão avaliada do Tipo A ou Tipo B, para cada uma das grandezas associadas $\mathrm{x}_{1}, \mathrm{x}_{2}, \ldots, \mathrm{x}_{\mathrm{n}}$.

\subsection{2}

\section{Cálculo dos componentes da incerteza}

De um modo geral, para o caso de estudo, as incertezas $\mathrm{u}\left(\mathrm{x}_{\mathrm{i}}\right)$ associadas à medição das grandezas envolvidas no processo, estão compostas pelas contribuições de quatro fontes principais. São elas: (i) incerteza associada à resolução do instrumento sendo calibrado ( $\mathrm{u}_{\mathrm{inst}}$ ); (ii) incerteza associada ao padrão de medição $\left(\mathrm{u}_{\mathrm{p}}\right)$; (iii) incerteza associada à repetibilidade da leitura do instrumento $\left(\mathrm{u}_{\mathrm{r}}\right)$ e (iv) incerteza do ajuste $\left(\mathrm{u}_{\mathrm{s}}\right)$.

\subsubsection{1}

Incerteza associada à resolução do instrumento

A incerteza expandida associada à resolução do instrumento é calculada pela Equação (42):

$$
u_{\text {inst }}=\frac{\text { Resolução }}{2 \sqrt{3}}
$$

A incerteza expandida associada ao padrão encontra-se especificada no Certificado de Calibração do instrumento padrão, que, também, documenta o respectivo valor de abrangência $k$ e o nível de confiança associado.

\subsubsection{2}

\section{Incerteza associada à repetibilidade do instrumento}

Em conformidade ao Vocabulário Internacional de Metrologia (VIM, 2012), a repetibilidade de um determinado experimento de calibração pode ocorrer segundo as seguintes cinco condições, denominadas condições de repetibilidade: 
“... o mesmo procedimento de medição, os mesmos operadores, o mesmo sistema de medição, as mesmas condições de operação e o mesmo local, assim como medições repetidas no mesmo objeto ou em objetos similares durante um curto período de tempo ...".

A incerteza $u_{r}$ associada a todas essas cinco condições de repetibilidade é calculada a partir do desvio padrão amostral $\boldsymbol{s}$ das $\boldsymbol{n}$ réplicas do experimento, dado pela Equação (37).

\subsubsection{3}

\section{Incerteza associada ao polinômio de ajuste}

Um polinômio de grau m (Equação 43) é usualmente utilizado para correlacionar o valor lido pelo instrumento com o respectivo valor indicado pelo padrão, para cada experimento da calibração realizada. O polinômio que mais bem representa a natureza física da calibração é selecionado dentre aqueles que oferecem a menor incerteza do ajuste.

$$
y\left(x_{i}\right)=a_{0}+a_{1} \cdot x+a_{2} \cdot x^{2}+a_{3} \cdot x^{3}+\cdots+a_{n} \cdot x^{m}
$$

$\mathrm{Na}$ expressão acima, $\mathbf{x}$ denota o resultado da medição indicada pelo instrumento e $\mathbf{y}\left(\mathrm{x}_{\mathrm{i}}\right)$ o valor ajustado pelo polinômio, valor esse que relaciona a leitura do instrumento com o valor dado pelo padrão. Já os coeficientes $a_{0}$, $a_{1} \cdots a_{n}$ são determinados aplicando-se o método dos mínimos quadrados ordinários (OLS, do inglês Ordinary Least Squares). Embora o uso de coeficientes de graus superiores possa oferecer um menor erro de ajuste (i.e.: diferença entre um valor medido e um valor calculado pelo ajuste polinomial), isto não garante que o desvio médio quadrático (também chamado de incerteza do ajuste) seja menor que aquele obtido quando um polinômio de grau superior seja utilizado. Isto é explicado devido ao fato de o cálculo da incerteza do ajuste considerar, na sua concepção matemática, que o número de graus de liberdade $(\varphi=n-m)$, parâmetro esse que depende de: (i) o número de pontos experimentais (n); (ii) o número de coeficientes estimados por cada polinômio $(\boldsymbol{m})$.

O valor desta incerteza associada ao ajuste é calculado (para cada polinômio avaliado) aplicando-se a Equação (44). 


$$
u_{s}=\sqrt{\left(\frac{1}{n-m}\right) \cdot \sum_{i=1}^{n}\left[y\left(x_{i}\right)-y_{i}\right]^{2}}
$$

Na equação acima:

- $\mathrm{u}_{\mathrm{s}}$ : denota a incerteza do ajuste

- $\mathrm{y}\left(\mathrm{x}_{\mathrm{i}}\right)$ : denota o valor ajustado pelo polinômio

- $\mathrm{y}_{\mathrm{i}}$ : denota $\mathrm{o}$ valor indicado pelo padrão

- n: denota o número de pontos experimentais (da calibração)

- m: denota o número de coeficientes do polinômio sendo avaliado

Na sequência, (i) escolhe-se o polinômio interpolador associado à menor incerteza do ajuste e (ii) determina-se o fator de abrangência $k$ (para um nível de confiança de 95,0\%), a partir da distribuição de probabilidade t-student e do número de graus de liberdade $(\varphi)$, dado pela Equação (45):

$$
\varphi=n-m
$$

Nesta equação, $\mathrm{n}$ denota o número de pontos experimentais da calibração e m o número de coeficientes estimados pelo polinômio.

Constitui-se boa prática de calibração testar pelo menos três graus de polinômio para se definir aquele que oferece a menor incerteza do ajuste e, por conseguinte, a menor incerteza associada à medição. Assim, uma vez determinados os coeficientes para cada polinômio, calculam-se os valores ajustados para cada polinômio de ajuste. A avaliação de um polinômio de quarto grau ou superior, embora ofereça um melhor resultado do ponto de vista matemático (i.e.: menores erros de ajuste), não representa, entretanto, a natureza física do fenômeno estudado.

A aplicação de um polinômio interpolador de ajuste permite corrigir os resultados experimentais medidos pelo instrumento de medição, assim eliminando o erro sistemático, que é inerente ao processo de medição e facilitando o processo de incorporação da calibração no processamento remoto dos dados.

\subsection{3}

\section{Fator de abrangência}

O fator de abrangência $k$ é obtido a partir dos graus de liberdade da incerteza ${ }^{5}$. Esse fator é um multiplicador adimensional da incerteza. É uma medida de

\footnotetext{
${ }^{5} \mathrm{O}$ número de graus de liberdade $\varphi$ é calculado pela diferença entre o número de possibilidades (número de pontos experimentais $\boldsymbol{n}$ ) e o número de restrições impostas (no caso de se usar polinômios de ajuste, o número de restrições é dado pelo número de coeficientes do polinômio).
} 
confiabilidade, obtida de uma distribuição de probabilidade $t$-student (para um nível de confiança de 95,0 \%) e usado para a obtenção da incerteza expandida de medida.

\subsection{4}

\section{Cálculo da incerteza expandida}

Uma vez calculados os diferentes componentes da incerteza, é possível calcular a incerteza expandida associada à medição. $\mathrm{Na}$ prática, torna-se fundamental conhecer o intervalo de confiança associado ao qual se encontra o valor verdadeiro da medição. Esse valor resulta da multiplicação da incerteza combinada pelo fator $\mathbf{k}$ (fator de abrangência), conforme indica a Equação (46):

$$
U=k \cdot u_{c}
$$

Assim, expressando-se o resultado da medição pela expressão:

$$
y=\bar{y} \pm U
$$

\section{2}

\section{Incerteza de medição: estratégia de monitoramento da efetividade}

O cálculo da efetividade do trocador sem fazer uso da medição da temperatura de saída do fluxo de ar (fluido quente do trocador) requer uma formulação fundamentada em hipóteses para solucionar as equações que governam o mecanismo de transferência de calor. Seguindo o formalismo clássico, a Equação (48), a seguir apresentada, define uma expressão para o cálculo da efetividade do trocador de calor:

$$
\varepsilon=\frac{\dot{Q}_{r e a l}}{C_{\min }\left(\dot{m}_{a g}, T_{a g, \text { in }}, T_{a g, o u t}\right)\left(T_{a r, i n}-T_{a g, i n}\right)}
$$

\subsection{1}

\section{Identificação das fontes primárias de incerteza}

Diante desta grande quantidade de variáveis envolvidas no cálculo da efetividade do trocador de calor, o diagrama de Ishikawa (1986) mostra-se conveniente para orientar a identificação dos componentes que impactam no cálculo da incerteza final associada à determinação da efetividade do trocador. A aplicação do critério Ishikawa à Equação (48), levando-se em conta todas as variáveis que impactam no cálculo de cada termo da equação), produz o "diagrama 
de causa e efeito" mostrado na Figura 14, especificando as variáveis que afetam diretamente no cálculo do valor da efetividade bem como a influência secundária relacionada às medições das grandezas físicas impactantes.

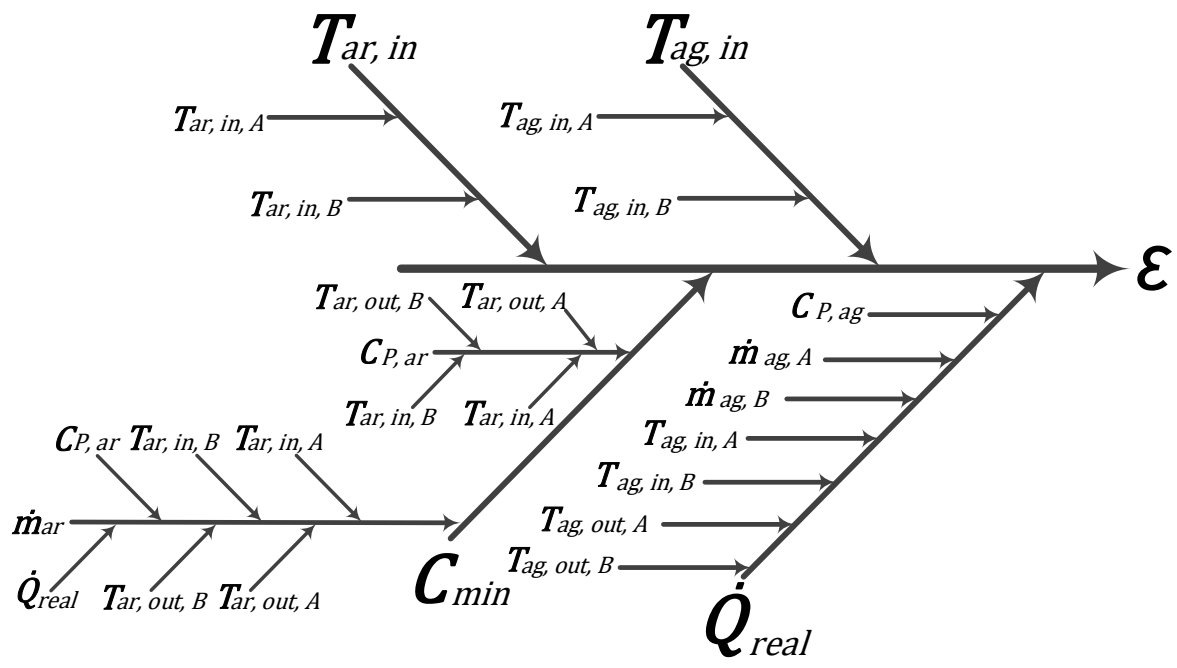

Figura 14. Diagrama de Ishikawa aplicável à Equação (48)

Conforme esquematicamente representado, o cálculo da incerteza associada à efetividade do trocador resulta de detalhado processo de identificação e mensuração de cada grandeza física impactante no cálculo final da efetividade, cujos resultados das medições estão sempre associados um valor de incerteza, que impacta no cálculo da incerteza final associada à efetividade do trocador.

Interessante observar que, ao se aplicar a metodologia de Ishikawa na Equação (18), que representa a forma compacta (após o processamento do balanço térmico entre os fluidos de trabalho do trocador) de se calcular a efetividade do trocador, o diagrama de Ishikawa também se simplifica já que os termos de vazão não mais aparecem na Equação (18), que incorpora o resultado do balanço térmico assim produzindo uma equação mais compacta (com menos variáveis) no cálculo da efetividade. A versão compacta do diagrama de Ishikawa, indicativo das fontes de incerteza no cálculo da efetividade é mostrado na Figura 15. 


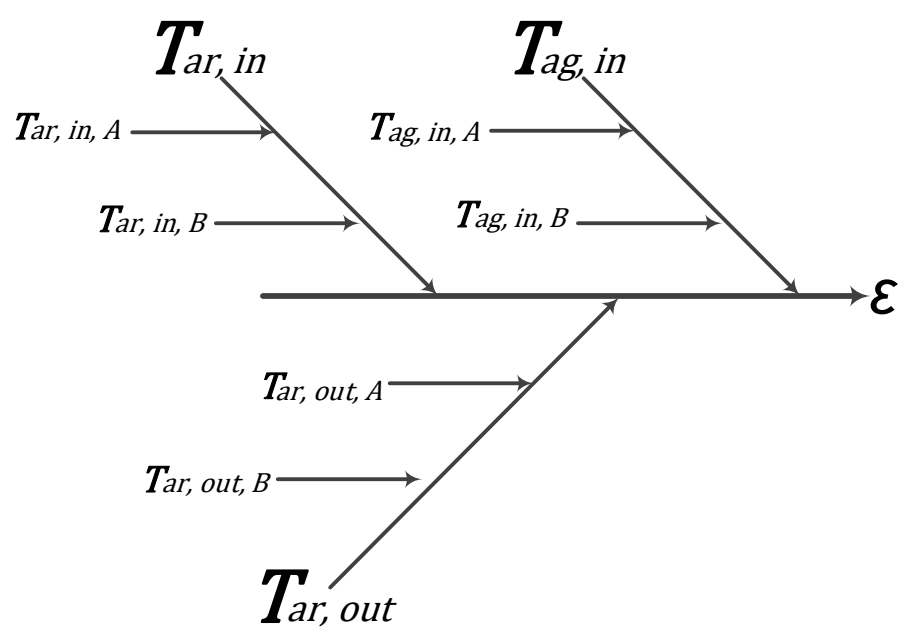

Figura 15. Diagrama de Ishikawa aplicável à Equação (18)

\subsection{2}

\section{Incerteza associada ao cálculo da efetividade}

Em conformidade ao método proposto no GUM (2008), cada fator impactante no cálculo da incerteza associada ao cálculo da efetividade deve ser propagado, segundo a Equação (49):

$$
\left(U_{\varepsilon}\left[T_{a r, \text { out }}, T_{a r, \text { in }}, T_{a g, \text { in }}\right]\right)^{2}=\left(\frac{\partial \varepsilon}{\partial T_{a r, \text { out }}} U_{T_{a r, \text { out }}}\right)^{2}+\left(\frac{\partial \varepsilon}{\partial T_{a r, \text { in }}} U_{T_{a r, \text { in }}}\right)^{2}+\left(\frac{\partial \varepsilon}{\partial T_{a g, \text { in }}} U_{T_{a g, \text { in }}}\right)^{2}
$$

\subsection{3}

\section{Coeficientes de sensibilidade}

A partir da equação de cálculo da efetividade (Equação 18), é possível derivar os coeficientes de sensibilidade associado a cada uma das temperaturas envolvidas. De acordo com o GUM (2008), é necessário estimar os componentes da incerteza associado a cada grandeza física medida, bem como os respectivos coeficientes de sensibilidade. Os coeficientes de sensibilidade para cada fonte de incerteza impactante no cálculo da efetividade são, respectivamente, definidos nas equações (50) a (52), a seguir:

$$
\begin{gathered}
\frac{\partial \varepsilon}{\partial T_{a r, \text { out }}}=-\frac{1}{\left(T_{a r, \text { in }}-T_{a g, \text { in }}\right)} \\
\frac{\partial \varepsilon}{\partial T_{a r, \text { in }}}=\frac{\left(T_{a r, \text { out }}-T_{a g, \text { in }}\right)}{\left(T_{a r, \text { in }}-T_{a g, \text { in }}\right)^{2}} \\
\frac{\partial \varepsilon}{\partial T_{a g, \text { in }}}=\frac{\left(T_{a r, \text { in }}-T_{a r, \text { out }}\right)}{\left(T_{a r, \text { in }}-T_{a g, \text { in }}\right)^{2}}
\end{gathered}
$$


Combinando as Equações (50) e (52) com a equação de definição da efetividade (Equação 18), o coeficiente de sensibilidade $\frac{\partial \varepsilon}{\partial T_{\text {ag,in }}}$ pode ser reescrito na forma:

$$
\frac{\partial \varepsilon}{\partial T_{a g, i n}}=-\varepsilon \cdot \frac{\partial \varepsilon}{\partial T_{a r, o u t}}
$$

A Tabela 7 mostra os respectivos valores da temperatura média dos fluidos de trabalho $\left(\mathrm{T}_{\mathrm{ar}, \mathrm{in}}, \mathrm{T}_{\mathrm{ar}, \mathrm{out}}\right.$ e $\left.\mathrm{T}_{\mathrm{ag}, \text { in }}\right)$ que aparecem na equação (18), assim como os coeficientes de sensibilidades calculados com base nesses valores médios de temperatura, utilizados no cálculo da incerteza expandida com base nos dados experimentais documentados no Apêndice D.

Tabela 7. Valor médio das temperaturas envolvidas no cálculo de $\varepsilon$

\begin{tabular}{|c|c|c|c|c|c|}
\hline \multicolumn{3}{|c|}{ Temperaturas médias $\left({ }^{\circ} \mathrm{C}\right)$} & \multicolumn{3}{|c|}{ Coeficientes de sensibilidade $\left({ }^{0} \mathrm{C}^{-1}\right)$} \\
\hline$T_{a r, i n}$ & $\boldsymbol{T}_{\text {ar,out }}$ & $T_{a g, i n}$ & $\frac{\partial \varepsilon}{\partial T_{a r, o u t}}$ & $\frac{\partial \varepsilon}{\partial T_{a r, i n}}$ & $\frac{\partial \varepsilon}{\partial T_{a g, i n}}$ \\
\hline 54,6 & 36,5 & 24,1 & $-0,032739$ & 0,013315 & 0,019424 \\
\hline
\end{tabular}

Fazendo uso dos resultados das medições realizadas durante o monitoramento da operação do trocador de calor em funcionamento na usina Fontes Nova (dados documentados no Apêndice D), foi possível calcular a incerteza associada à efetividade, fazendo uso de seus respectivos coeficientes de sensibilidade, mostrados na Figura 16, para uma sequência de medições de monitoramento de um dos trocadores de calor do sistema de arrefecimento do hidrogerador, ao longo de um período de 13 meses de operação. 


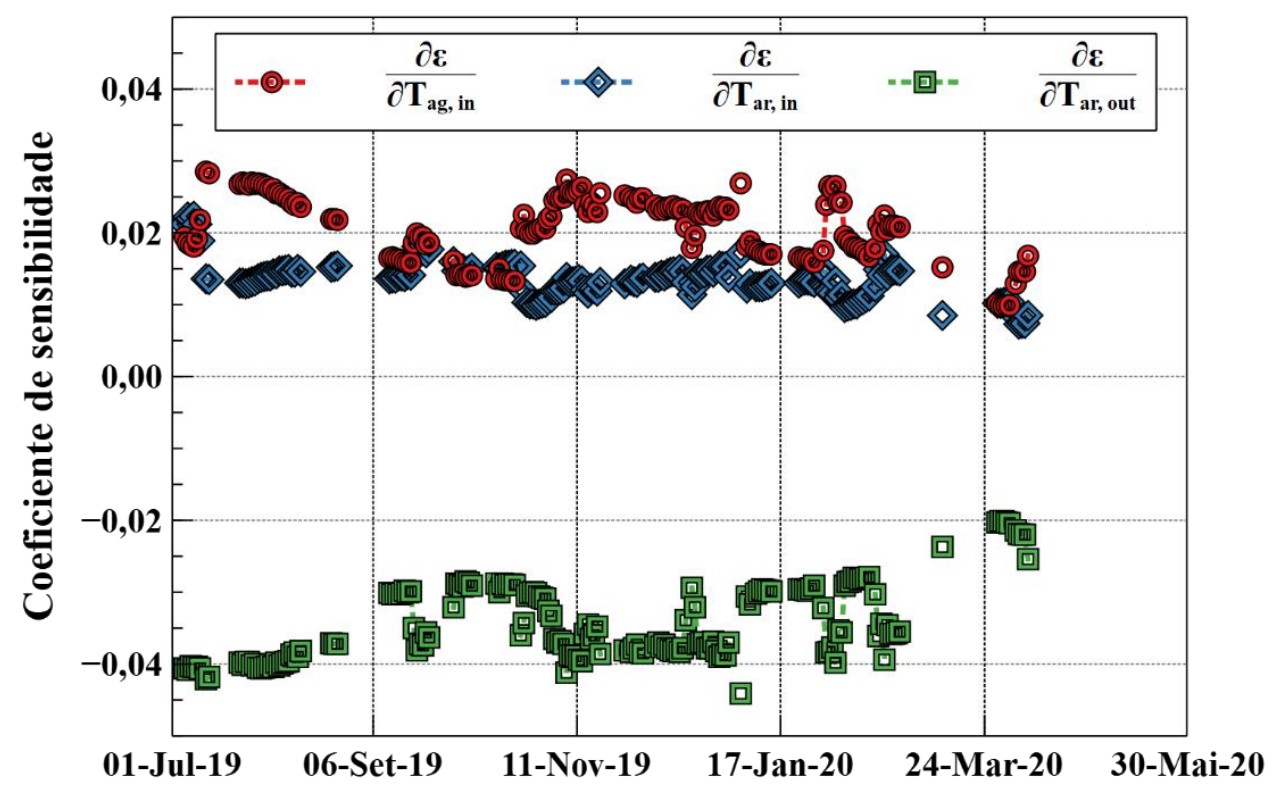

Figura 16. Coeficientes de sensibilidade associados ao cálculo da efetividade

Observa-se na figura acima que o perfil do coeficiente de sensibilidade associado a $\mathrm{T}_{\mathrm{ag}, \text { in }}$ (símbolos na cor vermelha) segue a tendência do comportamento da efetividade mostrado durante o seu monitoramento, lembrando que o valor da efetividade se reduz à medida em que o trocador acumula incrustação, recuperando o seu valor tão logo os tubos do trocador sejam limpos pelas esferas abrasivas utilizadas pelo sistema online de limpeza. Este mesmo comportamento é observado para o coeficiente de sensibilidade $\frac{\partial \varepsilon}{\partial T_{\text {ag in }}}$ (símbolos na cor vermelha). Já o coeficiente de sensibilidade da efetividade calculado em relação à temperatura do ar de entrada $\frac{\partial \varepsilon}{\partial T_{a r, i n}}$ (símbolos na cor azul) apresenta uma oscilação menos intensa, praticamente constante, exceto por pequenas flutuações que são intrínsecas do sistema de medição de temperatura. Um fato interessante que merece destaque é o "comportamento espelho" entre os coeficientes de sensibilidade calculados em relação à temperatura de entrada da água $\left(\frac{\partial \varepsilon}{\partial T_{a g, i n}}\right)$ e em relação à temperatura de saída do ar $\left(\frac{\partial \varepsilon}{\partial T_{\text {arout }}}\right)$, “correlação espelho" essa claramente explicada pela Equação (53). Ou seja, na Figura 16, os símbolos na cor verde representativos de um coeficiente de sensibilidade se mostram como espelho dos símbolos na cor vermelha representativos do outro coeficiente.

Adicionalmente, considerando as Equações (51) e (52), cabem ainda, as seguintes observações: 
- o valor absoluto da diferença $\left(T_{a r, o u t}-T_{a g, i n}\right)$ é sempre maior que o valor absoluto da diferença de temperatura $\left(T_{a r, i n}-T_{a r, o u t}\right)$, fato que confirma que o coeficiente de sensibilidade associado à $T_{a r, i n}$ (símbolos na cor azul) é sempre maior do que o coeficiente de sensibilidade calculado em relação à $T_{a g, \text { in }}$ (símbolos na cor verde) e

- o coeficiente de sensibilidade em relação à $T_{\text {ar,out }}$ não depende desta temperatura (Equação 50), considerada problemática pela baixa confiabilidade metrológica associada à sua medição.

Conhecidos esses coeficientes de sensibilidade, é possível calcular a contribuição individual de cada temperatura que impacta no cálculo da incerteza expandida, associada ao cálculo da efetividade do trocador de calor. O resultado desta análise de incerteza é resumido na Tabela 8, a seguir.

Tabela 8. Cálculo da efetividade: contribuição das incertezas individuais

$$
\left(U_{\varepsilon}\left[T_{a r, o u t}, T_{a r, i n}, T_{a g, i n}\right]\right)^{2}=\left(\frac{\partial \varepsilon}{\partial T_{a r, o u t}} U_{T_{a r, o u t}}\right)^{2}+\left(\frac{\partial \varepsilon}{\partial T_{a r, \text { in }}} U_{T_{\text {ar }, \text { in }}}\right)^{2}+\left(\frac{\partial \varepsilon}{\partial T_{\text {ag,in }}} U_{T_{\text {ag, in }}}\right)^{2} \text { (49) }
$$

\begin{tabular}{|c|c|c|c|c|}
\hline \multicolumn{4}{|c|}{$\begin{array}{l}\text { Contribuição de cada coeficiente de sensibilidade na incerteza } \\
\text { associada ao cálculo de } \varepsilon\end{array}$} & $\begin{array}{c}\text { Incerteza } \\
\text { Expandida }\end{array}$ \\
\hline$\left(\boldsymbol{U}_{\varepsilon}\left[T_{\text {ar,out }}, T_{\text {ar,in }}, T_{\text {ag,in }}\right]\right)^{2}$ & $\left(\frac{\partial \varepsilon}{\partial T_{a r, o u t}} U_{T_{\text {ar,out }}}\right)^{2}$ & $\left(\frac{\partial \varepsilon}{\partial T_{a r, i n}} U_{T_{a r, i n}}\right)^{2}$ & $\left(\frac{\partial \varepsilon}{\partial T_{a g, i n}} U_{T_{a g, i n}}\right)^{2}$ & $\boldsymbol{U}_{\boldsymbol{\varepsilon}}$ \\
\hline $\begin{array}{l}0,00015 \\
(100 \%)\end{array}$ & $\begin{array}{c}1,0140 \mathrm{E}-04 \\
(70 \%)\end{array}$ & $\begin{array}{c}1,9296 \mathrm{E}-05 \\
(13 \%)\end{array}$ & $\begin{array}{c}2,6420 \mathrm{E}-05 \\
(17 \%)\end{array}$ & 0,0121 \\
\hline
\end{tabular}

Pode-se, assim, comprovar que, de fato, a temperatura de saída do ar é a variável que mais impacta no cálculo da incerteza expandida associada ao cálculo da efetividade, não obstante o seu coeficiente de sensibilidade ser o menor (símbolos na cor verde, na Figura 16) dentre os três coeficientes de sensibilidade calculados. Isto confirma que, embora o coeficiente de sensibilidade tenha um valor baixo, a grande dispersão dos dados associados à medição da temperatura de saída do ar impacta de forma significativa no cálculo da incerteza expandida associada à efetividade.

Concluindo a análise da incerteza associada a cada termo da equação (49), transcrita no topo da Tabela 8 para facilitar a visualização, observa-se que o termo da equação associado ao coeficiente de sensibilidade relacionado à temperatura de saída do ar, calculado Equação (50), impacta em $70 \%$ no cálculo da incerteza expandida associada à efetividade. As contribuições associadas às equações (51) e (52), relacionadas, respectivamente, às temperaturas de entrada do ar e de entrada da água, impactam em $13 \%$ e 17\%, portanto com menor intensidade. A incerteza 
expandida final $(0,0121)$ associada ao cálculo da efetividade do trocador representa uma incerteza percentual de apenas $2 \%$ quando aplicada a um valor de efetividade da ordem de 0,6 (conforme dados reais documentados na Tabela 16). Durante a operação do trocador, os Pt 100 utilizados na medição de temperatura não estão acessíveis (lacrados dentro da carcaça do hidrogerador), enquanto os Pt 100 utilizados para medição das temperaturas da água de entrada e de saída do trocador estão acessíveis para inspeção. Ou seja, a contribuição de $18 \%$ devida à incerteza associada à temperatura de entrada da água que aparece na Tabela 8 certamente poderá ser melhorada quer via inspeção programada do acúmulo de fouling da ponta do elemento sensitivo do sensor Pt 100. Em outras palavras, esta análise de incerteza deve ser interpretada como uma alternativa eficaz de controle da qualidade do experimento que pode ser realizada pela equipe de manutenção da usina hidrelétrica responsável pelo monitoramento do hidrogerador. 


\section{4}

\section{Alternativas de cálculo da efetividade}

Tendo em vista a dificuldade experimental (discutida na seção anterior) de se medir a temperatura de saída do ar — variável presente na Equação (18), que fundamenta o cálculo da efetividade do trocador de calor-, este capítulo avalia diferentes alternativas de cálculo da efetividade do trocador.

\section{1}

\section{Fundamentos teóricos}

Esta seção apresenta a base teórica e o equacionamento matemático que fundamentam o fenômeno físico relacionado ao cálculo da efetividade de trocadores de calor, objeto de estudo nesta pesquisa de mestrado.

\subsection{1}

\section{Cálculo da efetividade do trocador: sistema de equações}

Quatro equações (fundamentadas na termodinâmica, na teoria clássica de transferência de calor e no conceito de efetividade térmica de trocadores de calor), compõem um sistema de equações que envolve a variável efetividade térmica do trocador. A Equação (54) resulta do balanço térmico entre os fluidos quente (ar) e frio (água) do trocador de calor. A Equação (55) resulta da equação básica da quantidade total de calor trocado entre os fluidos de trabalho, quer em função do coeficiente global de transferência de calor, quer pela média logarítmica das temperaturas dos fluidos de trabalho. A Equação (56) reflete as resistências térmicas impostas ao fluxo de calor pelos mecanismos de condução e convecção, incluindo a resistência térmica imposta pela indesejável incrustação que, inevitavelmente, obstrui as passagens internas dos tubos do trocador e que, drasticamente, impacta na redução da efetividade do trocador e nos custos de bombeamento do fluido de trabalho que circula por esses tubos do trocador. $\mathrm{O}$ sistema de equações é completado pela Equação (18), definida no Capítulo 2, que reflete o conceito da efetividade térmica do trocador de calor, calculada em função de apenas três temperaturas (resultou do balanço térmico), mais especificamente, pelas temperaturas do ar de entrada $\left(\mathrm{T}_{\mathrm{ar}, \mathrm{in}}\right)$, do ar de saída $\left(\mathrm{T}_{\mathrm{ar}, \text { out }}\right)$ e da água de entrada $\left(\mathrm{T}_{\mathrm{ag}, \mathrm{in}}\right)$. Embora já apresentada no Capítulo 2, esta equação é repetida, a seguir, apenas para explicitar o sistema de quatro equações que se deseja resolver 
visando ao cálculo da efetividade do trocador, sem a necessidade de realizar a problemática medição da temperatura do ar de saída do trocador.

$$
\begin{gathered}
\dot{Q}_{a g}=\dot{Q}_{a r}=\dot{m}_{a g} c_{p, a g}\left(T_{a g, \text { out }}-T_{a g, \text { in }}\right)=\dot{m}_{a r} c_{p, \text { ar }}\left(T_{a r, \text { in }}-T_{a r, \text { out }}\right) \\
\dot{Q}_{a g}=\dot{Q}_{a r}=U A \frac{\left(T_{a r, \text { in }}-T_{a g, \text { out }}\right)-\left(T_{a r, \text { out }}-T_{a g, \text { in }}\right)}{\ln \left(\frac{T_{a r, \text { in }}-T_{a g, \text { out }}}{T_{a r, \text { out }}-T_{a g, \text { in }}}\right)} \\
\frac{1}{U}=\frac{1}{h_{a r}}+\frac{1}{h_{a g}}+R_{\text {parede }}+R_{f} \\
\varepsilon=\frac{\left(T_{a r, \text { in }}-T_{a r, \text { out }}\right)}{\left(T_{a r, \text { in }}-T_{a g, \text { in }}\right)}
\end{gathered}
$$

Obtém-se, assim, um sistema de quatro equações e sete incógnitas: $\varepsilon, \dot{\mathrm{m}}_{\mathrm{ar}}, \mathrm{T}_{\mathrm{ar}, \text { out }}, \mathrm{U}, \mathrm{R}_{\mathrm{ag}}, \mathrm{h}_{\mathrm{ar}} \mathrm{e} \mathrm{h}_{\mathrm{ag}}$, em que as três últimas refletem coeficientes $\mathrm{e}$ propriedades que podem ser determinadas pela teoria clássica de transferência de calor entre os fluidos de trabalho.

A resistência térmica por condução $\left(R_{\text {parede }}\right)$ pode ser determinada pela Equação (57), em função do comprimento tubo (L), dos diâmetros interno e externo da tubulação $\left(D_{i}, D_{o}\right)$ e da condutividade térmica do material do tubo $(\mathrm{k})$.

$$
R_{\text {parede }}=\frac{\ln \left(D_{o} / D_{i}\right)}{2 \pi k L}
$$

O coeficiente de filme por convecção (h), pode ser calculado pela Equação (58), que relaciona os efeitos de transferência de calor por condução e convecção (definidos pelo Número de Nusselt, que é um parâmetro adimensional), pelo valor de $k$, que é coeficiente de condução do fluido e pelo valor $\mathrm{D}$, que representa um comprimento caraterístico do processo de transferência de calor, no presente caso, o diâmetro do tubo do trocador:

$$
h=\frac{N u \cdot k}{D}
$$

Determinado por correlações empíricas em função do regime hidrodinâmico do escoamento (Número de Reynolds) e de características dos processos de transferência de calor por convecção, caracterizados pelo Número de Prandtl, essas 
correlações variam em função do tipo de escoamento (interno ou externo), da natureza do processo de transferência de calor, das características dos fluidos de trabalho, dentre outros fatores. Assim, considerando que a água escoa pelo interior dos tubos do trocador de calor e está sendo aquecida, utilizou-se a correlação de transferência de calor para escoamentos internos proposta por Dittus-Boeler (Cengel, 2009), descrita pela Equação (59):

$$
N u=0,023 R e^{0,8} \operatorname{Pr}^{0,4}
$$

A equação acima é aplicável a regimes de escoamento definido por $2500<$ $\operatorname{Re}<1,24 \times 10^{5}$, para regime térmico na faixa $0,7<\operatorname{Pr}<160$, e L/D $\geq 60$ condições essas consideradas na solução do sistema de equações formalizado, com o propósito de se calcular a efetividade térmica do trocador de calor objeto do estudo.

Já o número de Reynolds devido al caráter interno do escoamento, é calculado pela Equação (60):

$$
R e=\frac{\rho V_{m} D_{i}}{\mu}=\frac{V_{m} D_{i}}{v}
$$

Nesta expressão, $\rho, \mu, v$ são a densidade, viscosidade dinâmica e viscosidade cinemática da água respetivamente, $V_{m}$ é a velocidade média do escoamento e $D_{i}$ é o diâmetro interno do tubo.

A Tabela 9 apresenta as expressões utilizadas (i) no cálculo da viscosidade cinemática do fluido frio (água); (ii) no cálculo do número de Prandt e (iii) no cálculo do coeficiente de condutividade térmica, entendidos como parâmetros adicionais requeridos no processo de cálculo dos mecanismos de troca de calor requeridos no cálculo da efetividade térmica do trocador. A expressão polinomial (de grau 3) para determinação da viscosidade cinemática do fluido frio (água) é determinada pelo ajuste polinomial proposto por Lemmon et al. (2013), processado pelo software de cálculo de propriedades termodinâmicas refprop v9.1. 
Tabela 9. Polinômios de cálculo de parâmetros auxiliares para a água

\begin{tabular}{|c|c|c|}
\hline Expressão & Unidades & Coeficientes \\
\hline $\begin{array}{c}v=A+B \cdot T_{a g, m}+C \cdot T_{a g, m}^{2}+D \cdot T_{a g, m}^{3} \\
\text { (v: é a viscosidade cinemática da água) }\end{array}$ & $\left(\mathrm{cm}^{2} / \mathrm{s}\right)$ & $\begin{array}{l}\text { A: } 0,00001331421190740 \\
\text { B: } 0,00000008796964294 \\
\text { C: } 0,00000000010386657\end{array}$ \\
\hline $\begin{array}{c}\operatorname{Pr}=A+B \cdot T_{a g, m}+C \cdot T_{a g, m}^{2}+D \cdot T_{a g, m}^{3} \\
\text { (Pr: é o número de Prandt, para o fluido } \\
\text { água) }\end{array}$ & - & $\begin{array}{l}\text { A: } 0,736333531133 \\
\text { B: }-0,000266754013 \\
\text { C: }-0,000000297518 \\
\text { D: } 0,000000004448\end{array}$ \\
\hline $\begin{array}{l}K=A+B \cdot T_{a r, m}+C \cdot T_{a r, m}^{2} \\
\text { ( } K: \text { é a condutividade térmica) }\end{array}$ & $(\mathrm{W} / \mathrm{m} \mathrm{K})$ & $\begin{array}{l}\text { A: } 0,5594801241340 \\
\text { B: } 0,0021578815640 \\
\text { C: }-0,0000096505997\end{array}$ \\
\hline
\end{tabular}

Para o caso do fluido quente do trocador de calor (ar), a correlação utilizada é a proposta por Zukauskas (Cengel, 2009), associada à transferência de calor calculada pelo fluido que circula externamente aos tubos do trocador, dada pela Equação (61):

$$
N u=0,35 \operatorname{Re}^{0,6} \operatorname{Pr}^{0,36}\left(\frac{s_{T}}{s_{L}}\right)^{0,2}\left(\frac{P r}{P r_{S}}\right)^{0,25}
$$

A equação acima é válida para as seguintes condições hidrodinâmicas e térmicas: $1000<\mathbf{R e}<2 \times 10^{5}$ e $0,7<\operatorname{Pr}<500$, condições essas igualmente aplicáveis ao regime hidrodinâmico e térmico estudado, portanto factíveis de serem utilizadas na solução do sistema de equações objeto do estudo.

Para ambos os fluidos de trabalho, ar e água, o regime hidrodinâmico do escoamento é caracterizado pelo número de Reynolds (razão entre as forças de inércia e viscosas, que controlam o escoamento), expresso pela Equação (62):

$$
R e_{\max }=\frac{\rho V_{\max } D_{0}}{\mu}=\frac{V_{\max } D_{0}}{v}
$$

Nesta expressão, $\rho, \mu, v$ denotam, respectivamente, a densidade, viscosidade dinâmica e viscosidade cinemática do fluido de trabalho. $\mathrm{D}_{0}$ representa o diâmetro característico para cada caso, o diâmetro externo do tubo, para o caso de se calcular o regime do escoamento do ar ou o diâmetro interno do tubo, caso se deseja calcular o Número de Reynolds para o escoamento interno da água. 
$\mathrm{Na}$ Figura 17, $\mathrm{V}_{\max }$ é a velocidade máxima do ar que escoa externamente aos tubos, ao longo do arranjo alternado dos tubos do trocador de calor, velocidade essa que pode ser estimada em função da velocidade média pela Equação (63):

$$
V_{\max }=\frac{S_{T}}{2\left(S_{D}-D_{0}\right)} V_{m}
$$

Nesta expressão, $S_{T}$ e $S_{D}$ denotam parâmetros geométricos (dimensões características) do arranjo de tubos do trocador objeto do estudo, conforme ilustrado na Figura 17.

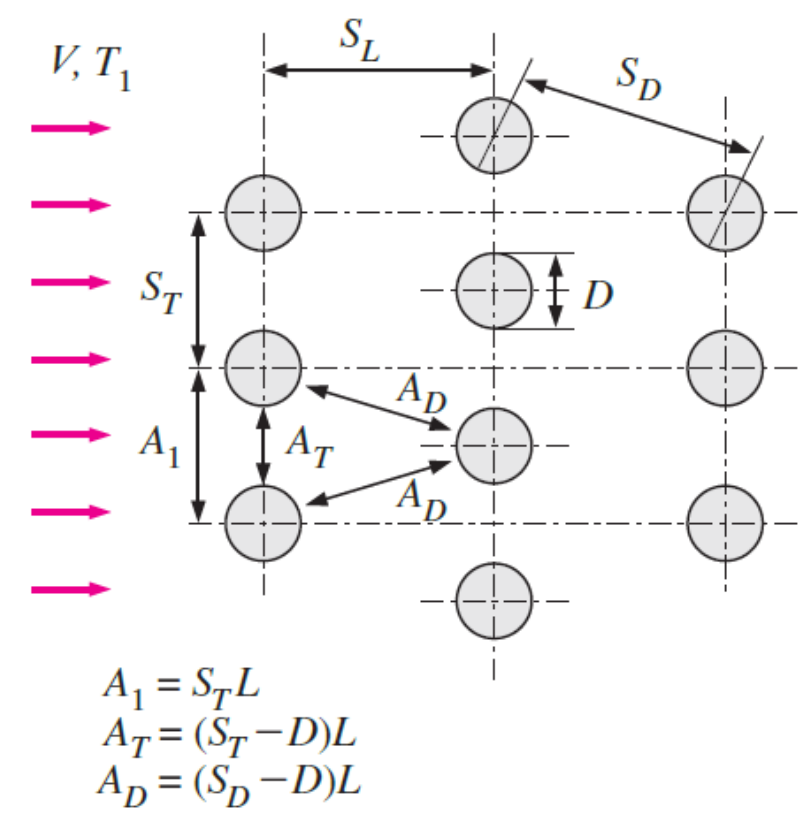

Figura 17. Esquema do arranjo de tubos do trocador estudado

$\mathrm{Na}$ figura acima, $\mathrm{S}_{\mathrm{T}}$ é o espaçamento transversal ao escoamento do ar; $\mathrm{S}_{\mathrm{L}}$, o escoamento longitudinal ou paralelo ao escoamento e $S_{D}$, o espaçamento diagonal em relação ao escoamento, dimensões características essas inter-relacionadas pela Equação (64):

$$
S_{D}=\sqrt{S_{L}^{2}+\left(\frac{S_{T}}{2}\right)^{2}}
$$

Conforme ilustrado pela Figura 17, e pelo princípio da conservação de massa, o escoamento externo do ar que atravessa a área $\mathrm{A}_{\mathrm{T}}$ se desacelera ao se dividir em dois fluxos simétricos que escoam pelas laterais, de área $A_{D}$; ou seja, quanto menor for a área do escoamento, maior será a sua velocidade e, portanto, maior será o número de Reynolds, mantidas as demais características. O projeto do trocador impõe esse arranjo de tubos para intencionalmente desacelerar o fluido no entorno 
dos tubos, assim aumentando o tempo de troca de calor. A Tabela 10 apresenta o valor estimado desses parâmetros geométricos para o tipo de trocador de calor estudado. Com base nessas dimensões características e nos valores das propriedades dos fluidos de trabalho ar e água, é possível calcular o valor do número de Reynolds, que é o parâmetro adimensional que caracteriza o regime do escoamento.

Tabela 10. Dados estimados para os parâmetros do arranjo de trocador

\begin{tabular}{cccc|c}
\hline \multicolumn{3}{c|}{ Fluido externo: ar } & $\begin{array}{c}\text { Fluido interno: } \\
\text { água }\end{array}$ \\
\hline $\mathbf{S}_{\mathbf{T}}[\mathrm{mm}]:$ & $\mathrm{S}_{\mathrm{L}}[\mathrm{mm}]:$ & $\mathrm{S}_{\mathrm{D}}[\mathrm{mm}]:$ & $D o(\mathrm{~mm})$ & $D i(\mathrm{~mm})$ \\
\hline 74,3 & 70,6 & 79,8 & 27,90 & 23,3 \\
\hline
\end{tabular}

$D o$ : diâmetro externo do tubo aletado; $D i$ : diâmetro interno do tubo

A Tabela 11 explicita os valores das áreas associadas às dimensões características $A_{T}$ e $A_{D}$, pelas quais escoa o ar, externamente aos tubos do trocador.

Tabela 11. Áreas entre os tubos do escoamento externo de ar

$$
\begin{array}{cc}
\mathbf{A}_{\mathbf{T}}\left[\mathbf{m}^{2}\right] & \mathbf{A}_{\mathbf{D}}\left[\mathbf{m}^{2}\right] \\
0,093 & 0,205
\end{array}
$$

Conforme ilustrado na Figura 17, devido ao princípio de continuidade, podese assegurar que toda a massa de ar que entra por $\mathrm{A}_{\mathrm{T}}$ vai sair pelo outro lado do tubo, dividindo-se de maneira uniforme ao cruzar as duas passagens $A_{D}$, devido à simetria do arranjo dos tubos entre essas duas áreas.

Assim, determinados os comprimentos característicos, com base nos quais podem ser calculados o Número de Reynolds, os dados da

Tabela 12 calcula, para um extrato dos dados do Apêndice F, o valor instantâneo do número de Reynolds para as condições caracterizadas. 
Tabela 12. Regime hidrodinâmicos dos escoamentos dos fluidos de trabalho do TC

\begin{tabular}{|c|c|c|c|c|c|c|c|}
\hline Data & $\mathbf{R e}\left(\mathbf{S}_{\mathbf{T}}\right)$ & $\mathbf{R e}\left(\mathbf{S}_{\mathbf{D}}\right)$ & $\mathbf{R e}\left(\mathbf{D}_{\mathbf{i}}\right)$ & $\mathbf{D a t a}$ & $\mathbf{R e}\left(\mathbf{S}_{\mathbf{T}}\right)$ & $\mathbf{R e}\left(\mathbf{S}_{\mathbf{D}}\right)$ & $\mathbf{R e}\left(\mathbf{D}_{\mathbf{i}}\right)$ \\
\hline $\mathbf{( d d} / \mathbf{m m} / \mathbf{a a})$ & $\mathbf{A r}$ & $\mathbf{A r}$ & $\mathbf{A} \mathbf{g u a}$ & $\mathbf{( d d} / \mathbf{m m} / \mathbf{a a})$ & $\mathbf{A r}$ & $\mathbf{A r}$ & $\mathbf{A} \mathbf{g u a}$ \\
\hline $05 / 07 / 2019$ & 14669,61 & 6636,77 & 2999,79 & $04 / 08 / 2019$ & 18780,84 & 8496,75 & 4395,85 \\
\hline $06 / 07 / 2019$ & 14403,73 & 6516,48 & 2786,34 & $05 / 08 / 2019$ & 18836,33 & 8521,86 & 4345,75 \\
\hline $07 / 07 / 2019$ & 14391,33 & 6510,87 & 2774,77 & $06 / 08 / 2019$ & 18728,24 & 8472,96 & 4317,46 \\
\hline $08 / 07 / 2019$ & 14401,23 & 6515,34 & 2736,94 & $07 / 08 / 2019$ & 18629,53 & 8428,30 & 4274,53 \\
\hline $09 / 07 / 2019$ & 15853,35 & 7172,31 & 3456,40 & $08 / 08 / 2019$ & 18214,04 & 8240,32 & 4300,54 \\
\hline $10 / 07 / 2019$ & 17080,00 & 7727,26 & 4263,99 & $09 / 08 / 2019$ & 18375,62 & 8313,42 & 4350,78 \\
\hline $12 / 07 / 2019$ & 18378,80 & 8314,86 & 4036,70 & $10 / 08 / 2019$ & 18093,30 & 8185,70 & 4357,03 \\
\hline $13 / 07 / 2019$ & 18793,35 & 8502,41 & 4195,39 & $11 / 08 / 2019$ & 17976,22 & 8132,73 & 4329,55 \\
\hline $23 / 07 / 2019$ & 19802,85 & 8959,12 & 4671,62 & $12 / 08 / 2019$ & 17827,79 & 8065,58 & 4311,16 \\
\hline $24 / 07 / 2019$ & 19433,35 & 8791,96 & 4368,37 & $22 / 08 / 2019$ & 16665,85 & 7539,89 & 3890,26 \\
\hline $25 / 07 / 2019$ & 19388,05 & 8771,46 & 4396,59 & $23 / 08 / 2019$ & 16957,43 & 7671,81 & 3964,09 \\
\hline $26 / 07 / 2019$ & 19330,80 & 8745,56 & 4429,68 & $24 / 08 / 2019$ & 16856,47 & 7626,14 & 3933,10 \\
\hline $27 / 07 / 2019$ & 19285,08 & 8724,88 & 4435,72 & $10 / 09 / 2019$ & 16603,20 & 7511,55 & 4276,23 \\
\hline $28 / 07 / 2019$ & 19173,06 & 8674,20 & 4436,77 & $11 / 09 / 2019$ & 16733,13 & 7570,34 & 4364,53 \\
\hline $29 / 07 / 2019$ & 19130,85 & 8655,10 & 4414,65 & $12 / 09 / 2019$ & 16698,59 & 7554,71 & 4427,32 \\
\hline $30 / 07 / 2019$ & 19128,24 & 8653,92 & 4424,67 & $13 / 09 / 2019$ & 16732,87 & 7570,22 & 4481,25 \\
\hline $31 / 07 / 2019$ & 19064,54 & 8625,10 & 4421,69 & $14 / 09 / 2019$ & 16762,48 & 7583,62 & 4470,96 \\
\hline $01 / 08 / 2019$ & 18925,21 & 8562,07 & 4420,82 & $15 / 09 / 2019$ & 16556,73 & 7490,53 & 4303,00 \\
\hline $02 / 08 / 2019$ & 18738,29 & 8477,50 & 4417,26 & $16 / 09 / 2019$ & 16411,52 & 7424,84 & 4129,80 \\
\hline $03 / 08 / 2019$ & 18739,93 & 8478,24 & 4417,93 & $17 / 09 / 2019$ & 16355,96 & 7399,70 & 4141,95 \\
\hline
\end{tabular}

A Tabela 13 apresenta as expressões utilizadas para o cálculo da viscosidade cinemática do fluido quente (ar), do Número de Prandtl e do coeficiente k de condutividade térmica do ar. A expressão polinomial para determinação da viscosidade cinemática do ar é determinada pelo ajuste polinomial (de grau 2) igualmente proposto por Lemmon et al. (2013), processado pelo software de cálculo de propriedades termodinâmicas refprop v9.1, resolvido pela ferramenta computacional Matlab®. 
Tabela 13. Polinômios de cálculo de parâmetros auxiliares para o ar

\begin{tabular}{|c|c|c|}
\hline Expressão & Unidades & Coeficientes \\
\hline $\begin{array}{c}v=A+B \cdot T_{a r, m}+C \cdot T_{a r, m}^{2} \\
(v: \text { é a viscosidade cinemática do ar) }\end{array}$ & $\left(\mathrm{cm}^{2} / \mathrm{s}\right)$ & $\begin{array}{l}\text { A: } 0,00001331421190740 \\
\text { B: } 0,00000008796964294 \\
\text { C: } 0,00000000010386657\end{array}$ \\
\hline $\begin{array}{c}\operatorname{Pr}=A+B \cdot T_{a r, m}+C \cdot T_{a r, m}^{2}+D \cdot T_{a r, m}^{3} \\
\operatorname{Pr}: \text { é o número de Prandt, para o } \\
\text { escoamento de ar) }\end{array}$ & - & $\begin{array}{l}\text { A: } 0,736333531133 \\
\text { B: }-0,000266754013 \\
\text { C: }-0,000000297518 \\
\text { D: } 0,000000004448\end{array}$ \\
\hline $\begin{array}{c}K=A+B \cdot T_{a r, m}+C \cdot T_{a r, m}^{2} \\
(K: \text { é a condutividade térmica do ar) }\end{array}$ & $(\mathrm{W} / \mathrm{m} \mathrm{K})$ & $\begin{array}{l}\text { A: } 0,0236339066297 \\
\text { B: } 0,0000756317379 \\
\text { C: }-0,0000000246340\end{array}$ \\
\hline
\end{tabular}

Equacionadas as metodologias de cálculo desses parâmetros, recai-se num sistema de quatro equações com quatro incógnitas (efetividade $\boldsymbol{\varepsilon}$; vazão mássica do ar $\dot{\mathrm{m}}_{\mathrm{a}}$; temperatura de saída do ar $\mathbf{T}_{\mathrm{ar} \text {,out }}$ e o coeficiente global de transferência de calor $\mathbf{U}$ ), cuja variável de interesse (efetividade, $\boldsymbol{\varepsilon}$ ), entretanto, não é passível de ser explicitada e cuja temperatura de saída do ar $\left(\mathbf{T}_{\mathbf{a r}, \mathbf{o u t}}\right)$ oferece dificuldades experimentais de medição.

Visando ganhos de efetividade, o trocador de calor objeto do estudo é do tipo aletado, exposto ao ar de arrefecimento que circula em escoamento cruzado externo, conforme ilustrado na Figura 18, que caracteriza as dimensões das aletas e o espaçamento entre elas no corpo externo do tubo do trocador de calor.

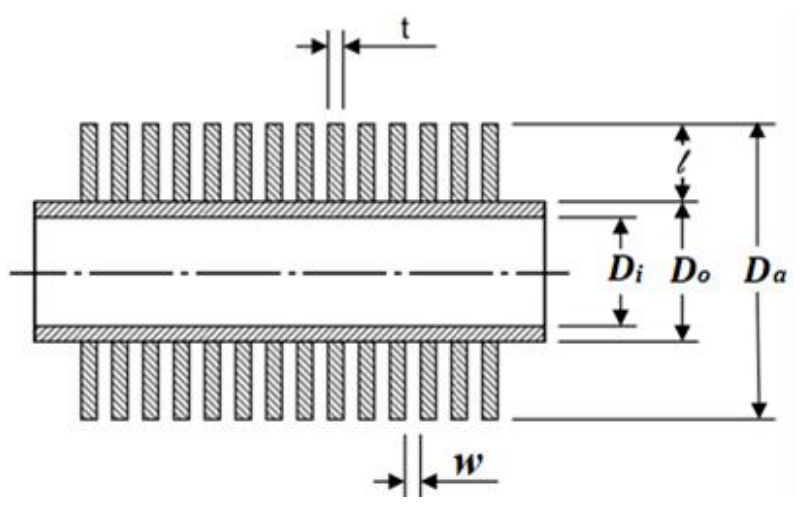


Figura 18. Esquema dos tubos aletados do trocador de calor

A Tabela 14 apresenta as dimensões espaçamento das aletas do tubo.

Tabela 14. Dimensões das aletas dos tubos do trocador de calor

\begin{tabular}{c|c|c|c|c|c}
\hline $\boldsymbol{D}_{\boldsymbol{i}}$ & $\boldsymbol{D}_{\boldsymbol{o}}$ & $\boldsymbol{D}_{\boldsymbol{a}}$ & $\boldsymbol{\ell}$ & $\boldsymbol{t}$ & $\boldsymbol{w}$ \\
\hline$(\mathrm{mm})$ & $(\mathrm{mm})$ & $(\mathrm{mm})$ & $(\mathrm{mm})$ & $(\mathrm{mm})$ & $(\mathrm{mm})$ \\
\hline 22,30 & 27,90 & 48,02 & 10,06 & 0,18 & 3,48 \\
\hline \hline
\end{tabular}

A área das aletas foi considerada na hora do cálculo acrescentado a área total de troca de calor, portanto, a área total de troca de calor (lado da água) resulta ser a suma da área superficial do banco de tubos e a área das aletas de ditos tubos. Assim:

Tabela 15. Resumo do cálculo da área de troca de calor

$\begin{array}{ccc}\boldsymbol{A}_{\text {tubos }}\left[\mathrm{m}^{2}\right] & \boldsymbol{A}_{\text {aletas }}\left[\mathbf{m}^{2}\right] & \boldsymbol{A}_{\text {troca de calor }}\left[\mathbf{m}^{2}\right] \\ 11,70 & 40,63 & 52,33\end{array}$

A Tabela 15 resume as áreas superficiais tanto dos tubos como das aletas para a determinação da área total de troca de calor, área aumentada essa que contribui para a melhoria do Coeficiente Gobal de Transferência de calor entre os fluidos de trabalho do trocador de calor.

\subsection{2}

\section{Método numérico para solução do sistema de equações}

A solução do sistema de equações não lineares descrito na seção anterior que envolve um termo não linear (função logarítmica) — foi obtida pelo método (equations' solver) de Newton-Raphson, cujo cálculo da raiz (valor que zera a equação) é forçado pela hipótese fundamental descrita pela Equação (65).

$$
F_{(\vec{x})}=\overrightarrow{0}
$$

nesta expressão,

$$
F=\left(f_{1}, f_{2}, f_{3}, \ldots, f_{n}\right) ; \quad \vec{x}=\left(x_{1}, x_{2}, x_{3}, \ldots, x_{n}\right)
$$

condição que assegura que F pode ser uma função composta por múltiplas outras funções, que representam o número total de soluções de F, ou seja, F terá tantas soluções $(\vec{x})$ quantas forem as funções (f) que constituem o sistema de equações que se deseja resolver. 
No contexto desta formulação, as soluções das $x_{n}$ variáveis são obtidas a partir da Equação (66):

$$
\vec{x}^{(k+1)}=\vec{x}^{(k)}-\left(J^{(k)}\right)^{-1} F_{(\vec{x})}
$$

nesta expressão, ${ }^{(\mathrm{k})}$ é a matriz Jacobiana de funções.

Matricialmente, com o propósito de apresentar um arranjo ordenado, as equações (65) a (66) podem ser expressas na forma:

$$
\begin{gathered}
\vec{x}^{(k+1)}=\left[\begin{array}{c}
x_{1}^{(k+1)} \\
\vdots \\
x_{n}^{(k+1)}
\end{array}\right] ; \quad \vec{x}^{(k)}=\left[\begin{array}{c}
x_{1}^{(k)} \\
\vdots \\
x_{n}^{(k)}
\end{array}\right] \\
F^{(k)}=\left[\begin{array}{c}
f_{1}^{(k)} \\
\vdots \\
f_{n}^{(k)}
\end{array}\right] \\
J^{(k)}=\left[\begin{array}{ccc}
\frac{\partial f_{1}^{(k)}}{\partial x_{1}} & \ldots & \frac{\partial f_{1}^{(k)}}{\partial x_{n}} \\
\vdots & \ddots & \vdots \\
\frac{\partial f_{n}^{(k)}}{\partial x_{1}} & \ldots & \frac{\partial f_{n}^{(k)}}{\partial x_{n}}
\end{array}\right], k=0,1,2, \ldots
\end{gathered}
$$

Embora prático do ponto de vista de cálculo, como ferramenta, este método apresenta certas desvantagens, notadamente: (i) baixa convergência para os casos em que a função não presenta mudança de sinal, dificultando o procedimento de se determinar a raiz e (ii) dificuldade de se atingir a convergência, o que ocorre quando o valor inicial escolhido se encontra muito distante do valor da raiz.

Considerando as essas desvantagens, que são inerentes deste método e que prejudicam a sua implementação, o algoritmo elaborado para a solução desse sistema de equações estrutura-se em quatro fases complementares de cálculo: (i) leitura dos dados de medições coletados, devidamente ajustado para incorporar a calibração do instrumento de medição utilizado; (ii) uso do código computacional, que descreve a geometria do escoamento e as constantes envolvidas; (iii) aplicação da lógica de cálculo pelo método de Newton-Raphson, utilizado na resolução do sistema de equações formulado. Seguindo essa sistemática de cálculo visando alcançar a solução do sistema de equações, foi considerada uma tolerância de 
$1 \times 10^{-4}$ para cada uma das raízes, ou seja, para cada uma das variáveis associadas ao sistema de equações $\left(\varepsilon, \dot{\mathrm{m}}_{\mathrm{ar}}, \mathrm{T}_{\mathrm{ar}, \mathrm{out}}, \mathrm{U}\right)$, mais precisamente

- para $\varepsilon: 1 \times 10^{-4}$ adimensional;

- para $\dot{\mathrm{m}}_{\mathrm{ar}}: 1 \times 10^{-4} \mathrm{~kg} / \mathrm{s}$;

- para $\mathrm{T}_{\mathrm{ar}, \text { out }}: 1 \times 10^{-4}{ }^{\circ} \mathrm{C}$;

- $\quad$ para $\mathrm{U}: 1 \times 10^{-4} \mathrm{~kW} / \mathrm{m}^{2} \mathrm{~K}$

$\mathrm{Na}$ sequência, a fase (iv) de cálculo refere-se ao armazenamento dos resultados realizados pelo código numérico proposto (equations' solver), que resolve o sistema de equações e exporta os resultados para uma planilha Excel, assim permitindo a visualização dos dados e o seu processamento para orientar a análise de resultados.

A título de ilustração, a Tabela 16 resume apenas um extrato dos resultados da aplicação desse código computacional (dados coletados entre os dias 23/07 e 24/08 de 2019) utilizado para resolver o sistema de equações (18), (54), (55) e (56), enquanto a totalidade dos dados processados (armazenados a cada hora, ou seja, 24 dados por dia, resultantes de médias realizadas a cada $15 \mathrm{~min}$ ) encontram-se apresentados na íntegra no Apêndice B: Cálculo da efetividade pelas equações.

Tabela 16. Extrato dos dados compilados, 23/07 a 24/08 de 2019

\begin{tabular}{c|c|c|c|c|c|c|c|c|c}
\hline Data & $\boldsymbol{T}_{\boldsymbol{a r}, \boldsymbol{o u t}}$ & $\boldsymbol{m}_{\boldsymbol{a r}}$ & $\boldsymbol{U}$ & $\boldsymbol{\varepsilon}$ & Data & $\boldsymbol{T}_{\boldsymbol{a r}, \boldsymbol{o u t}}$ & $\boldsymbol{m}_{\boldsymbol{a r}}$ & $\boldsymbol{U}$ & $\boldsymbol{\varepsilon}$ \\
\hline $\boldsymbol{d}$ d: $\boldsymbol{m m}: \boldsymbol{a a}$ & \multirow{2}{*}{$\boldsymbol{C})$} & $(\boldsymbol{k g} / \boldsymbol{s})$ & $\left(\boldsymbol{k W} / \boldsymbol{m}^{2} \boldsymbol{K}\right)$ & - & $\boldsymbol{d} \boldsymbol{d}: \boldsymbol{m} \boldsymbol{m}: \boldsymbol{a a}$ & $\left({ }^{\circ} \boldsymbol{C}\right)$ & $(\boldsymbol{k g} / \boldsymbol{s})$ & $\left(\boldsymbol{k W} / \boldsymbol{m}^{2} \boldsymbol{K}\right)$ & - \\
\hline $23 / 07 / 2019$ & 30,25 & 7,53 & 0,696 & 0,62 & $04 / 08 / 2019$ & 31,54 & 7,16 & 0,643 & 0,61 \\
$24 / 07 / 2019$ & 30,29 & 7,39 & 0,686 & 0,62 & $05 / 08 / 2019$ & 30,81 & 7,17 & 0,644 & 0,61 \\
$25 / 07 / 2019$ & 30,61 & 7,38 & 0,685 & 0,62 & $06 / 08 / 2019$ & 30,53 & 7,12 & 0,635 & 0,61 \\
$26 / 07 / 2019$ & 30,92 & 7,36 & 0,681 & 0,62 & $07 / 08 / 2019$ & 30,52 & 7,09 & 0,630 & 0,61 \\
$27 / 07 / 2019$ & 31,02 & 7,34 & 0,677 & 0,62 & $08 / 08 / 2019$ & 31,06 & 6,93 & 0,599 & 0,60 \\
$28 / 07 / 2019$ & 31,13 & 7,30 & 0,669 & 0,62 & $09 / 08 / 2019$ & 31,75 & 7,01 & 0,613 & 0,60 \\
$29 / 07 / 2019$ & 31,04 & 7,28 & 0,665 & 0,62 & $10 / 08 / 2019$ & 32,63 & 6,92 & 0,597 & 0,60 \\
$30 / 07 / 2019$ & 31,00 & 7,28 & 0,663 & 0,61 & $11 / 08 / 2019$ & 32,91 & 6,88 & 0,592 & 0,60 \\
$31 / 07 / 2019$ & 31,12 & 7,26 & 0,660 & 0,61 & $12 / 08 / 2019$ & 33,47 & 6,83 & 0,584 & 0,59 \\
$01 / 08 / 2019$ & 31,43 & 7,21 & 0,651 & 0,61 & $22 / 08 / 2019$ & 32,87 & 6,38 & 0,517 & 0,58 \\
$02 / 08 / 2019$ & 31,73 & 7,15 & 0,639 & 0,61 & $23 / 08 / 2019$ & 32,44 & 6,48 & 0,532 & 0,58 \\
$03 / 08 / 2019$ & 31,72 & 7,15 & 0,641 & 0,61 & $24 / 08 / 2019$ & 32,40 & 6,44 & 0,524 & 0,58 \\
\hline
\end{tabular}

Conforme mostrado, o trocador de calor perde efetividade ao longo do seu funcionamento, em função da incrustação que se acumula durante o seu funcionamento. 


\section{2}

\section{Considerações sobre o código proposto}

Embora adaptado aos interesses do estudo realizado, o código proposto é baseado na teoria clássica da transferência de calor e na formulação de NewtonRaphson para a solução de um sistema de equações não lineares, quando a variável de interesse não aparece de forma explícita.

O código foi desenvolvido fazendo-se uso da ferramenta de cálculo Matlab®, na sua versão R2020a, com uma tolerância de solução para cada uma das variáveis envolvidas de $1 \times 10^{-4}$, conforme discutido na secção 4.1.2.

Todos os dados processados foram ajustados previamente no software Excel, fazendo-se uso dos polinômios de ajuste pertinentes, obtidos no curso do processo de calibração dos instrumentos de medição utilizados. Após o processamento dos dados e obtenção da solução do sistema de equações, estes dados são exportados para uma planilha Excel, para serem convenientemente visualizados e analisados.

Conforme demostrado, a despeito das diferenças encontradas, o método de solução fundamentado na formulação de Newton-Raphson mostrou-se adequado para o cálculo da efetividade, já que este procedimento não requer o conhecimento (resultado da medição) da temperatura de saída do ar. Conforme já discutido, a medição da temperatura de saída do ar é problemática devido à natureza do seu escoamento na face de saída do trocador de calor. As diferenças entre os valores da efetividade obtida pelo balanço térmico e pelo método de cálculo proposto podem ser atribuídas aos seguintes fatores: (i) dificuldade experimental associada à medição da temperatura de saída do ar; (ii) dificuldades associadas à determinação das propriedades físico-químicas dos fluidos de trabalho do trocador e de seus materiais construtivos; (iii) erros inerentes às correlações envolvidas no cálculo da efetividade.

\section{3}

\section{Formulação do método NTU para o tipo de trocador em estudo}

O método do NTU mostra-se muito útil quando o trocador de calor não precisa ser projetado sob medida (o trocador já existe e são conhecidos tanto o tipo de arranjo como suas dimensões geométricas) e quando nem todas as temperaturas dos fluidos de trabalho são conhecidas (usualmente o método é útil quando apenas a temperatura de entrada é conhecida) (Kays \& London, 1964). 
A metodologia que envolve o cálculo da efetividade a partir do uso do conceito do NTU está baseada na pesquisa desenvolvida por Silaipillayarputhur et al. (2017) para um trocador de calor de escoamento cruzado de múltiplos passes. Esta alternativa fundamenta-se na consideração de o trocador possuir múltiplos passes e poder ser estudado como se fosse formado por um conjunto de trocadores de um único passe. De forma genuína, um trocador de $t$ passes é estudado como um arranjo de $t$ trocadores em série de um único passe.

Nessa formulação, a capacidade térmica de cada passe é expressa pela Equação (70), a seguir:

$$
c^{\prime \prime}=c=\frac{\left(\dot{m} c_{p}\right)_{a r}}{\left(\dot{m} c_{p}\right)_{a g}}
$$

enquanto o parâmetro NTU proposto por Kays \& London (1964) para cada passe do trocador pode ser expresso pela Equação (71):

$$
N T U^{\prime \prime}=\frac{U A / t}{C_{\min }}=\frac{U A}{t\left(\dot{m} c_{p}\right)_{a r}}
$$

Nesta expressão, $\boldsymbol{t}$ denota o número de passes do fluido frio (água) que escoa pelo interior do trocador de calor.

Ao simular o trocador de $\boldsymbol{t}$ passes por um arranjo de $\boldsymbol{t}$ trocadores em série de um único passe, a sua efetividade pode ser calculada pela expressão definida na Tabela 5, proposta por Kays \& London (1964), que se aplica para o caso de um trocador de escoamento cruzado com o valor $\mathrm{C}_{\text {mim }}$ de um fluido misturado (i.e.: o fluido externo, que é o fluido quente ar, escoa sem placas separadoras) e com valor de $\mathrm{C}_{\max }$ associado ao fluido frio, que é o fluido não misturado água, conforme definido pela Equação (72):

$$
\varepsilon^{\prime \prime}=1-\exp \left[-\frac{1}{c^{\prime \prime}}\left\{1-\exp \left(-c^{\prime \prime} N T U^{\prime \prime}\right)\right\}\right]
$$

Em outras palavras, modelar um trocador de $t$ passes pelo arranjo de $t$ trocadores em série de um único passe possui grande interesse já que permite fazer uso da formulação clássica, não diretamente aplicável a trocadores de múltiplos passes. De fato, uma solução genuína. Fundamenta-se em uma lógica de funcionamento de caráter matricial, que possui respaldo no balanço de energia, o que permite calcular a efetividades de cada passe do trocador. Segundo esse enfoque, a temperatura de saída do ar em um passe é contabilizada no cálculo como 
a temperatura de entrada no passe subsequente. Assim, para um trocador de $\boldsymbol{t}$ passes, é possível montar $2 t$ equações simultâneas, que precisam ser resolvidas. Associado a cada passe, têm-se duas incógnitas: a temperatura de saída do fluido externo (fluido quente-ar) e a temperatura de saída do fluido de resfriamento (fluido frio, água), que escoa ao interior da tubulação. Essa abordagem matricial aplicada a um trocador de calor que opera com fluxo cruzado, de múltiplos passes, pode ser descrita pelas seguintes equações:

Para $\mathrm{j}=1$

$$
c^{\prime \prime} T_{a r j, j+1}+T_{a g j, j+1}=c^{\prime \prime} T_{a r, i n}+T_{a g, i n}
$$

Para $\mathrm{j}=2 ; t-1$

$$
c^{\prime \prime} T_{a r j-1, j}-c^{\prime \prime} T_{a r j, j+1}+T_{a g j-1, j}-T_{a g j, j+1}=0
$$

Para $\mathrm{j}=t$

$$
c^{\prime \prime} T_{a r j-1, j}-c^{\prime \prime} T_{a r, o u t}+T_{a g j-1, j}-T_{a g, o u t}=0
$$

Para $\mathrm{j}=t+1$

$$
T_{\text {ar12 }}=\left(1-\varepsilon_{1}^{\prime \prime}\right) T_{a r, i n}+\varepsilon_{1}^{\prime \prime} T_{a g, i n}
$$

Para $\mathrm{j}=t+2 ; k-1$

$$
\left(1-\varepsilon_{j-t}^{\prime \prime}\right) T_{a r j-(t+1), j-t}-T_{a r j-t, j-t+1}+\varepsilon_{j-t}^{\prime \prime} T_{a g j-(t+1), j-t}=0
$$

Para $\mathrm{j}=k$

$$
\left(1-\varepsilon_{j-t}^{\prime \prime}\right) T_{a r j-(t+1), j-t}-T_{a r, o u t}+\varepsilon_{j-t}^{\prime \prime} T_{a g j-(t+1), j-t}=0
$$

Nessa formulação, $\boldsymbol{t}$ é o número de passes do trocador de calor, $\boldsymbol{k}$ é um número igual ao dobro desse número de passos e $\boldsymbol{j}$ um parâmetro de controle, cujo valor inteiro varia entre 1 e $\boldsymbol{k}$.

Após a solução das equações anteriores, a efetividade global do trocador de calor foi recalculada pela Equação (18), fazendo-se uso apenas das temperaturas de entrada do ar e da água, enquanto a temperatura de saída do ar resultará da solução da equação, eliminando-se, assim, a dificuldade experimental associada à medição da temperatura de saída do ar, cuja medição não oferece confiabilidade metrológica. 
No Apêndice C encontram-se os resultados dessa análise para as três situações estudadas: alternativas 1 e 2 propostas e pelo método clássico, que faz uso do resultado da medição da temperatura de saída do ar $\left(\mathrm{T}_{\mathrm{ar}, \text { out }}\right)$, opções essas que visam o cálculo da efetividade térmica do trocador de calor.

A Figura 19 mostra, na cor vermelha, os resultados do cálculo da efetividade do trocador fazendo-se uso do resultado (não confiável) da temperatura de saída do ar e, nas cores azul e verde, respectivamente, os resultados do cálculo da efetividade pelas alternativas 1 (via solução do sistema não linear das equações que governam os mecanismos de transferência de calor entre os fluidos de trabalho) pela alternativa 2 (adaptação do método $\varepsilon-\mathrm{NTU}$, i.e.: adaptação da metodologia proposta por Silaipillayarputhur et al., 2017).

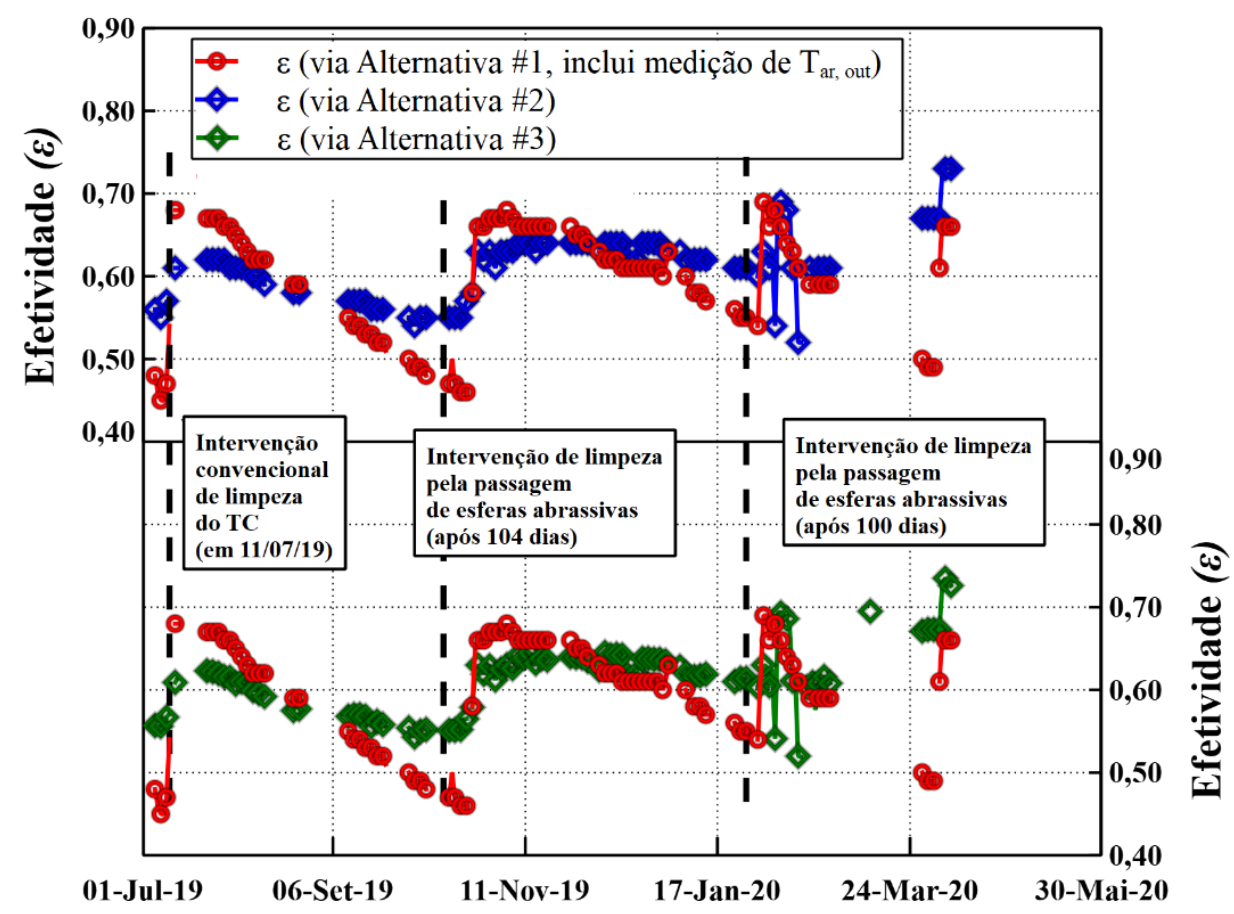

Figura 19. Comparação entre as alternativas de cálculo da efetividade

Conforme pode ser observado, os resultados obtidos pelas três alternativas 1 , 2 e 3, estas duas últimas propostas respondem corretamente à física do problema, quer durante o tempo de uso do trocador, quando se observa um decaimento da efetividade em função do acúmulo de incrustação, quer como resultado do procedimento online de limpeza do trocador, quando se observa um expressivo aumento no valor da efetividade do trocador. As discrepâncias entre a alternativa 2 (dados na cor azul) e alternativa 3 (dados na cor verde) quando comparados com os 
resultados obtidos via medição da temperatura de saída do ar (Alternativa 1), método que se deseja descartar, mostrados na cor vermelha, não devem ser observados como falta de concordância entre os métodos empregados, mas sim como o desvio gerado no cálculo em função de se utilizar o valor não confiável da temperatura medida do ar, que resultam de erros associados ao seu valor medido, suscetível às instabilidades já discutidas do escoamento externo do fluido de ar que circula externamente aos tubos do trocador.

Os dados da Tabela 17 (extrato do Apêndice C) fundamentam a comparação entre os resultados da efetividade pelos três métodos alternativos de cálculo.

Tabela 17. Comparação entre as alternativas 1,2 e 3

\begin{tabular}{|c|c|c|c|c|c|c|}
\hline \multirow{2}{*}{$\frac{\text { Data }}{(\mathrm{dd} / \mathrm{mm} / \mathbf{a a})}$} & \multicolumn{3}{|c|}{ Cálculo da efetividade $(\varepsilon)$ via } & \multicolumn{3}{|c|}{ Diferença percentual } \\
\hline & $\begin{array}{c}\text { Alternativa } \\
\quad \# 1\end{array}$ & $\begin{array}{l}\text { Alternativa } \\
\quad \# 2\end{array}$ & $\begin{array}{c}\text { Alternativa } \\
\quad \# 3\end{array}$ & $\begin{array}{c}\text { (Alternativa \#1) / } \\
\text { (Alternativa \#2) }\end{array}$ & $\begin{array}{c}\text { (Alternativa \#1) / } \\
\text { (Alternativa \#3) }\end{array}$ & $\begin{array}{l}\text { (Alternativa \#2)/ } \\
\text { (Alternativa \#3) }\end{array}$ \\
\hline $08 / 02 / 2020$ & 0,65 & 0,69 & 0,69 & $5,5 \%$ & $5,5 \%$ & $0,1 \%$ \\
\hline $09 / 02 / 2020$ & 0,64 & 0,68 & 0,69 & $6,3 \%$ & $6,4 \%$ & $0,1 \%$ \\
\hline $10 / 02 / 2020$ & 0,64 & 0,68 & 0,68 & $5,7 \%$ & $5,9 \%$ & $0,2 \%$ \\
\hline $11 / 02 / 2020$ & 0,63 & 0,61 & 0,61 & $2,6 \%$ & $2,7 \%$ & $0,1 \%$ \\
\hline $12 / 02 / 2020$ & 0,62 & 0,61 & 0,61 & $0,6 \%$ & $0,8 \%$ & $0,2 \%$ \\
\hline $13 / 02 / 2020$ & 0,61 & 0,52 & 0,52 & $16,9 \%$ & $16,9 \%$ & $0,0 \%$ \\
\hline $14 / 02 / 2020$ & 0,60 & 0,52 & 0,52 & $14,9 \%$ & $15,0 \%$ & $0,1 \%$ \\
\hline $16 / 02 / 2020$ & 0,59 & 0,60 & 0,60 & $2,5 \%$ & $2,5 \%$ & $0,0 \%$ \\
\hline $17 / 02 / 2020$ & 0,59 & 0,61 & 0,61 & $4,1 \%$ & $4,0 \%$ & $0,1 \%$ \\
\hline $18 / 02 / 2020$ & 0,59 & 0,61 & 0,61 & $3,3 \%$ & $3,3 \%$ & $0,0 \%$ \\
\hline $19 / 02 / 2020$ & 0,55 & 0,58 & 0,58 & $4,3 \%$ & $4,4 \%$ & $0,1 \%$ \\
\hline $20 / 02 / 2020$ & 0,59 & 0,61 & 0,61 & $2,7 \%$ & $2,9 \%$ & $0,2 \%$ \\
\hline $21 / 02 / 2020$ & 0,59 & 0,61 & 0,61 & $3,8 \%$ & $3,8 \%$ & $0,0 \%$ \\
\hline $22 / 02 / 2020$ & 0,59 & 0,61 & 0,62 & $4,3 \%$ & $4,7 \%$ & $0,3 \%$ \\
\hline $23 / 02 / 2020$ & 0,59 & 0,61 & 0,61 & $4,5 \%$ & $4,4 \%$ & $0,1 \%$ \\
\hline $24 / 02 / 2020$ & 0,59 & 0,61 & 0,61 & $3,5 \%$ & $3,4 \%$ & $0,1 \%$ \\
\hline 09/03/2020 & 0,63 & 0,70 & 0,69 & $9,0 \%$ & $8,8 \%$ & $0,2 \%$ \\
\hline $27 / 03 / 2020$ & 0,50 & 0,67 & 0,67 & $25,8 \%$ & $25,7 \%$ & $0,1 \%$ \\
\hline $28 / 03 / 2020$ & 0,49 & 0,67 & 0,67 & $26,8 \%$ & $26,9 \%$ & $0,2 \%$ \\
\hline $29 / 03 / 2020$ & 0,49 & 0,67 & 0,67 & $27,2 \%$ & $27,3 \%$ & $0,2 \%$ \\
\hline $30 / 03 / 2020$ & 0,49 & 0,67 & 0,67 & $27,6 \%$ & $27,6 \%$ & $0,0 \%$ \\
\hline $31 / 03 / 2020$ & 0,49 & 0,67 & 0,67 & $27,5 \%$ & $27,6 \%$ & $0,2 \%$ \\
\hline $02 / 04 / 2020$ & 0,61 & 0,67 & 0,67 & $9,6 \%$ & $9,6 \%$ & $0,1 \%$ \\
\hline 03/04/2020 & 0,67 & 0,73 & 0,73 & $8,9 \%$ & $8,9 \%$ & $0,1 \%$ \\
\hline $04 / 04 / 2020$ & 0,66 & 0,73 & 0,73 & $9,7 \%$ & $9,7 \%$ & $0,0 \%$ \\
\hline 05/04/2020 & 0,66 & 0,73 & 0,73 & $9,3 \%$ & $9,4 \%$ & $0,1 \%$ \\
\hline $06 / 04 / 2020$ & 0,66 & 0,73 & 0,73 & $8,6 \%$ & $8,6 \%$ & $0,0 \%$ \\
\hline
\end{tabular}

Conforme documentado, ambos os métodos alternativos propostos produzem valores calculados da efetividade com concordância da ordem de 1\%, valores esses, entretanto, que podem diferir em até $30 \%$ quando a efetividade é calculada com base na temperatura de saída do ar, medida na face externa do trocador, onde o escoamento é instável. 


\section{$\mathbf{5}$ Conclusões e recomendações}

Este capítulo resume as principais conclusões do trabalho e encaminha recomendações para desdobramentos futuros que possam contribuir para a consolidação de conhecimento sobre o tema da pesquisa.

\section{1}

\section{Conclusões}

No que concerne ao objetivo geral da dissertação -i.e.: desenvolver uma metodologia de cálculo e de monitoramento da efetividade de trocadores de calor do sistema de arrefecimento de hidrogeradores-, o trabalho validou duas alternativas independentes de cálculo da efetividade que não requerem conhecimento do resultado da medição da temperatura de saída do fluido de trabalho quente do trocador de calor, portanto eliminando a dificuldade experimental de se medir a temperatura do fluxo de saída do ar, que escoa externamente aos tubos do trocador em um complexo escoamento perturbado pelos sucessivos descolamentos da camada limite do escoamento em torno dos tubos do trocador. Já no que concernem aos objetivos específicos, o trabalho não apenas identificou as grandezas físicas críticas que impactam no cálculo da efetividade do trocador de calor, calculando as incertezas que são associadas às suas medições, como, também validou, com base em um estudo de caso que envolve dados reais de monitoramento de um trocador de calor de hidrogerador, as alternativas propostas de cálculo da efetividade do trocador. Completando os objetivos específicos, a dissertação de mestrado investigou métodos numéricos capazes de resolver o sistema não-linear de equações que regem os mecanismos de transferência de calor entre os fluidos de trabalho do trocador, propondo uma alternativa de cálculo fundamentada no método de Newton-Raphson. Dentre os resultados da pesquisa, as duas alternativas propostas de cálculo da efetividade do trocador produzem resultados da efetividade com concordância de cerca de $1 \%$ e com incerteza expandida de 0,012 (representa 2\% para um nível de operação com efetividade de 0,6). Já quando a efetividade é calculada pelo método convencional fundamentado na indesejável medição da temperatura de saída do ar, diferenças de até $30 \%$ podem ocorrer em relação às alternativas de cálculo propostas. Em relação às contribuições individuais da incerteza associada a cada temperatura que impacta 
no cálculo da efetividade térmica do trocador, a maior contribuição relativa é atribuída à temperatura de saída do ar (69\%), portanto, comprovando que o método convencional que faz uso da temperatura de saída do ar não se mostra adequado para as práticas convencionais de monitoramento da efetividade do trocador de calor estudado na usina hidrelétrica objeto do estudo de caso em questão. No âmbito de um estudo de caso realizado, que analisa dados processados ao longo de 335 dias de monitoramento da operação de um trocador de calor acoplado ao sistema de arrefecimento de um dos hidrogeradores em funcionamento na usina Fontes Nova, de propriedade da Light energia S/A, as alternativas de cálculo da efetividade do trocador de calor monitorado mostrou-se eficaz e adequada para os propósitos de monitoramento pretendido.

\section{2}

\section{Recomendações para desdobramentos futuros}

Embora a metodologia testada de monitoramento da operação do trocador de calor tenha sido fundamentada em 335 dias (11 meses) de operação do hidrogerador, as medições realizadas sofreram várias interrupções em virtude de paradas técnicas não programadas de manutenção da unidade geradora instrumentada. Com o propósito de gerar uma massa de dados mais robusta, recomenda-se realizar novas campanhas de medição e de monitoramento do desempenho térmico dos trocadores de calor do sistema de arrefecimento do hidrogerador, assim consolidando uma base de dados com dados de medição capaz de orientar e validar as simulações realizadas do valor da efetividade medida versus simulada.

Tendo em vista a atratividade da alternativa de se calcular a efetividade pelo método $\varepsilon-$ NTU (Número de unidades de transferência de calor do trocador), recomenda-se desenvolver uma expressão analítica que relacione NTU com a efetividade $\varepsilon$ para o trocador de calor de feixes paralelos de tubos com escoamento cruzado, porém levando-se em conta a não uniformidade do número de tubos por passes do trocador. Recomenda-se, também, aprofundar o estudo da composição das incrustações, com o objetivo de determinar $\boldsymbol{\lambda}$ (condutividade térmica da incrustação), assim contribuindo para a proposição de um modelo matemático confiável para determinação da resistência térmica devida às incrustações. 


\section{Referências bibliográficas}

ASSOCIAÇÃO BRASILEIRA DE NORMAS TÉCNICAS. NBR 12555:

Trocadores de calor - Terminologia. Rio de Janeiro: ABNT, 1991.

ASSOCIAÇÃO BRASILEIRA DE NORMAS TÉCNICAS. NBR 5462:

Confiabilidade e Mantenabilidade. Novembro, Rio de Janeiro: ABNT, 1994.

BAKER, J.S.; JUDD, S.J. Magnetic amelioration of scale formation. Water Research, v. 30, n. 2, p. 247-260. 1996.

BARBOSA, C. R. H, NUNES, J. R. C.; GERMANO, S. B.; FROTA, M. N.; VALENTE, G. Sistema Optoeletrônico na Faixa do Infravermelho para Contagem de Esferas em Meios Turvos. In: Anais do $9^{\circ}$ Congresso Brasileiro de Metrologia. 2017. Anais... Fortaleza: Gran Mareiro Hotel, 27 de novembro de 2017.

BELL, J.; JUDD, S. J. Measurement good practice guide no. 11. A beginner's guide to uncertainty of measurement. Teddington, Middlesex, United Kingdom: National Physical Laboratory, 1999.

BERGMAN, T. L.; LAVINE, A. S.; INCROPERA, F.P.; DEWITT, D.P.; Fundamentos de Transferência de Calor e de Massa, 7a edição, LTC - Livros Técnicos e Científicos Editora S. A., R. J., 2016.

BOTT, T. R. Fouling of heat exchangers and its mitigation with special reference to biofouling. In: 2nd European Thermal Science UTI National Heat Transfer Conference, 1996, Rome. Proceedings of the 2nd European Thermal Science UTI National Heat Transfer Conference. Rome: UIT, 1996, vol 1, pp 115-125.

BOTT, T. R., MELO, L.F. Fouling of heat exchangers. Experimental termal and fluid science, v.14, n.4, p.315, 1997.

BRAGA, S.L., FROTA, M.N., MILON, J.J., TICONA, E.M., NETO, J.R.C.A. Hydrodynamic and thermal evaluation of fouling mitigation in hydro generators heat exchangers. In: 8th International Conference on Heat Transfer, Fluid Mechanics and Thermodynamics, 2011, Point Aux Piments, Mauritius Island. (2011. Proceedings of the 8th International Conference on Heat Transfer, Fluid Mechanics and Thermodynamics). June 26th -July 1st, 2011.

CAMELO, F; RODRÍGUEZ, S. Una revisión histórica del concepto de calor: algunas implicaciones para su aprendizaje. Tecné Episteme y Didaxis: TED, n.23, 2008.

CASSIOLATO, C. Medição de Vazão. Disponível em: <http://www.smar.com/newsletter/marketing/index40.html>. Acesso em: 23 set. 2017.

CENGEL, Y. A.; GHAJAR, A. J. Tranferência de Calor e Massa. Amgh Editora, 2009.

CHO, S.M. Uncertainty Analysis of Heat Exchanger Thermal-Hydraulic Designs. Heat Transfer Engineering. v.8, n.2, 2007. 
CHO, Y. I.; CHOI, B. G. Experimental validation of electronic anti-fouling technology with a plate heat exchanger. In: International Heat Transfer Conference Digital Library. Begel House Inc., 1998.

CHO, Y. I.; CHOI, B. G; DRAZNER, B. J. Electronic anti-fouling technology to mitigate precipitation fouling in plate-and-frame heat exchangers. International journal of heat and mass transfer, v. 41, n. 17, p. 2565-2571, 1998.

FAN, C.F. A study of electronic descaling technology to control precipitation fouling. 1997. Ph.D. Thesis, Department of Mechanical Engineering. Drexel University.

FAN, C.F.; CHO, Y.I. A new electronic anti-fouling method to control fouling. In: National Heat Transfer conference. Baltimore: HTD-v. 350, v. 12, 1997, p. $183-$ 188. 1997.

FROTA M.N.; BARBOSA C.R. H.; Germano S.B.; Valente. G. Jr. Cabeça de série de um sistema inovador de limpeza de trocadores de calor de hidrogeradores. In: anais do $10^{\circ}$ Congresso de Inovação Tecnológica e Eficiência Energética no Setor Elétrico (CITENEL). 2019. Anais... Campinas: outubro de 2019.

FROTA, M.N.; HERNÁNDEZ-VÁSQUEZ, J.D.; CASTRO-PACHECO, E.R.; GERMANO, S.B. Enhancing the Effectiveness of Hydrogenerator Heat Exchangers Through the Control of Measurement Uncertainties. In: XIII Heat Exchanger Fouling and Cleaning Conference. n.11, p. 100-109, 2-7 June, Warsaw, Poland, 2019.

FROTA M. N.; TICONA, E. M.; VALENTE, G. P. On-line cleaning technique for mitigation of biofouling in heat exchangers: A case study of a hydroelectric power plant in Brazil. Experimental Thermal and Fluid Science, v. 53, p. 197-206, 2014. https://doi.org/10.1016/j.expthermflusci.2013.12.006.

FROTA, M.N.; BRAGA, S.L.; TICONA, E.M.; GUZMAN, J.J.M.; TICONA, J.M.; NETO, J.R.C.A. Avaliação hidrodinâmica e térmica de alternativas tecnológicas para mitigação de incrustações em trocadores de calor de hidrogeradores. In: VI Congresso de Inovação Tecnológica em Energia Elétrica CITENEL e o II Seminário de Eficiência Energética no Setor Elétrico - SEENEL. 2011. Fortaleza, 2011.

HANS, U.; ZETTLER, Proceedings of the XIII Heat Exchanger Fouling and Cleaning Conference. 2-7 June, Warsaw, Poland, 2019

ISHIKAWA, K. Guide to Quality Control, 2nd Edition. Asia Productivity Organization/Quality Resources, White Plains, New York, 1986.

ISO GUM 2008, Avaliação de dados de Medição - Guia para a expressão de incerteza de medição. $1^{\mathrm{a}}$ ed. Rio de Janeiro, 2012.

ISO. Norma ISO 12212. Petroleum, petrochemical, and natural gas industries - Hairpin-type heat exchangers. Switzerland: 2012.

JAMES, C.A.; TAYLOR, R.P.; HODGE, B.K. The Application of Uncertainty Analysis to Cross-Flow Heat Exchanger Performance Predictions. Heat Transfer Engineering. v. 16, n. 4, 2007. 
JARDINE, A. K. S.; BUZACOTT, J. A. Equipment reliability and maintenance. European Journal of Operational Research, 1985, v. 19, n. 3, p. 285-296, 1985.

KAKAC, S; LIU, H. Heat Exchangers Selection, Rating and Thermal Design, Department. of Mechanical Engineering. University of Miami, Coral Gables, Florida, 2002.

KAYS, W. M.; LONDON, A. L. Compact heat exchangers. McGraw-Hill, New York, 1964.

LEMMON, E. W.; HUBER, M. L.; MCLINDEN, M. O. NIST standard reference database 23: reference fluid thermodynamic and transport properties-REFPROP, Tech. pre., version 9.1. Standard Reference Data Program, National Institute of Standards and Technology, Gaithersburg, 2013.

LIRA, I. The GUM revision: the Bayesian view toward the expression of measurement uncertainty. European Journal of Physics, 2016, v. 37, n. 2, p. 025803.

LIRA, I.; GRIENTSCHNIG, D. Error-in-variables models in calibration. Metrologia, 2017, v. 54, n. 6, p. S133, 2017.

MALLOVE, E. Los misterios y los mitos del calor: Una breve historia de lo caliente y lo frío. Revista Attos, 2005.

MARTINS, R. O universo: teorias sobre sua origem e evolução. São Paulo: Moderna, 1994.

MIRANDA, K. F., VASCONCELOS, A. C. D., LUCA, M. M. M. D.; CABRAL, J. E. D. O. A capacidade inovativa e o desempenho econômico-financeiro de empresas inovadoras brasileiras. REAd. Revista Eletrônica de Administração (Porto Alegre), v. 21, n. 2, p. 269-299, 2015.

NETO, J.R.C.A.; GUZMAN, J.J.M.; TICONA, E.M.; TICONA, J.M.; FROTA, M.N. Avaliação técnica e econômica da bioincrustação de trocadores de calor em sistemas de hidrogenação. In: Anais do XX Seminário Nacional de Produção e Transmissão de Energia Elétrica (XX SNPTEE). 2009. Anais... Recife., 2009.

NUNES, J. R. C. Dispositivo optoeletrônico na faixa do infravermelho para detecção e medição de velocidade de esferas utilizadas como artefatos de limpeza de trocadores de calor. Rio de Janeiro, 2018, 89 p. Dissertação (Mestrado) - Programa de Pós-Graduação em Metrologia. Pontifícia Universidade Católica do Rio de Janeiro.

OKABE, S.; TSUBOI, T.; TAKAMI, J. Reliability evaluation with weibull distribution on AC withstand voltage test of substation equipment. IEEE Transactions on Dielectrics and Electrical Insulation, v. 15, n. 5, p. 1242-1251, 2008.

OLIVEIRA, V. H. Alternativa tecnológica para monitoramento e mitigação de incrustação em trocadores de calor pela circulação de esferas abrasivas. 2015. 90 p. Dissertação (Mestrado em Metrologia). Departamento de Pós-Graduação em Metrologia, Pontifícia Universidade Católica do Rio de Janeiro, Rio de Janeiro.

OLIVEIRA, V. H.; FROTA, M. N.; VALENTE, G. Estudo do comportamento de esferas abrasivas usadas como artefatos de limpeza de trocadores de calor. 
In: Anais do $9^{\circ}$ Congresso Brasileiro de Metrologia. 2017. Anais... Fortaleza: Gran Mareiro Hotel, 27 de novembro de 2017.

PAN, C. C.; CHU, L. Reliability assessment for one-shot product with Weibull lifetime components. International Journal of Quality \& Reliability Management, 2010.

Relatório Técnico. FROTA, M. N, VALENTE, G. J. Relatório final do Projeto de P\&D Light-Aneel Ref.: 5161-010/2016 - Cabeça de Série de um sistema inovador de limpeza de trocadores de calor de hidrogeradores. Rio de Janeiro: PUC-Rio, 2018. 144p. Relatório Técnico.

Relatório Técnico. FROTA, M. N. Relatório final P\&D Light-Aneel Ref.: 07/2011 -Proposição de solução inovadora para o sistema de resfriamento dos hidrogeradores da Usina Fontes Nova. Rio de Janeiro: PUC-Rio, 2014. 84p. Relatório Técnico.

Relatório Técnico. FROTA M.N. (COORD). Relatório Final do Projeto Light/Aneel de P\&D, Tecnologia de Tratamento de Água de Refrigeração da Usina Fontes Nova. Julho, 2013.

RIOS, J. L. R.; FROTA, M. N.; GERMANO, S. B. Sistema inteligente para ablução de trocadores de calor. In: Anais do $9^{\circ}$ Congresso Brasileiro de Metrologia. 2017. Anais... Fortaleza: Gran Mareiro Hotel, 27 de novembro de 2017.

RIOS, J. L. R. Dispositivo servo-hidráulico para introdução e recuperação de partículas em escoamentos internos de interesse industrial. 2017. p155. Trabalho de Conclusão de Curso (Graduação em Engenharia Mecânica). Departamento de Graduação em Engenharia Mecânica, Pontifícia Universidade Católica do Rio de Janeiro, Rio de Janeiro.

ROMO, R.; PITTS, M.M.; HANDAGAMA, N.B. Biofouling control in heat exchangers using high voltage capacitance-based technology. In: Heat Exchanger Fouling and Cleaning VII, ECI Symposium Series. 2007.

SADIK, K.; HONGTAN, L. Heat exchangers: selection, rating, and thermal design. Mechanical engineering department, University of Miami, Coral Gables, Florida, 2002.

SILAIPILLAYARPUTHUR, K.; AL-MUGHANAM, T.; AL-NINIYA, A. I. Sensible Performance Analysis of Multi-Pass Cross Flow Heat Exchangers. In: MATEC Web of conferences, v. 108, p. 11002, 2017.

SILVA, A.P.; DE MELLO FORATO, T.C.; GOMES, J.L. Concepções sobre a natureza do calor em diferentes contextos históricos. Caderno Brasileiro de Ensino de Física, v.30, n. 3, p. 492-537, 2013.

TAKAHASHI, S.; INAGAKI, S.; NAKASHIMA. Electrical anti-biofouling system for power plants. Toshiba Rev. v. 57, p. 64-67. 2002.

TATON; R. História general de las ciências. Editorial Destino, v.3,1972.

TUBULAR EXCHANGER MANUFACTURERS ASSOCIATION, et al. Standards of TEMA. TEM Assoc. Incorporated, 1941.

VAN WYLEN, G. J. Fundamentos de termodinámica. Limusa, 2002. 
VEMEIREN, T. Magnetic treatment of liquids for scale and corrosion prevention. Corros. Technol, v. 5, p. 215-219, 1958.

VERGARA, S.C. Metodologia do trabalho científico. $22^{a}$ ed. São Paulo: Cortez. 2002.

VIM, I. S. O. International vocabulary of basic and general terms in metrology (VIM). International Organization, 2004, v. 2004, p. 09-14.

WELTY, J. R.; WICKS, R. E. Fundamentos de transferencia de momento, calor y masa. 1982.

WU, D., LU, G., JIANG, H.; LI, Y. Improved estimation of Weibull parameters with the linear regression method. Journal of the American Ceramic Society, v. 87, n. 9, p. 1799-1802, 2004. 


\section{Apêndice A: Resultados de medições de monitoramento da efetividade}

(Monitoramento de Trocador de Calor TC\#1 do grupo hidrogerador C da Usina Fontes Nova).

Tabela 18. Medição de monitoramento do TC (jul a ago/2019)

\begin{tabular}{|c|c|c|c|c|c|c|c|c|c|c|c|c|}
\hline \multirow[b]{2}{*}{ Data } & \multicolumn{6}{|c|}{ Fluido Água } & \multicolumn{4}{|c|}{ Fluido: Ar } & \multirow[b]{2}{*}{$\varepsilon$} & \multirow[b]{2}{*}{$F F$} \\
\hline & $P_{\text {IN }}$ & $T_{\text {IN }}$ & Pout & ToUT & $\mathbf{Q}$ & $\dot{\mathbf{m}}$ & $\mathbf{T}_{\mathrm{IN}}$ & ToUT $_{\text {OU }}$ & $\mathbf{Q}$ & $\dot{\mathbf{m}}$ & & \\
\hline (dd/mm/aa) & (bar) & $\left({ }^{\circ} \mathrm{C}\right)$ & (bar) & $\left({ }^{\circ} \mathrm{C}\right)$ & $\left(\mathrm{m}^{3} / \mathrm{h}\right)$ & $(\mathrm{kg} / \mathrm{s})$ & $\left({ }^{\circ} \mathrm{C}\right)$ & $\left({ }^{\circ} \mathrm{C}\right)$ & $\left(m^{3} / h\right)$ & $(\mathrm{kg} / \mathrm{s})$ & - & - \\
\hline 05/07/2019 & 2,47 & 23,23 & 2,22 & 27,66 & 15,10 & 4,19 & 47,87 & 36,11 & 21043,76 & 6,55 & 0,48 & 0,61 \\
\hline 06/07/2019 & 2,50 & 22,55 & 2,26 & 27,13 & 14,23 & 3,95 & 47,07 & 35,87 & 21491,97 & 6,70 & 0,46 & 0,64 \\
\hline 07/07/2019 & 2,50 & 22,11 & 2,26 & 26,70 & 14,32 & 3,97 & 46,91 & 35,67 & 21575,61 & 6,73 & 0,45 & 0,65 \\
\hline 08/07/2019 & 2,51 & 21,69 & 2,27 & 26,30 & 14,26 & 3,96 & 46,47 & 35,38 & 21850,68 & 6,82 & 0,45 & 0,66 \\
\hline 09/07/2019 & 2,44 & 21,30 & 2,02 & 25,31 & 18,32 & 5,08 & 46,04 & 34,29 & 22163,79 & 6,94 & 0,47 & 0,61 \\
\hline $10 / 07 / 2019$ & 2,35 & 21,04 & 1,74 & 24,51 & 22,89 & 6,35 & 45,64 & 32,46 & 22138,05 & 6,95 & 0,54 & 0,51 \\
\hline $12 / 07 / 2019$ & 2,36 & 21,12 & 1,97 & 25,20 & 21,47 & 5,96 & 44,89 & 28,81 & 19847,35 & 6,28 & 0,68 & 0,26 \\
\hline 13/07/2019 & 2,38 & 21,21 & 1,99 & 25,30 & 22,26 & 6,18 & 45,13 & 28,94 & 20468,78 & 6,47 & 0,68 & 0,26 \\
\hline 23/07/2019 & 2,51 & 20,73 & 2,07 & 24,80 & 25,09 & 6,96 & 45,87 & 28,92 & 21462,38 & 6,78 & 0,67 & 0,27 \\
\hline 24/07/2019 & 2,37 & 20,83 & 1,98 & 25,08 & 23,35 & 6,48 & 45,78 & 28,95 & 21526,61 & 6,80 & 0,67 & 0,27 \\
\hline 25/07/2019 & 2,37 & 21,05 & 1,97 & 25,34 & 23,36 & 6,48 & 46,24 & 29,25 & 21525,10 & 6,79 & 0,67 & 0,27 \\
\hline 26/07/2019 & 2,38 & 21,35 & 1,98 & 25,62 & 23,37 & 6,49 & 46,52 & 29,58 & 21508,78 & 6,78 & 0,67 & 0,27 \\
\hline 27/07/2019 & 2,38 & 21,54 & 1,98 & 25,75 & 23,31 & 6,47 & 46,41 & 29,72 & 21479,25 & 6,77 & 0,67 & 0,27 \\
\hline 28/07/2019 & 2,38 & 21,56 & 1,98 & 25,75 & 23,32 & 6,47 & 46,53 & 29,84 & 21391,10 & 6,74 & 0,67 & 0,28 \\
\hline 29/07/2019 & 2,37 & 21,55 & 1,96 & 25,69 & 23,22 & 6,44 & 46,25 & 29,86 & 21433,80 & 6,75 & 0,66 & 0,29 \\
\hline $30 / 07 / 2019$ & 2,40 & 21,52 & 1,98 & 25,62 & 23,30 & 6,46 & 46,14 & 29,89 & 21501,76 & 6,78 & 0,66 & 0,29 \\
\hline 31/07/2019 & 2,39 & 21,61 & 1,96 & 25,72 & 23,23 & 6,45 & 46,28 & 30,10 & 21569,78 & 6,79 & 0,66 & 0,30 \\
\hline 01/08/2019 & 2,39 & 21,82 & 1,96 & 25,92 & 23,11 & 6,41 & 46,58 & 30,39 & 21443,98 & 6,75 & 0,65 & 0,30 \\
\hline 02/08/2019 & 2,39 & 21,98 & 1,95 & 26,06 & 23,01 & 6,38 & 46,89 & 30,67 & 21236,74 & 6,68 & 0,65 & 0,31 \\
\hline 03/08/2019 & 2,39 & 22,04 & 1,96 & 26,12 & 22,98 & 6,38 & 46,82 & 30,80 & 21431,27 & 6,74 & 0,65 & 0,32 \\
\hline 04/08/2019 & 2,38 & 21,73 & 1,94 & 25,87 & 23,02 & 6,39 & 46,87 & 30,74 & 21648,87 & 6,81 & 0,64 & 0,32 \\
\hline 05/08/2019 & 2,38 & 21,10 & 1,94 & 25,19 & 23,12 & 6,42 & 46,01 & 30,21 & 21882,14 & 6,89 & 0,63 & 0,34 \\
\hline 06/08/2019 & 2,43 & 20,71 & 1,98 & 24,77 & 23,20 & 6,44 & 45,77 & 29,92 & 21701,89 & 6,84 & 0,63 & 0,34 \\
\hline 07/08/2019 & 2,38 & 20,63 & 1,94 & 24,72 & 23,00 & 6,38 & 45,80 & 30,01 & 21736,01 & 6,85 & 0,63 & 0,35 \\
\hline 08/08/2019 & 2,36 & 20,91 & 1,92 & 24,86 & 23,02 & 6,39 & 46,16 & 30,42 & 21044,43 & 6,63 & 0,62 & 0,36 \\
\hline 09/08/2019 & 2,38 & 21,46 & 1,91 & 25,58 & 22,94 & 6,36 & 47,30 & 31,15 & 21495,82 & 6,75 & 0,62 & 0,35 \\
\hline $10 / 08 / 2019$ & 2,38 & 22,12 & 1,90 & 26,25 & 22,60 & 6,27 & 48,19 & 31,97 & 21194,50 & 6,64 & 0,62 & 0,36 \\
\hline $11 / 08 / 2019$ & 2,37 & 22,56 & 1,89 & 26,65 & 22,23 & 6,17 & 48,17 & 32,34 & 21180,41 & 6,63 & 0,62 & 0,37 \\
\hline 12/08/2019 & 2,37 & 22,83 & 1,89 & 27,01 & 21,97 & 6,10 & 49,00 & 32,83 & 20992,95 & 6,56 & 0,62 & 0,37 \\
\hline 22/08/2019 & 2,38 & 21,41 & 1,86 & 25,60 & 20,52 & 5,69 & 48,38 & 32,44 & 19836,91 & 6,20 & 0,59 & 0,41 \\
\hline
\end{tabular}


\begin{tabular}{|l|llllll|llll|ll|}
$23 / 08 / 2019$ & 2,39 & 21,14 & 1,86 & 25,31 & 21,05 & 5,84 & 48,02 & 32,23 & 20418,47 & 6,39 & 0,59 & 0,42 \\
\hline
\end{tabular}

Tabela 19. Medição de monitoramento do TC (ago a out/2019)

\begin{tabular}{|c|c|c|c|c|c|c|c|c|c|c|c|c|}
\hline \multirow[b]{2}{*}{ Data } & \multicolumn{6}{|c|}{ Fluido Água } & \multicolumn{4}{|c|}{ Fluido: Ar } & \multirow[b]{2}{*}{$\varepsilon$} & \multirow[b]{2}{*}{$F F$} \\
\hline & $P_{\text {IN }}$ & $\mathbf{T}_{\mathbf{I N}}$ & Pout & Tout $_{\text {OUt }}$ & $\mathbf{Q}$ & $\dot{\mathbf{m}}$ & $T_{\text {IN }}$ & ToUt $_{\text {OUt }}$ & $\mathbf{Q}$ & $\dot{\mathbf{m}}$ & & \\
\hline (dd/mm/aa) & (bar) & $\left({ }^{\circ} \mathrm{C}\right)$ & (bar) & $\left({ }^{\circ} \mathrm{C}\right)$ & $\left(m^{3} / h\right)$ & $(\mathrm{kg} / \mathrm{s})$ & $\left({ }^{\circ} \mathrm{C}\right)$ & $\left({ }^{\circ} \mathrm{C}\right)$ & $\left(m^{3} / h\right)$ & $(\mathrm{kg} / \mathrm{s})$ & - & - \\
\hline $24 / 08 / 2019$ & 2,37 & 21,04 & 1,85 & 25,18 & 20,94 & 5,81 & 47,91 & 32,18 & 20278,43 & 6,35 & 0,59 & 0,42 \\
\hline $10 / 09 / 2019$ & 2,36 & 23,08 & 1,81 & 28,01 & 21,47 & 5,96 & 56,34 & 38,13 & 21844,77 & 6,69 & 0,55 & 0,49 \\
\hline $11 / 09 / 2019$ & 2,34 & 23,50 & 1,79 & 28,40 & 21,70 & 6,02 & 56,52 & 38,46 & 22142,94 & 6,77 & 0,55 & 0,49 \\
\hline $12 / 09 / 2019$ & 2,36 & 23,95 & 1,81 & 28,84 & 21,79 & 6,04 & 57,10 & 39,05 & 22225,00 & 6,79 & 0,54 & 0,49 \\
\hline $13 / 09 / 2019$ & 2,35 & 24,12 & 1,79 & 28,95 & 21,98 & 6,10 & 57,12 & 39,34 & 22512,27 & 6,87 & 0,54 & 0,50 \\
\hline 14/09/2019 & 2,36 & 24,01 & 1,80 & 28,86 & 21,98 & 6,10 & 57,14 & 39,36 & 22636,99 & 6,91 & 0,54 & 0,51 \\
\hline $15 / 09 / 2019$ & 2,37 & 23,74 & 1,84 & 28,75 & 21,25 & 5,89 & 57,25 & 39,35 & 22417,20 & 6,84 & 0,53 & 0,51 \\
\hline $16 / 09 / 2019$ & 2,39 & 23,68 & 1,91 & 28,83 & 20,39 & 5,66 & 57,01 & 39,41 & 22498,01 & 6,87 & 0,53 & 0,52 \\
\hline $17 / 09 / 2019$ & 2,39 & 23,86 & 1,92 & 29,01 & 20,36 & 5,65 & 57,30 & 39,68 & 22480,81 & 6,85 & 0,53 & 0,52 \\
\hline $18 / 09 / 2019$ & 2,40 & 24,17 & 1,92 & 28,38 & 20,06 & 5,57 & 52,75 & 37,57 & 20832,80 & 6,42 & 0,53 & 0,52 \\
\hline $19 / 09 / 2019$ & 2,40 & 24,53 & 1,92 & 28,51 & 20,04 & 5,56 & 50,81 & 37,06 & 21604,41 & 6,68 & 0,52 & 0,53 \\
\hline 20/09/2019 & 2,40 & 24,81 & 1,91 & 28,86 & 19,97 & 5,54 & 51,68 & 37,67 & 21514,22 & 6,64 & 0,52 & 0,53 \\
\hline $21 / 09 / 2019$ & 2,40 & 24,74 & 1,91 & 28,75 & 20,11 & 5,58 & 51,45 & 37,60 & 21679,85 & 6,69 & 0,52 & 0,54 \\
\hline 22/09/2019 & 2,40 & 24,34 & 1,91 & 28,52 & 19,96 & 5,54 & 52,42 & 37,88 & 21460,38 & 6,61 & 0,52 & 0,54 \\
\hline 23/09/2019 & 2,40 & 23,56 & 1,91 & 27,67 & 19,81 & 5,50 & 51,12 & 37,02 & 21528,66 & 6,66 & 0,51 & 0,55 \\
\hline 01/10/2019 & 2,36 & 22,74 & 1,87 & 27,33 & 19,93 & 5,53 & 53,87 & 38,25 & 21869,59 & 6,72 & 0,50 & 0,56 \\
\hline 02/10/2019 & 2,16 & 22,83 & 1,72 & 27,99 & 19,29 & 5,35 & 57,53 & 40,49 & 22097,12 & 6,73 & 0,49 & 0,58 \\
\hline 03/10/2019 & 2,16 & 23,22 & 1,72 & 28,35 & 18,55 & 5,15 & 57,67 & 40,86 & 21396,93 & 6,51 & 0,49 & 0,59 \\
\hline 04/10/2019 & 2,16 & 23,47 & 1,73 & 28,59 & 19,36 & 5,37 & 57,72 & 41,09 & 22538,78 & 6,85 & 0,49 & 0,59 \\
\hline 05/10/2019 & 2,15 & 23,67 & 1,72 & 28,89 & 19,43 & 5,39 & 58,72 & 41,62 & 22535,18 & 6,84 & 0,49 & 0,59 \\
\hline 06/10/2019 & 2,14 & 24,01 & 1,71 & 29,19 & 19,55 & 5,42 & 58,81 & 41,91 & 22708,52 & 6,88 & 0,49 & 0,59 \\
\hline 07/10/2019 & 2,13 & 24,19 & 1,71 & 29,31 & 19,57 & 5,43 & 58,52 & 41,93 & 22933,71 & 6,96 & 0,48 & 0,60 \\
\hline $15 / 10 / 2019$ & 2,13 & 24,78 & 1,69 & 29,91 & 19,89 & 5,52 & 59,51 & 43,06 & 23631,74 & 7,14 & 0,47 & 0,61 \\
\hline $16 / 10 / 2019$ & 2,12 & 25,23 & 1,68 & 30,30 & 20,18 & 5,60 & 58,52 & 41,93 & 23367,38 & 7,09 & 0,50 & 0,57 \\
\hline $17 / 10 / 2019$ & 2,12 & 25,26 & 1,69 & 30,33 & 20,17 & 5,60 & 59,96 & 43,74 & 24039,53 & 7,25 & 0,47 & 0,63 \\
\hline $18 / 10 / 2019$ & 2,11 & 25,13 & 1,68 & 30,18 & 20,28 & 5,62 & 59,65 & 43,65 & 24354,34 & 7,35 & 0,46 & 0,63 \\
\hline $19 / 10 / 2019$ & 2,09 & 25,07 & 1,65 & 30,10 & 20,41 & 5,66 & 59,69 & 43,68 & 24422,78 & 7,37 & 0,46 & 0,63 \\
\hline 20/10/2019 & 2,07 & 24,62 & 1,64 & 29,65 & 21,57 & 5,98 & 59,19 & 43,25 & 25892,94 & 7,83 & 0,46 & 0,64 \\
\hline $21 / 10 / 2019$ & 2,06 & 24,05 & 1,64 & 29,05 & 21,90 & 6,07 & 58,59 & 42,69 & 26173,87 & 7,93 & 0,46 & 0,64 \\
\hline 23/10/2019 & 2,21 & 24,25 & 1,97 & 28,03 & 25,30 & 7,02 & 52,05 & 36,14 & 21682,77 & 6,70 & 0,58 & 0,43 \\
\hline $24 / 10 / 2019$ & 2,08 & 23,44 & 1,82 & 28,98 & 20,03 & 5,56 & 52,56 & 33,45 & 21318,97 & 6,61 & 0,65 & 0,30 \\
\hline
\end{tabular}




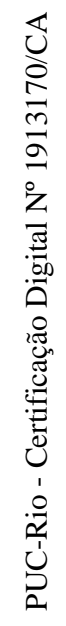


Tabela 20. Medição de monitoramento do TC (out a dez/2019)

\begin{tabular}{|c|c|c|c|c|c|c|c|c|c|c|c|c|}
\hline \multirow[b]{2}{*}{ Data } & \multicolumn{6}{|c|}{ Fluido Água } & \multicolumn{4}{|c|}{ Fluido: Ar } & & \multirow[b]{2}{*}{$F F$} \\
\hline & $P_{\text {IN }}$ & $T_{\text {IN }}$ & $\mathbf{P}_{\text {out }}$ & $\mathbf{T}_{\text {OUT }}$ & $\mathbf{Q}$ & $\dot{\mathbf{m}}$ & $T_{\text {IN }}$ & $\mathbf{T}_{\text {OUT }}$ & $\mathbf{Q}$ & $\dot{\mathbf{m}}$ & & \\
\hline (dd/mm/aa) & (bar) & $\left({ }^{\circ} \mathrm{C}\right)$ & (bar) & $\left({ }^{\circ} \mathrm{C}\right)$ & $\left(m^{3} / h\right)$ & $(\mathrm{kg} / \mathrm{s})$ & $\left({ }^{\circ} \mathrm{C}\right)$ & $\left({ }^{\circ} \mathrm{C}\right)$ & $\left(m^{3} / h\right)$ & $(\mathrm{kg} / \mathrm{s})$ & - & - \\
\hline $25 / 10 / 2019$ & 2,14 & 23,78 & 1,85 & 30,11 & 21,36 & 5,92 & 56,61 & 34,86 & 22811,51 & 7,02 & 0,66 & 0,29 \\
\hline $26 / 10 / 2019$ & 2,07 & 24,25 & 1,81 & 30,89 & 19,54 & 5,42 & 57,51 & 35,46 & 22052,13 & 6,77 & 0,66 & 0,29 \\
\hline $27 / 10 / 2019$ & 2,09 & 24,81 & 1,82 & 31,49 & 18,88 & 5,24 & 58,10 & 36,03 & 21433,20 & 6,56 & 0,66 & 0,29 \\
\hline $28 / 10 / 2019$ & 2,22 & 25,36 & 1,87 & 31,70 & 21,44 & 5,95 & 58,54 & 36,31 & 21699,05 & 6,64 & 0,67 & 0,28 \\
\hline 29/10/2019 & 2,24 & 25,78 & 1,93 & 32,12 & 21,23 & 5,89 & 58,48 & 36,58 & 22135,23 & 6,77 & 0,67 & 0,28 \\
\hline $30 / 10 / 2019$ & 2,20 & 26,20 & 1,89 & 32,43 & 20,64 & 5,72 & 58,64 & 36,91 & 21667,13 & 6,62 & 0,67 & 0,28 \\
\hline $31 / 10 / 2019$ & 2,12 & 25,66 & 1,85 & 31,90 & 19,36 & 5,37 & 58,03 & 36,49 & 21027,78 & 6,43 & 0,67 & 0,28 \\
\hline $01 / 11 / 2019$ & 2,20 & 26,62 & 1,90 & 32,66 & 20,43 & 5,67 & 57,32 & 36,68 & 22323,98 & 6,84 & 0,67 & 0,27 \\
\hline $02 / 11 / 2019$ & 2,11 & 26,29 & 1,86 & 32,40 & 19,19 & 5,32 & 56,29 & 36,22 & 21872,57 & 6,71 & 0,67 & 0,28 \\
\hline 03/11/2019 & 2,11 & 26,21 & 1,85 & 31,70 & 18,93 & 5,25 & 53,57 & 35,20 & 21089,03 & 6,51 & 0,67 & 0,27 \\
\hline $04 / 11 / 2019$ & 2,25 & 26,56 & 1,90 & 31,74 & 21,43 & 5,94 & 53,60 & 35,30 & 21691,93 & 6,70 & 0,68 & 0,26 \\
\hline 05/11/2019 & 2,06 & 26,98 & 1,81 & 32,46 & 19,41 & 5,38 & 54,12 & 35,86 & 21737,35 & 6,70 & 0,67 & 0,27 \\
\hline $06 / 11 / 2019$ & 2,06 & 27,28 & 1,81 & 32,80 & 19,05 & 5,28 & 54,18 & 36,17 & 21822,99 & 6,72 & 0,67 & 0,28 \\
\hline 07/11/2019 & 2,08 & 26,55 & 1,83 & 31,29 & 19,40 & 5,38 & 50,83 & 34,66 & 20914,24 & 6,49 & 0,67 & 0,28 \\
\hline 08/11/2019 & 2,09 & 24,81 & 1,84 & 30,07 & 20,73 & 5,75 & 50,58 & 33,48 & 23592,21 & 7,34 & 0,66 & 0,29 \\
\hline $09 / 11 / 2019$ & 2,11 & 23,79 & 1,85 & 29,03 & 20,54 & 5,70 & 49,57 & 32,58 & 23367,67 & 7,29 & 0,66 & 0,29 \\
\hline $10 / 11 / 2019$ & 2,10 & 23,55 & 1,85 & 28,78 & 20,47 & 5,68 & 49,27 & 32,34 & 23301,21 & 7,28 & 0,66 & 0,30 \\
\hline $11 / 11 / 2019$ & 2,15 & 23,79 & 1,90 & 28,78 & 21,12 & 5,86 & 49,17 & 32,47 & 22830,04 & 7,13 & 0,66 & 0,30 \\
\hline $12 / 11 / 2019$ & 2,11 & 23,68 & 1,85 & 28,89 & 20,72 & 5,75 & 48,94 & 32,18 & 23696,42 & 7,41 & 0,66 & 0,29 \\
\hline $13 / 11 / 2019$ & 2,11 & 24,41 & 1,86 & 30,05 & 19,83 & 5,50 & 52,38 & 33,79 & 22208,75 & 6,89 & 0,66 & 0,29 \\
\hline $14 / 11 / 2019$ & 2,10 & 25,13 & 1,85 & 31,09 & 19,77 & 5,48 & 54,13 & 34,86 & 22798,12 & 7,04 & 0,66 & 0,29 \\
\hline $15 / 11 / 2019$ & 2,09 & 24,94 & 1,84 & 30,56 & 20,50 & 5,69 & 52,35 & 34,15 & 2349 & 7,28 & 0,66 & 0,29 \\
\hline $16 / 11 / 2019$ & 2,11 & 24,93 & 1,85 & 30,62 & 20,50 & 5,69 & 52,70 & 34,30 & 23554,36 & 7,30 & 0,66 & 0,29 \\
\hline $17 / 11 / 2019$ & 2,11 & 24,92 & 1,86 & 30,82 & 20,30 & 5,63 & 53,65 & 34,73 & 23560,65 & 7,28 & 0,66 & 0,30 \\
\hline $18 / 11 / 2019$ & 2,18 & 24,38 & 1,90 & 29,32 & 22,02 & 6,11 & 50,27 & 33,19 & 23018,86 & 7,17 & 0,66 & 0,30 \\
\hline $26 / 11 / 2019$ & 2,13 & 23,72 & 1,89 & 28,94 & 21,46 & 5,95 & 49,94 & 32,60 & 23877,71 & 7,45 & 0,66 & 0,29 \\
\hline $28 / 11 / 2019$ & 2,11 & 24,09 & 1,84 & 29,27 & 21,31 & 5,91 & 50,17 & 33,22 & 24076,93 & 7,50 & 0,65 & 0,31 \\
\hline $29 / 11 / 2019$ & 2,11 & 24,43 & 1,84 & 29,66 & 21,33 & 5,92 & 50,91 & 33,69 & 24015,42 & 7,47 & 0,65 & 0,31 \\
\hline $30 / 11 / 2019$ & 2,11 & 24,51 & 1,85 & 29,80 & 21,32 & 5,92 & 51,32 & 33,91 & 23991,18 & 7,45 & 0,65 & 0,31 \\
\hline $01 / 12 / 2019$ & 2,12 & 24,52 & 1,85 & 29,66 & 21,32 & 5,91 & 50,54 & 33,72 & 24084,99 & 7,49 & 0,65 & 0,32 \\
\hline $02 / 12 / 2019$ & 2,11 & 24,90 & 1,85 & 30,03 & 21,20 & 5,88 & 50,87 & 34,13 & 24099,25 & 7,49 & 0,64 & 0,32 \\
\hline
\end{tabular}


Tabela 21. Medição de monitoramento do TC (dez/2019 a jan/2020)

\begin{tabular}{|c|c|c|c|c|c|c|c|c|c|c|c|c|}
\hline \multirow[b]{2}{*}{ Data } & \multicolumn{6}{|c|}{ Fluido Água } & \multicolumn{4}{|c|}{ Fluido: Ar } & \multirow[b]{2}{*}{$\varepsilon$} & \multirow[b]{2}{*}{$F F$} \\
\hline & $\mathbf{P}_{\text {IN }}$ & $T_{\text {IN }}$ & $P_{\text {out }}$ & $\mathrm{T}_{\text {OUT }}$ & $\mathbf{Q}$ & $\dot{\mathbf{m}}$ & $T_{\text {IN }}$ & $T_{\text {OUT }}$ & $\mathbf{Q}$ & $\dot{\mathbf{m}}$ & & \\
\hline (dd/mm/aa) & (bar) & $\left({ }^{\circ} \mathrm{C}\right)$ & (bar) & $\left({ }^{\circ} \mathrm{C}\right)$ & $\left(m^{3} / h\right)$ & $(\mathrm{kg} / \mathrm{s})$ & $\left({ }^{\circ} \mathrm{C}\right)$ & $\left({ }^{\circ} \mathrm{C}\right)$ & $\left(m^{3} / h\right)$ & $(\mathrm{kg} / \mathrm{s})$ & - & - \\
\hline 06/12/2019 & 2,13 & 24,59 & 1,93 & 29,38 & 22,55 & 6,25 & 51,17 & 34,35 & 23399,03 & 7,27 & 0,63 & 0,34 \\
\hline 07/12/2019 & 2,13 & 24,48 & 1,86 & 29,90 & 21,05 & 5,84 & 51,49 & 34,58 & 25007,63 & 7,76 & 0,63 & 0,35 \\
\hline 08/12/2019 & 2,13 & 24,52 & 1,86 & 29,88 & 21,59 & 5,99 & 51,15 & 34,52 & 25775,56 & 8,00 & 0,62 & 0,35 \\
\hline 09/12/2019 & 2,12 & 24,61 & 1,85 & 30,03 & 21,36 & 5,92 & 51,44 & 34,71 & 25660,96 & 7,96 & 0,62 & 0,36 \\
\hline $10 / 12 / 2019$ & 2,10 & 24,61 & 1,84 & 29,97 & 21,23 & 5,89 & 51,03 & 34,61 & 25725,38 & 7,98 & 0,62 & 0,36 \\
\hline $11 / 12 / 2019$ & 2,10 & 24,60 & 1,84 & 29,95 & 21,17 & 5,87 & 50,88 & 34,59 & 25760,94 & 8,00 & 0,62 & 0,36 \\
\hline $12 / 12 / 2019$ & 2,10 & 24,76 & 1,85 & 30,08 & 21,00 & 5,83 & 50,93 & 34,73 & 25537,69 & 7,93 & 0,62 & 0,36 \\
\hline $13 / 12 / 2019$ & 2,11 & 24,05 & 1,85 & 29,40 & 21,00 & 5,82 & 50,46 & 34,19 & 25548,30 & 7,94 & 0,62 & 0,37 \\
\hline 14/12/2019 & 2,10 & 23,67 & 1,84 & 28,98 & 20,92 & 5,80 & 49,78 & 33,82 & 25725,00 & 8,01 & 0,61 & 0,38 \\
\hline 15/12/2019 & 2,10 & 23,61 & 1,84 & 28,95 & 20,92 & 5,80 & 50,06 & 33,83 & 25451,69 & 7,92 & 0,61 & 0,37 \\
\hline $16 / 12 / 2019$ & 2,10 & 23,73 & 1,84 & 29,63 & 20,87 & 5,79 & 53,19 & 35,13 & 25391,25 & 7,85 & 0,61 & 0,37 \\
\hline 19/12/2019 & 2,10 & 24,12 & 1,84 & 30,35 & 20,89 & 5,80 & 55,25 & 36,26 & 25635,45 & 7,88 & 0,61 & 0,38 \\
\hline 20/12/2019 & 2,10 & 24,07 & 1,84 & 29,42 & 21,24 & 5,89 & 50,98 & 34,50 & 25555,20 & 7,93 & 0,61 & 0,38 \\
\hline 21/12/2019 & 2,10 & 24,08 & 1,84 & 29,43 & 21,37 & 5,93 & 51,12 & 34,56 & 25619,71 & 7,95 & 0,61 & 0,38 \\
\hline 22/12/2019 & 2,10 & 24,03 & 1,83 & 29,38 & 21,24 & 5,89 & 51,09 & 34,55 & 25450,25 & 7,90 & 0,61 & 0,38 \\
\hline 23/12/2019 & 2,10 & 23,88 & 1,83 & 29,12 & 21,14 & 5,86 & 50,30 & 34,22 & 25518,51 & 7,93 & 0,61 & 0,38 \\
\hline 24/12/2019 & 2,10 & 23,82 & 1,83 & 29,07 & 21,04 & 5,84 & 50,25 & 34,18 & 25444,25 & 7,91 & 0,61 & 0,38 \\
\hline 25/12/2019 & 2,10 & 23,73 & 1,83 & 29,12 & 21,07 & 5,85 & 50,85 & 34,39 & 25582,26 & 7,95 & 0,61 & 0,38 \\
\hline 26/12/2019 & 2,10 & 24,95 & 1,83 & 30,17 & 20,97 & 5,82 & 51,11 & 35,22 & 25554,06 & 7,92 & 0,61 & 0,38 \\
\hline 27/12/2019 & 2,12 & 25,53 & 1,86 & 30,65 & 20,94 & 5,81 & 51,19 & 35,66 & 25642,97 & 7,94 & 0,61 & 0,39 \\
\hline 28/12/2019 & 2,13 & 25,32 & 1,86 & 30,44 & 21,22 & 5,89 & 51,16 & 35,56 & 25852,64 & 8,01 & 0,60 & 0,39 \\
\hline 29/12/2019 & 2,14 & 25,66 & 1,86 & 30,75 & 20,92 & 5,80 & 51,45 & 35,84 & 25371,97 & 7,85 & 0,61 & 0,39 \\
\hline $30 / 12 / 2019$ & 2,13 & 24,48 & 1,86 & 29,90 & 21,05 & 5,84 & 51,49 & 34,58 & 25007,63 & 7,76 & 0,63 & 0,35 \\
\hline 03/01/2020 & 2,13 & 27,10 & 1,84 & 31,54 & 20,45 & 5,67 & 49,77 & 35,93 & 24266,47 & 7,53 & 0,61 & 0,38 \\
\hline 05/01/2020 & 2,13 & 26,10 & 1,86 & 32,47 & 19,95 & 5,53 & 58,83 & 39,32 & 24631,16 & 7,50 & 0,60 & 0,40 \\
\hline 06/01/2020 & 2,14 & 26,12 & 1,85 & 31,92 & 20,09 & 5,57 & 57,64 & 38,95 & 23281,94 & 7,10 & 0,59 & 0,41 \\
\hline 08/01/2020 & 2,18 & 26,05 & 1,87 & 32,40 & 19,97 & 5,54 & 59,20 & 39,82 & 24728,95 & 7,52 & 0,58 & 0,42 \\
\hline 09/01/2020 & 2,18 & 26,29 & 1,87 & 32,65 & 20,20 & 5,60 & 59,69 & 40,27 & 25049,75 & 7,60 & 0,58 & 0,43 \\
\hline $10 / 01 / 2020$ & 2,18 & 26,53 & 1,87 & 32,94 & 20,39 & 5,66 & 60,28 & 40,78 & 25457,37 & 7,71 & 0,58 & 0,44 \\
\hline $11 / 01 / 2020$ & 2,18 & 26,56 & 1,87 & 32,91 & 20,54 & 5,70 & 60,18 & 40,95 & 25767,29 & 7,81 & 0,57 & 0,44 \\
\hline $12 / 01 / 2020$ & 2,20 & 26,75 & 1,87 & 33,08 & 20,68 & 5,74 & 60,26 & 41,18 & 26033,72 & 7,88 & 0,57 & 0,45 \\
\hline
\end{tabular}


Tabela 22. Medição de monitoramento do TC (jan a fev/2020)

\begin{tabular}{|c|c|c|c|c|c|c|c|c|c|c|c|c|}
\hline \multirow[b]{2}{*}{ Data } & \multicolumn{6}{|c|}{ Fluido Água } & \multicolumn{4}{|c|}{ Fluido: Ar } & \multirow[b]{2}{*}{$\varepsilon$} & \multirow[b]{2}{*}{$F F$} \\
\hline & $\mathbf{P}_{\text {IN }}$ & $\mathbf{T}_{\mathbf{I N}}$ & Pout & TOUT & $\mathbf{Q}$ & $\dot{\mathbf{m}}$ & $\mathbf{T}_{\mathrm{IN}}$ & ToUT & $\mathbf{Q}$ & $\dot{\mathbf{m}}$ & & \\
\hline (dd/mm/aa) & (bar) & $\left({ }^{\circ} \mathrm{C}\right)$ & (bar) & $\left({ }^{\circ} \mathrm{C}\right)$ & $\left(\mathrm{m}^{3} / \mathrm{h}\right)$ & $(\mathrm{kg} / \mathrm{s})$ & $\left({ }^{\circ} \mathrm{C}\right)$ & $\left({ }^{\circ} \mathrm{C}\right)$ & $\left(m^{3} / h\right)$ & $(\mathrm{kg} / \mathrm{s})$ & - & - \\
\hline $13 / 01 / 2020$ & 2,19 & 26,67 & 1,86 & 32,94 & 20,42 & 5,66 & 60,08 & 41,14 & 25662,40 & 7,77 & 0,57 & 0,45 \\
\hline $22 / 01 / 2020$ & 2,27 & 25,99 & 1,91 & 32,13 & 20,64 & 5,73 & 59,77 & 40,84 & 25386,63 & 7,70 & 0,56 & 0,46 \\
\hline 23/01/2020 & 2,21 & 25,16 & 1,82 & 31,32 & 21,20 & 5,88 & 58,93 & 40,35 & 26618,72 & 8,09 & 0,55 & 0,48 \\
\hline 24/01/2020 & 2,21 & 25,30 & 1,81 & 31,45 & 21,05 & 5,84 & 58,93 & 40,41 & 26464,38 & 8,04 & 0,55 & 0,48 \\
\hline $25 / 01 / 2020$ & 2,21 & 25,26 & 1,81 & 31,40 & 21,10 & 5,85 & 58,86 & 40,39 & 26569,81 & 8,07 & 0,55 & 0,48 \\
\hline $26 / 01 / 2020$ & 2,22 & 25,11 & 1,80 & 31,30 & 21,08 & 5,85 & 59,04 & 40,41 & 26539,51 & 8,06 & 0,55 & 0,48 \\
\hline $27 / 01 / 2020$ & 2,21 & 25,25 & 1,78 & 31,52 & 20,64 & 5,72 & 59,65 & 40,81 & 26050,98 & 7,90 & 0,55 & 0,49 \\
\hline $30 / 01 / 2020$ & 2,24 & 26,58 & 1,78 & 32,26 & 19,72 & 5,47 & 57,68 & 40,74 & 25039,63 & 7,62 & 0,54 & 0,49 \\
\hline $31 / 01 / 2020$ & 2,07 & 27,80 & 1,63 & 32,28 & 23,19 & 6,43 & 53,85 & 37,62 & 23445,81 & 7,21 & 0,62 & 0,36 \\
\hline 01/02/2020 & 1,91 & 28,03 & 1,43 & 32,31 & 26,72 & 7,41 & 54,16 & 36,09 & 23615,99 & 7,28 & 0,69 & 0,24 \\
\hline 02/02/2020 & 1,89 & 28,19 & 1,40 & 32,56 & 26,49 & 7,35 & 54,73 & 36,33 & 23549,23 & 7,25 & 0,69 & 0,24 \\
\hline 03/02/2020 & 1,88 & 27,87 & 1,39 & 31,56 & 26,76 & 7,42 & 52,97 & 36,25 & 20491,02 & 6,32 & 0,66 & 0,30 \\
\hline 04/02/2020 & 1,89 & 27,18 & 1,39 & 31,73 & 26,83 & 7,44 & 55,49 & 36,01 & 23468,63 & 7,22 & 0,69 & 0,24 \\
\hline 05/02/2020 & 1,91 & 25,98 & 1,40 & 30,39 & 28,06 & 7,78 & 54,07 & 34,94 & 23983,59 & 7,40 & 0,68 & 0,26 \\
\hline 06/02/2020 & 1,97 & 24,52 & 1,46 & 29,89 & 29,40 & 8,15 & 58,89 & 35,88 & 25759,60 & 7,88 & 0,67 & 0,28 \\
\hline 07/02/2020 & 1,92 & 24,53 & 1,39 & 29,98 & 28,96 & 8,03 & 59,46 & 36,43 & 25836,23 & 7,89 & 0,66 & 0,29 \\
\hline 08/02/2020 & 1,86 & 24,61 & 1,33 & 30,12 & 27,88 & 7,73 & 59,68 & 36,84 & 25352,26 & 7,74 & 0,65 & 0,31 \\
\hline 09/02/2020 & 1,87 & 23,69 & 1,28 & 29,29 & 27,05 & 7,50 & 59,36 & 36,48 & 24923,41 & 7,61 & 0,64 & 0,33 \\
\hline $10 / 02 / 2020$ & 1,92 & 26,18 & 1,27 & 31,75 & 26,13 & 7,25 & 61,90 & 39,12 & 24210,47 & 7,34 & 0,64 & 0,33 \\
\hline $11 / 02 / 2020$ & 1,93 & 26,17 & 1,25 & 31,69 & 26,03 & 7,22 & 61,60 & 39,36 & 24503,06 & 7,43 & 0,63 & 0,35 \\
\hline $12 / 02 / 2020$ & 1,92 & 25,42 & 1,22 & 30,96 & 26,37 & 7,31 & 61,01 & 39,02 & 25185,61 & 7,64 & 0,62 & 0,37 \\
\hline $13 / 02 / 2020$ & 1,97 & 24,59 & 1,25 & 30,01 & 27,74 & 7,70 & 60,27 & 38,57 & 26245,53 & 7,98 & 0,61 & 0,38 \\
\hline $14 / 02 / 2020$ & 1,96 & 24,31 & 1,23 & 29,70 & 27,91 & 7,74 & 60,10 & 38,72 & 26629,08 & 8,10 & 0,60 & 0,40 \\
\hline $16 / 02 / 2020$ & 1,96 & 25,83 & 1,23 & 30,57 & 27,35 & 7,58 & 58,87 & 39,47 & 25298,44 & 7,70 & 0,59 & 0,42 \\
\hline $17 / 02 / 2020$ & 1,97 & 26,13 & 1,24 & 30,16 & 28,10 & 7,79 & 53,80 & 37,55 & 26062,33 & 8,02 & 0,59 & 0,42 \\
\hline $18 / 02 / 2020$ & 1,98 & 26,18 & 1,25 & 30,38 & 27,92 & 7,74 & 55,28 & 38,15 & 25704,93 & 7,88 & 0,59 & 0,42 \\
\hline $19 / 02 / 2020$ & 1,96 & 26,29 & 1,24 & 29,45 & 27,79 & 7,71 & 51,67 & 37,26 & 20615,33 & 6,35 & 0,55 & 0,48 \\
\hline $20 / 02 / 2020$ & 1,96 & 26,42 & 1,25 & 30,61 & 27,57 & 7,65 & 55,36 & 38,27 & 25356,09 & 7,77 & 0,59 & 0,41 \\
\hline $21 / 02 / 2020$ & 1,96 & 26,44 & 1,25 & 30,52 & 27,81 & 7,71 & 54,39 & 37,96 & 25837,22 & 7,93 & 0,59 & 0,42 \\
\hline 22/02/2020 & 1,95 & 26,18 & 1,25 & 30,28 & 28,13 & 7,80 & 54,13 & 37,71 & 26241,06 & 8,07 & 0,59 & 0,42 \\
\hline 23/02/2020 & 1,94 & 25,69 & 1,24 & 29,78 & 28,29 & 7,85 & 53,69 & 37,26 & 26378,88 & 8,12 & 0,59 & 0,42 \\
\hline
\end{tabular}


Tabela 23. Medição de monitoramento do TC (fev a abr/2020)

\begin{tabular}{|c|c|c|c|c|c|c|c|c|c|c|c|c|}
\hline \multirow[b]{2}{*}{ Data } & \multicolumn{6}{|c|}{ Fluido Água } & \multicolumn{4}{|c|}{ Fluido: Ar } & \multirow[b]{2}{*}{$\varepsilon$} & \multirow[b]{2}{*}{$F F$} \\
\hline & $\mathbf{P}_{\mathrm{IN}}$ & $T_{\text {IN }}$ & $P_{\text {oUt }}$ & $\mathrm{T}_{\text {OUT }}$ & $\mathbf{Q}$ & $\dot{\mathbf{m}}$ & $T_{\text {IN }}$ & $T_{\text {OUT }}$ & $\mathbf{Q}$ & $\dot{\mathbf{m}}$ & & \\
\hline (dd/mm/aa) & (bar) & $\left({ }^{\circ} \mathrm{C}\right)$ & (bar) & $\left({ }^{\circ} \mathrm{C}\right)$ & $\left(m^{3} / h\right)$ & $(\mathrm{kg} / \mathrm{s})$ & $\left({ }^{\circ} \mathrm{C}\right)$ & $\left({ }^{\circ} \mathrm{C}\right)$ & $\left(m^{3} / h\right)$ & $(\mathrm{kg} / \mathrm{s})$ & - & - \\
\hline 24/02/2020 & 1,93 & 25,25 & 1,23 & 29,36 & 27,30 & 7,57 & 53,42 & 36,88 & 25382,17 & 7,82 & 0,59 & 0,42 \\
\hline 09/03/2020 & 2,28 & 23,76 & 1,84 & 31,14 & 25,65 & 7,11 & 65,92 & 38,95 & 24921,99 & 7,51 & 0,63 & 0,34 \\
\hline 27/03/2020 & 2,25 & 24,84 & 1,74 & 34,11 & 20,37 & 5,65 & 74,00 & 49,50 & 30242,78 & 8,86 & 0,50 & 0,57 \\
\hline 28/03/2020 & 2,30 & 25,10 & 1,77 & 34,24 & 21,06 & 5,84 & 74,86 & 50,40 & 30937,02 & 9,04 & 0,49 & 0,58 \\
\hline 29/03/2020 & 2,29 & 25,26 & 1,76 & 34,39 & 21,12 & 5,86 & 74,98 & 50,66 & 31198,49 & 9,11 & 0,49 & 0,59 \\
\hline 30/03/2020 & 2,28 & 25,47 & 1,76 & 34,56 & 21,22 & 5,89 & 74,71 & 50,70 & 31620,03 & 9,23 & 0,49 & 0,59 \\
\hline $31 / 03 / 2020$ & 2,26 & 25,44 & 1,75 & 34,47 & 21,11 & 5,85 & 74,58 & 50,65 & 31323,85 & 9,15 & 0,49 & 0,59 \\
\hline 02/04/2020 & 2,45 & 25,44 & 2,05 & 33,89 & 27,78 & 7,70 & 72,26 & 43,90 & 28722,51 & 8,50 & 0,61 & 0,38 \\
\hline 03/04/2020 & 2,28 & 25,34 & 2,07 & 36,73 & 19,90 & 5,52 & 70,96 & 40,61 & 28799,78 & 8,59 & 0,67 & 0,28 \\
\hline 04/04/2020 & 2,30 & 25,25 & 2,10 & 36,60 & 20,47 & 5,68 & 70,69 & 40,53 & 29671,34 & 8,85 & 0,66 & 0,29 \\
\hline 05/04/2020 & 2,28 & 25,18 & 2,08 & 36,56 & 19,78 & 5,48 & 70,56 & 40,48 & 28837,98 & 8,60 & 0,66 & 0,29 \\
\hline 06/04/2020 & 2,25 & 25,79 & 2,05 & 35,72 & 18,81 & 5,22 & 65,21 & 39,04 & 27266,00 & 8,22 & 0,66 & 0,29 \\
\hline
\end{tabular}




\section{Apêndice B: Cálculo da efetividade pelas equações de governo}

Tabela 24. Extrato de resultados de medições (julho a out/2019)

\begin{tabular}{|c|c|c|c|c|c|c|c|c|c|c|c|c|c|c|c|c|c|c|c|}
\hline \multirow[b]{2}{*}{ Data } & \multicolumn{3}{|c|}{ Uso da Tar medida } & \multicolumn{3}{|c|}{ Código } & \multicolumn{3}{|c|}{ Diferença percentual } & \multirow[b]{2}{*}{ Data } & \multicolumn{3}{|c|}{ Uso da Tar medida } & \multicolumn{3}{|c|}{ Código } & \multicolumn{3}{|c|}{ Diferença percentual } \\
\hline & $\mathrm{T}_{\text {OUt }}$ & $\dot{\mathbf{m}}$ & $\varepsilon$ & $\mathbf{T}_{\text {OUT }}$ & $\dot{\mathbf{m}}$ & $\varepsilon$ & Tar_out & $\varepsilon$ & $\dot{\mathbf{m}}$ & & $\mathrm{T}_{\text {OUt }}$ & $\dot{\mathbf{m}}$ & $\varepsilon$ & $\mathrm{T}_{\text {OUt }}$ & $\dot{\mathbf{m}}$ & $\varepsilon$ & Tar_out & $\varepsilon$ & $\dot{\mathbf{m}}$ \\
\hline (dd/mm/aa) & $\left({ }^{\circ} \mathrm{C}\right)$ & $(\mathrm{kg} / \mathrm{s})$ & - & $\left({ }^{\circ} \mathrm{C}\right)$ & $(\mathrm{kg} / \mathrm{s})$ & - & (\%) & (\%) & $(\%)$ & (dd/mm/aa) & $\left({ }^{\circ} \mathrm{C}\right)$ & $(\mathrm{kg} / \mathrm{s})$ & - & $\left({ }^{\circ} \mathrm{C}\right)$ & $(\mathrm{kg} / \mathrm{s})$ & - & (\%) & (\%) & (\%) \\
\hline $05 / 07 / 2019$ & 36,11 & 6,55 & 0,48 & 34,16 & 5,62 & 0,56 & $5,40 \%$ & $16,60 \%$ & $14,22 \%$ & $24 / 08 / 2019$ & 32,18 & 6,35 & 0,59 & 32,40 & 6,44 & 0,58 & $0,69 \%$ & $1,41 \%$ & $1,44 \%$ \\
\hline 06/07/2019 & 35,87 & 6,70 & 0,46 & 33,44 & 5,51 & 0,56 & $6,77 \%$ & $21,69 \%$ & $17,82 \%$ & $10 / 09 / 2019$ & 38,13 & 6,69 & 0,55 & 37,43 & 6,45 & 0,57 & $1,84 \%$ & $3,86 \%$ & $3,60 \%$ \\
\hline $07 / 07 / 2019$ & 35,67 & 6,73 & 0,45 & 33,15 & 5,50 & 0,55 & $7,06 \%$ & $22,41 \%$ & $18,30 \%$ & $11 / 09 / 2019$ & 38,46 & 6,77 & 0,55 & 37,68 & 6,50 & 0,57 & $2,03 \%$ & $4,32 \%$ & $4,03 \%$ \\
\hline 08/07/2019 & 35,38 & 6,82 & 0,45 & 32,70 & 5,50 & 0,56 & $7,57 \%$ & $24,16 \%$ & $19,45 \%$ & $12 / 09 / 2019$ & 39,05 & 6,79 & 0,54 & 38,22 & 6,49 & 0,57 & $2,12 \%$ & $4,60 \%$ & $4,28 \%$ \\
\hline $09 / 07 / 2019$ & 34,29 & 6,94 & 0,47 & 32,03 & 6,04 & 0,57 & $6,59 \%$ & $19,20 \%$ & $12,91 \%$ & $13 / 09 / 2019$ & 39,34 & 6,87 & 0,54 & 38,33 & 6,51 & 0,57 & $2,56 \%$ & $5,67 \%$ & $5,25 \%$ \\
\hline $10 / 07 / 2019$ & 32,46 & 6,95 & 0,54 & 31,54 & 6,50 & 0,57 & $2,83 \%$ & $6,98 \%$ & $6,49 \%$ & $14 / 09 / 2019$ & 39,36 & 6,91 & 0,54 & 38,28 & 6,52 & 0,57 & $2,74 \%$ & $6,06 \%$ & $5,60 \%$ \\
\hline $12 / 07 / 2019$ & 28,81 & 6,28 & 0,68 & 30,42 & 6,98 & 0,61 & $5,60 \%$ & $10,03 \%$ & $11,19 \%$ & $15 / 09 / 2019$ & 39,35 & 6,84 & 0,53 & 38,21 & 6,44 & 0,57 & $2,91 \%$ & $6,39 \%$ & $5,83 \%$ \\
\hline $13 / 07 / 2019$ & 28,94 & 6,47 & 0,68 & 30,45 & 7,14 & 0,61 & $5,23 \%$ & $9,35 \%$ & $10,35 \%$ & $16 / 09 / 2019$ & 39,41 & 6,87 & 0,53 & 38,05 & 6,38 & 0,57 & $3,45 \%$ & $7,73 \%$ & $7,06 \%$ \\
\hline $23 / 07 / 2019$ & 28,92 & 6,78 & 0,67 & 30,25 & 7,53 & 0,62 & $4,60 \%$ & $7,83 \%$ & $11,09 \%$ & $17 / 09 / 2019$ & 39,68 & 6,85 & 0,53 & 38,32 & 6,36 & 0,57 & & $7,73 \%$ & $7,16 \%$ \\
\hline $24 / 07 / 2019$ & 28,95 & 6,80 & 0,67 & 30,29 & 7,39 & 0,62 & $4,64 \%$ & $7,97 \%$ & $8,68 \%$ & $18 / 09 / 2019$ & 37,57 & 6,42 & 0,53 & 36,86 & 6,12 & 0,56 & $1,90 \%$ & $4,76 \%$ & $4,69 \%$ \\
\hline $25 / 07 / 2019$ & 29,25 & 6,79 & 0,67 & 30,61 & 7,38 & 0,62 & $4,62 \%$ & $7,96 \%$ & $8,67 \%$ & $19 / 09 / 2019$ & 37,06 & 6,68 & 0,52 & 36,01 & 6,21 & 0,56 & $2,83 \%$ & $7,64 \%$ & $7,08 \%$ \\
\hline $26 / 07 / 2019$ & 29,58 & 6,78 & 0,67 & 30,92 & 7,36 & 0,62 & $4,53 \%$ & $7,92 \%$ & $8,61 \%$ & $20 / 09 / 2019$ & 37,67 & 6,64 & 0,52 & 36,61 & 6,17 & 0,56 & $2,82 \%$ & $7,58 \%$ & $7,06 \%$ \\
\hline $27 / 07 / 2019$ & 29,72 & 6,77 & 0,67 & 31,02 & 7,34 & 0,62 & $4,40 \%$ & $7,83 \%$ & $8,50 \%$ & $21 / 09 / 2019$ & 37,60 & 6,69 & 0,52 & 36,45 & 6,18 & 0,56 & $3,04 \%$ & $8,25 \%$ & $7,61 \%$ \\
\hline $28 / 07 / 2019$ & 29,84 & 6,74 & 0,67 & 31,13 & 7,30 & 0,62 & $4,32 \%$ & $7,73 \%$ & $8,39 \%$ & $22 / 09 / 2019$ & 37,88 & 6,61 & 0,52 & 36,75 & 6,14 & 0,56 & $2,97 \%$ & $7,73 \%$ & $7,17 \%$ \\
\hline $29 / 07 / 2019$ & 29,86 & 6,75 & 0,66 & 31,04 & 7,28 & 0,62 & $3,95 \%$ & $7,20 \%$ & $7,84 \%$ & $23 / 09 / 2019$ & 37,02 & 6,66 & 0,51 & 35,75 & 6,11 & 0,56 & $3,43 \%$ & $9,04 \%$ & $8,21 \%$ \\
\hline $30 / 07 / 2019$ & 29,89 & 6,78 & 0,66 & 31,00 & 7,28 & 0,61 & $3,73 \%$ & $6,85 \%$ & $7,45 \%$ & $01 / 10 / 2019$ & 38,25 & 6,72 & 0,50 & 36,59 & 6,10 & 0,55 & $4,32 \%$ & $10,35 \%$ & $9,21 \%$ \\
\hline $31 / 07 / 2019$ & 30,10 & 6,79 & 0,66 & 31,12 & 7,26 & 0,61 & $3,41 \%$ & $6,33 \%$ & $6,86 \%$ & 02/10/2019 & 40,49 & 6,73 & 0,49 & 38,45 & 6,01 & 0,55 & $5,03 \%$ & $11,95 \%$ & $10,68 \%$ \\
\hline $01 / 08 / 2019$ & 30,39 & 6,75 & 0,65 & 31,43 & 7,21 & 0,61 & $3,42 \%$ & $6,42 \%$ & $6,87 \%$ & $03 / 10 / 2019$ & 40,86 & 6,51 & 0,49 & 38,97 & 5,85 & 0,54 & $4,61 \%$ & $11,20 \%$ & $10,12 \%$ \\
\hline 02/08/2019 & 30,67 & 6,68 & 0,65 & 31,73 & 7,15 & 0,61 & $3,47 \%$ & $6,56 \%$ & $7,03 \%$ & $04 / 10 / 2019$ & 41,09 & 6,85 & 0,49 & 38,84 & 6,03 & 0,55 & $5,48 \%$ & $13,55 \%$ & $11,94 \%$ \\
\hline 03/08/2019 & 30,80 & 6,74 & 0,65 & 31,72 & 7,15 & 0,61 & $2,97 \%$ & $5,71 \%$ & $6,07 \%$ & 05/10/2019 & 41,62 & 6,84 & 0,49 & 39,42 & 6,05 & 0,55 & $5,30 \%$ & $12,92 \%$ & $11,46 \%$ \\
\hline 04/08/2019 & 30,74 & 6,81 & 0,64 & 31,54 & 7,16 & 0,61 & $2,59 \%$ & $4,94 \%$ & $5,21 \%$ & 06/10/2019 & 41,91 & 6,88 & 0,49 & 39,62 & 6,06 & 0,55 & $5,46 \%$ & $13,56 \%$ & $11,95 \%$ \\
\hline 05/08/2019 & 30,21 & 6,89 & 0,63 & 30,81 & 7,17 & 0,61 & $1,99 \%$ & $3,80 \%$ & $3,97 \%$ & $07 / 10 / 2019$ & 41,93 & 6,96 & 0,48 & 39,56 & 6,09 & 0,55 & $5,65 \%$ & $14,29 \%$ & $12,49 \%$ \\
\hline $06 / 08 / 2019$ & 29,92 & 6,84 & 0,63 & 30,53 & 7,12 & 0,61 & $2,06 \%$ & $3,89 \%$ & $4,08 \%$ & $15 / 10 / 2019$ & 43,06 & 7,14 & 0,47 & 40,32 & 6,12 & 0,55 & & & $14,28 \%$ \\
\hline $07 / 08 / 2019$ & 30,01 & 6,85 & 0,63 & 30,52 & 7,09 & 0,61 & $1,71 \%$ & $3,25 \%$ & $3,39 \%$ & $16 / 10 / 2019$ & 41,93 & 7,09 & 0,50 & 39,79 & 6,28 & 0,56 & $5,10 \%$ & $12,89 \%$ & $11,43 \%$ \\
\hline 08/08/2019 & 30,42 & 6,63 & 0,62 & 31,06 & 6,93 & 0,60 & $2,08 \%$ & $3,95 \%$ & $4,66 \%$ & $17 / 10 / 2019$ & 43,74 & 7,25 & 0,47 & 40,80 & 6,14 & 0,55 & $6,72 \%$ & $18,11 \%$ & $15,36 \%$ \\
\hline 09/08/2019 & 31,15 & 6,75 & 0,62 & 31,75 & 7,01 & 0,60 & $1,94 \%$ & $3,74 \%$ & $3,89 \%$ & $18 / 10 / 2019$ & 43,65 & 7,35 & 0,46 & 40,55 & 6,16 & 0,55 & $7,10 \%$ & $19,38 \%$ & $16,24 \%$ \\
\hline $10 / 08 / 2019$ & 31,97 & 6,64 & 0,62 & 32,63 & 6,92 & 0,60 & $2,07 \%$ & $4,08 \%$ & $4,26 \%$ & $19 / 10 / 2019$ & 43,68 & 7,37 & 0,46 & 40,55 & 6,17 & 0,55 & $7,16 \%$ & $19,53 \%$ & $16,35 \%$ \\
\hline $11 / 08 / 2019$ & 32,34 & 6,63 & 0,62 & 32,91 & 6,88 & 0,60 & $1,76 \%$ & $3,59 \%$ & $3,74 \%$ & 20/10/2019 & 43,25 & 7,83 & 0,46 & 39,71 & 6,40 & 0,56 & $8,19 \%$ & $22,24 \%$ & $18,20 \%$ \\
\hline $12 / 08 / 2019$ & 32,83 & 6,56 & 0,62 & 33,47 & 6,83 & 0,59 & $1,94 \%$ & $3,94 \%$ & $4,19 \%$ & $21 / 10 / 2019$ & 42,69 & 7,93 & 0,46 & 39,06 & 6,46 & 0,57 & $8,50 \%$ & $22,84 \%$ & $18,49 \%$ \\
\hline $22 / 08 / 2019$ & 32,44 & 6,20 & 0,59 & 32,87 & 6,38 & 0,58 & $1,31 \%$ & $2,68 \%$ & $2,76 \%$ & $23 / 10 / 2019$ & 36,14 & 6,70 & 0,58 & 35,95 & 6,84 & 0,58 & $0,53 \%$ & $0,21 \%$ & $2,11 \%$ \\
\hline $23 / 08 / 2019$ & 32,23 & 6,39 & 0,59 & 32,44 & 6,48 & 0,58 & $0,66 \%$ & $1,35 \%$ & $1,40 \%$ & $24 / 10 / 2019$ & 33,45 & 6,61 & 0,65 & 34,57 & 7,11 & 0,62 & $3,34 \%$ & $5,61 \%$ & $7,61 \%$ \\
\hline
\end{tabular}


Tabela 25. Extrato de resultados de medições (out/2019 a jan/2020)

\begin{tabular}{|c|c|c|c|c|c|c|c|c|c|c|c|c|c|c|c|c|c|c|c|}
\hline \multirow[b]{2}{*}{ Data } & \multicolumn{3}{|c|}{ Uso da Tar medida } & \multicolumn{3}{|c|}{ Código } & \multicolumn{3}{|c|}{ Diferença percentual } & \multirow[b]{2}{*}{ Data } & \multicolumn{3}{|c|}{ Uso da Tar medida } & \multicolumn{3}{|c|}{ Código } & \multicolumn{3}{|c|}{ Diferença percentual } \\
\hline & Tout & $\dot{\mathbf{m}}$ & $\varepsilon$ & Tout & $\dot{\mathbf{m}}$ & $\varepsilon$ & Tar_out & $\varepsilon$ & $\dot{\mathbf{m}}$ & & Tout & $\dot{\mathbf{m}}$ & $\varepsilon$ & Tout & $\dot{\mathbf{m}}$ & $\varepsilon$ & Tar_out & $\varepsilon$ & $\dot{\mathbf{m}}$ \\
\hline (dd/mm/aa) & $\left({ }^{\circ} \mathrm{C}\right)$ & $(\mathrm{kg} / \mathrm{s})$ & - & $\left({ }^{\circ} \mathrm{C}\right)$ & $(\mathrm{kg} / \mathrm{s})$ & - & $(\%)$ & $(\%)$ & $(\%)$ & (dd/mm/aa) & $\left({ }^{\circ} \mathrm{C}\right)$ & $(\mathrm{kg} / \mathrm{s})$ & - & $\left({ }^{\circ} \mathrm{C}\right)$ & $(\mathrm{kg} / \mathrm{s})$ & - & (\%) & $(\%)$ & $(\%)$ \\
\hline $25 / 10 / 2019$ & 34,86 & 7,02 & 0,66 & 35,92 & 7,53 & 0,63 & $3,04 \%$ & $4,88 \%$ & $7,26 \%$ & $06 / 12 / 2019$ & 34,35 & 7,27 & 0,63 & 34,55 & 7,49 & 0,63 & $0,6 \%$ & $1,2 \%$ & $3,2 \%$ \\
\hline $26 / 10 / 2019$ & 35,46 & 6,77 & 0,66 & 36,78 & 7,21 & 0,62 & $3,74 \%$ & $6,01 \%$ & $6,52 \%$ & $07 / 12 / 2019$ & 34,58 & 7,76 & 0,63 & 34,23 & 7,61 & 0,64 & $1,0 \%$ & $2,1 \%$ & $1,9 \%$ \\
\hline $27 / 10 / 2019$ & 36,03 & 6,56 & 0,66 & 37,52 & 7,05 & 0,62 & $4,14 \%$ & $6,75 \%$ & $7,37 \%$ & 08/12/2019 & 34,52 & 8,00 & 0,62 & 33,99 & 7,76 & 0,64 & $1,5 \%$ & $3,2 \%$ & $3,0 \%$ \\
\hline 28/10/2019 & 36,31 & 6,64 & 0,67 & 37,71 & 7,51 & 0,63 & $3,86 \%$ & $6,31 \%$ & $13,07 \%$ & 09/12/2019 & 34,71 & 7,96 & 0,62 & 34,18 & 7,72 & 0,64 & $1,5 \%$ & $3,2 \%$ & $3,0 \%$ \\
\hline $29 / 10 / 2019$ & 36,58 & 6,77 & 0,67 & 37,90 & 7,53 & 0,63 & $3,61 \%$ & $6,03 \%$ & $11,22 \%$ & $10 / 12 / 2019$ & 34,61 & 7,98 & 0,62 & 34,03 & 7,72 & 0,64 & $1,7 \%$ & $3,5 \%$ & $3,3 \%$ \\
\hline $30 / 10 / 2019$ & 36,91 & 6,62 & 0,67 & 38,45 & 7,33 & 0,62 & $4,18 \%$ & $7,10 \%$ & $10,65 \%$ & $11 / 12 / 2019$ & 34,59 & 8,00 & 0,62 & 33,96 & 7,71 & 0,64 & $1,8 \%$ & $3,9 \%$ & $3,6 \%$ \\
\hline $31 / 10 / 2019$ & 36,49 & 6,43 & 0,67 & 38,20 & 7,02 & 0,61 & $4,67 \%$ & $7,91 \%$ & $9,12 \%$ & $12 / 12 / 2019$ & 34,73 & 7,93 & 0,62 & 34,13 & 7,65 & 0,64 & $1,7 \%$ & $3,7 \%$ & $3,5 \%$ \\
\hline $01 / 11 / 2019$ & 36,68 & 6,84 & 0,67 & 38,08 & 7,39 & 0,63 & $3,79 \%$ & $6,75 \%$ & $8,01 \%$ & $13 / 12 / 2019$ & 34,19 & 7,94 & 0,62 & 33,52 & 7,63 & 0,64 & $2,0 \%$ & $4,2 \%$ & $3,9 \%$ \\
\hline $02 / 11 / 2019$ & 36,22 & 6,71 & 0,67 & 37,54 & 7,19 & 0,63 & $3,62 \%$ & $6,55 \%$ & $7,15 \%$ & $14 / 12 / 2019$ & 33,82 & 8,01 & 0,61 & 33,01 & 7,63 & 0,64 & $2,4 \%$ & $5,0 \%$ & $4,7 \%$ \\
\hline 03/11/2019 & 35,20 & 6,51 & 0,67 & 36,60 & 7,05 & 0,62 & $3,97 \%$ & $7,61 \%$ & $8,22 \%$ & $15 / 12 / 2019$ & 33,83 & 7,92 & 0,61 & 33,12 & 7,60 & 0,64 & $2,1 \%$ & $4,3 \%$ & $4,1 \%$ \\
\hline $04 / 11 / 2019$ & 35,30 & 6,70 & 0,68 & 36,57 & 7,51 & 0,63 & $3,59 \%$ & $6,91 \%$ & $12,09 \%$ & $16 / 12 / 2019$ & 35,13 & 7,85 & 0,61 & 35,01 & 7,80 & 0,62 & $0,4 \%$ & $0,7 \%$ & $0,6 \%$ \\
\hline $05 / 11 / 2019$ & 35,86 & 6,70 & 0,67 & 37,14 & 7,21 & 0,63 & $3,57 \%$ & $7,01 \%$ & $7,64 \%$ & $19 / 12 / 2019$ & 36,26 & 7,88 & 0,61 & 35,95 & 7,77 & 0,62 & $0,9 \%$ & $1,6 \%$ & $1,5 \%$ \\
\hline 06/11/2019 & 36,17 & 6,72 & 0,67 & 37,33 & 7,19 & 0,63 & $3,22 \%$ & $6,46 \%$ & $7,01 \%$ & 20/12/2019 & 34,50 & 7,93 & 0,61 & 33,79 & 7,61 & 0,64 & $2,1 \%$ & $4,3 \%$ & $4,0 \%$ \\
\hline $07 / 11 / 2019$ & 34,66 & 6,49 & 0,67 & 35,81 & 7,05 & 0,62 & $3,32 \%$ & $7,03 \%$ & $8,61 \%$ & $21 / 12 / 2019$ & 34,56 & 7,95 & 0,61 & 33,85 & 7,63 & 0,64 & $2,1 \%$ & $4,3 \%$ & $4,0 \%$ \\
\hline 08/11/2019 & 33,48 & 7,34 & 0,66 & 34,06 & 7,60 & 0,64 & $1,72 \%$ & $3,38 \%$ & $3,59 \%$ & $22 / 12 / 2019$ & 34,55 & 7,90 & 0,61 & 33,84 & 7,58 & 0,64 & $2,0 \%$ & $4,3 \%$ & $4,0 \%$ \\
\hline $09 / 11 / 2019$ & 32,58 & 7,29 & 0,66 & 33,10 & 7,53 & 0,64 & $1,60 \%$ & $3,06 \%$ & $3,26 \%$ & $23 / 12 / 2019$ & 34,22 & 7,93 & 0,61 & 33,45 & 7,58 & 0,64 & $2,2 \%$ & $4,8 \%$ & $4,5 \%$ \\
\hline $10 / 11 / 2019$ & 32,34 & 7,28 & 0,66 & 32,84 & 7,50 & 0,64 & $1,53 \%$ & $2,93 \%$ & $3,11 \%$ & $24 / 12 / 2019$ & 34,18 & 7,91 & 0,61 & 33,41 & 7,55 & 0,64 & $2,3 \%$ & $4,8 \%$ & $4,5 \%$ \\
\hline $11 / 11 / 2019$ & 32,47 & 7,13 & 0,66 & 33,03 & 7,52 & 0,64 & $1,74 \%$ & $3,41 \%$ & $5,52 \%$ & $25 / 12 / 2019$ & 34,39 & 7,95 & 0,61 & 33,56 & 7,57 & 0,64 & $2,4 \%$ & $5,0 \%$ & $4,7 \%$ \\
\hline $12 / 11 / 2019$ & 32,18 & 7,41 & 0,66 & 32,67 & 7,64 & 0,64 & $1,52 \%$ & $2,92 \%$ & $3,10 \%$ & $26 / 12 / 2019$ & 35,22 & 7,92 & 0,61 & 34,44 & 7,56 & 0,64 & $2,2 \%$ & $4,9 \%$ & $4,6 \%$ \\
\hline $13 / 11 / 2019$ & 33,79 & 6,89 & 0,66 & 34,76 & 7,31 & 0,63 & $2,86 \%$ & $5,16 \%$ & $6,09 \%$ & $27 / 12 / 2019$ & 35,66 & 7,94 & 0,61 & 34,85 & 7,56 & 0,64 & $2,3 \%$ & $5,2 \%$ & $4,9 \%$ \\
\hline $14 / 11 / 2019$ & 34,86 & 7,04 & 0,66 & 35,76 & 7,40 & 0,63 & $2,60 \%$ & $4,70 \%$ & $5,06 \%$ & $28 / 12 / 2019$ & 35,56 & 8,01 & 0,60 & 34,69 & 7,59 & 0,64 & $2,4 \%$ & $5,6 \%$ & $5,2 \%$ \\
\hline $15 / 11 / 2019$ & 34,15 & 7,28 & 0,66 & 34,82 & 7,57 & 0,64 & $1,95 \%$ & $3,66 \%$ & $3,91 \%$ & $29 / 12 / 2019$ & 35,84 & 7,85 & 0,61 & 35,10 & 7,50 & 0,63 & $2,1 \%$ & $4,8 \%$ & $4,5 \%$ \\
\hline $16 / 11 / 2019$ & 34,30 & 7,30 & 0,66 & 34,94 & 7,57 & 0,64 & $1,87 \%$ & $3,50 \%$ & $3,75 \%$ & $30 / 12 / 2019$ & 34,58 & 7,76 & 0,63 & 34,23 & 7,61 & 0,64 & $1,0 \%$ & $2,1 \%$ & $1,9 \%$ \\
\hline $17 / 11 / 2019$ & 34,73 & 7,28 & 0,66 & 35,32 & 7,53 & 0,64 & $1,72 \%$ & $3,16 \%$ & $3,41 \%$ & 03/01/2020 & 35,93 & 7,53 & 0,61 & 35,52 & 7,34 & 0,63 & $1,1 \%$ & $2,8 \%$ & $2,5 \%$ \\
\hline $18 / 11 / 2019$ & 33,19 & 7,17 & 0,66 & 33,82 & 7,62 & 0,64 & $1,91 \%$ & $3,58 \%$ & $6,36 \%$ & $05 / 01 / 2020$ & 39,32 & 7,50 & 0,60 & 38,55 & 7,22 & 0,62 & $2,0 \%$ & $4,0 \%$ & $3,7 \%$ \\
\hline $26 / 11 / 2019$ & 32,60 & 7,45 & 0,66 & 33,12 & 7,69 & 0,64 & $1,60 \%$ & $3,01 \%$ & $3,19 \%$ & 06/01/2020 & 38,95 & 7,10 & 0,59 & 38,48 & 7,00 & 0,61 & $1,2 \%$ & $2,7 \%$ & $1,4 \%$ \\
\hline $28 / 11 / 2019$ & 33,22 & 7,50 & 0,65 & 33,49 & 7,62 & 0,64 & $0,82 \%$ & $1,61 \%$ & $1,66 \%$ & $08 / 01 / 2020$ & 39,82 & 7,52 & 0,58 & 38,79 & 7,14 & 0,62 & $2,6 \%$ & $5,4 \%$ & $5,0 \%$ \\
\hline $29 / 11 / 2019$ & 33,69 & 7,47 & 0,65 & 34,02 & 7,61 & 0,64 & $0,98 \%$ & $1,91 \%$ & $1,96 \%$ & 09/01/2020 & 40,27 & 7,60 & 0,58 & 39,11 & 7,18 & 0,62 & $2,9 \%$ & $6,0 \%$ & $5,5 \%$ \\
\hline $30 / 11 / 2019$ & 33,91 & 7,45 & 0,65 & 34,23 & 7,59 & 0,64 & $0,96 \%$ & $1,86 \%$ & $1,89 \%$ & $10 / 01 / 2020$ & 40,78 & 7,71 & 0,58 & 39,45 & 7,23 & 0,62 & $3,3 \%$ & $6,8 \%$ & $6,3 \%$ \\
\hline $01 / 12 / 2019$ & 33,72 & 7,49 & 0,65 & 33,94 & 7,59 & 0,64 & $0,64 \%$ & $1,29 \%$ & $1,32 \%$ & $11 / 01 / 2020$ & 40,95 & 7,81 & 0,57 & 39,44 & 7,25 & 0,62 & $3,7 \%$ & $7,9 \%$ & $7,2 \%$ \\
\hline $02 / 12 / 2019$ & 34,13 & 7,49 & 0,64 & 34,33 & 7,59 & 0,64 & $0,59 \%$ & $1,20 \%$ & $1,32 \%$ & $12 / 01 / 2020$ & 41,18 & 7,88 & 0,57 & 39,55 & 7,27 & 0,62 & $3,9 \%$ & $8,5 \%$ & $7,7 \%$ \\
\hline
\end{tabular}


Tabela 26. Extrato de resultados de medições (jan a abr/2020)

\begin{tabular}{|c|c|c|c|c|c|c|c|c|c|c|c|c|c|c|c|c|c|c|c|}
\hline \multirow[b]{2}{*}{ Data } & \multicolumn{3}{|c|}{ Uso da Tar medida } & \multicolumn{3}{|c|}{ Código } & \multicolumn{3}{|c|}{ Diferença percentual } & \multirow[b]{2}{*}{ Data } & \multicolumn{3}{|c|}{ Uso da Tar medida } & \multicolumn{3}{|c|}{ Código } & \multicolumn{3}{|c|}{ Diferença percentual } \\
\hline & Tout & $\dot{\mathbf{m}}$ & $\varepsilon$ & Tout & $\dot{\mathbf{m}}$ & $\varepsilon$ & Tar_out & $\varepsilon$ & $\dot{\mathbf{m}}$ & & Tout & $\dot{\mathbf{m}}$ & $\varepsilon$ & TоUт & $\dot{\mathbf{m}}$ & $\varepsilon$ & Tar_out & $\varepsilon$ & $\dot{\mathbf{m}}$ \\
\hline (dd/mm/aa) & $\left({ }^{\circ} \mathrm{C}\right)$ & $(\mathrm{kg} / \mathrm{s})$ & - & $\left({ }^{\circ} \mathrm{C}\right)$ & $(\mathrm{kg} / \mathrm{s})$ & - & (\%) & $(\%)$ & (\%) & (dd/mm/aa) & $\left({ }^{\circ} \mathrm{C}\right)$ & $(\mathrm{kg} / \mathrm{s})$ & - & $\left({ }^{\circ} \mathrm{C}\right)$ & $(\mathrm{kg} / \mathrm{s})$ & - & (\%) & (\%) & (\%) \\
\hline $13 / 01 / 2020$ & 41,14 & 7,77 & 0,57 & 39,55 & 7,18 & 0,61 & $3,86 \%$ & $8,38 \%$ & $7,61 \%$ & $14 / 02 / 2020$ & 38,72 & 8,10 & 0,60 & 41,49 & 9,30 & 0,52 & $7,16 \%$ & $12,97 \%$ & $14,82 \%$ \\
\hline $22 / 01 / 2020$ & 40,84 & 7,70 & 0,56 & 39,21 & 7,09 & 0,61 & $3,99 \%$ & $8,61 \%$ & $7,83 \%$ & $16 / 02 / 2020$ & 39,47 & 7,70 & 0,59 & 38,96 & 7,49 & 0,60 & $1,27 \%$ & $2,57 \%$ & $2,73 \%$ \\
\hline $23 / 01 / 2020$ & 40,35 & 8,09 & 0,55 & 38,17 & 7,25 & 0,61 & $5,40 \%$ & $11,74 \%$ & $10,38 \%$ & $17 / 02 / 2020$ & 37,55 & 8,02 & 0,59 & 36,85 & 7,68 & 0,61 & $1,87 \%$ & $4,31 \%$ & $4,15 \%$ \\
\hline $24 / 01 / 2020$ & 40,41 & 8,04 & 0,55 & 38,28 & 7,22 & 0,61 & $5,28 \%$ & $11,54 \%$ & $10,22 \%$ & $18 / 02 / 2020$ & 38,15 & 7,88 & 0,59 & 37,56 & 7,62 & 0,61 & $1,54 \%$ & $3,44 \%$ & $3,37 \%$ \\
\hline $25 / 01 / 2020$ & 40,39 & 8,07 & 0,55 & 38,22 & 7,24 & 0,61 & $5,36 \%$ & $11,72 \%$ & $10,36 \%$ & $19 / 02 / 2020$ & 37,26 & 6,35 & 0,55 & 37,06 & 6,91 & 0,58 & $0,54 \%$ & $4,45 \%$ & $8,93 \%$ \\
\hline $26 / 01 / 2020$ & 40,41 & 8,06 & 0,55 & 38,22 & 7,22 & 0,61 & $5,43 \%$ & $11,78 \%$ & $10,42 \%$ & 20/02/2020 & 38,27 & 7,77 & 0,59 & 37,78 & 7,57 & 0,61 & $1,26 \%$ & $2,82 \%$ & $2,64 \%$ \\
\hline $27 / 01 / 2020$ & 40,81 & 7,90 & 0,55 & 38,68 & 7,11 & 0,61 & $5,21 \%$ & $11,29 \%$ & $10,02 \%$ & $21 / 02 / 2020$ & 37,96 & 7,93 & 0,59 & 37,31 & 7,63 & 0,61 & $1,71 \%$ & $3,95 \%$ & $3,83 \%$ \\
\hline $30 / 01 / 2020$ & 40,74 & 7,62 & 0,54 & 38,94 & 6,89 & 0,60 & $4,43 \%$ & $10,61 \%$ & $9,60 \%$ & 22/02/2020 & 37,71 & 8,07 & 0,59 & 36,96 & 7,71 & 0,61 & $1,97 \%$ & $4,53 \%$ & $4,36 \%$ \\
\hline $31 / 01 / 2020$ & 37,62 & 7,21 & 0,62 & 37,76 & 7,44 & 0,62 & $0,37 \%$ & $0,93 \%$ & $3,15 \%$ & 23/02/2020 & 37,26 & 8,12 & 0,59 & 36,48 & 7,75 & 0,61 & $2,10 \%$ & $4,75 \%$ & $4,57 \%$ \\
\hline 01/02/2020 & 36,09 & 7,28 & 0,69 & 37,69 & 7,99 & 0,63 & $4,45 \%$ & $8,89 \%$ & $9,87 \%$ & $24 / 02 / 2020$ & 36,88 & 7,82 & 0,59 & 36,28 & 7,54 & 0,61 & $1,62 \%$ & $3,62 \%$ & $3,53 \%$ \\
\hline 02/02/2020 & 36,33 & 7,25 & 0,69 & 38,01 & 7,98 & 0,63 & $4,63 \%$ & $9,14 \%$ & $10,18 \%$ & 09/03/2020 & 38,95 & 7,51 & 0,63 & 36,56 & 7,44 & 0,70 & $6,13 \%$ & $9,93 \%$ & $0,95 \%$ \\
\hline 03/02/2020 & 36,25 & 6,32 & 0,66 & 37,75 & 7,47 & 0,61 & $4,14 \%$ & $7,51 \%$ & $18,27 \%$ & $27 / 03 / 2020$ & 49,50 & 8,86 & 0,50 & 40,97 & 6,57 & 0,67 & $17,23 \%$ & $34,82 \%$ & $25,82 \%$ \\
\hline 04/02/2020 & 36,01 & 7,22 & 0,69 & 37,76 & 7,94 & 0,63 & $4,84 \%$ & $8,98 \%$ & $9,98 \%$ & 28/03/2020 & 50,40 & 9,04 & 0,49 & 41,46 & 6,62 & 0,67 & $17,74 \%$ & $36,56 \%$ & $26,78 \%$ \\
\hline 05/02/2020 & 34,94 & 7,40 & 0,68 & 38,88 & 9,38 & 0,54 & $11,26 \%$ & $20,57 \%$ & $26,75 \%$ & 29/03/2020 & 50,66 & 9,11 & 0,49 & 41,59 & 6,63 & 0,67 & $17,91 \%$ & $37,31 \%$ & $27,18 \%$ \\
\hline 06/02/2020 & 35,88 & 7,88 & 0,67 & 35,06 & 7,62 & 0,69 & $2,28 \%$ & $3,55 \%$ & $3,27 \%$ & $30 / 03 / 2020$ & 50,70 & 9,23 & 0,49 & 41,54 & 6,70 & 0,67 & $18,07 \%$ & $38,17 \%$ & $27,43 \%$ \\
\hline 07/02/2020 & 36,43 & 7,89 & 0,66 & 35,21 & 7,51 & 0,69 & $3,37 \%$ & $5,33 \%$ & $4,88 \%$ & $31 / 03 / 2020$ & 50,65 & 9,15 & 0,49 & 41,57 & 6,65 & 0,67 & $17,93 \%$ & $37,94 \%$ & $27,31 \%$ \\
\hline 08/02/2020 & 36,84 & 7,74 & 0,65 & 35,50 & 7,32 & 0,69 & $3,63 \%$ & $5,86 \%$ & $5,35 \%$ & 02/04/2020 & 43,90 & 8,50 & 0,61 & 40,71 & 8,57 & 0,67 & $7,27 \%$ & $10,68 \%$ & $0,81 \%$ \\
\hline 09/02/2020 & 36,48 & 7,61 & 0,64 & 34,94 & 7,15 & 0,68 & $4,23 \%$ & $6,74 \%$ & $6,14 \%$ & $03 / 04 / 2020$ & 40,61 & 8,59 & 0,67 & 37,64 & 7,84 & 0,73 & $7,32 \%$ & $9,79 \%$ & $8,71 \%$ \\
\hline $10 / 02 / 2020$ & 39,12 & 7,34 & 0,64 & 37,74 & 6,93 & 0,68 & $3,52 \%$ & $6,04 \%$ & $5,50 \%$ & 04/04/2020 & 40,53 & 8,85 & 0,66 & 37,30 & 8,01 & 0,73 & $7,97 \%$ & $10,72 \%$ & $9,48 \%$ \\
\hline $11 / 02 / 2020$ & 39,36 & 7,43 & 0,63 & 39,93 & 7,63 & 0,61 & $1,43 \%$ & $2,53 \%$ & $2,78 \%$ & 05/04/2020 & 40,48 & 8,60 & 0,66 & 37,40 & 7,82 & 0,73 & $7,62 \%$ & $10,25 \%$ & $9,08 \%$ \\
\hline $12 / 02 / 2020$ & 39,02 & 7,64 & 0,62 & 39,15 & 7,70 & 0,61 & $0,34 \%$ & $0,60 \%$ & $0,80 \%$ & 06/04/2020 & 39,04 & 8,22 & 0,66 & 36,60 & 7,52 & 0,73 & $6,27 \%$ & $9,35 \%$ & $8,48 \%$ \\
\hline $13 / 02 / 2020$ & 38,57 & 7,98 & 0,61 & 41,71 & 9,32 & 0,52 & $8,13 \%$ & $14,45 \%$ & $16,80 \%$ & & & & & & & & & & \\
\hline
\end{tabular}


Apêndice C: Cálculo da efetividade pela abordagem matricial $\varepsilon$-NTU

Tabela 27. Extrato de resultados de medições (05/jul a 11/ago/2019)

\begin{tabular}{|c|c|c|c|c|c|c|}
\hline \multirow{2}{*}{$\begin{array}{c}\text { Data } \\
\text { (dd/mm/aa) }\end{array}$} & \multicolumn{3}{|c|}{ Cálculo da efetividade $(\varepsilon)$ vía } & \multicolumn{3}{|c|}{ Diferença percentual } \\
\hline & Alternativa 1 & Alternativa 2 & Alternativa 3 & Alternativa 1 / Alternativa 2 & Alternativa 1 / Alternativa 2 & Alternativa 1 / Alternativa 2 \\
\hline 05/07/2019 & 0,48 & 0,56 & 0,56 & $14,2 \%$ & $14,3 \%$ & $0,1 \%$ \\
\hline 06/07/2019 & 0,46 & 0,56 & 0,56 & $17,8 \%$ & $17,8 \%$ & $0,0 \%$ \\
\hline 07/07/2019 & 0,45 & 0,55 & 0,56 & $18,3 \%$ & $18,4 \%$ & $0,2 \%$ \\
\hline 08/07/2019 & 0,45 & 0,56 & 0,56 & $19,5 \%$ & $19,4 \%$ & $0,1 \%$ \\
\hline 09/07/2019 & 0,47 & 0,57 & 0,57 & $16,1 \%$ & $16,2 \%$ & $0,1 \%$ \\
\hline 10/07/2019 & 0,54 & 0,57 & 0,57 & $6,5 \%$ & $6,2 \%$ & $0,3 \%$ \\
\hline $12 / 07 / 2019$ & 0,68 & 0,61 & 0,61 & $11,2 \%$ & $11,1 \%$ & $0,0 \%$ \\
\hline $13 / 07 / 2019$ & 0,68 & 0,61 & 0,62 & $10,3 \%$ & $10,1 \%$ & $0,2 \%$ \\
\hline $23 / 07 / 2019$ & 0,67 & 0,62 & 0,62 & $8,5 \%$ & $8,3 \%$ & $0,2 \%$ \\
\hline $24 / 07 / 2019$ & 0,67 & 0,62 & 0,62 & $8,7 \%$ & $8,9 \%$ & $0,2 \%$ \\
\hline 25/07/2019 & 0,67 & 0,62 & 0,62 & $8,7 \%$ & $8,5 \%$ & $0,1 \%$ \\
\hline $26 / 07 / 2019$ & 0,67 & 0,62 & 0,62 & $8,6 \%$ & $8,3 \%$ & $0,3 \%$ \\
\hline $27 / 07 / 2019$ & 0,67 & 0,62 & 0,62 & $8,5 \%$ & $8,3 \%$ & $0,2 \%$ \\
\hline 28/07/2019 & 0,67 & 0,62 & 0,62 & $8,4 \%$ & $8,3 \%$ & $0,0 \%$ \\
\hline 29/07/2019 & 0,66 & 0,62 & 0,62 & $7,8 \%$ & $7,7 \%$ & $0,1 \%$ \\
\hline $30 / 07 / 2019$ & 0,66 & 0,61 & 0,61 & $7,4 \%$ & $7,4 \%$ & $0,1 \%$ \\
\hline $31 / 07 / 2019$ & 0,66 & 0,61 & 0,61 & $6,8 \%$ & $6,7 \%$ & $0,1 \%$ \\
\hline 01/08/2019 & 0,65 & 0,61 & 0,61 & $6,9 \%$ & $7,0 \%$ & $0,1 \%$ \\
\hline 02/08/2019 & 0,65 & 0,61 & 0,61 & $7,0 \%$ & $7,3 \%$ & $0,3 \%$ \\
\hline 03/08/2019 & 0,65 & 0,61 & 0,61 & $6,1 \%$ & $6,0 \%$ & $0,1 \%$ \\
\hline 04/08/2019 & 0,64 & 0,61 & 0,61 & $5,2 \%$ & $5,2 \%$ & $0,0 \%$ \\
\hline 05/08/2019 & 0,63 & 0,61 & 0,61 & $3,9 \%$ & $3,9 \%$ & $0,0 \%$ \\
\hline 06/08/2019 & 0,63 & 0,61 & 0,61 & $4,0 \%$ & $3,9 \%$ & $0,2 \%$ \\
\hline 07/08/2019 & 0,63 & 0,61 & 0,61 & $3,4 \%$ & $3,1 \%$ & $0,2 \%$ \\
\hline 08/08/2019 & 0,62 & 0,60 & 0,60 & $4,1 \%$ & $3,9 \%$ & $0,2 \%$ \\
\hline 09/08/2019 & 0,62 & 0,60 & 0,60 & $3,9 \%$ & $3,9 \%$ & $0,0 \%$ \\
\hline 10/08/2019 & 0,62 & 0,60 & 0,60 & $4,2 \%$ & $4,5 \%$ & $0,2 \%$ \\
\hline $11 / 08 / 2019$ & 0,62 & 0,60 & 0,59 & $3,7 \%$ & $4,1 \%$ & $0,4 \%$ \\
\hline
\end{tabular}


Tabela 28. Extrato de resultados de medições (12/ago a 17/out/2019)

\begin{tabular}{|c|c|c|c|c|c|c|}
\hline \multirow{2}{*}{$\begin{array}{c}\text { Data } \\
\text { (dd/mm/aa) }\end{array}$} & \multicolumn{3}{|c|}{ Cálculo da efetividade $(\varepsilon)$ vía } & \multicolumn{3}{|c|}{ Diferença percentual } \\
\hline & Alternativa 1 & Alternativa 2 & Alternativa 3 & Alternativa 1 / Alternativa 2 & Alternativa 1 / Alternativa 2 & Alternativa 1 / Alternativa 2 \\
\hline $12 / 08 / 2019$ & 0,62 & 0,59 & 0,59 & $4,1 \%$ & $4,4 \%$ & $0,3 \%$ \\
\hline $22 / 08 / 2019$ & 0,59 & 0,58 & 0,58 & $2,7 \%$ & $2,7 \%$ & $0,0 \%$ \\
\hline 23/08/2019 & 0,59 & 0,58 & 0,58 & $1,4 \%$ & $1,1 \%$ & $0,2 \%$ \\
\hline $24 / 08 / 2019$ & 0,59 & 0,58 & 0,58 & $1,4 \%$ & $1,4 \%$ & $0,0 \%$ \\
\hline $10 / 09 / 2019$ & 0,55 & 0,57 & 0,57 & $3,7 \%$ & $3,6 \%$ & $0,1 \%$ \\
\hline $11 / 09 / 2019$ & 0,55 & 0,57 & 0,57 & $4,1 \%$ & $4,2 \%$ & $0,0 \%$ \\
\hline $12 / 09 / 2019$ & 0,54 & 0,57 & 0,57 & $4,4 \%$ & $4,4 \%$ & $0,0 \%$ \\
\hline $13 / 09 / 2019$ & 0,54 & 0,57 & 0,57 & $5,4 \%$ & $5,4 \%$ & $0,0 \%$ \\
\hline $14 / 09 / 2019$ & 0,54 & 0,57 & 0,57 & $5,7 \%$ & $5,8 \%$ & $0,1 \%$ \\
\hline $15 / 09 / 2019$ & 0,53 & 0,57 & 0,57 & $6,0 \%$ & $6,0 \%$ & $0,0 \%$ \\
\hline $16 / 09 / 2019$ & 0,53 & 0,57 & 0,57 & $7,2 \%$ & $7,0 \%$ & $0,1 \%$ \\
\hline $17 / 09 / 2019$ & 0,53 & 0,57 & 0,57 & $7,2 \%$ & $6,9 \%$ & $0,3 \%$ \\
\hline $18 / 09 / 2019$ & 0,53 & 0,56 & 0,56 & $4,5 \%$ & $4,5 \%$ & $0,0 \%$ \\
\hline $19 / 09 / 2019$ & 0,52 & 0,56 & 0,56 & $7,1 \%$ & $7,1 \%$ & $0,0 \%$ \\
\hline 20/09/2019 & 0,52 & 0,56 & 0,56 & $7,0 \%$ & $7,3 \%$ & $0,2 \%$ \\
\hline 21/09/2019 & 0,52 & 0,56 & 0,56 & $7,6 \%$ & $7,8 \%$ & $0,1 \%$ \\
\hline 22/09/2019 & 0,52 & 0,56 & 0,56 & $7,2 \%$ & $7,1 \%$ & $0,0 \%$ \\
\hline 23/09/2019 & 0,51 & 0,56 & 0,56 & $8,3 \%$ & $8,1 \%$ & $0,2 \%$ \\
\hline $01 / 10 / 2019$ & 0,50 & 0,55 & 0,55 & $9,4 \%$ & $9,3 \%$ & $0,1 \%$ \\
\hline 02/10/2019 & 0,49 & 0,55 & 0,55 & $10,7 \%$ & $10,5 \%$ & $0,2 \%$ \\
\hline 03/10/2019 & 0,49 & 0,54 & 0,54 & $10,1 \%$ & $10,2 \%$ & $0,1 \%$ \\
\hline $04 / 10 / 2019$ & 0,49 & 0,55 & 0,55 & $11,9 \%$ & $12,0 \%$ & $0,0 \%$ \\
\hline 05/10/2019 & 0,49 & 0,55 & 0,55 & $11,4 \%$ & $11,3 \%$ & $0,2 \%$ \\
\hline 06/10/2019 & 0,49 & 0,55 & 0,55 & $11,9 \%$ & $12,2 \%$ & $0,3 \%$ \\
\hline 07/10/2019 & 0,48 & 0,55 & 0,55 & $12,5 \%$ & $12,5 \%$ & $0,0 \%$ \\
\hline $15 / 10 / 2019$ & 0,47 & 0,55 & 0,55 & $14,3 \%$ & $14,1 \%$ & $0,2 \%$ \\
\hline $16 / 10 / 2019$ & 0,50 & 0,56 & 0,56 & $11,4 \%$ & $11,6 \%$ & $0,2 \%$ \\
\hline $17 / 10 / 2019$ & 0,47 & 0,55 & 0,55 & $15,3 \%$ & $15,2 \%$ & $0,1 \%$ \\
\hline
\end{tabular}


Tabela 29. Extrato de resultados de medições (18/out a 15/nov/2019)

\begin{tabular}{|c|c|c|c|c|c|c|}
\hline \multirow{2}{*}{$\frac{\text { Data }}{(\mathrm{dd} / \mathrm{mm} / \mathrm{aa})}$} & \multicolumn{3}{|c|}{ Cálculo da efetividade $(\varepsilon)$ vía } & \multicolumn{3}{|c|}{ Diferença percentual } \\
\hline & Alternativa 1 & Alternativa 2 & Alternativa 3 & Alternativa 1 / Alternativa 2 & $\begin{array}{c}\text { Alternativa } 1 \text { / Alternativa } \\
2\end{array}$ & Alternativa 1 / Alternativa 2 \\
\hline $18 / 10 / 2019$ & 0,46 & 0,55 & 0,55 & $16,2 \%$ & $16,3 \%$ & $0,1 \%$ \\
\hline 19/10/2019 & 0,46 & 0,55 & 0,55 & $16,3 \%$ & $16,3 \%$ & $0,1 \%$ \\
\hline 20/10/2019 & 0,46 & 0,56 & 0,56 & $18,2 \%$ & $18,2 \%$ & $0,1 \%$ \\
\hline $21 / 10 / 2019$ & 0,46 & 0,57 & 0,57 & $18,6 \%$ & $18,6 \%$ & $0,0 \%$ \\
\hline 23/10/2019 & 0,58 & 0,58 & 0,58 & $0,2 \%$ & $0,1 \%$ & $0,1 \%$ \\
\hline $24 / 10 / 2019$ & 0,65 & 0,62 & 0,62 & $5,9 \%$ & $6,0 \%$ & $0,0 \%$ \\
\hline $25 / 10 / 2019$ & 0,66 & 0,63 & 0,63 & $5,1 \%$ & $5,2 \%$ & $0,0 \%$ \\
\hline $26 / 10 / 2019$ & 0,66 & 0,62 & 0,62 & $6,4 \%$ & $6,3 \%$ & $0,1 \%$ \\
\hline $27 / 10 / 2019$ & 0,66 & 0,62 & 0,62 & $7,2 \%$ & $7,1 \%$ & $0,2 \%$ \\
\hline 28/10/2019 & 0,67 & 0,63 & 0,63 & $6,7 \%$ & $6,6 \%$ & $0,1 \%$ \\
\hline $29 / 10 / 2019$ & 0,67 & 0,63 & 0,63 & $6,4 \%$ & $6,4 \%$ & $0,0 \%$ \\
\hline $30 / 10 / 2019$ & 0,67 & 0,62 & 0,62 & $7,6 \%$ & $7,4 \%$ & $0,2 \%$ \\
\hline $31 / 10 / 2019$ & 0,67 & 0,61 & 0,61 & $8,6 \%$ & $8,7 \%$ & $0,1 \%$ \\
\hline $01 / 11 / 2019$ & 0,67 & 0,63 & 0,63 & $7,2 \%$ & $7,3 \%$ & $0,0 \%$ \\
\hline 02/11/2019 & 0,67 & 0,63 & 0,62 & $7,0 \%$ & $7,1 \%$ & $0,1 \%$ \\
\hline 03/11/2019 & 0,67 & 0,62 & 0,62 & $8,2 \%$ & $8,4 \%$ & $0,2 \%$ \\
\hline 04/11/2019 & 0,68 & 0,63 & 0,63 & $7,4 \%$ & $7,4 \%$ & $0,0 \%$ \\
\hline $05 / 11 / 2019$ & 0,67 & 0,63 & 0,63 & $7,5 \%$ & $7,6 \%$ & $0,1 \%$ \\
\hline 06/11/2019 & 0,67 & 0,63 & 0,63 & $6,9 \%$ & $7,0 \%$ & $0,1 \%$ \\
\hline $07 / 11 / 2019$ & 0,67 & 0,62 & 0,62 & $7,6 \%$ & $7,7 \%$ & $0,1 \%$ \\
\hline 08/11/2019 & 0,66 & 0,64 & 0,64 & $3,5 \%$ & $3,4 \%$ & $0,1 \%$ \\
\hline 09/11/2019 & 0,66 & 0,64 & 0,64 & $3,2 \%$ & $3,1 \%$ & $0,0 \%$ \\
\hline $10 / 11 / 2019$ & 0,66 & 0,64 & 0,64 & $3,0 \%$ & $2,9 \%$ & $0,1 \%$ \\
\hline $11 / 11 / 2019$ & 0,66 & 0,64 & 0,64 & $3,5 \%$ & $3,5 \%$ & $0,1 \%$ \\
\hline $12 / 11 / 2019$ & 0,66 & 0,64 & 0,64 & $3,0 \%$ & $3,0 \%$ & $0,0 \%$ \\
\hline $13 / 11 / 2019$ & 0,66 & 0,63 & 0,63 & $5,4 \%$ & $5,4 \%$ & $0,0 \%$ \\
\hline $14 / 11 / 2019$ & 0,66 & 0,63 & 0,63 & $4,9 \%$ & $5,1 \%$ & $0,2 \%$ \\
\hline $15 / 11 / 2019$ & 0,66 & 0,64 & 0,64 & $3,8 \%$ & $3,6 \%$ & $0,2 \%$ \\
\hline
\end{tabular}


Tabela 30. Extrato de resultados de medições (16/nov a 26/dez/2019)

\begin{tabular}{|c|c|c|c|c|c|c|}
\hline \multirow{2}{*}{$\begin{array}{c}\text { Data } \\
\text { (dd/mm/aa) }\end{array}$} & \multicolumn{3}{|c|}{ Cálculo da efetividade $(\varepsilon)$ vía } & \multicolumn{3}{|c|}{ Diferença percentual } \\
\hline & Alternativa 1 & Alternativa 2 & Alternativa 3 & Alternativa 1 / Alternativa 2 & Alternativa 1 / Alternativa 2 & Alternativa 1 / Alternativa 2 \\
\hline $16 / 11 / 2019$ & 0,66 & 0,64 & 0,64 & $3,6 \%$ & $3,8 \%$ & $0,2 \%$ \\
\hline $17 / 11 / 2019$ & 0,66 & 0,64 & 0,64 & $3,3 \%$ & $3,3 \%$ & $0,0 \%$ \\
\hline $18 / 11 / 2019$ & 0,66 & 0,64 & 0,64 & $3,7 \%$ & $3,6 \%$ & $0,1 \%$ \\
\hline $26 / 11 / 2019$ & 0,66 & 0,64 & 0,64 & $3,1 \%$ & $3,3 \%$ & $0,2 \%$ \\
\hline $28 / 11 / 2019$ & 0,65 & 0,64 & 0,64 & $1,6 \%$ & $1,8 \%$ & $0,1 \%$ \\
\hline $29 / 11 / 2019$ & 0,65 & 0,64 & 0,64 & $1,9 \%$ & $2,1 \%$ & $0,1 \%$ \\
\hline $30 / 11 / 2019$ & 0,65 & 0,64 & 0,64 & $1,9 \%$ & $1,7 \%$ & $0,2 \%$ \\
\hline $01 / 12 / 2019$ & 0,65 & 0,64 & 0,64 & $1,3 \%$ & $1,1 \%$ & $0,2 \%$ \\
\hline $02 / 12 / 2019$ & 0,64 & 0,64 & 0,64 & $1,2 \%$ & $1,5 \%$ & $0,3 \%$ \\
\hline $06 / 12 / 2019$ & 0,63 & 0,63 & 0,62 & $1,2 \%$ & $1,5 \%$ & $0,3 \%$ \\
\hline $07 / 12 / 2019$ & 0,63 & 0,64 & 0,64 & $2,0 \%$ & $2,0 \%$ & $0,0 \%$ \\
\hline 08/12/2019 & 0,62 & 0,64 & 0,65 & $3,1 \%$ & $3,2 \%$ & $0,1 \%$ \\
\hline 09/12/2019 & 0,62 & 0,64 & 0,64 & $3,1 \%$ & $3,1 \%$ & $0,0 \%$ \\
\hline $10 / 12 / 2019$ & 0,62 & 0,64 & 0,64 & $3,4 \%$ & $3,2 \%$ & $0,2 \%$ \\
\hline $11 / 12 / 2019$ & 0,62 & 0,64 & 0,64 & $3,7 \%$ & $3,8 \%$ & $0,1 \%$ \\
\hline $12 / 12 / 2019$ & 0,62 & 0,64 & 0,64 & $3,6 \%$ & $3,8 \%$ & $0,2 \%$ \\
\hline $13 / 12 / 2019$ & 0,62 & 0,64 & 0,64 & $4,0 \%$ & $4,2 \%$ & $0,2 \%$ \\
\hline $14 / 12 / 2019$ & 0,61 & 0,64 & 0,64 & $4,8 \%$ & $4,7 \%$ & $0,1 \%$ \\
\hline $15 / 12 / 2019$ & 0,61 & 0,64 & 0,64 & $4,2 \%$ & $4,3 \%$ & $0,1 \%$ \\
\hline $16 / 12 / 2019$ & 0,61 & 0,62 & 0,62 & $0,7 \%$ & $0,8 \%$ & $0,2 \%$ \\
\hline $19 / 12 / 2019$ & 0,61 & 0,62 & 0,62 & $1,6 \%$ & $1,5 \%$ & $0,1 \%$ \\
\hline $20 / 12 / 2019$ & 0,61 & 0,64 & 0,64 & $4,1 \%$ & $4,2 \%$ & $0,1 \%$ \\
\hline $21 / 12 / 2019$ & 0,61 & 0,64 & 0,64 & $4,1 \%$ & $4,1 \%$ & $0,1 \%$ \\
\hline 22/12/2019 & 0,61 & 0,64 & 0,64 & $4,1 \%$ & $4,1 \%$ & $0,1 \%$ \\
\hline $23 / 12 / 2019$ & 0,61 & 0,64 & 0,64 & $4,6 \%$ & $4,6 \%$ & $0,0 \%$ \\
\hline $24 / 12 / 2019$ & 0,61 & 0,64 & 0,64 & $4,6 \%$ & $4,5 \%$ & $0,1 \%$ \\
\hline $25 / 12 / 2019$ & 0,61 & 0,64 & 0,64 & $4,8 \%$ & $4,7 \%$ & $0,1 \%$ \\
\hline $26 / 12 / 2019$ & 0,61 & 0,64 & 0,64 & $4,7 \%$ & $4,7 \%$ & $0,0 \%$ \\
\hline
\end{tabular}


Tabela 31. Extrato de resultados de medições (27/dez/2019 a 07/fev/2020)

\begin{tabular}{|c|c|c|c|c|c|c|}
\hline \multirow{2}{*}{$\begin{array}{c}\text { Data } \\
\text { (dd/mm/aa) }\end{array}$} & \multicolumn{3}{|c|}{ Cálculo da efetividade $(\varepsilon)$ vía } & \multicolumn{3}{|c|}{ Diferença percentual } \\
\hline & Alternativa 1 & Alternativa 2 & Alternativa 3 & Alternativa 1 / Alternativa 2 & Alternativa 1 / Alternativa 2 & Alternativa 1 / Alternativa 2 \\
\hline $27 / 12 / 2019$ & 0,61 & 0,64 & 0,64 & $4,9 \%$ & $5,0 \%$ & $0,1 \%$ \\
\hline 28/12/2019 & 0,60 & 0,64 & 0,64 & $5,3 \%$ & $5,2 \%$ & $0,1 \%$ \\
\hline 29/12/2019 & 0,61 & 0,63 & 0,63 & $4,6 \%$ & $4,7 \%$ & $0,1 \%$ \\
\hline $30 / 12 / 2019$ & 0,63 & 0,64 & 0,64 & $2,0 \%$ & $2,0 \%$ & $0,0 \%$ \\
\hline 03/01/2020 & 0,61 & 0,63 & 0,63 & $2,7 \%$ & $2,6 \%$ & $0,2 \%$ \\
\hline 05/01/2020 & 0,60 & 0,62 & 0,62 & $3,8 \%$ & $3,8 \%$ & $0,0 \%$ \\
\hline 06/01/2020 & 0,59 & 0,61 & 0,61 & $2,6 \%$ & $2,5 \%$ & $0,1 \%$ \\
\hline $08 / 01 / 2020$ & 0,58 & 0,62 & 0,62 & $5,1 \%$ & $5,1 \%$ & $0,0 \%$ \\
\hline 09/01/2020 & 0,58 & 0,62 & 0,62 & $5,6 \%$ & $5,6 \%$ & $0,0 \%$ \\
\hline $10 / 01 / 2020$ & 0,58 & 0,62 & 0,62 & $6,4 \%$ & $6,3 \%$ & $0,0 \%$ \\
\hline $11 / 01 / 2020$ & 0,57 & 0,62 & 0,62 & $7,3 \%$ & $7,3 \%$ & $0,1 \%$ \\
\hline $12 / 01 / 2020$ & 0,57 & 0,62 & 0,62 & $7,9 \%$ & $8,1 \%$ & $0,2 \%$ \\
\hline $13 / 01 / 2020$ & 0,57 & 0,61 & 0,62 & $7,7 \%$ & $7,9 \%$ & $0,2 \%$ \\
\hline $22 / 01 / 2020$ & 0,56 & 0,61 & 0,61 & $7,9 \%$ & $8,1 \%$ & $0,2 \%$ \\
\hline $23 / 01 / 2020$ & 0,55 & 0,61 & 0,61 & $10,5 \%$ & $10,4 \%$ & $0,1 \%$ \\
\hline $24 / 01 / 2020$ & 0,55 & 0,61 & 0,61 & $10,3 \%$ & $10,3 \%$ & $0,1 \%$ \\
\hline $25 / 01 / 2020$ & 0,55 & 0,61 & 0,61 & $10,5 \%$ & $10,3 \%$ & $0,2 \%$ \\
\hline $26 / 01 / 2020$ & 0,55 & 0,61 & 0,61 & $10,5 \%$ & $10,6 \%$ & $0,1 \%$ \\
\hline $27 / 01 / 2020$ & 0,55 & 0,61 & 0,61 & $10,1 \%$ & $10,2 \%$ & $0,0 \%$ \\
\hline $30 / 01 / 2020$ & 0,54 & 0,60 & 0,60 & $9,6 \%$ & $9,6 \%$ & $0,0 \%$ \\
\hline $31 / 01 / 2020$ & 0,62 & 0,62 & 0,62 & $0,9 \%$ & $1,1 \%$ & $0,2 \%$ \\
\hline $01 / 02 / 2020$ & 0,69 & 0,63 & 0,63 & $9,8 \%$ & $9,8 \%$ & $0,1 \%$ \\
\hline $02 / 02 / 2020$ & 0,69 & 0,63 & 0,63 & $10,1 \%$ & $10,3 \%$ & $0,2 \%$ \\
\hline 03/02/2020 & 0,66 & 0,61 & 0,60 & $8,1 \%$ & $8,3 \%$ & $0,2 \%$ \\
\hline 04/02/2020 & 0,69 & 0,63 & 0,63 & $9,9 \%$ & $10,0 \%$ & $0,2 \%$ \\
\hline 05/02/2020 & 0,68 & 0,54 & 0,54 & $25,9 \%$ & $25,8 \%$ & $0,1 \%$ \\
\hline $06 / 02 / 2020$ & 0,67 & 0,69 & 0,69 & $3,4 \%$ & $3,6 \%$ & $0,1 \%$ \\
\hline 07/02/2020 & 0,66 & 0,69 & 0,69 & $5,1 \%$ & $4,9 \%$ & $0,1 \%$ \\
\hline
\end{tabular}


Tabela 32. Extrato de resultados de medições (08/fev a 06/abr/2020)

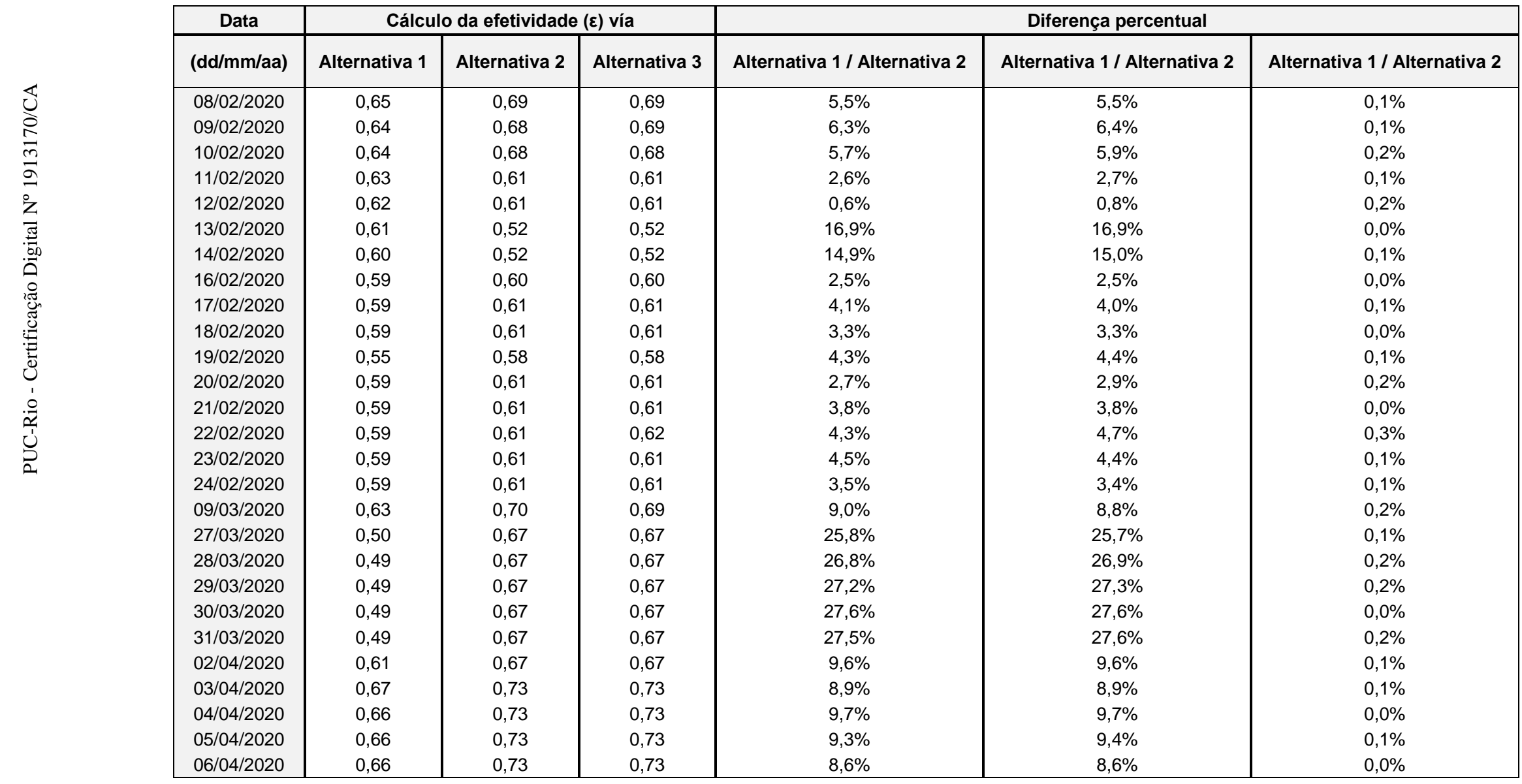




\section{Apêndice D: Incerteza associada ao cálculo da efetividade}

\begin{tabular}{|c|c|c|c|c|c|c|c|c|c|c|c|c|c|c|c|c|}
\hline $\begin{array}{ccc}\stackrel{a}{a} & \text { ta } \\
\left(\mathrm{d}^{\circ} \mathbf{Z}\right. & \mathrm{m} / \mathrm{aa})\end{array}$ & $\partial \varepsilon / \partial \mathrm{Ta}$,out & u_tipo A & u_tipo B & u_Ta,out & 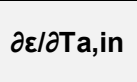 & u_tipo A & u_tipo B & u_Ta,in & 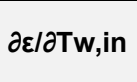 & u_tipo A & u_tipo B & u_Tw,in & Ta,out & Ta,in & Tw,in & uع \\
\hline $0 ! \overline{12019}$ & $-0,0406$ & 0,0234 & 0,3167 & 0,3175 & 0,0212 & 0,0805 & 0,3167 & 0,3267 & 0,0194 & 0,0541 & 0,2597 & 0,2653 & $69,0 \%$ & $20,0 \%$ & $11,0 \%$ & 0,0155 \\
\hline $0 \leftarrow \cdot \overline{00} / 2019$ & $-0,0408$ & 0,0106 & 0,3167 & 0,3168 & 0,0222 & 0,0252 & 0,3167 & 0,3177 & 0,0186 & 0,0191 & 0,2597 & 0,2604 & $69,6 \%$ & $20,6 \%$ & $9,8 \%$ & 0,0155 \\
\hline 0i: & $-0,0403$ & 0,0222 & 0,3167 & 0,3174 & 0,0220 & 0,0290 & 0,3167 & 0,3180 & 0,0183 & 0,0244 & 0,2597 & 0,2609 & $69,5 \%$ & $20,8 \%$ & $9,6 \%$ & 0,0154 \\
\hline 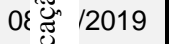 & $-0,0404$ & 0,0183 & 0,3167 & 0,3172 & 0,0223 & 0,0316 & 0,3167 & 0,3182 & 0,0181 & 0,0216 & 0,2597 & 0,2606 & $69,3 \%$ & $21,3 \%$ & $9,4 \%$ & 0,0154 \\
\hline $0 \leftrightarrow: 2019$ & $-0,0404$ & 0,1960 & 0,3167 & 0,3724 & 0,0212 & 0,0461 & 0,3167 & 0,3200 & 0,0192 & 0,0227 & 0,2597 & 0,2607 & $76,1 \%$ & $15,5 \%$ & $8,4 \%$ & 0,0173 \\
\hline $1\left(\begin{array}{ll}0 & 1 \\
0 & 12019\end{array}\right.$ & $-0,0406$ & 0,0376 & 0,3167 & 0,3189 & 0,0189 & 0,0257 & 0,3167 & 0,3177 & 0,0218 & 0,0105 & 0,2597 & 0,2599 & $71,2 \%$ & $15,2 \%$ & $13,6 \%$ & 0,0154 \\
\hline $1 \% 12019$ & $-0,0421$ & 0,0269 & 0,2951 & 0,2963 & 0,0136 & 0,0341 & 0,2951 & 0,2971 & 0,0285 & 0,0165 & 0,2597 & 0,2602 & $68,6 \%$ & $7,2 \%$ & $24,2 \%$ & 0,0151 \\
\hline $11: \frac{12019}{2}$ & $-0,0418$ & 0,0305 & 0,2951 & 0,2967 & 0,0135 & 0,0594 & 0,2951 & 0,3010 & 0,0283 & 0,0186 & 0,2597 & 0,2604 & $68,5 \%$ & $7,4 \%$ & $24,2 \%$ & 0,0150 \\
\hline 2: 2019 & $-0,0398$ & 0,1445 & 0,2951 & 0,3286 & 0,0130 & 0,0537 & 0,2951 & 0,2999 & 0,0268 & 0,0381 & 0,2597 & 0,2625 & $72,5 \%$ & $6,4 \%$ & $21,1 \%$ & 0,0153 \\
\hline 2: 2019 & $-0,0401$ & 0,0371 & 0,2951 & 0,2974 & 0,0130 & 0,0791 & 0,2951 & 0,3055 & 0,0270 & 0,0261 & 0,2597 & 0,2610 & $68,4 \%$ & $7,6 \%$ & $24,0 \%$ & 0,0144 \\
\hline 5/07/2019 & $-0,0397$ & 0,0445 & 0,2951 & 0,2984 & 0,0129 & 0,0832 & 0,2951 & 0,3066 & 0,0268 & 0,0205 & 0,2597 & 0,2605 & $68,6 \%$ & $7,7 \%$ & $23,8 \%$ & 0,0143 \\
\hline /07/2019 & $-0,0397$ & 0,0314 & 0,2951 & 0,2967 & 0,0130 & 0,0635 & 0,2951 & 0,3018 & 0,0267 & 0,0304 & 0,2597 & 0,2615 & $68,4 \%$ & $7,6 \%$ & $24,0 \%$ & 0,0143 \\
\hline $707 / 2019$ & $-0,0402$ & 0,0299 & 0,2951 & 0,2966 & 0,0132 & 0,0537 & 0,2951 & 0,2999 & 0,0270 & 0,0160 & 0,2597 & 0,2602 & $68,6 \%$ & $7,6 \%$ & $23,8 \%$ & 0,0144 \\
\hline 3/07/2019 & $-0,0400$ & 0,0257 & 0,2951 & 0,2962 & 0,0133 & 0,0622 & 0,2951 & 0,3016 & 0,0268 & 0,0070 & 0,2597 & 0,2598 & $68,6 \%$ & $7,8 \%$ & $23,6 \%$ & 0,0143 \\
\hline$/ 07 / 2019$ & $-0,0405$ & 0,0115 & 0,2951 & 0,2953 & 0,0136 & 0,0428 & 0,2951 & 0,2982 & 0,0269 & 0,0088 & 0,2597 & 0,2599 & $68,7 \%$ & $7,9 \%$ & $23,4 \%$ & 0,0144 \\
\hline$/ 07 / 2019$ & $-0,0406$ & 0,0194 & 0,2951 & 0,2957 & 0,0138 & 0,0331 & 0,2951 & 0,2969 & 0,0268 & 0,0076 & 0,2597 & 0,2598 & $68,8 \%$ & $8,0 \%$ & $23,2 \%$ & 0,0145 \\
\hline /07/2019 & $-0,0405$ & 0,0249 & 0,2951 & 0,2961 & 0,0139 & 0,0296 & 0,2951 & 0,2966 & 0,0266 & 0,0135 & 0,2597 & 0,2601 & $68,9 \%$ & $8,2 \%$ & $22,9 \%$ & 0,0145 \\
\hline 01/08/2019 & $-0,0404$ & 0,0338 & 0,2951 & 0,2970 & 0,0140 & 0,0532 & 0,2951 & 0,2998 & 0,0264 & 0,0275 & 0,2597 & 0,2612 & $68,8 \%$ & $8,4 \%$ & $22,8 \%$ & 0,0145 \\
\hline 02/08/2019 & $-0,0401$ & 0,0293 & 0,2951 & 0,2965 & 0,0140 & 0,0562 & 0,2951 & 0,3004 & 0,0261 & 0,0163 & 0,2597 & 0,2602 & $68,9 \%$ & $8,6 \%$ & $22,5 \%$ & 0,0143 \\
\hline 03/08/2019 & $-0,0404$ & 0,0080 & 0,2951 & 0,2952 & 0,0143 & 0,0131 & 0,2951 & 0,2954 & 0,0261 & 0,0030 & 0,2597 & 0,2597 & $69,0 \%$ & $8,6 \%$ & $22,3 \%$ & 0,0143 \\
\hline $04 / 08 / 2019$ & $-0,0398$ & 0,0274 & 0,2951 & 0,2964 & 0,0143 & 0,0608 & 0,2951 & 0,3013 & 0,0255 & 0,0338 & 0,2597 & 0,2619 & $68,8 \%$ & $9,1 \%$ & $22,1 \%$ & 0,0142 \\
\hline /08/2019 & $-0,0402$ & 0,0228 & 0,2951 & 0,2960 & 0,0147 & 0,0207 & 0,2951 & 0,2958 & 0,0255 & 0,0324 & 0,2597 & 0,2617 & $69,0 \%$ & $9,2 \%$ & $21,7 \%$ & 0,0143 \\
\hline //08/2019 & $-0,0399$ & 0,0065 & 0,2951 & 0,2952 & 0,0147 & 0,0199 & 0,2951 & 0,2958 & 0,0252 & 0,0156 & 0,2597 & 0,2602 & $69,1 \%$ & $9,4 \%$ & $21,5 \%$ & 0,0142 \\
\hline 07/08/2019 & $-0,0397$ & 0,0226 & 0,2951 & 0,2959 & 0,0148 & 0,0391 & 0,2951 & 0,2977 & 0,0249 & 0,0151 & 0,2597 & 0,2602 & $69,2 \%$ & $9,7 \%$ & $21,1 \%$ & 0,0141 \\
\hline 08/08/2019 & $-0,0396$ & 0,0621 & 0,2951 & 0,3016 & 0,0149 & 0,2210 & 0,2951 & 0,3687 & 0,0247 & 0,0322 & 0,2597 & 0,2617 & $66,5 \%$ & $14,1 \%$ & $19,4 \%$ & 0,0147 \\
\hline 09/08/2019 & $-0,0387$ & 0,0840 & 0,2951 & 0,3068 & 0,0145 & 0,1218 & 0,2951 & 0,3192 & 0,0242 & 0,0562 & 0,2597 & 0,2657 & $69,2 \%$ & $10,5 \%$ & $20,3 \%$ & 0,0143 \\
\hline $10 / 08 / 2019$ & $-0,0384$ & 0,0387 & 0,2951 & 0,2976 & 0,0145 & 0,0367 & 0,2951 & 0,2973 & 0,0239 & 0,0437 & 0,2597 & 0,2634 & $69,2 \%$ & $9,9 \%$ & $21,0 \%$ & 0,0137 \\
\hline $11 / 08 / 2019$ & $-0,0390$ & 0,0332 & 0,2951 & 0,2969 & 0,0149 & 0,0337 & 0,2951 & 0,2970 & 0,0241 & 0,0264 & 0,2597 & 0,2611 & $69,4 \%$ & $10,1 \%$ & $20,5 \%$ & 0,0139 \\
\hline 12/08/2019 & $-0,0382$ & 0,0577 & 0,2951 & 0,3007 & 0,0146 & 0,1269 & 0,2951 & 0,3212 & 0,0236 & 0,0169 & 0,2597 & 0,2603 & $68,8 \%$ & $11,5 \%$ & $19,7 \%$ & 0,0138 \\
\hline 22/08/2019 & $-0,0371$ & 0,0094 & 0,2951 & 0,2952 & 0,0152 & 0,0152 & 0,2951 & 0,2955 & 0,0219 & 0,0115 & 0,2597 & 0,2600 & $69,5 \%$ & $11,6 \%$ & $18,8 \%$ & 0,0131 \\
\hline
\end{tabular}


Tabela 34. Incerteza associada à medição (dados entre ago a out/2019)

\begin{tabular}{|c|c|c|c|c|c|c|c|c|c|c|c|c|c|c|c|c|}
\hline $\begin{array}{ll}\stackrel{\varrho}{\rho} \text { ta } \\
(\mathrm{d}\end{array}$ & 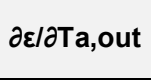 & u_tipo A & u_tipo B & u_Ta,out & $\partial \varepsilon / \partial \mathrm{Ta}$,in & u_tipo A & u_tipo B & u_Ta,in & $\partial \varepsilon / \partial T w, i n$ & u_tipo A & u_tipo B & u_Tw,in & Ta,out & Ta,in & Tw,in & $u \varepsilon$ \\
\hline 2河 12019 & $-0,0372$ & 0,0138 & 0,2951 & 0,2954 & 0,0153 & 0,0260 & 0,2951 & 0,2962 & 0,0219 & 0,0000 & 0,2597 & 0,2597 & $69,5 \%$ & $11,9 \%$ & $18,6 \%$ & 0,0132 \\
\hline $2{ }^{2}{ }^{-} / 2019$ & $-0,0372$ & 0,0153 & 0,2951 & 0,2955 & 0,0154 & 0,0255 & 0,2951 & 0,2962 & 0,0218 & 0,0138 & 0,2597 & 0,2601 & $69,5 \%$ & $12,0 \%$ & $18,5 \%$ & 0,0132 \\
\hline $1\left(\frac{2}{\pi} / 2019\right.$ & $-0,0301$ & 0,0486 & 0,2951 & 0,2991 & 0,0136 & 0,0708 & 0,2951 & 0,3035 & 0,0165 & 0,0471 & 0,2597 & 0,2640 & $69,2 \%$ & $14,6 \%$ & $16,2 \%$ & 0,0108 \\
\hline $1.0 / 2019$ & $-0,0303$ & 0,0598 & 0,2951 & 0,3011 & 0,0137 & 0,0836 & 0,2951 & 0,3067 & 0,0166 & 0,0453 & 0,2597 & 0,2636 & $69,3 \%$ & $14,8 \%$ & $15,9 \%$ & 0,0110 \\
\hline 1 1 2019 & $-0,0302$ & 0,0628 & 0,2951 & 0,3017 & 0,0137 & 0,0991 & 0,2951 & 0,3113 & 0,0164 & 0,0348 & 0,2597 & 0,2620 & $69,2 \%$ & $15,3 \%$ & $15,5 \%$ & 0,0109 \\
\hline 11: 2019 & $-0,0303$ & 0,0129 & 0,2951 & 0,2954 & 0,0140 & 0,0128 & 0,2951 & 0,2954 & 0,0163 & 0,0074 & 0,2597 & 0,2598 & $69,6 \%$ & $14,8 \%$ & $15,6 \%$ & 0,0107 \\
\hline $1<\stackrel{0}{:} / 2019$ & $-0,0302$ & 0,0140 & 0,2951 & 0,2954 & 0,0140 & 0,0222 & 0,2951 & 0,2959 & 0,0162 & 0,0169 & 0,2597 & 0,2603 & $69,5 \%$ & $15,0 \%$ & $15,5 \%$ & 0,0107 \\
\hline $15=2019$ & $-0,0298$ & 0,0320 & 0,2951 & 0,2968 & 0,0139 & 0,0529 & 0,2951 & 0,2998 & 0,0159 & 0,0182 & 0,2597 & 0,2604 & $69,4 \%$ & $15,4 \%$ & $15,2 \%$ & 0,0106 \\
\hline $1 \in \mathbb{U} / 2019$ & $-0,0300$ & 0,0303 & 0,2951 & 0,2966 & 0,0142 & 0,0461 & 0,2951 & 0,2987 & 0,0158 & 0,0212 & 0,2597 & 0,2606 & $69,4 \%$ & $15,7 \%$ & $14,9 \%$ & 0,0107 \\
\hline 17o 1019 & $-0,0299$ & 0,0452 & 0,2951 & 0,2985 & 0,0141 & 0,0628 & 0,2951 & 0,3017 & 0,0158 & 0,0320 & 0,2597 & 0,2617 & $69,4 \%$ & $15,8 \%$ & $14,8 \%$ & 0,0107 \\
\hline 12019 & $-0,0350$ & 0,2332 & 0,2951 & 0,3761 & 0,0164 & 0,5333 & 0,2951 & 0,6095 & 0,0186 & 0,0398 & 0,2597 & 0,2628 & $58,3 \%$ & $33,7 \%$ & $8,0 \%$ & 0,0172 \\
\hline 2019 & $-0,0381$ & 0,0391 & 0,2951 & 0,2977 & 0,0181 & 0,0333 & 0,2951 & 0,2970 & 0,0199 & 0,0288 & 0,2597 & 0,2613 & $69,6 \%$ & $15,7 \%$ & $14,7 \%$ & 0,0136 \\
\hline 20/uy/2019 & $-0,0372$ & 0,0787 & 0,2951 & 0,3054 & 0,0178 & 0,1655 & 0,2951 & 0,3383 & 0,0194 & 0,0231 & 0,2597 & 0,2607 & $67,6 \%$ & $19,0 \%$ & $13,4 \%$ & 0,0138 \\
\hline $21 / 09 / 2019$ & $-0,0374$ & 0,0146 & 0,2951 & 0,2954 & 0,0180 & 0,0172 & 0,2951 & 0,2956 & 0,0194 & 0,0228 & 0,2597 & 0,2607 & $69,4 \%$ & $16,1 \%$ & $14,5 \%$ & 0,0133 \\
\hline 22/09/2019 & $-0,0356$ & 0,0729 & 0,2951 & 0,3040 & 0,0172 & 0,1739 & 0,2951 & 0,3425 & 0,0184 & 0,0361 & 0,2597 & 0,2622 & $66,9 \%$ & $19,8 \%$ & $13,3 \%$ & 0,0132 \\
\hline $23 / 09 / 2019$ & $-0,0363$ & 0,1404 & 0,2951 & 0,3268 & 0,0177 & 0,2761 & 0,2951 & 0,4041 & 0,0186 & 0,0525 & 0,2597 & 0,2650 & $65,1 \%$ & $23,7 \%$ & $11,2 \%$ & 0,0147 \\
\hline 01/10/2019 & $-0,0321$ & 0,3819 & 0,2951 & 0,4826 & 0,0160 & 0,6639 & 0,2951 & 0,7265 & 0,0161 & 0,0252 & 0,2597 & 0,2609 & $61,1 \%$ & $34,4 \%$ & $4,5 \%$ & 0,0198 \\
\hline 02/10/2019 & $-0,0288$ & 0,0441 & 0,2951 & 0,2984 & 0,0147 & 0,0580 & 0,2951 & 0,3007 & 0,0141 & 0,0371 & 0,2597 & 0,2624 & $69,0 \%$ & $18,2 \%$ & $12,9 \%$ & 0,0104 \\
\hline 03/10/2019 & $-0,0290$ & 0,0512 & 0,2951 & 0,2995 & 0,0149 & 0,0670 & 0,2951 & 0,3026 & 0,0142 & 0,0410 & 0,2597 & 0,2629 & $68,9 \%$ & $18,4 \%$ & $12,7 \%$ & 0,0105 \\
\hline 04/10/2019 & $-0,0292$ & 0,0646 & 0,2951 & 0,3021 & 0,0150 & 0,0745 & 0,2951 & 0,3043 & 0,0142 & 0,0760 & 0,2597 & 0,2706 & $68,6 \%$ & $18,4 \%$ & $13,0 \%$ & 0,0107 \\
\hline 05/10/2019 & $-0,0285$ & 0,0778 & 0,2951 & 0,3052 & 0,0146 & 0,1620 & 0,2951 & 0,3366 & 0,0139 & 0,0200 & 0,2597 & 0,2605 & $67,0 \%$ & $21,4 \%$ & $11,6 \%$ & 0,0106 \\
\hline 06/10/2019 & $-0,0287$ & 0,0118 & 0,2951 & 0,2953 & 0,0148 & 0,0679 & 0,2951 & 0,3028 & 0,0140 & 0,0267 & 0,2597 & 0,2611 & $68,4 \%$ & $19,0 \%$ & $12,6 \%$ & 0,0103 \\
\hline 07/10/2019 & $-0,0291$ & 0,0208 & 0,2951 & 0,2958 & 0,0151 & 0,0392 & 0,2951 & 0,2977 & 0,0141 & 0,0114 & 0,2597 & 0,2600 & $68,9 \%$ & $18,6 \%$ & $12,4 \%$ & 0,0104 \\
\hline $15 / 10 / 2019$ & $-0,0288$ & 0,1459 & 0,2951 & 0,3292 & 0,0152 & 0,1120 & 0,2951 & 0,3156 & 0,0136 & 0,0941 & 0,2597 & 0,2762 & $70,8 \%$ & $18,0 \%$ & $11,2 \%$ & 0,0113 \\
\hline 16/10/2019 & $-0,0300$ & 0,0208 & 0,2951 & 0,2958 & 0,0151 & 0,0392 & 0,2951 & 0,2977 & 0,0150 & 0,0150 & 0,2597 & 0,2602 & $69,1 \%$ & $17,6 \%$ & $13,3 \%$ & 0,0107 \\
\hline $17 / 10 / 2019$ & $-0,0288$ & 0,0304 & 0,2951 & 0,2966 & 0,0153 & 0,0572 & 0,2951 & 0,3006 & 0,0135 & 0,0139 & 0,2597 & 0,2601 & $68,5 \%$ & $20,0 \%$ & $11,5 \%$ & 0,0103 \\
\hline $18 / 10 / 2019$ & $-0,0290$ & 0,0173 & 0,2951 & 0,2956 & 0,0155 & 0,0286 & 0,2951 & 0,2965 & 0,0134 & 0,0057 & 0,2597 & 0,2598 & $68,7 \%$ & $19,9 \%$ & $11,4 \%$ & 0,0103 \\
\hline 19/10/2019 & $-0,0289$ & 0,0214 & 0,2951 & 0,2959 & 0,0155 & 0,0378 & 0,2951 & 0,2975 & 0,0134 & 0,0099 & 0,2597 & 0,2599 & $68,6 \%$ & $20,0 \%$ & $11,3 \%$ & 0,0103 \\
\hline $20 / 10 / 2019$ & $-0,0289$ & 0,0335 & 0,2951 & 0,2970 & 0,0156 & 0,0404 & 0,2951 & 0,2978 & 0,0133 & 0,0460 & 0,2597 & 0,2638 & $68,5 \%$ & $20,0 \%$ & $11,5 \%$ & 0,0104 \\
\hline $21 / 10 / 2019$ & $-0,0290$ & 0,0467 & 0,2951 & 0,2987 & 0,0156 & 0,0705 & 0,2951 & 0,3034 & 0,0133 & 0,0373 & 0,2597 & 0,2624 & $68,3 \%$ & $20,5 \%$ & $11,2 \%$ & 0,0105 \\
\hline
\end{tabular}


Tabela 35. Incerteza associada à medição (dados entre out a nov/2019)

\begin{tabular}{|c|c|c|c|c|c|c|c|c|c|c|c|c|c|c|c|c|c|}
\hline & $\begin{array}{l}\text { Ita } \\
\text { m/aa) }\end{array}$ & $\partial \varepsilon / \partial \mathrm{Ta}$, out & u_tipo A & u_tipo B & u_Ta,out & $\partial \varepsilon / \partial T a$, in & u_tipo A & u_tipo B & u_Ta,in & $\partial \varepsilon / \partial T w$, in & u_tipo A & u_tipo B & u_Tw,in & Ta,out & Ta,in & Tw,in & uع \\
\hline 2io & 12019 & $-0,0360$ & 0,7371 & 0,2951 & 0,7940 & 0,0154 & 0,2500 & 0,2951 & 0,3868 & 0,0206 & 0,1620 & 0,2597 & 0,3061 & $91,6 \%$ & $4,0 \%$ & $4,5 \%$ & 0,0298 \\
\hline $2<\frac{m}{m}$ & /2019 & $-0,0343$ & 0,2029 & 0,2951 & 0,3581 & 0,0118 & 0,6635 & 0,2951 & 0,7261 & 0,0225 & 0,0206 & 0,2597 & 0,2605 & $58,3 \%$ & $28,4 \%$ & $13,3 \%$ & 0,0161 \\
\hline 2๘ล & 12019 & $-0,0305$ & 0,0498 & 0,2951 & 0,2993 & 0,0103 & 0,0517 & 0,2951 & 0,2996 & 0,0202 & 0,0719 & 0,2597 & 0,2695 & $68,0 \%$ & $7,8 \%$ & $24,2 \%$ & 0,0111 \\
\hline & 12019 & $-0,0301$ & 0,0519 & 0,2951 & 0,2996 & 0,0101 & 0,0890 & 0,2951 & 0,3082 & 0,0199 & 0,0413 & 0,2597 & 0,2630 & $68,5 \%$ & $8,2 \%$ & $23,2 \%$ & 0,0109 \\
\hline $2: \frac{2}{3}$ & 12019 & $-0,0300$ & 0,0703 & 0,2951 & 0,3033 & 0,0101 & 0,1039 & 0,2951 & 0,3128 & 0,0199 & 0,0631 & 0,2597 & 0,2673 & $68,4 \%$ & $8,3 \%$ & $23,3 \%$ & 0,0110 \\
\hline $2 \varepsilon$ & 12019 & $-0,0301$ & 0,0838 & 0,2951 & 0,3067 & 0,0099 & 0,0881 & 0,2951 & 0,3080 & 0,0202 & 0,0447 & 0,2597 & 0,2635 & $69,4 \%$ & $7,6 \%$ & $23,0 \%$ & 0,0111 \\
\hline $2 \leqslant 0$ & /2019 & $-0,0306$ & 0,1141 & 0,2951 & 0,3164 & 0,0101 & 0,0786 & 0,2951 & 0,3054 & 0,0205 & 0,0654 & 0,2597 & 0,2678 & $70,3 \%$ & $7,1 \%$ & $22,6 \%$ & 0,0115 \\
\hline 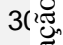 & 12019 & $-0,0308$ & 0,0741 & 0,2951 & 0,3042 & 0,0102 & 0,0498 & 0,2951 & 0,2993 & 0,0207 & 0,0843 & 0,2597 & 0,2731 & $68,2 \%$ & $7,2 \%$ & $24,6 \%$ & 0,0114 \\
\hline $3 . \tilde{J}$ & 12019 & $-0,0309$ & 0,2071 & 0,2951 & 0,3605 & 0,0103 & 0,3077 & 0,2951 & 0,4263 & 0,0206 & 0,2103 & 0,2597 & 0,3342 & $65,1 \%$ & $10,2 \%$ & $24,7 \%$ & 0,0138 \\
\hline $0 .=$ & 12019 & $-0,0326$ & 0,1597 & 0,2951 & 0,3355 & 0,0107 & 0,4517 & 0,2951 & 0,5396 & 0,0219 & 0,0273 & 0,2597 & 0,2611 & $64,4 \%$ & $17,9 \%$ & $17,6 \%$ & 0,0136 \\
\hline Ũ & 12019 & $-0,0333$ & 0,1478 & 0,2951 & 0,3300 & 0,0110 & 0,3791 & 0,2951 & 0,4804 & 0,0223 & 0,0256 & 0,2597 & 0,2610 & $66,1 \%$ & $15,4 \%$ & $18,5 \%$ & 0,0135 \\
\hline & /2019 & $-0,0365$ & 0,0616 & 0,2951 & 0,3014 & 0,0120 & 0,1637 & 0,2951 & 0,3374 & 0,0245 & 0,0264 & 0,2597 & 0,2611 & $67,9 \%$ & $9,2 \%$ & $22,9 \%$ & 0,0134 \\
\hline $0<\frac{2}{1}$ & 12019 & $-0,0370$ & 0,0796 & 0,2951 & 0,3056 & 0,0120 & 0,0922 & 0,2951 & 0,3091 & 0,0250 & 0,0430 & 0,2597 & 0,2633 & $69,1 \%$ & $7,4 \%$ & $23,5 \%$ & 0,0136 \\
\hline ת? & /2019 & $-0,0368$ & 0,0869 & 0,2951 & 0,3076 & 0,0121 & 0,1536 & 0,2951 & 0,3326 & 0,0248 & 0,0539 & 0,2597 & 0,2652 & $68,4 \%$ & $8,6 \%$ & $23,0 \%$ & 0,0137 \\
\hline 06ी & ו/2019 & $-0,0372$ & 0,0262 & 0,2951 & 0,2962 & 0,0123 & 0,0798 & 0,2951 & 0,3057 & 0,0249 & 0,0122 & 0,2597 & 0,2600 & $68,4 \%$ & $8,0 \%$ & $23,6 \%$ & 0,0133 \\
\hline $07 / 1$ & 1/2019 & $-0,0412$ & 0,1580 & 0,2951 & 0,3347 & 0,0138 & 0,2438 & 0,2951 & 0,3828 & 0,0274 & 0,1661 & 0,2597 & 0,3083 & $65,7 \%$ & $9,6 \%$ & $24,7 \%$ & 0,0170 \\
\hline $08 / 1$ & $1 / 2019$ & $-0,0388$ & 0,0822 & 0,2951 & 0,3063 & 0,0131 & 0,0796 & 0,2951 & 0,3056 & 0,0258 & 0,0933 & 0,2597 & 0,2760 & $68,0 \%$ & $7,7 \%$ & $24,3 \%$ & 0,0144 \\
\hline $09 / 1$ & 1/2019 & $-0,0388$ & 0,0672 & 0,2951 & 0,3026 & 0,0132 & 0,0569 & 0,2951 & 0,3005 & 0,0256 & 0,0772 & 0,2597 & 0,2709 & $68,4 \%$ & $7,8 \%$ & $23,8 \%$ & 0,0142 \\
\hline $10 / 1$ & $1 / 2019$ & $-0,0389$ & 0,0614 & 0,2951 & 0,3014 & 0,0133 & 0,0471 & 0,2951 & 0,2988 & 0,0256 & 0,0755 & 0,2597 & 0,2705 & $68,3 \%$ & $7,9 \%$ & $23,8 \%$ & 0,0142 \\
\hline $11 / 1$ & 1/2019 & $-0,0394$ & 0,1267 & 0,2951 & 0,3211 & 0,0135 & 0,0490 & 0,2951 & 0,2991 & 0,0259 & 0,1051 & 0,2597 & 0,2802 & $69,9 \%$ & $7,1 \%$ & $23,0 \%$ & 0,0151 \\
\hline $12 / 1$ & 1/2019 & $-0,0396$ & 0,0645 & 0,2951 & 0,3021 & 0,0133 & 0,0572 & 0,2951 & 0,3006 & 0,0263 & 0,0826 & 0,2597 & 0,2725 & $68,0 \%$ & $7,6 \%$ & $24,4 \%$ & 0,0145 \\
\hline $13 / 1$ & $1 / 2019$ & $-0,0358$ & 0,3931 & 0,2951 & 0,4915 & 0,0120 & 0,8110 & 0,2951 & 0,8630 & 0,0238 & 0,1981 & 0,2597 & 0,3267 & $64,9 \%$ & $22,5 \%$ & $12,7 \%$ & 0,0218 \\
\hline $14 / 1$ & 1/2019 & $-0,0345$ & 0,1542 & 0,2951 & 0,3330 & 0,0116 & 0,4190 & 0,2951 & 0,5124 & 0,0229 & 0,0138 & 0,2597 & 0,2601 & $65,1 \%$ & $17,3 \%$ & $17,5 \%$ & 0,0142 \\
\hline $15 / 1$ & 1/2019 & $-0,0365$ & 0,1188 & 0,2951 & 0,3181 & 0,0123 & 0,3207 & 0,2951 & 0,4358 & 0,0242 & 0,0164 & 0,2597 & 0,2602 & $66,4 \%$ & $14,1 \%$ & $19,6 \%$ & 0,0142 \\
\hline $16 / 1$ & $1 / 2019$ & $-0,0360$ & 0,1570 & 0,2951 & 0,3343 & 0,0122 & 0,4052 & 0,2951 & 0,5012 & 0,0238 & 0,0247 & 0,2597 & 0,2609 & $65,6 \%$ & $16,8 \%$ & $17,5 \%$ & 0,0149 \\
\hline $17 / 1$ & 1/2019 & $-0,0348$ & 0,1653 & 0,2951 & 0,3382 & 0,0119 & 0,4484 & 0,2951 & 0,5368 & 0,0229 & 0,0211 & 0,2597 & 0,2606 & $64,5 \%$ & $18,9 \%$ & $16,6 \%$ & 0,0147 \\
\hline $18 / 1$ & 1/2019 & $-0,0386$ & 0,1683 & 0,2951 & 0,3397 & 0,0131 & 0,2726 & 0,2951 & 0,4017 & 0,0255 & 0,0897 & 0,2597 & 0,2748 & $69,1 \%$ & $11,2 \%$ & $19,7 \%$ & 0,0158 \\
\hline $26 / 1$ & 1/2019 & $-0,0381$ & 0,1257 & 0,2951 & 0,3207 & 0,0129 & 0,1366 & 0,2951 & 0,3252 & 0,0252 & 0,0853 & 0,2597 & 0,2734 & $69,7 \%$ & $8,2 \%$ & $22,1 \%$ & 0,0147 \\
\hline $28 / 1$ & $1 / 2019$ & $-0,0383$ & 0,0577 & 0,2951 & 0,3007 & 0,0134 & 0,1055 & 0,2951 & 0,3134 & 0,0249 & 0,0561 & 0,2597 & 0,2657 & $68,4 \%$ & $9,1 \%$ & $22,5 \%$ & 0,0139 \\
\hline $29 / 1$ & 1/2019 & $-0,0378$ & 0,0523 & 0,2951 & 0,2997 & 0,0132 & 0,0802 & 0,2951 & 0,3058 & 0,0246 & 0,0680 & 0,2597 & 0,2685 & $68,2 \%$ & $8,7 \%$ & $23,1 \%$ & 0,0137 \\
\hline
\end{tabular}


Tabela 36. Incerteza associada à medição (dados entre nov/2019 a jan/2020)

\begin{tabular}{|c|c|c|c|c|c|c|c|c|c|c|c|c|c|c|c|c|c|}
\hline & $\begin{array}{l}\text { Ita } \\
\text { m/aa) }\end{array}$ & $\partial \varepsilon / \partial \mathrm{Ta}$, out & u_tipo A & u_tipo B & u_Ta,out & $\partial \varepsilon / \partial T a$, in & u_tipo A & u_tipo B & u_Ta,in & $\partial \varepsilon / \partial T w$, in & u_tipo A & u_tipo B & u_Tw,in & Ta,out & Ta,in & Tw,in & uع \\
\hline $3(2$ & 12019 & $-0,0373$ & 0,0724 & 0,2951 & 0,3038 & 0,0131 & 0,1925 & 0,2951 & 0,3523 & 0,0242 & 0,0599 & 0,2597 & 0,2665 & $67,1 \%$ & $11,1 \%$ & $21,8 \%$ & 0,0138 \\
\hline $0 \div \frac{\mathrm{m}}{\mathrm{n}}$ & /2019 & $-0,0384$ & 0,0670 & 0,2951 & 0,3026 & 0,0136 & 0,0560 & 0,2951 & 0,3003 & 0,0248 & 0,0840 & 0,2597 & 0,2730 & $68,3 \%$ & $8,4 \%$ & $23,2 \%$ & 0,0141 \\
\hline 0:- & 12019 & $-0,0385$ & 0,0710 & 0,2951 & 0,3035 & 0,0137 & 0,0720 & 0,2951 & 0,3037 & 0,0248 & 0,0810 & 0,2597 & 0,2721 & $68,5 \%$ & $8,7 \%$ & $22,9 \%$ & 0,0141 \\
\hline & 12019 & $-0,0376$ & 0,2440 & 0,2951 & 0,3829 & 0,0138 & 0,0690 & 0,2951 & 0,3030 & 0,0238 & 0,1210 & 0,2597 & 0,2865 & $76,4 \%$ & $6,5 \%$ & $17,1 \%$ & 0,0165 \\
\hline 0 & 12019 & $-0,0370$ & 0,0550 & 0,2951 & 0,3002 & 0,0138 & 0,0750 & 0,2951 & 0,3045 & 0,0232 & 0,0630 & 0,2597 & 0,2672 & $68,7 \%$ & $9,9 \%$ & $21,4 \%$ & 0,0134 \\
\hline 08.0 & 12019 & $-0,0376$ & 0,0576 & 0,2951 & 0,3007 & 0,0141 & 0,0637 & 0,2951 & 0,3019 & 0,0235 & 0,0680 & 0,2597 & 0,2685 & $68,8 \%$ & $9,8 \%$ & $21,4 \%$ & 0,0136 \\
\hline $0 \leqslant \theta$ & /2019 & $-0,0373$ & 0,0593 & 0,2951 & 0,3010 & 0,0140 & 0,0623 & 0,2951 & 0,3016 & 0,0232 & 0,0688 & 0,2597 & 0,2687 & $68,9 \%$ & $9,8 \%$ & $21,3 \%$ & 0,0135 \\
\hline 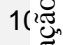 & 12019 & $-0,0378$ & 0,0536 & 0,2951 & 0,2999 & 0,0143 & 0,0588 & 0,2951 & 0,3009 & 0,0235 & 0,0698 & 0,2597 & 0,2689 & $68,7 \%$ & $9,9 \%$ & $21,3 \%$ & 0,0137 \\
\hline $1 . \tilde{J}$ & 12019 & $-0,0381$ & 0,0534 & 0,2951 & 0,2999 & 0,0145 & 0,0442 & 0,2951 & 0,2984 & 0,0236 & 0,0696 & 0,2597 & 0,2689 & $68,9 \%$ & $9,9 \%$ & $21,3 \%$ & 0,0138 \\
\hline $1 \%$ & 12019 & $-0,0382$ & 0,0558 & 0,2951 & 0,3003 & 0,0146 & 0,0400 & 0,2951 & 0,2978 & 0,0237 & 0,0678 & 0,2597 & 0,2684 & $69,0 \%$ & $9,9 \%$ & $21,1 \%$ & 0,0138 \\
\hline $1: 0$ & 12019 & $-0,0379$ & 0,1207 & 0,2951 & 0,3188 & 0,0145 & 0,1444 & 0,2951 & 0,3285 & 0,0233 & 0,1333 & 0,2597 & 0,2919 & $67,8 \%$ & $10,6 \%$ & $21,6 \%$ & 0,0147 \\
\hline & /2019 & $-0,0383$ & 0,0579 & 0,2951 & 0,3007 & 0,0149 & 0,0479 & 0,2951 & 0,2989 & 0,0234 & 0,0767 & 0,2597 & 0,2708 & $68,9 \%$ & $10,3 \%$ & $20,9 \%$ & 0,0139 \\
\hline $1 \leqslant \frac{2}{1}$ & 12019 & $-0,0378$ & 0,0701 & 0,2951 & 0,3033 & 0,0146 & 0,0588 & 0,2951 & 0,3009 & 0,0232 & 0,0946 & 0,2597 & 0,2764 & $68,5 \%$ & $10,1 \%$ & $21,4 \%$ & 0,0139 \\
\hline 16 & /2019 & $-0,0339$ & 0,2876 & 0,2951 & 0,4120 & 0,0131 & 0,6867 & 0,2951 & 0,7474 & 0,0208 & 0,1005 & 0,2597 & 0,2785 & $60,1 \%$ & $29,6 \%$ & $10,3 \%$ & 0,0180 \\
\hline $18 ी$ & $</ 2019$ & $-0,0294$ & 0,0512 & 0,2951 & 0,2995 & 0,0114 & 0,0341 & 0,2951 & 0,2970 & 0,0179 & 0,0787 & 0,2597 & 0,2714 & $68,7 \%$ & $10,3 \%$ & $21,0 \%$ & 0,0106 \\
\hline $19 / 1$ & 2/2019 & $-0,0321$ & 0,2559 & 0,2951 & 0,3906 & 0,0125 & 0,5829 & 0,2951 & 0,6533 & 0,0196 & 0,1218 & 0,2597 & 0,2869 & $61,5 \%$ & $26,2 \%$ & $12,4 \%$ & 0,0160 \\
\hline $20 / 1$ & 2/2019 & $-0,0372$ & 0,0853 & 0,2951 & 0,3072 & 0,0144 & 0,0656 & 0,2951 & 0,3023 & 0,0228 & 0,1167 & 0,2597 & 0,2847 & $68,1 \%$ & $9,9 \%$ & $22,0 \%$ & 0,0138 \\
\hline $21 / 1$ & 2/2019 & $-0,0370$ & 0,0749 & 0,2951 & 0,3044 & 0,0143 & 0,0878 & 0,2951 & 0,3079 & 0,0226 & 0,0925 & 0,2597 & 0,2757 & $68,4 \%$ & $10,5 \%$ & $21,0 \%$ & 0,0136 \\
\hline $22 / 1$ & 2/2019 & $-0,0370$ & 0,0658 & 0,2951 & 0,3023 & 0,0144 & 0,0641 & 0,2951 & 0,3020 & 0,0226 & 0,0860 & 0,2597 & 0,2736 & $68,6 \%$ & $10,3 \%$ & $21,0 \%$ & 0,0135 \\
\hline $23 / 1$ & 2/2019 & $-0,0378$ & 0,0708 & 0,2951 & 0,3035 & 0,0148 & 0,1235 & 0,2951 & 0,3199 & 0,0230 & 0,0808 & 0,2597 & 0,2720 & $68,1 \%$ & $11,6 \%$ & $20,3 \%$ & 0,0139 \\
\hline $24 / 1$ & 2/2019 & $-0,0378$ & 0,0573 & 0,2951 & 0,3006 & 0,0148 & 0,0622 & 0,2951 & 0,3016 & 0,0230 & 0,0712 & 0,2597 & 0,2693 & $68,9 \%$ & $10,7 \%$ & $20,4 \%$ & 0,0137 \\
\hline $25 / 1$ & 2/2019 & $-0,0369$ & 0,0581 & 0,2951 & 0,3008 & 0,0145 & 0,0934 & 0,2951 & 0,3095 & 0,0224 & 0,0663 & 0,2597 & 0,2681 & $68,7 \%$ & $11,2 \%$ & $20,1 \%$ & 0,0134 \\
\hline $26 / 1$ & 2/2019 & $-0,0382$ & 0,1131 & 0,2951 & 0,3160 & 0,0150 & 0,1224 & 0,2951 & 0,3194 & 0,0232 & 0,1224 & 0,2597 & 0,2871 & $68,4 \%$ & $10,8 \%$ & $20,8 \%$ & 0,0146 \\
\hline $27 / 1$ & 2/2019 & $-0,0390$ & 0,0450 & 0,2951 & 0,2985 & 0,0154 & 0,0446 & 0,2951 & 0,2984 & 0,0236 & 0,0602 & 0,2597 & 0,2666 & $69,1 \%$ & $10,7 \%$ & $20,2 \%$ & 0,0140 \\
\hline $28 / 1$ & 2/2019 & $-0,0387$ & 0,0324 & 0,2951 & 0,2969 & 0,0153 & 0,0468 & 0,2951 & 0,2988 & 0,0234 & 0,0343 & 0,2597 & 0,2620 & $69,3 \%$ & $11,0 \%$ & $19,7 \%$ & 0,0138 \\
\hline $29 / 1$ & 2/2019 & $-0,0388$ & 0,0380 & 0,2951 & 0,2975 & 0,0153 & 0,0553 & 0,2951 & 0,3002 & 0,0235 & 0,0336 & 0,2597 & 0,2619 & $69,3 \%$ & $11,0 \%$ & $19,7 \%$ & 0,0139 \\
\hline $30 / 1$ & 2/2019 & $-0,0370$ & 0,0551 & 0,2951 & 0,3002 & 0,0138 & 0,0750 & 0,2951 & 0,3045 & 0,0232 & 0,0628 & 0,2597 & 0,2672 & $68,8 \%$ & $9,9 \%$ & $21,4 \%$ & 0,0134 \\
\hline $03 / 0$ & 1/2020 & $-0,0441$ & 0,1663 & 0,2951 & 0,3387 & 0,0172 & 0,9590 & 0,2951 & 1,0033 & 0,0269 & 0,5110 & 0,2597 & 0,5732 & $29,4 \%$ & $39,1 \%$ & $31,4 \%$ & 0,0275 \\
\hline $05 / 0$ & $1 / 2020$ & $-0,0306$ & 0,0378 & 0,2951 & 0,2975 & 0,0123 & 0,1031 & 0,2951 & 0,3126 & 0,0182 & 0,0300 & 0,2597 & 0,2614 & $68,7 \%$ & $12,4 \%$ & $18,9 \%$ & 0,0110 \\
\hline $06 / 0$ & 1/2020 & $-0,0317$ & 0,3261 & 0,2951 & 0,4398 & 0,0129 & 0,8082 & 0,2951 & 0,8604 & 0,0188 & 0,0784 & 0,2597 & 0,2713 & $56,6 \%$ & $35,9 \%$ & $7,6 \%$ & 0,0186 \\
\hline
\end{tabular}


Tabela 37. Incerteza associada à medição (dados entre jan a fev/2020)

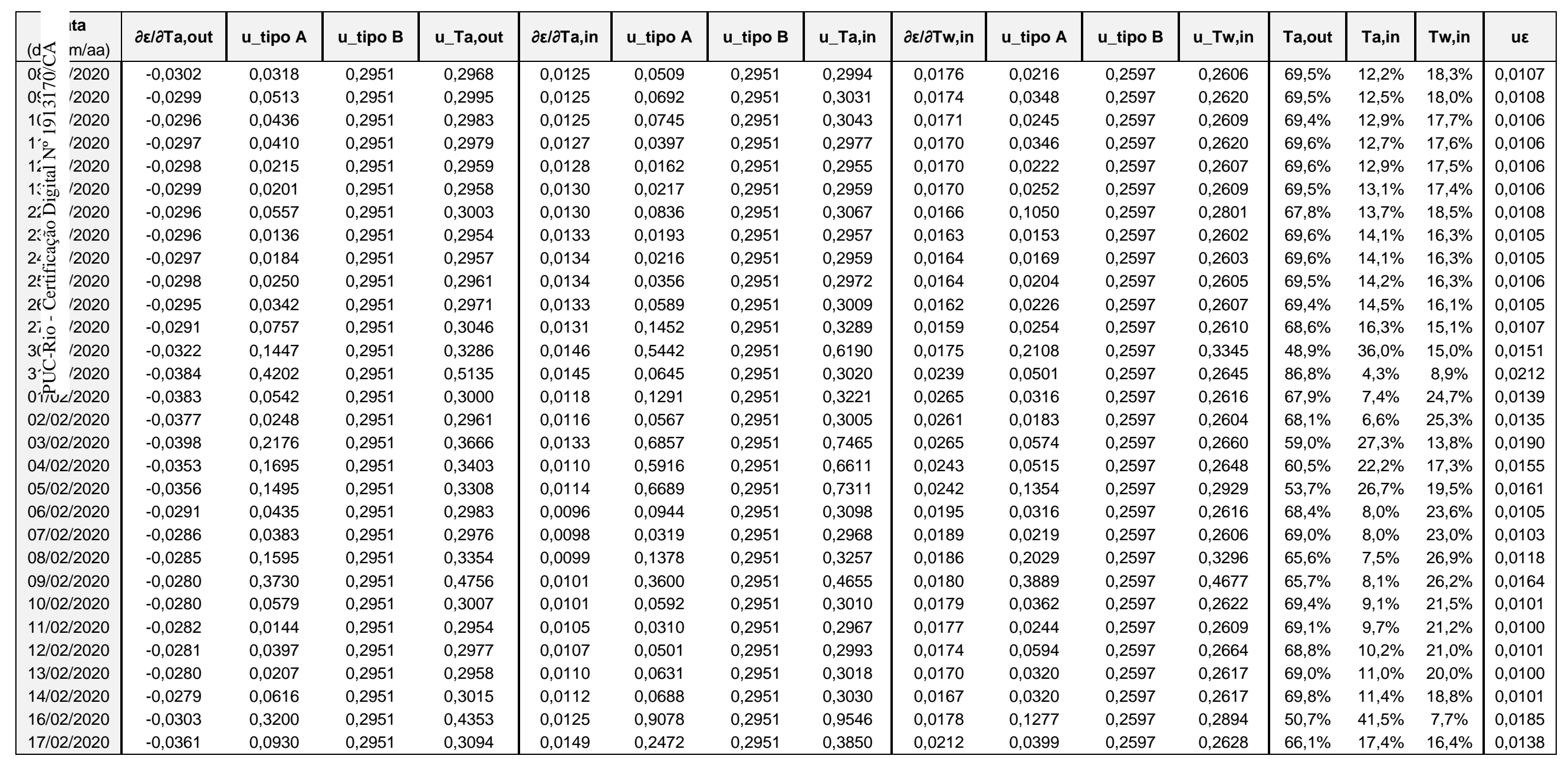


Tabela 38. Incerteza associada à medição (dados entre fev a abr/2020)

\begin{tabular}{|c|c|c|c|c|c|c|c|c|c|c|c|c|c|c|c|c|c|}
\hline & $\begin{array}{l}\text { Ita } \\
\text { m/aa) }\end{array}$ & $\partial \varepsilon / \partial \mathrm{T}$ a,out & u_tipo A & u_tipo B & u_Ta,out & $\partial \varepsilon / \partial \mathrm{Ta}$,in & u_tipo A & u_tipo B & u_Ta,in & $\partial \varepsilon / \partial T w$,in & u_tipo A & u_tipo B & u_Tw,in & Ta,out & Ta,in & Tw,in & uع \\
\hline $1 £$ & 12020 & $-0,0344$ & 0,0795 & 0,2951 & 0,3056 & 0,0141 & 0,1852 & 0,2951 & 0,3484 & 0,0202 & 0,0336 & 0,2597 & 0,2619 & $67,8 \%$ & $14,9 \%$ & $17,3 \%$ & 0,0128 \\
\hline $1 \leqslant \frac{\pi}{m}$ & 12020 & $-0,0394$ & 0,2325 & 0,2951 & 0,3757 & 0,0170 & 0,9959 & 0,2951 & 1,0387 & 0,0224 & 0,0351 & 0,2597 & 0,2621 & $38,7 \%$ & $55,3 \%$ & $6,1 \%$ & 0,0238 \\
\hline $21 \overline{0}$ & 12020 & $-0,0346$ & 0,0510 & 0,2951 & 0,2995 & 0,0141 & 0,1657 & 0,2951 & 0,3384 & 0,0204 & 0,0370 & 0,2597 & 0,2623 & $67,5 \%$ & $14,4 \%$ & $18,1 \%$ & 0,0126 \\
\hline $2{ }^{\circ}$ & 12020 & $-0,0358$ & 0,0268 & 0,2951 & 0,2963 & 0,0147 & 0,0475 & 0,2951 & 0,2989 & 0,0210 & 0,0282 & 0,2597 & 0,2612 & $69,4 \%$ & $12,0 \%$ & $18,6 \%$ & 0,0127 \\
\hline $2 x$ & 12020 & $-0,0358$ & 0,0232 & 0,2951 & 0,2960 & 0,0148 & 0,0311 & 0,2951 & 0,2967 & 0,0210 & 0,0249 & 0,2597 & 0,2609 & $69,5 \%$ & $11,9 \%$ & $18,6 \%$ & 0,0127 \\
\hline $2:=$ & 12020 & $-0,0357$ & 0,0300 & 0,2951 & 0,2966 & 0,0148 & 0,0197 & 0,2951 & 0,2957 & 0,0209 & 0,0394 & 0,2597 & 0,2627 & $69,5 \%$ & $11,8 \%$ & $18,8 \%$ & 0,0127 \\
\hline $2<\bar{\theta}$ & 12020 & $-0,0355$ & 0,0125 & 0,2951 & 0,2953 & 0,0147 & 0,0221 & 0,2951 & 0,2959 & 0,0208 & 0,0124 & 0,2597 & 0,2600 & $69,5 \%$ & $11,9 \%$ & $18,6 \%$ & 0,0126 \\
\hline 0 0ฺ̊ & 12020 & $-0,0237$ & 0,4485 & 0,2951 & 0,5368 & 0,0085 & 1,7985 & 0,2951 & 1,8225 & 0,0152 & 0,2538 & 0,2597 & 0,3632 & $37,3 \%$ & $55,8 \%$ & $7,0 \%$ & 0,0209 \\
\hline 2 , & 12020 & $-0,0203$ & 0,1238 & 0,2951 & 0,3200 & 0,0102 & 0,1036 & 0,2951 & 0,3128 & 0,0101 & 0,0403 & 0,2597 & 0,2628 & $71,0 \%$ & $17,1 \%$ & $11,9 \%$ & 0,0077 \\
\hline $2 \varepsilon=$ & 12020 & $-0,0201$ & 0,0522 & 0,2951 & 0,2997 & 0,0102 & 0,0810 & 0,2951 & 0,3060 & 0,0099 & 0,0130 & 0,2597 & 0,2600 & $68,9 \%$ & $18,6 \%$ & $12,5 \%$ & 0,0073 \\
\hline 2 & 12020 & $-0,0201$ & 0,0216 & 0,2951 & 0,2959 & 0,0103 & 0,0318 & 0,2951 & 0,2968 & 0,0098 & 0,0195 & 0,2597 & 0,2605 & $69,1 \%$ & $18,1 \%$ & $12,8 \%$ & 0,0072 \\
\hline $310^{1}$ & 12020 & $-0,0203$ & 0,0228 & 0,2951 & 0,2960 & 0,0104 & 0,0163 & 0,2951 & 0,2955 & 0,0099 & 0,0188 & 0,2597 & 0,2604 & $69,2 \%$ & $18,1 \%$ & $12,7 \%$ & 0,0072 \\
\hline $3 . \overline{1}$ & 12020 & $-0,0204$ & 0,0259 & 0,2951 & 0,2962 & 0,0104 & 0,0302 & 0,2951 & 0,2966 & 0,0099 & 0,0134 & 0,2597 & 0,2601 & $69,1 \%$ & $18,2 \%$ & $12,6 \%$ & 0,0073 \\
\hline 象 & 12020 & $-0,0214$ & 1,0153 & 0,2951 & 1,0574 & 0,0084 & 0,2557 & 0,2951 & 0,3905 & 0,0129 & 0,2126 & 0,2597 & 0,3356 & $94,5 \%$ & $2,0 \%$ & $3,5 \%$ & 0,0232 \\
\hline $03 / 1$ & 14/2020 & $-0,0219$ & 0,0213 & 0,2951 & 0,2959 & 0,0073 & 0,0234 & 0,2951 & 0,2960 & 0,0146 & 0,0205 & 0,2597 & 0,2605 & $68,7 \%$ & $7,7 \%$ & $23,6 \%$ & 0,0078 \\
\hline $04 / C$ & $4 / 2020$ & $-0,0220$ & 0,0293 & 0,2951 & 0,2965 & 0,0074 & 0,0291 & 0,2951 & 0,2965 & 0,0146 & 0,0348 & 0,2597 & 0,2620 & $68,6 \%$ & $7,8 \%$ & $23,6 \%$ & 0,0079 \\
\hline $05 / C$ & $4 / 2020$ & $-0,0220$ & 0,0205 & 0,2951 & 0,2958 & 0,0074 & 0,0221 & 0,2951 & 0,2959 & 0,0146 & 0,0175 & 0,2597 & 0,2603 & $68,8 \%$ & $7,8 \%$ & $23,4 \%$ & 0,0079 \\
\hline $06 / C$ & $4 / 2020$ & $-0,0254$ & 0,2788 & 0,2951 & 0,4059 & 0,0085 & 0,8866 & 0,2951 & 0,9345 & 0,0168 & 0,0472 & 0,2597 & 0,2640 & $56,0 \%$ & $33,6 \%$ & $10,4 \%$ & 0,0138 \\
\hline
\end{tabular}




\section{Apêndice E: Coeficiente global U e resistência térmica $R f$}

Tabela 39. Coeficiente global e resistência às incrustações (jul a out/2019)

\begin{tabular}{|c|c|c|c|c|c|c|c|c|}
\hline Data & $\mathbf{U}$ & Rf & Data & $\mathbf{U}$ & Rf & Data & $\mathbf{U}$ & $\mathbf{R f}$ \\
\hline (dd/mm/aa) & $\left(\mathrm{kW} / \mathrm{m}^{2} \mathrm{~K}\right)$ & $\left(m^{2} \mathrm{~K} / \mathrm{kW}\right)$ & (dd/mm/aa) & $\left(\mathrm{kW} / \mathrm{m}^{2} \mathrm{~K}\right)$ & $\left(m^{2} \mathrm{~K} / \mathrm{kW}\right)$ & (dd/mm/aa) & $\left(\mathrm{kW} / \mathrm{m}^{2} \mathrm{~K}\right)$ & $\left(m^{2} \mathrm{~K} / \mathrm{kW}\right)$ \\
\hline 05/07/2019 & 0,439 & 2,272 & $04 / 08 / 2019$ & 0,643 & 1,550 & $18 / 09 / 2019$ & 0,468 & 2,133 \\
\hline 06/07/2019 & 0,432 & 2,310 & 05/08/2019 & 0,644 & 1,547 & 19/09/2019 & 0,485 & 2,054 \\
\hline 07/07/2019 & 0,429 & 2,323 & 06/08/2019 & 0,635 & 1,569 & 20/09/2019 & 0,479 & 2,081 \\
\hline 08/07/2019 & 0,430 & 2,317 & $07 / 08 / 2019$ & 0,630 & 1,581 & $21 / 09 / 2019$ & 0,481 & 2,075 \\
\hline 09/07/2019 & 0,480 & 2,079 & 08/08/2019 & 0,599 & 1,663 & 22/09/2019 & 0,472 & 2,113 \\
\hline $10 / 07 / 2019$ & 0,519 & 1,921 & 09/08/2019 & 0,613 & 1,626 & 23/09/2019 & 0,469 & 2,126 \\
\hline $12 / 07 / 2019$ & 0,627 & 1,589 & $10 / 08 / 2019$ & 0,597 & 1,670 & 01/10/2019 & 0,465 & 2,145 \\
\hline $13 / 07 / 2019$ & 0,650 & 1,532 & $11 / 08 / 2019$ & 0,592 & 1,684 & 02/10/2019 & 0,452 & 2,208 \\
\hline 23/07/2019 & 0,696 & 1,432 & $12 / 08 / 2019$ & 0,584 & 1,708 & 03/10/2019 & 0,431 & 2,313 \\
\hline 24/07/2019 & 0,686 & 1,451 & $22 / 08 / 2019$ & 0,517 & 1,930 & 04/10/2019 & 0,456 & 2,187 \\
\hline 25/07/2019 & 0,685 & 1,455 & $23 / 08 / 2019$ & 0,532 & 1,875 & 05/10/2019 & 0,456 & 2,185 \\
\hline 26/07/2019 & 0,681 & 1,463 & $24 / 08 / 2019$ & 0,524 & 1,901 & 06/10/2019 & 0,458 & 2,177 \\
\hline 27/07/2019 & 0,677 & 1,470 & $10 / 09 / 2019$ & 0,510 & 1,955 & 07/10/2019 & 0,461 & 2,163 \\
\hline 28/07/2019 & 0,669 & 1,488 & $11 / 09 / 2019$ & 0,517 & 1,927 & $15 / 10 / 2019$ & 0,464 & 2,151 \\
\hline 29/07/2019 & 0,665 & 1,497 & $12 / 09 / 2019$ & 0,515 & 1,935 & $16 / 10 / 2019$ & 0,490 & 2,033 \\
\hline 30/07/2019 & 0,663 & 1,502 & $13 / 09 / 2019$ & 0,515 & 1,934 & $17 / 10 / 2019$ & 0,464 & 2,149 \\
\hline $31 / 07 / 2019$ & 0,660 & 1,509 & $14 / 09 / 2019$ & 0,516 & 1,930 & $18 / 10 / 2019$ & 0,467 & 2,134 \\
\hline 01/08/2019 & 0,651 & 1,529 & $15 / 09 / 2019$ & 0,510 & 1,956 & $19 / 10 / 2019$ & 0,467 & 2,135 \\
\hline 02/08/2019 & 0,639 & 1,560 & $16 / 09 / 2019$ & 0,507 & 1,965 & 20/10/2019 & 0,500 & 1,996 \\
\hline 03/08/2019 & 0,641 & 1,555 & $17 / 09 / 2019$ & 0,505 & 1,975 & $21 / 10 / 2019$ & 0,506 & 1,971 \\
\hline
\end{tabular}


Tabela 40. Coeficiente global e resistência às incrustações (out/2019 a jan/2020)

\begin{tabular}{|c|c|c|c|c|c|c|c|c|}
\hline Data & $\mathbf{U}$ & Rf & Data & $\mathbf{U}$ & Rf & Data & $\mathbf{U}$ & Rf \\
\hline (dd/mm/aa) & $\left(\mathrm{kW} / \mathrm{m}^{2} \mathrm{~K}\right)$ & $\left(m^{2} K / k W\right)$ & (dd/mm/aa) & $\left(\mathrm{kW} / \mathrm{m}^{2} \mathrm{~K}\right)$ & $\left(m^{2} \mathrm{~K} / \mathrm{kW}\right)$ & (dd/mm/aa) & $\left(\mathrm{kW} / \mathrm{m}^{2} \mathrm{~K}\right)$ & $\left(m^{2} \mathrm{~K} / \mathrm{kW}\right)$ \\
\hline $23 / 10 / 2019$ & 0,553 & 1,803 & $12 / 11 / 2019$ & 0,775 & 1,284 & $13 / 12 / 2019$ & 0,767 & 1,298 \\
\hline $24 / 10 / 2019$ & 0,663 & 1,501 & 13/11/2019 & 0,711 & 1,401 & $14 / 12 / 2019$ & 0,769 & 1,295 \\
\hline $25 / 10 / 2019$ & 0,728 & 1,368 & 14/11/2019 & 0,728 & 1,367 & 15/12/2019 & 0,761 & 1,309 \\
\hline $26 / 10 / 2019$ & 0,687 & 1,450 & 15/11/2019 & 0,758 & 1,314 & $16 / 12 / 2019$ & 0,732 & 1,361 \\
\hline $27 / 10 / 2019$ & 0,663 & 1,502 & 16/11/2019 & 0,757 & 1,315 & 19/12/2019 & 0,735 & 1,355 \\
\hline 28/10/2019 & 0,720 & 1,383 & 17/11/2019 & 0,750 & 1,327 & 20/12/2019 & 0,757 & 1,315 \\
\hline 29/10/2019 & 0,727 & 1,369 & 18/11/2019 & 0,747 & 1,333 & 21/12/2019 & 0,758 & 1,313 \\
\hline $30 / 10 / 2019$ & 0,693 & 1,437 & $26 / 11 / 2019$ & 0,770 & 1,293 & 22/12/2019 & 0,751 & 1,326 \\
\hline $31 / 10 / 2019$ & 0,647 & 1,540 & 28/11/2019 & 0,760 & 1,310 & 23/12/2019 & 0,751 & 1,325 \\
\hline $01 / 11 / 2019$ & 0,710 & 1,403 & 29/11/2019 & 0,755 & 1,318 & 24/12/2019 & 0,748 & 1,331 \\
\hline $02 / 11 / 2019$ & 0,691 & 1,440 & $30 / 11 / 2019$ & 0,752 & 1,324 & 25/12/2019 & 0,750 & 1,327 \\
\hline 03/11/2019 & 0,668 & 1,492 & 01/12/2019 & 0,753 & 1,322 & 26/12/2019 & 0,749 & 1,329 \\
\hline $04 / 11 / 2019$ & 0,725 & 1,373 & 02/12/2019 & 0,750 & 1,328 & 27/12/2019 & 0,748 & 1,330 \\
\hline 05/11/2019 & 0,693 & 1,436 & 06/12/2019 & 0,709 & 1,404 & 28/12/2019 & 0,752 & 1,323 \\
\hline $06 / 11 / 2019$ & 0,695 & 1,433 & 07/12/2019 & 0,758 & 1,313 & 29/12/2019 & 0,736 & 1,353 \\
\hline $07 / 11 / 2019$ & 0,662 & 1,505 & 08/12/2019 & 0,785 & 1,268 & $30 / 12 / 2019$ & 0,758 & 1,313 \\
\hline 08/11/2019 & 0,764 & 1,303 & 09/12/2019 & 0,779 & 1,277 & 03/01/2020 & 0,709 & 1,405 \\
\hline 09/11/2019 & 0,752 & 1,324 & 10/12/2019 & 0,780 & 1,276 & 05/01/2020 & 0,679 & 1,466 \\
\hline $10 / 11 / 2019$ & 0,749 & 1,330 & $11 / 12 / 2019$ & 0,780 & 1,276 & 06/01/2020 & 0,633 & 1,574 \\
\hline $11 / 11 / 2019$ & 0,741 & 1,343 & 12/12/2019 & 0,770 & 1,293 & 08/01/2020 & 0,663 & 1,501 \\
\hline
\end{tabular}


Tabela 41. Coeficiente global e resistência às incrustações (jan a abr/2020)

\begin{tabular}{|c|c|c|c|c|c|c|c|c|}
\hline Data & $\mathbf{U}$ & Rf & Data & $\mathbf{U}$ & Rf & Data & $\mathbf{U}$ & Rf \\
\hline (dd/mm/aa) & $\left(\mathrm{kW} / \mathrm{m}^{2} \mathrm{~K}\right)$ & $\left(m^{2} \mathrm{~K} / \mathrm{kW}\right)$ & (dd/mm/aa) & $\left(\mathrm{kW} / \mathrm{m}^{2} \mathrm{~K}\right)$ & $\left(m^{2} \mathrm{~K} / \mathrm{kW}\right)$ & (dd/mm/aa) & $\left(\mathrm{kW} / \mathrm{m}^{2} \mathrm{~K}\right)$ & $\left(m^{2} \mathrm{~K} / \mathrm{kW}\right)$ \\
\hline 09/01/2020 & 0,667 & 1,493 & $04 / 02 / 2020$ & 0,743 & 1,340 & $21 / 02 / 2020$ & 0,679 & 1,467 \\
\hline $10 / 01 / 2020$ & 0,673 & 1,480 & 05/02/2020 & 0,691 & 1,442 & 22/02/2020 & 0,693 & 1,437 \\
\hline $11 / 01 / 2020$ & 0,674 & 1,478 & 06/02/2020 & 0,857 & 1,162 & 23/02/2020 & 0,696 & 1,430 \\
\hline $12 / 01 / 2020$ & 0,678 & 1,468 & 07/02/2020 & 0,845 & 1,177 & 24/02/2020 & 0,666 & 1,495 \\
\hline $13 / 01 / 2020$ & 0,662 & 1,504 & 08/02/2020 & 0,814 & 1,222 & 09/03/2020 & 0,853 & 1,166 \\
\hline $22 / 01 / 2020$ & 0,642 & 1,553 & 09/02/2020 & 0,784 & 1,269 & 27/03/2020 & 0,713 & 1,397 \\
\hline $23 / 01 / 2020$ & 0,667 & 1,494 & 10/02/2020 & 0,742 & 1,341 & 28/03/2020 & 0,714 & 1,394 \\
\hline $24 / 01 / 2020$ & 0,663 & 1,502 & 11/02/2020 & 0,684 & 1,456 & 29/03/2020 & 0,717 & 1,390 \\
\hline $25 / 01 / 2020$ & 0,665 & 1,498 & 12/02/2020 & 0,695 & 1,433 & $30 / 03 / 2020$ & 0,727 & 1,370 \\
\hline $26 / 01 / 2020$ & 0,662 & 1,504 & 13/02/2020 & 0,646 & 1,541 & $31 / 03 / 2020$ & 0,717 & 1,389 \\
\hline $27 / 01 / 2020$ & 0,645 & 1,545 & 14/02/2020 & 0,644 & 1,548 & 02/04/2020 & 0,927 & 1,072 \\
\hline $30 / 01 / 2020$ & 0,613 & 1,625 & 16/02/2020 & 0,650 & 1,532 & 03/04/2020 & 1,048 & 0,948 \\
\hline $31 / 01 / 2020$ & 0,685 & 1,454 & 17/02/2020 & 0,687 & 1,450 & 04/04/2020 & 1,085 & 0,916 \\
\hline $01 / 02 / 2020$ & 0,758 & 1,313 & 18/02/2020 & 0,673 & 1,480 & 05/04/2020 & 1,047 & 0,949 \\
\hline 02/02/2020 & 0,757 & 1,315 & 19/02/2020 & 0,550 & 1,812 & 06/04/2020 & 0,994 & 1,000 \\
\hline 03/02/2020 & 0,656 & 1,519 & 20/02/2020 & 0,665 & 1,498 & & & \\
\hline
\end{tabular}




\section{Apêndice F: Caracterização dos regimes hidrodinâmicos (ar e água)}

Cálculo do Número de Reynolds referenciado às dimensões críticas que definem as áreas $\mathbf{A}_{\mathbf{T}}$ e $\mathbf{A}_{\mathbf{D}}$

Tabela 42. Número de Reynolds - interior do trocador (jul a out/2019)

\begin{tabular}{|c|c|c|c|c|c|c|c|c|c|c|c|}
\hline Data & $\operatorname{Re}\left(S_{T}\right)$ & $\operatorname{Re}\left(\mathbf{S}_{\mathrm{T}}\right)$ & $\operatorname{Re}($ Água) & Data & $\operatorname{Re}\left(\mathbf{S}_{\mathrm{T}}\right)$ & $\operatorname{Re}\left(\mathbf{S}_{\mathbf{T}}\right)$ & Re (Água) & Data & $\operatorname{Re}\left(\mathbf{S}_{\mathbf{T}}\right)$ & $\operatorname{Re}\left(\mathbf{S}_{\mathbf{T}}\right)$ & Re (Água) \\
\hline (dd/mm/aa) & - & - & - & (dd/mm/aa) & - & - & - & (dd/mm/aa) & - & - & - \\
\hline 05/07/2019 & 14669,61 & 6636,77 & 2999,79 & 04/08/2019 & 18780,84 & 8496,75 & 4395,85 & 18/09/2019 & 15832,32 & 7162,80 & 4065,06 \\
\hline 06/07/2019 & 14403,73 & 6516,48 & 2786,34 & 05/08/2019 & 18836,33 & 8521,86 & 4345,75 & 19/09/2019 & 16122,59 & 7294,12 & 4084,65 \\
\hline 07/07/2019 & 14391,33 & 6510,87 & 2774,77 & 06/08/2019 & 18728,24 & 8472,96 & 4317,46 & 20/09/2019 & 15994,59 & 7236,21 & 4101,79 \\
\hline 08/07/2019 & 14401,23 & 6515,34 & 2736,94 & 07/08/2019 & 18629,53 & 8428,30 & 4274,53 & $21 / 09 / 2019$ & 16037,24 & 7255,50 & 4121,10 \\
\hline 09/07/2019 & 15853,35 & 7172,31 & 3456,40 & 08/08/2019 & 18214,04 & 8240,32 & 4300,54 & 22/09/2019 & 15895,95 & 7191,58 & 4059,29 \\
\hline $10 / 07 / 2019$ & 17080,00 & 7727,26 & 4263,99 & 09/08/2019 & 18375,62 & 8313,42 & 4350,78 & 23/09/2019 & 15863,84 & 7177,05 & 3952,36 \\
\hline $12 / 07 / 2019$ & 18378,80 & 8314,86 & 4036,70 & 10/08/2019 & 18093,30 & 8185,70 & 4357,03 & $01 / 10 / 2019$ & 15773,59 & 7136,23 & 3919,91 \\
\hline $13 / 07 / 2019$ & 18793,35 & 8502,41 & 4195,39 & $11 / 08 / 2019$ & 17976,22 & 8132,73 & 4329,55 & 02/10/2019 & 15436,14 & 6983,56 & 3829,63 \\
\hline $23 / 07 / 2019$ & 19802,85 & 8959,12 & 4671,62 & $12 / 08 / 2019$ & 17827,79 & 8065,58 & 4311,16 & 03/10/2019 & 15017,65 & 6794,23 & 3714,53 \\
\hline $24 / 07 / 2019$ & 19433,35 & 8791,96 & 4368,37 & $22 / 08 / 2019$ & 16665,85 & 7539,89 & 3890,26 & 04/10/2019 & 15492,92 & 7009,25 & 3901,00 \\
\hline $25 / 07 / 2019$ & 19388,05 & 8771,46 & 4396,59 & $23 / 08 / 2019$ & 16957,43 & 7671,81 & 3964,09 & 05/10/2019 & 15509,40 & 7016,70 & 3937,26 \\
\hline $26 / 07 / 2019$ & 19330,80 & 8745,56 & 4429,68 & $24 / 08 / 2019$ & 16856,47 & 7626,14 & 3933,10 & 06/10/2019 & 15529,10 & 7025,61 & 3992,30 \\
\hline $27 / 07 / 2019$ & 19285,08 & 8724,88 & 4435,72 & 10/09/2019 & 16603,20 & 7511,55 & 4276,23 & 07/10/2019 & 15598,74 & 7057,12 & 4010,43 \\
\hline 28/07/2019 & 19173,06 & 8674,20 & 4436,77 & $11 / 09 / 2019$ & 16733,13 & 7570,34 & 4364,53 & $15 / 10 / 2019$ & 15662,66 & 7086,04 & 4133,33 \\
\hline 29/07/2019 & 19130,85 & 8655,10 & 4414,65 & $12 / 09 / 2019$ & 16698,59 & 7554,71 & 4427,32 & $16 / 10 / 2019$ & 16082,07 & 7275,78 & 4235,41 \\
\hline $30 / 07 / 2019$ & 19128,24 & 8653,92 & 4424,67 & $13 / 09 / 2019$ & 16732,87 & 7570,22 & 4481,25 & $17 / 10 / 2019$ & 15688,61 & 7097,78 & 4236,10 \\
\hline $31 / 07 / 2019$ & 19064,54 & 8625,10 & 4421,69 & 14/09/2019 & 16762,48 & 7583,62 & 4470,96 & 18/10/2019 & 15748,17 & 7124,72 & 4244,85 \\
\hline 01/08/2019 & 18925,21 & 8562,07 & 4420,82 & 15/09/2019 & 16556,73 & 7490,53 & 4303,00 & 19/10/2019 & 15769,51 & 7134,38 & 4265,52 \\
\hline 02/08/2019 & 18738,29 & 8477,50 & 4417,26 & $16 / 09 / 2019$ & 16411,52 & 7424,84 & 4129,80 & 20/10/2019 & 16396,85 & 7418,20 & 4460,26 \\
\hline 03/08/2019 & 18739,93 & 8478,24 & 4417,93 & 17/09/2019 & 16355,96 & 7399,70 & 4141,95 & 21/10/2019 & 16570,17 & 7496,61 & 4466,50 \\
\hline
\end{tabular}


Tabela 43. Número de Reynolds - interior do trocador (out/2019 a jan/2020)

\begin{tabular}{|c|c|c|c|c|c|c|c|c|c|c|c|}
\hline Data & $\operatorname{Re}\left(S_{T}\right)$ & $\operatorname{Re}\left(S_{T}\right)$ & $\operatorname{Re}$ (Água) & Data & $\operatorname{Re}\left(S_{T}\right)$ & $\operatorname{Re}\left(\mathbf{S}_{\mathrm{T}}\right)$ & $\operatorname{Re}$ (Água) & Data & $\operatorname{Re}\left(S_{T}\right)$ & $\operatorname{Re}\left(S_{T}\right)$ & $\overline{R e}$ (Água) \\
\hline (dd/mm/aa) & - & - & - & (dd/mm/aa) & - & - & - & (dd/mm/aa) & - & - & - \\
\hline $23 / 10 / 2019$ & 17729,01 & 8020,89 & 5109,49 & $12 / 11 / 2019$ & 19955,79 & 9028,32 & 4200,25 & $13 / 12 / 2019$ & 19886,88 & 8997,14 & 4300,50 \\
\hline $24 / 10 / 2019$ & 18461,63 & 8352,34 & 4053,15 & $13 / 11 / 2019$ & 18967,24 & 8581,08 & 4109,97 & 14/12/2019 & 19917,02 & 9010,78 & 4243,39 \\
\hline $26 / 10 / 2019$ & 18553,87 & 8394,07 & 4081,48 & $15 / 11 / 2019$ & 19642,71 & 8886,68 & 4300,65 & 16/12/2019 & 20222,48 & 9148,97 & 4269,31 \\
\hline $27 / 10 / 2019$ & 18115,72 & 8195,84 & 3997,82 & $16 / 11 / 2019$ & 19636,87 & 8884,03 & 4303,29 & 19/12/2019 & 20068,51 & 9079,31 & 4331,05 \\
\hline $28 / 10 / 2019$ & 19276,97 & 8721,21 & 4579,96 & $17 / 11 / 2019$ & 19504,84 & 8824,30 & 4272,05 & $20 / 12 / 2019$ & 19818,80 & 8966,34 & 4352,73 \\
\hline $30 / 10 / 2019$ & 18798,87 & 8504,91 & 4489,95 & $26 / 11 / 2019$ & 20045,66 & 9068,98 & 4355,32 & 22/12/2019 & 19738,78 & 8930,14 & 4348,68 \\
\hline $31 / 10 / 2019$ & 18032,41 & 8158,15 & 4160,98 & 28/11/2019 & 19871,80 & 8990,32 & 4360,80 & 23/12/2019 & 19754,33 & 8937,17 & 4306,41 \\
\hline $01 / 11 / 2019$ & 18988,56 & 8590,73 & 4479,87 & 29/11/2019 & 19812,06 & 8963,29 & 4401,29 & $24 / 12 / 2019$ & 19688,29 & 8907,30 & 4280,83 \\
\hline $02 / 11 / 2019$ & 18530,83 & 8383,64 & 4178,42 & $30 / 11 / 2019$ & 19745,16 & 8933,03 & 4411,67 & $25 / 12 / 2019$ & 19717,30 & 8920,42 & 4284,60 \\
\hline $03 / 11 / 2019$ & 18231,86 & 8248,38 & 4085,44 & $01 / 12 / 2019$ & 19766,70 & 8942,77 & 4404,35 & 26/12/2019 & 19653,03 & 8891,35 & 4379,95 \\
\hline $04 / 11 / 2019$ & 19420,88 & 8786,32 & 4645,06 & 02/12/2019 & 19737,14 & 8929,40 & 4417,91 & 27/12/2019 & 19644,59 & 8887,53 & 4428,91 \\
\hline 08/11/2019 & 19798,64 & 8957,22 & 4317,48 & 09/12/2019 & 20083,57 & 9086,13 & 4435,59 & 03/01/2020 & 19092,31 & 8637,67 & 4450,63 \\
\hline 09/11/2019 & 19651,02 & 8890,44 & 4174,87 & $10 / 12 / 2019$ & 20089,06 & 9088,61 & 4405,66 & 05/01/2020 & 18515,51 & 8376,71 & 4338,40 \\
\hline $10 / 11 / 2019$ & 19597,65 & 8866,29 & 4136,33 & $11 / 12 / 2019$ & 20058,13 & 9074,62 & 4392,54 & 06/01/2020 & 17993,42 & 8140,51 & 4341,45 \\
\hline $11 / 11 / 2019$ & 19647,52 & 8888,85 & 4280,23 & $12 / 12 / 2019$ & 19903,14 & 9004,50 & 4372,89 & 08/01/2020 & 18310,20 & 8283,83 & 4336,36 \\
\hline
\end{tabular}


Tabela 44. Número de Reynolds - interior do trocador (jan a abr/2020)

\begin{tabular}{|c|c|c|c|c|c|c|c|c|c|c|c|}
\hline Data & $\operatorname{Re}\left(\mathbf{S}_{\mathbf{T}}\right)$ & $\operatorname{Re}\left(\mathbf{S}_{\mathbf{T}}\right)$ & Re (Água) & Data & $\operatorname{Re}\left(\mathbf{S}_{\mathbf{T}}\right)$ & $\operatorname{Re}\left(\mathbf{S}_{\mathrm{T}}\right)$ & Re (Água) & Data & $\operatorname{Re}\left(\mathbf{S}_{\mathbf{T}}\right)$ & $\operatorname{Re}\left(\mathbf{S}_{\mathbf{T}}\right)$ & Re (Água) \\
\hline (dd/mm/aa) & - & - & - & (dd/mm/aa) & - & - & - & (dd/mm/aa) & - & - & - \\
\hline 09/01/2020 & 18396,69 & 8322,96 & 4411,69 & 04/02/2020 & 20457,97 & 9255,51 & 5856,88 & 21/02/2020 & 19702,39 & 8913,68 & 5935,20 \\
\hline $10 / 01 / 2020$ & 18497,47 & 8368,55 & 4479,57 & 05/02/2020 & 24189,07 & 10943,52 & 5947,98 & 22/02/2020 & 19930,25 & 9016,76 & 5968,47 \\
\hline $11 / 01 / 2020$ & 18542,44 & 8388,90 & 4513,39 & 06/02/2020 & 19632,47 & 8882,04 & 6089,35 & 23/02/2020 & 20041,17 & 9066,94 & 5934,32 \\
\hline $12 / 01 / 2020$ & 18605,18 & 8417,28 & 4563,28 & 07/02/2020 & 19313,56 & 8737,76 & 6005,65 & 24/02/2020 & 19524,73 & 8833,30 & 5669,51 \\
\hline $13 / 01 / 2020$ & 18373,23 & 8312,34 & 4493,78 & 08/02/2020 & 18829,56 & 8518,79 & 5797,32 & 09/03/2020 & 18961,79 & 8578,62 & 5343,33 \\
\hline 22/01/2020 & 18163,69 & 8217,54 & 4465,53 & 09/02/2020 & 18396,26 & 8322,76 & 5508,59 & 27/03/2020 & 16516,97 & 7472,54 & 4449,01 \\
\hline $23 / 01 / 2020$ & 18596,81 & 8413,49 & 4498,93 & $10 / 02 / 2020$ & 17735,74 & 8023,93 & 5638,96 & $28 / 03 / 2020$ & 16608,98 & 7514,17 & 4619,08 \\
\hline $24 / 01 / 2020$ & 18518,58 & 8378,10 & 4480,29 & $11 / 02 / 2020$ & 19481,69 & 8813,83 & 5613,98 & 29/03/2020 & 16643,35 & 7529,72 & 4650,25 \\
\hline $25 / 01 / 2020$ & 18567,38 & 8400,18 & 4487,73 & $12 / 02 / 2020$ & 19697,49 & 8911,46 & 5589,94 & $30 / 03 / 2020$ & 16823,44 & 7611,19 & 4692,02 \\
\hline $26 / 01 / 2020$ & 18525,93 & 8381,42 & 4470,82 & 13/02/2020 & 23780,59 & 10758,72 & 5759,54 & $31 / 03 / 2020$ & 16698,95 & 7554,87 & 4661,33 \\
\hline $27 / 01 / 2020$ & 18215,47 & 8240,97 & 4394,76 & 14/02/2020 & 23729,83 & 10735,76 & 5754,35 & 02/04/2020 & 21603,02 & 9773,55 & 6092,49 \\
\hline $30 / 01 / 2020$ & 17678,07 & 7997,84 & 4300,90 & $16 / 02 / 2020$ & 19197,58 & 8685,29 & 5798,46 & 03/04/2020 & 19850,28 & 8980,58 & 4504,24 \\
\hline $31 / 01 / 2020$ & 19207,01 & 8689,56 & 5131,20 & 17/02/2020 & 19863,20 & 8986,43 & 5949,50 & 04/04/2020 & 20303,56 & 9185,65 & 4620,18 \\
\hline 01/02/2020 & 20639,24 & 9337,52 & 5929,80 & $18 / 02 / 2020$ & 19636,57 & 8883,90 & 5931,35 & 05/04/2020 & 19825,65 & 8969,44 & 4458,88 \\
\hline 02/02/2020 & 20590,89 & 9315,65 & 5906,46 & 19/02/2020 & 17908,27 & 8101,99 & 5846,57 & 06/04/2020 & 19195,60 & 8684,40 & 4229,83 \\
\hline 03/02/2020 & 19315,09 & 8738,46 & 5875,35 & 20/02/2020 & 19503,67 & 8823,77 & 5889,38 & & & & \\
\hline
\end{tabular}

